\title{
Les aléas de la transmission
}

\section{Claudine Vassas (dir.)}




\section{Les aléas de la transmission}

\section{Claudine Vassas (dir.)}

DOI : $10.4000 /$ books.cths. 14727

Éditeur : Éditions du Comité des travaux historiques et scientifiques Année d'édition : 2021

Date de mise en ligne : 3 février 2021

Collection : Actes des congrès nationaux des sociétés historiques et scientifiques

ISBN électronique : 9782735508952

\section{Sbooks}

http://books.openedition.org

\section{Référence électronique}

VASSAS, Claudine (dir.). Les aléas de la transmission. Nouvelle édition [en ligne]. Paris : Éditions du Comité des travaux historiques et scientifiques, 2021 (généré le 04 février 2021). Disponible sur Internet : <http://books.openedition.org/cths/14727>. ISBN : 9782735508952 . DOI : https://doi.org/ 10.4000/books.cths. 14727 .

Ce document a été généré automatiquement le 4 février 2021

(c) Éditions du Comité des travaux historiques et scientifiques, 2021

Conditions d'utilisation

http://www.openedition.org/6540 
La question de la transmission sous des formes variées, et selon des problématiques renouvelées, constitue aujourd'hui encore l'une des interrogations majeures de l'ethnologie. Indissociable de l'idée de «continuité culturelle » sur laquelle s'est fondée la discipline, elle n'en reste pas moins essentielle dans les sociétés modernes. La transmission se conjugue donc le plus souvent avec « la tradition » et « l'identité », et celles-ci sont également soumises à des questionnements multiples et surtout à de fréquentes réévaluations critiques de la part des anthropologues. Les contributions réunies dans ce recueil ne reflètent pas tous les aspects du problème mais permettent de mieux saisir la perspective qui fût la nôtre et sa portée heuristique. En effet, elles sont d'une très grande diversité et permettent d'appréhender quelques-unes des formes inédites, actuelles, que peut prendre la transmission avec ses impasses, ses transformations, ses renversements même. Enfin, elles font la preuve qu'à défaut d'être "organisée » elle reste de toute façon «bonne à penser » en dépit de tous les aléas auxquels, aujourd'hui, elle est le plus souvent soumise.

Le Congrès national des sociétés historiques et scientifiques rassemble chaque année universitaires, membres de sociétés savantes et jeunes chercheurs. Ce recueil est issu de travaux présentés lors du $143^{\mathrm{e}}$ Congrès sur le thème « La transmission des savoirs ».

\section{CLAUDINE VASSAS}

Ethnologue, directrice de recherche émérite au CNRS, membre du Laboratoire interdisciplinaire solidarités, sociétés, territoires (LISST, Centre d'anthropologie de Toulouse, EHESS/CNRS) 
SOMMAIRE

Introduction
Claudine Vassas

Modernité et rupture dans la transmission intergénérationnelle des proverbes kabyles Rabiha Ait Hamou Ali

La praxématique : théorie de la production dynamique du sens en langage

Le proverbe parmi les formes orales standardisées kabyles

De la famille traditionnelle à la famille nucléaire : une hypothèse à vérifier

Du souhait à la réalité

Le Psaume 104 : témoin des aléas de la transmission d'un savoir à Jérusalem dans l'Antiquité Stéphanie Anthonioz

Les témoins hébraïques anciens du Ps 104

Les aléas de la transmission : le Grand Hymne à Aton

La structure du psaume : quelle cohérence?

Les aléas de la transmission : diversité et richesse des traditions de la création

Les questions de transmission posées par les associations mémorielles dans les dispositifs muséographiques

Malika Bordes-Boudellal

Mettre la guerre en musée pour transmettre l'histoire et la mémoire

Des musées pour des publics : de la réparation à la transmission

Le cas du camp d'internement de Septfonds

Le projet de musée de la Résistance et de la déportation de Haute-Savoie

La transmission mémorielle s'enrichit de nouvelles disciplines

Les associations mémorielles et le champ exploré des « valeurs»

Les jeunes deviennent à leur tour passeurs de mémoire

Femmes au cœur d'une transmission : le cas de la kafala dans le contexte migratoire français

Noria Boukhobza

Enfant du péché (aw-lad lahram)

Toujours plus d'enfants...

Ils font enfanter leurs femmes pour leur sœur

Femmes ménopausées : des mères de substitution

Filiation symbolique

Fille de famille (bent famillia)

Kafala complexe pour une adoption simple

Transmission du savoir-faire et ordre généalogique dans la danse Odissi à Bhubaneswar (Inde)

Barbara Čurda

Un ordre social régissant les réseaux de la danse

Le déroulement des entraînements

Les discours en action dans les séances de transmission

Les savoirs perdus de l'ancienne Polynésie

Véronique Dorbe-Larcade

Une conscience malheureuse

Une disparition

Une déperdition

La possibilité de la sauvegarde 
Le sentiment religieux chez les nomades Mbororo du Tchad : une adhésion opportuniste à l'islam?

Yassine Kervella-Mansaré

Repères méthodologiques

Perpétuels migrants

Le culte des apparences

Une négociation paradoxale

De quelques censures manquées

Empire, paix et vérité : la résistance des savoirs dans l'Europe de la Renaissance (1500-1540) Laureano Lopez

La réalité politique de l'Europe chrétienne vers 1500

Thomas More, J. L. Vives et Érasme dans l'essor de la rationalité politique

La transmission des savoirs et savoir-faire dans la production semi-industrielle des anches: analyse d'un cas d'étude italien

Raffaele Pinelli

L'anche libre métallique et les lieux de sa facture

La transmission des savoirs et du savoir-faire

Les aléas du manque ou de l'interruption de la transmission

Les savoirs traditionnels de pêcheurs artisanaux à Huanchaco (La Libertad, Pérou) : la problématique de leur transmission et de leur continuité

Marina Quiñe

Huanchaco et son littoral côtier : importance pour la pêche

Huanchaco et la pêche en caballito de totora : contexte historique

La problématique de la pêche en caballito de totora et la perte de savoirs traditionnels

Les savoirs des pêcheurs et leur transmission

La transmission de l'art vétérinaire équin en France à travers le prisme de l'ethnobotanique Mathilde Richard

La médecine vétérinaire équine, un héritage thérapeutique antique

Le soin équin au Moyen Âge

L’État français s'empare de la santé publique : création des écoles vétérinaires

L'opposition de deux formes de médecine vétérinaire équine

La santé équine à l'ère de l'Industrie

La médecine populaire équine, un patrimoine médicinal à redécouvrir

Les nouvelles perspectives offertes par l'ethnopharmacognosie

La récupération du savoir-faire dans la construction de l'État moderne en Roumanie:

l'exemple des frères Lapedatu

Andreas Wild

La construction étatique en Roumanie entre les deux guerres

L'oubli

La transmission du savoir 


\section{NOTE DE L'ÉDITEUR}

Les articles de cet ouvrage ont été validés par le comité de lecture des Éditions du Comité des travaux historiques et scientifiques dans le cadre de la publication des actes du $143^{e}$ Congrès national des sociétés historiques et scientifiques tenu à Paris en 2018. 


\title{
Introduction
}

\author{
Claudine Vassas
}

1 La question de la transmission sous des formes variées et selon des problématiques renouvelées constitue aujourd'hui encore l'une des interrogations majeures de l'ethnologie, en effet elle reste indissociable de l'idée de "continuité culturelle » sur laquelle s'est fondée la discipline. Les folkloristes du XIX ${ }^{\mathrm{e}}$ siècle, attachés à la collecte, à l'archivage, à la préservation et par voie de conséquence à la transmission de savoirfaire et de savoirs souvent associés à des "pratiques et croyances" dites «traditionnelles », en avaient fait un élément central de leurs investigations. Elle n'en reste pas moins essentielle dans les sociétés modernes, que ces dernières entendent rompre avec elles, les rejettent, les modifient par nécessité ou en fonction de choix délibérés, à moins qu'elles ne prétendent en garantir la pérennité, voire la reproduction à l'identique, autre gageure impossible à tenir. La transmission se conjugue donc le plus souvent avec «la tradition » et "l'identité », et celles-ci sont également soumises à des questionnements multiples et surtout à de fréquentes réévaluations critiques de la part des anthropologues.

David Berliner dans un article récent intitulé "Anthropologie et Transmission» a retracé l'historicité de la relation de la discipline avec cette notion et considère qu'aujourd'hui le concept reste d'autant plus valide qu'elle peut aussi être abordée en tenant compte de la dimension réflexive qu'elle revêt chez les acteurs eux-mêmes ${ }^{1}$. Il relève la façon dont, pour Marcel Mauss ou Levi-Bruhl, elle est d'abord liée à une définition des sociétés dites "traditionnelles", ces dernières s'attachant essentiellement à reproduire et perpétuer leurs coutumes, leur culture, en privilégiant une certaine clôture d'où leur fragilité, leur vulnérabilité et l'urgence pour l'ethnologue de les étudier avant qu'elles ne disparaissent. C'est sur ce paradigme romantique que s'est construite pour une grande part l'ethnologie exotique, ethnologie de sauvetage de ce qui bientôt ne serait plus (Malinowski, Evans Pritchard participent de cette idéologie) mais avec laquelle on renoue ces dernières années à propos des sociétés contemporaines, elles aussi jugées « en péril » à l'instar de leurs monuments ! faisant, de mettre l'ethnologue qui les recueillait en position de les transmettre de fait 
aux générations futures? Les appels d'offres proposés alors on fait la part belle à ces thématiques et les nombreuses publications qui en ont découlé en portent témoignage ${ }^{2}$. Quant à une institution comme l'uNESCO, en inscrivant des pans entiers de notre « culture matérielle et immatérielle » au patrimoine mondial de l'humanité, elle entend œuvrer à la préservation de la transmission. Non sans conflits d'interprétation d'ailleurs avec les acteurs qui se voient contraints pour en garantir l'« authenticité » de figer leurs « traditions » et de muséifier leur cadre de vie, de reproduire leurs rituels « à l'identique ", d'immobiliser leurs pratiques artistiques (théâtrales, musicales) - ce qui dès lors interdit toute création - en conformité avec la définition proposée par l'instance qui décide de leur légitimité et finance leur " sauvetage ${ }^{3}$ »!

4 Or une société ne se perpétue pas seulement en raison de la rigidité de ses traditions et de leur transmission consciente. Ce que Pierre Bourdieu a nommé l'« habitus » social, ces manières de faire et d'être qui façonnent les individus et qu'ils se transmettent à leur insu parfois - elles concernent aussi bien le corps que le langage - ouvrent à la question de la mémoire involontaire et de la part qu'elle joue dans tout processus de transmission. À l'inverse, s'appliquer à la remémoration avec fidélité relève tout autant $\mathrm{du}$ leurre, car toute transmission opère des modifications et comme le souligne Catherine Choron-Baix relève d'une «dynamique subtile, traversée de contradictions, entravée par les obstacles, les interférences, les brouillages et autres ratages, mais capable aussi d'engendrer de la création ou de la recréation ${ }^{4} »$. En outre interviennent des paramètres qui viennent perturber une telle possibilité : les guerres, la colonisation ont joué un rôle dans la transmission en l'entravant voire en la rendant impossible et nombre de travaux en témoignent. Les migrations forcées auxquelles des populations sont contraintes aujourd'hui entraînent les mêmes effets. L'actualité de la transmission est donc entière, surtout selon David Berliner lorsqu'« en tant que posture épistémologique elle interroge la manière de décrire le réel et nourrit les prémices d'une réflexion sur la continuité des sociétés humaines à l'épreuve des ruptures de l'histoire ${ }^{5}$ ».

5 C'est en cela que la section Anthropologie sociale, ethnologie et langues régionales du CTHS a choisi de faire porter le colloque pluridisciplinaire qu'elle a proposé au Comité national sur ces difficultés, ces échecs, ces refus et l'a intitulé "Les aléas de la transmission »: par là elle entendait mettre l'accent sur les connaissances que les acteurs ne souhaitent ou ne peuvent transmettre à leurs descendants ou à leur entourage. Lorsqu'il s'agit de choix, les raisons qui y président sont multiples: des savoirs peuvent relever d'un interdit imposé par une politique autoritaire et hégémonique (ainsi les pratiques religieuses et chamaniques durant la période soviétique) mais aussi être considérés comme obsolètes par ceux qui les ont reçus en héritage, ou même comme honteux (pratiques ou connaissances qui sont devenues socialement inopérantes ou moralement inacceptables). Ainsi une situation de domination (esclavage, colonialisme ou immigration) peut conduire les acteurs à refuser de transmettre un certain type de savoirs (historiques, linguistiques, religieux, etc.) à leurs descendants pour les mettre à l'abri d'un danger ou leur permettre une meilleure chance d'intégration sociale. Cependant, cette volonté de tenir à distance les jeunes générations d'un savoir n'a pas toujours comme objectif de les protéger, mais peut les conduire à une forme de conquête individuelle d'un savoir tenu caché. Elle peut aussi les inciter à le découvrir, à s'engager dans un apprentissage: ne pas transmettre une langue (ou un dialecte minoritaire) ne relève pas seulement d'un 
sentiment de honte pour son origine, c'est aussi l'idée que la langue que l'on décide de parler doit faire l'objet d'un choix.

6 Les contributions réunies dans ce recueil ne reflètent pas tous les aspects du problème mais permettent de mieux saisir la perspective qui fût la nôtre et sa portée heuristique. En effet, elles sont d'une très grande diversité et permettent d'appréhender quelquesunes des formes inédites, actuelles, que peut prendre la transmission avec ses impasses, ses transformations, ses renversements même. Enfin, et ce, en dépit de l'assertion de Bonte et Izard, soutenant que « chaque société pense et organise à sa manière propre la transmission ${ }^{6}$ », elles font la preuve qu'à défaut d'être " organisée », elle reste de toute façon « bonne à penser » en dépit de tous les aléas auxquels, aujourd'hui, elle est le plus souvent soumise.

\section{BIBLIOGRAPHIE}

BERLINER David, « Transmettre », TERRAIN, nº 55, 2010, p. 4-16.

BERLINER David, « Perdre l'esprit du lieu. Les politiques de l'UNESCO à Luang Prabang », TERRAIN, $\mathrm{n}^{\circ} 55,2010$, p. 91-105.

BONTE Pierre et IZARD Michel, Dictionnaire de l'ethnologie et de l'anthropologie. PUF, Quadrige, Paris, 1991.

CHEVALLIER Denis, «Savoir faire et pouvoir transmettre : transmission et apprentissage des savoir-faire et des techniques », Paris, Ministère de la Culture et de la Communication, Éditions de la Maison des Sciences de l'Homme, Collection Ethnologie de la France, 1991.

CHORON-BAIX Catherine, «Transmettre et perpétuer aujourd'hui », Ethnologie française, vol. 3, n 30 , 2000 , p. 357-360.

POUILLON Jean, «Tradition » dans BONTE Pierre et IZARD Michel (dir.), Dictionnaire de l'ethnologie et de l'anthropologie, Paris, PUF, Quadrige, 1991, p. 710-712.

ZONABEND Françoise, La mémoire longue, Paris, Jean Michel Place, 1999.

\section{NOTES}

1. D. Berliner, "Anthropologie et transmission», p.4-19. Sur la tradition, voir J. Pouillon, « Tradition».

2. Voir à titre indicatif, car les exemples sont nombreux, l'ouvrage collectif sous la direction de Denis Chevallier intitulé «Savoir faire et pouvoir transmettre. Transmission et apprentissage des savoirs faire et des techniques ».

3. D. Berliner, «Perdre l'esprit du lieu. Les politiques de L'UNESco à Luang Prabang ", p. 91-105. 
4. C. Choron-Baix, «Transmettre et perpétuer aujourd'hui ». Sur la question de la mémoire, se reporter à $\mathrm{F}$. Zonabend, La mémoire longue.

5. D. Berliner, «Perdre l'esprit du lieu. Les politiques de l'unEsco à Luang Prabang », p. 16 .

6. P. Bonte et M. Izard, Dictionnaire de l'ethnologie et de l'anthropologie, p. 712.

\section{AUTEUR}

\section{CLAUDINE VASSAS}

Ethnologue, directrice de recherche émérite au CNRS, membre du Laboratoire interdisciplinaire solidarités, sociétés, territoires (LISST, Centre d'anthropologie de Toulouse, EHESS/CNRS) 


\title{
Modernité et rupture dans la transmission intergénérationnelle des proverbes kabyles
}

\author{
Rabiha Ait Hamou Ali
}

1 Nous nous proposons dans la présente contribution d'expliciter le rapport de causalité entre la modernité, d'un côté, et la fragilisation dans la chaîne des acteurs de la transmission intergénérationnelle des proverbes kabyles, de l'autre. La transmission de ces derniers y paraît de moins en moins certaine, à l'instar des autres formes orales standardisées ${ }^{1}$ kabyles et de cette langue de façon générale, si on considère le degré de son hybridation dans la bouche des jeunes et même des moins jeunes locuteurs, notamment en zone urbaine. Vu sous cet angle, ce rapport semble conduire à des ruptures intergénérationnelles dans la transmission de l'héritage immatériel kabyle qui justifient l'inquiétude des défenseurs de cette langue. Il fait partie du processus de modernisation et de mutations sociopolitiques que connaît actuellement l'Algérie et de leurs corollaires socioculturels. Il est indissociable de l'urbanisation en devenir et de la généralisation du mode de vie de famille nucléaire, lieu et moteur des évolutions en cours $^{2}$.

2 Nous rendons compte ici de quelques analyses praxématiques de discours coproduits avec des hommes et des femmes lors de rencontres familiales, amicales et professionnelles au sujet de la pratique et surtout de la transmission des proverbes kabyles auprès des jeunes générations, en général, et de leur propre progéniture, en particulier. La conception et la réalisation de l'étude empruntent donc les principes de la théorie de la production dynamique du sens en langage pour répondre aux questions suivantes : que représentent ces proverbes pour ces personnes? Les emploient-elles? Dans quelles situations? Avec qui? Pensent-elles nécessaire que les nouvelles générations les adoptent? Pourquoi ? Font-elles le nécessaire justement pour que les jeunes générations les perpétuent, les acquièrent donc, les pratiquent et les transmettent à leur tour ? Comment? 


\section{La praxématique : théorie de la production dynamique du sens en langage}

3 En plus de l'observation directe et participante en situation de festivités sociales, de rencontres amicales et professionnelles, dont les données ont servi à l'élaboration d'un guide d'entretien de désambiguïsation de propos tenus, de pratiques révélées et de tout autre réglage de sens de diverses natures, nous conduisons des entrevues, selon les principes de la praxématique, avec treize partenaires qui ont accepté d'échanger autour de l'état de la pratique et de la transmission des proverbes kabyles. Ce sont donc des discours coproduits en amont de l'analyse et bien sûr en aval. En effet, la constitution du corpus obtenu tient compte de cette coproduction tout comme l'analyse des réglages de sens que suggèrent les " hétérogénéités constitutives ${ }^{3}$ », les "dialogisations ${ }^{4}$ » internes et externes des discursivités retranscrites et les voix polyphoniques ou tendues qui "feuillettent les discours ${ }^{5}$ » recueillis en situation d'intersubjectivités dans laquelle nous assumons la responsabilité de provoquer et d'orienter les échanges en fonction des besoins de notre étude.

Il va de soi que le recul recherché dans ce type de relations n'est que relatif, voire hypothétique. C'est pourquoi est-il plus indiqué de considérer notre subjectivité comme partie prenante du matériau à analyser au lieu de prétendre la contourner ou la neutraliser, alors que nous cherchons justement à saisir les procédés linguistiques de réglage plutôt discordant de sens dans les trajectoires de signifiance à l'œuvre dans ces échanges forcément intersubjectifs. Bégaiements, hésitations, reformulations, interruptions de programmes de sens, etc. sont autant de preuves matérielles de cette œuvre au niveau dialogal et de marques d'autocensure, de refoulement, de non-dits, etc. au niveau dialogique. Révélateur de tensions sociales, elles-mêmes moteurs de constructions discursives, ce matériau, qualifié ailleurs ${ }^{6}$ de «ratages conversationnels ", est loin d'être en marge de la construction sociale du sens comme le montre le tuilage des instances du temps opératif. En effet, celui-ci est inséparable des conditions présentes de l'échange. Il l'est aussi, et à la fois, de celles à qui ces conditions succèdent et de celles qui leur succèdent. Dans le premier cas, elles se manifestent sous forme d'indices d'accord ou de désaccord, de continuité ou de discontinuité de la mémoire syntaxique, etc. Dans le second cas, elles se traduisent sous forme de projets de discours d'un à-dire coincé entre et par le dire et le dit, c'est-à-dire des discussions dialogales et dialogiques/polyphoniques passées, présentes et à venir.

5 En adoptant ce cadre conceptuel de recueil et d'analyse de données, nous n'ignorons pas l'exigence sociolinguistique des mutations en cours dont l'impact sur les discours recueillis en situation d'interactions sollicitée rend davantage problématique sa saisie d'autant plus qu'à la région de Kabylie est posé le défi de conserver son authenticité culturelle tout en se mobilisant, d'une part, contre l'archaïsme linguistique et l'extrémisme religieux et, d'autre part, pour la modernité dans la conception de la citoyenneté en droits et en devoirs. Dans ce contexte, les mises en discours des rapports des uns et des autres aux proverbes, à cette espèce de mémoire expérientielle collective standardisée, pourraient contenir des indicateurs des évolutions en cours et à venir. 


\section{Le proverbe parmi les formes orales standardisées kabyles}

6 Appelé «forme brève $e^{7}$ ", "forme simple ${ }^{8}$ " et «langage formulaire ${ }^{9}$ ", le proverbe fonctionne, en effet, comme des bouts de langue où sont condensées sagesse et expérience de générations. Ils sont pratiqués socialement comme une espèce de standards linguistiques mémorisables et actualisés dans des conditions rendant leur illocution perlocutoire. Jack Goody ${ }^{10}$ les range parmi les produits de l'oralité qu'on pourrait dire performantes ou performatives performante ou performative. Ces « formes orales standardisées » du langage semblent, selon les travaux de cet auteur et en raison de l'anonymat de leur standardisation, résister mieux aux aléas de la transmission intergénérationnelle, notamment dans les sociétés sans écriture. Cela estil vérifiable dans le cas du kabyle et, à travers celui-ci, de l'amazigh en général ?

7 En effet, malgré la présence de l'écriture des langues des civilisations qui ont successivement dominé l'Afrique du Nord, malgré le progrès incontestable du passage actuel du kabyle à l'écrit, la société de ce nom demeure de traditions plutôt orales. L'écrit y concerne surtout les procédés de pensée de langues et de cultures arabe et française ${ }^{11}$. Les effets socioculturels de l'écriture constatés ailleurs se limitent ici, du moins jusqu'au $\mathrm{xx}^{\mathrm{e}}$ siècle, aux grands centres urbains. Ils concernent moins « la culture vécue $^{12}$ » que « la culture savante ${ }^{13}$ ». En effet, le proverbe mais aussi les devinettes, les contes, les légendes, les berceuses et les chants de différentes natures fonctionnent sur des modes d'énonciation spécifique au régime de l'oralité, et leur transmission aussi obéit à des procédés propres aux sociétés sans écriture comme le montrent les travaux de Jack Goody ${ }^{14}$.

8 Dans le cas du kabyle, cette transmission subit une fragilisation continue depuis l'éruption de la modernité, c'est-à-dire depuis l'apparition puis la généralisation de l'habitation urbaine, de l'urbanisation et de ce qu'elle implique comme mode et forme de langue de communication ainsi que de l'émancipation de la femme (à la façon occidentale). Les retombées de cette modernité sur l'évolution de l'organisation sociale se traduisent par le passage du mode de vie de famille traditionnelle (regroupant les parents, les grands-parents mais aussi les enfants, les petits-enfants, etc.) à celui de la famille nucléaire ou restreinte aux parents et aux enfants (des cas qu'on pourrait qualifier de "transitionnels ", car ils comprennent les grands-parents sans les tantes et oncles encore célibataires). Au niveau des pratiques langagière et culturelle, cette évolution se fait ressentir, comme nous l'avons déjà montré ailleurs ${ }^{15}$, en particulier dans la rupture dans la chaîne des acteurs de la transmission des prénoms kabyles ou kabylisés. C'est-à-dire dans l'abandon des croyances qui fondaient autrefois l'attribution des prénoms et dans l'adoption massive de prénoms orientaux et occidentaux et, à un degré moindre - depuis l'occupation pacifique de la rue par les défenseurs de l'amazighité dans les années 1980-1990 - de ceux issus de noms de rois, de princes et de guerriers amazighs.

9 Cette évolution se fait aussi ressentir dans la rupture de la chaîne des acteurs de la transmission des proverbes, des devinettes, des contes, des légendes, etc. Ces formes orales standardisées kabyles se transmettaient par habitudes langagières, mais aussi par devoir intergénérationnel car on les considérait comme des biens symboliques impératifs à la (sur)vie du groupe. Elles constituaient, de ce fait, un patrimoine immatériel à sauvegarder et dont il est de la responsabilité de chacun de perpétuer la 
pratique pour assurer une certaine pérennité culturelle intergénérationnelle, garante de l'identification au groupe d'appartenance et de référence.

Évidemment, il ne s'agit pas pour nous d'incriminer cette modernité, encore moins de lui préférer le moindre passéisme, l'avenir de cette langue étant, pour nous, dans la capacité de ses locuteurs à la servir pour s'en servir, c'est-à-dire à l'équiper de sorte à exprimer les besoins modernes de ses locuteurs qui, sans cet équipement, adopteront l'arabe et/ou le français ${ }^{16}$ qui leur offrent déjà ces moyens. Notre hypothèse de recherche des raisons de cette déperdition serait d'ailleurs incomplète sans la prise en considération de la politique culturelle et linguistique en Algérie. Pour généraliser l'emploi exclusif de l'arabe à tous les niveaux de l'administration et à long terme de la société, cette politique devait conduire à la disparition de l'amazigh dont le kabyle paraît, en raison de la mobilisation politique et de l'engagement productif de ses défenseurs, le dialecte en voie d'incarner la référence aux autres groupes amazighophones en Algérie et même ailleurs en termes de grammatisation ${ }^{17}$ et d'expérience éditoriale, d'industrie de la langue... Pour nous, les effets de la combinaison des trois facteurs (modernité, urbanisation, émancipation féminine), associés à la dévalorisation sociopolitique et socioculturelle du kabyle et de l'amazighité, de façon globale et jusqu'à une date récente ${ }^{18}$, constituent un constat qui pourrait avoir des implications sur les représentations de cette langue par ses propres locuteurs et d'où pourraient découler des attitudes qui prédisposeraient à des conduites déterminantes de l'avenir de cette langue et culture. C'est pourquoi nous jugeons important d'interroger ceux d'entre eux qui acceptent de discuter avec nous cette question de transmission de ces formes pour, au moins, provoquer un débat autour de cette question en espérant un écho socioculturel et sociopolitique sur la place publique. Nous conduisons ces discussions dans le cadre du projet de recherche universitaire intitulé justement "Pratiques et transmissions intergénérationnelles de langues en contexte de mutations plurilingues ${ }^{19}$ ». À cet effet, nous privilégions la démarche qualitative bien que le nombre soit en lui-même, dans certaines situations et certains cas de variables et même de répondants, porteur d'indices à combiner avec les données de nos observations directes et/ou camouflées, et le matériau verbal que nous recueillons en situation d'entretiens de désambiguïsation adoptant les principes de la linguistique praxématique ${ }^{20}$. Le recueil de ces données est encore en cours et les résultats que nous présentons ici sont partiels et appellent la confrontation avec ceux des autres membres de l'équipe en charge de ce projet.

\section{De la famille traditionnelle à la famille nucléaire : une hypothèse à vérifier}

Pour constituer une variable, c'est-à-dire une hypothèse de recherche à partir de laquelle on pourrait enquêter systématiquement, la distinction entre l'espace familial nucléaire et l'espace familial traditionnel, c'est-à-dire large, suppose des enquêtes sociologiques de confirmation qui nécessitent d'importants moyens humains et matériels que seule l'infrastructure étatique est en mesure de fournir. Elle s'apparente pour nous, en fait, à une découverte dans nos contributions antérieures aux deux projets de recherche réalisés pour le compte du Centre de recherche en anthropologie sociale et culturelle ${ }^{21}$, «Pratiques intrafamiliales et transmission des langues dans un milieu plurilingue » et «Attribution de prénoms en contexte de mutations sociales et 
culturelles en milieu plurilingue ». Cette " découverte » réoriente complètement nos recherches sur la transmission de la langue amazighe de Kabylie ${ }^{22}$ et tend à nuancer l'autre hypothèse qui semble recevoir l'adhésion de tous sans avoir à la vérifier comme si elle allait de soi ; ce qui lui confère le caractère d'une cause conduisant à des effets selon une logique toute simple de cause à effet. Il s'agit du rôle de gardienne des traditions qu'on attribue aux femmes de sociétés traditionnelles sans écriture, en général, et à la femme kabyle de façon spécifique, pour ce qui nous concerne ici.

En fait, les déclarations que nous avons recueillies et les observations que nous avons relevées et analysées nous ont "suggéré » de repenser ce rapport ou, au moins, ce rôle de la femme kabyle dans la sauvegarde des traditions, en matière de répartition des tâches sociales dans le cadre familial et villageois traditionnel. Cette répartition concernait aussi les hommes. Et les implications qui en découlaient également. Ce rôle tout comme ce statut de gardiennes de traditions concerne en fait certaines traditions. Celles-ci sont liées à l'espace féminin. Certes, elles les recevaient de leurs aînées selon des procédés implicites en usage dans les sociétés sans écriture; comme les hommes d'ailleurs. Elles les rechercheraient sans doute selon les modalités de socialisation en vigueur. Mais avaient-elles conscience de la nécessité de les sauvegarder en tant que patrimoine ancestral et constitutif d'une spécificité culturelle à défendre face à l'agressivité pénétrante des traditions exogènes? Largement touchée par la mobilité sociale et spatiale qui faisait que les hommes, partis ailleurs pour "gagner le pain", revenaient avec des bribes d'arabe, de français, etc., étaient-elles volontairement imperméables aux nouveautés, en particulier lorsque celles-ci procuraient une vie meilleure à leurs enfants, d'abord, et à elles, ensuite?

Nos conclusions, devenues depuis des hypothèses à vérifier et à discuter pour une meilleure reformulation, supposaient que ces femmes transmettaient ce qu'elles recevaient de leurs mères, grands-mères, belles-mères et autres autorités ou hiérarchies de la parole dans ce monde traditionnel sans toujours en avoir l'intention, c'est-à-dire sans avoir la conscience des défenseur(se)s actuel(le)s du kabyle. Cette transmission faisait partie des activités socio-éducatives des enfants et petits-enfants, des filles plus particulièrement. Nous avons en effet constaté que, pour ce qui est du choix et de l'attribution des prénoms, ce sont les locutrices (et rarement les locuteurs) qui semblent hésiter à reproduire les procédés traditionnels de cet exercice autrefois réservé non pas aux parents géniteurs mais aux grands-parents et/ou à l'entourage de ces derniers ${ }^{23}$. Souvent, elles s'opposaient, quand elles le pouvaient, à reproduire, par exemple, le prénom de la belle-mère avec ce non-dit lourd de signification socioconflictuelle opposant la belle-mère et la belle-fille, avec cette indication relevant d'une certaine croyance traditionnelle et selon laquelle, en reproduisant le prénom d'un membre de la famille disparu, on perpétuait sa mémoire et même sa "présence " parmi les vivants; ce que ne semblaient pas souhaiter celles qui s'opposaient à cette pratique. Naturellement, tout cela participe d'une certaine tendance à une émancipation qui passe, entre autres, par le rejet des référents sociaux de ces pratiques d'essence symbolique.

$\mathbf{E}^{24} \mathbf{1 2 3}$ : /c'est ancestral/25

F124 : / oui je sais/ je sais/mais que m'importe cela?// je [ne] vais pas condamner ma fille quand même à ::/ à ::/ à :: subir comme moi/ et puis c'est ma fille et je la prénomme comme je veux///

E125 : / la condamner avec le prénom de sa \#\#/

F126 : /c'est quand même vieux par rapport à sa génération// et puis je veux aussi 
la libérer de tout ça///

E127 : / tout ça///

F128 : / oui je l'ai eue toute seule ${ }^{26}$ et je l'élève toute seule donc euh:: / donc voilà je [vois] pas ce que je dois à cette tradition de de ::/ de perpétuer ces prénoms//bon j'ai accepté ce prénom mais je l'appelle Sabrina/ son père aussi/ et maintenant tout le monde/ même ses camarades d'école//

Nos travaux sur l'acquisition du français chez des lycéens de la ville de Tizi-Ouzou ${ }^{27}$ montrent aussi que la parole parentale adopte le même principe dans une autre perspective qui est celle de la réussite sociale et dans laquelle la maitrise des langues, et du français en particulier, constitue le pivot. Et c'est en gros la même logique qui ressort des observations directes que des observations camouflées (mobilisant un[e] enquêteur[-trice] de l'intérieur à la manière de William Labov) ont largement confirmées à propos de la pratique proverbiale comparant l'espace familial nucléaire à celui de la famille traditionnelle. À Tizi-Ouzou ${ }^{28}$ surtout, mais aussi dans les zones d'extension urbaine comme Azazga, Larbaa Nath Iraten, Mékla, Boghni, Draa El Mizan, Tamda, Draa Ben Khedda, etc., les pratiques proverbiales des locutrices de moins de 50 ans évoluant en familles traditionnelles semblent se distinguer de celles de la même tranche d'âge évoluant en famille nucléaire. Tout en déclarant avoir hérité (des parents, des grands-parents mais aussi des beaux-parents avec qui elles ont partagé le toit durant une période de leur vie de belle-fille et dont l'âge est toujours supérieur à 70 ans) plusieurs proverbes mais aussi des contes, des chants, des berceuses, etc., ces dernières admettent leurs difficultés à bercer leurs enfants en kabyle, à leur conter des légendes d'autrefois et à pratiquer les jeux des devinettes.

$\mathrm{M}^{29} 3^{29}$ : /avec leur grand-mère oui/ et même le grand-père aussi/ comme d'ailleurs quand on vivait ensemble// oui de ce côté c'était agréable/ oui c'était agréable à entendre/ c'était toujours doux et les filles s'endormaient paisiblement/ [En essuyant tendrement une larme de nostalgie et de déchirement.]

E94 : /c'est la vie/ c'est la vie//

M95: / c'est dommage c'est vraiment dommage/ils voulaient/ ils voulaient absolument un garçon//[Éclat de pleurs.]

E96 : / c'est la tradition/ c'est la tradition euh ::/

M97 : /je [n'y] suis pour rien// Nous [n'y] sommes pour rien// on [ne] l'a eu qu'à leur disparition// [Nouvel éclat de pleurs.]

Certaines d'entre elles disent que ces condensés respectivement d'affection, de fantastique et de subtilité leur reviennent à l'esprit durant nos échanges. C'est là un aveu pour signifier combien le manque trop prolongé de ces pratiques (avec les parents et grands-parents donc) leur a fait oublier ces souvenirs d'enfant auxquels les programmes scolaires, les chants et les activités ludiques de la télévision et autres médias de distraction sont substitués dans la vie actuelle, si bien qu'aujourd'hui elles éprouvent la nécessité de fournir des efforts pour se les réapproprier et, pourquoi pas, les actualiser. Leur pratique proverbiale, bien qu'elle paraisse échapper à la brutalité de la rupture (constatée dans la transmission des prénoms), n'est pas fréquente ni variée comme nous l'avons remarqué chez les locutrices de la première catégorie. Dans la plupart des cas, ces locutrices insinuent cet impératif énonciatif lié à la présence des grands-parents avec qui les échanges de toute façon ne peuvent pas se passer de ces condensés de sagesse, de morale et de philosophie de la vie.

$\mathrm{R} 112^{30}$ : / ah oui/ de toutes les façons quand mon beau-père parlait euh il il résumait euh il abrégeait tout avec un proverbe/ ou il euh :: euh :: il racontait une anecdote/ enfin une une euh::/ de toutes les façons il parlait toujours avec des proverbes/euh donc il faut connaître les proverbes pour parler avec lui// 
Ce constat est vérifié chez les locuteurs (masculins) chez qui, en plus, la défense du kabyle est assumée ouvertement. Alors que ces femmes, relativement jeunes et de familles nucléaires, semblent plutôt chercher à transmettre à leurs enfants, y compris dans leurs relations et échanges intrafamiliaux, les langues qu'elles considèrent comme le pivot de l'idée qu'elles se donnent de la réussite sociale : les langues scolaires et le français, en particulier ${ }^{31}$. C'est là, nous semble-t-il, un paradoxe à questionner à la lumière de données quantifiables à relever systématiquement.

$\mathrm{T}^{32}$ : /évidemment ça part/ oui ça part avec les monolingues/ et il y en a presque plus/ et ces proverbes aussi/ comme notre langue d'ailleurs/déjà il y a l'arabisation de l'école/il y a le français l'internet et tous les médias/d'ailleurs il y a beaucoup qui parlent carrément en français à leurs enfants/ en arabe c'est déjà le cas depuis longtemps// bon c'est c'est leur affaire bien sûr/ mais euh mais euh ::///

E75:/mais ::: ///

T76: /si tu veux tura/ tura einh ?/tura [à présent] il faut des militants de la langue//

E77 : /il [n']y en a pas ?/

T78: /je dirais qu'il [n']y en a plus/ en tout cas peu// mais je [ne] parle pas des militants politiques//

E79 : /c'est-à-dire ?/

T80 : /je veux dire des activistes/ des activistes// il faut un activisme/ des activistes en kabyle// il faut réactiver tout ça/ les proverbes/ les contes et tout/ c'est ça notre langue/ notre patrimoine aussi//

E81 : /et tu le fais toi ?/

T82 : /évidemment/ évidemment/ je parle uniquement kabyle à mes enfants/ ah oui et et tu peux tu peux euh tu peux le vérifier si tu veux avec eux/ ils sont bilingues c'est vrai// mais ils parlent le kabyle très bien et ils parlent sans mélanger//

\section{Du souhait à la réalité}

17 Dans leurs déclarations, les femmes interrogées partagent l'idée d'identification culturelle et de défense du kabyle avec leur époux. Sans aucune exception ni ambiguïté, elles s'opposent à toute velléité de rupture dans la transmission des proverbes et des autres formes orales standardisées (kabyles). Elles souhaitent les voir enseignées à l'école et faire partie de manière très audible dans les dialogues du jeune cinéma kabyle, en général, et, de façon plus particulière, dans les séries télévisées doublées en kabyle et diffusées sur le canal de la télévision de l'État.

Elles signifient donc, et sans le dire explicitement, qu'elles suivent les programmes de cette télévision depuis que ces derniers sont diffusés. Chacun connaît, en effet, le degré du rejet, dans l'espace kabylophone, de cette télévision significativement baptisée la Zéro!

En se défendant de toute idée de rejet de ces proverbes et avec eux des autres "langages formulaires» kabyles ${ }^{33}$, nos interlocutrices comme nos interlocuteurs se précipitent dans ce qu'il convient d'appeler un élan endogroupal irréel. Un élan affectivement recherché parce que justement, dans la réalité, les choses se passent autrement et très loin de ce qui fait pour eux, durant ces échanges, des objets désirés avant d'être des objets de discours. Des objets qu'ils souhaitent entendre dans la bouche de leurs enfants devenus adultes et dans la situation d'énonciation leur donnant toute leur force illocutoire, pour reprendre le paradigme de la théorie des actes de langage et ce que celle-ci partage avec les théories de la pertinence et de l'accommodation. Ces 
propos résonnent comme des récipients de frustration. C'est comme si nos interlocutrices et interlocuteurs avaient été dépossédés injustement de ces objets qui leur rappelaient leur enfance. Cette enfance que l'école et ses promesses d'une vie matérielle meilleure ont tant préoccupé, que l'activité sociale quotidienne, même au contact des plus âgés dans des circonstances appropriées qui pouvaient et devaient fixer cette pratique, s'est révélée trop impuissante devant la machine idéologique de l'uniformisation culturelle de la pensée unique des années 1960-1990 et l'urbanisation en cours de généralisation. Tout porte à entendre dans leur voix ces paroles longtemps enfouies dans un passé qui ressurgit subitement dans un présent en rupture de lien avec ces lieux de mémoire, d'expérience, de sagesse et autres événements heureux ou malheureux de la vie en collectivité familiale, d'abord, et villageoise, ensuite. Aujourd'hui, cela fonctionne presque comme un ailleurs, car les porteurs/passeurs de ces condensés de traditions de l'oralité deviennent, pour les générations de l'école de la République, d'Occident et d'Orient, qui arrivent sur des supports non-humains, qui se tiennent rectilignes dans les chambres des enfants pour les endormir à coups de répétition, sans la moindre variabilité vocale et lexicale. Et les sentences d'auteurs de traditions écrites remplacent les adages et les dictons des "forgerons de la parole » disparus dans le temps, et avec eux les biens qu'ils auraient, sans doute, voulus léguer à ceux qui pouvaient ou voulaient les recevoir, les sauvegarder et les transmettre. Cela pouvait-il en être autrement dans l'univers actuel d'individualisme social et de biens matériels ? ${ }^{34}$

M40 : / oui c'est vrai/ c'est vrai on entend encore quelques-unes chanter cela/ oui on entend même lors des enterrements/ mais mais euh :: c'est vrai ça donne ça donne des frissons/ des frissons//

E41 :/vous en connaissez ?//

M42 : / des frissons ? [E:/XXX/] déjà maintenant là à l'instant j'ai j'ai j'ai euh : j'ai la chair de poule/ oui regarde regarde/ [Marzouk retire sa manche et exhibe son bras gauche]/oh la la laaaa!//

E43 : [rire d'étonnement]/ à ce point !à ce point !//

M44: / c'est c'est plus fort/ c'est pas c'est pas simple tout ça/ ces souvenirs ça peut pas euh::/ ça revient ça revient/ ça revient à chaque fois euh ::/ à chaque évènement//

E45 : / à ce point ?//

M46: / oui à chaque fois/ et parfois il suffit euh : oui une simple discussion et ça provoque tout ça/ que veux tu hein? c'est moi/ c'est ma culture/ c'est nous oui c'est nous/ et tout ça hein! tout ce monde est est euh/ c'est nous tout ça/les proverbes et tous nos chants etc./c'est nous tout ça/ et tout ça tout ça part ça part//

E47 : /pourquoi ça part euh:/ j[e] veux dire on peut bien les transmettre $\mathrm{XXX}^{35}$ /

M48: /oui on veut bien/ on veut bien/[...]/mais où ? à l'école/ c'est l'arabe qu'ils euh : ou le français/ après c'est la télé en arabe et en français aussi et maintenant c'est carrément l'internet/ il les poursuit même au lit//

E49 : / au sommeil et au réveil//

M50: / exactement/ exactement/ tout s'impose à nous/ c'est c'est quand même euh : c'est c'est euh ::/

E51 : /frustrant?/

M52 : / voilà/ c'est frustrant/ merci/ c'est très frustrant//

E53 : /et on n'y peut rien?/

M54: /c'est difficile/ c'est très difficile/ très difficile à vivre/ c'est très pénible/ la vie a beaucoup changé//

E55 : /en bien non ?/

M56: /en bien matériel/ en bien matériel/ et encore il faut dire que tout est 
matériel maintenant// et tout ce qui [ne] rapporte pas est rejeté/ c'est d'ailleurs un proverbe en arabe/li mayenfaa adfaa// [jeter ce qui n'est pas utile] au réglage de sens de son contenu par l'expressivité francophone de Marzouk, linguiste en exercice et auteur de travaux en littérature orale amazighe. Cependant, les innombrables hésitations que rendent les prolongements vocaliques, les ruptures de programmes de sens et les appels à l'aide pour trouver les " mots » (comme en M50) et surtout les chevauchements (M42, E46) ainsi que le réglage de sens détourné (comme en M42), etc., illustrent toute la difficulté, pour nous d'abord, de (re)centrer l'échange sur les proverbes et, pour nos interlocuteurs ensuite, de les dissocier des autres formes orales standardisées kabyles. On pourrait y voir, en effet, des répliques à la fois de superpositions et de confrontations de voix, en ce sens que ces formes orales standardisées constituent et fonctionnent comme un tout dont les constituants s'appellent et s'impliquent. Nous avons perçu, plus particulièrement dans cet exemple en raison du statut d'auteur de notre vis-à-vis, une tendance à la réorientation non pas du fil de nos codiscours (la transmission intergénérationnelle), mais de l'objet qu'il amène aux chants traditionnels: le sujet de ses travaux. Point d'évitement ni de camouflage encore moins de contournement de sens, y compris dans ce qui s'apparente dans les enchaînements de M42, E43, M44, E45 et M46 à une espèce de théâtralisation où dramatisation et dédramatisation se succèdent et peinent à faire émerger ce qui nous distinguerait, sur ce point, de notre vis-à-vis, sinon notre souci d'impliquer sa subjectivité pour provoquer davantage de mises en discours comme avec les autres partenaires des échanges réalisés.

21 L'aveu d'impuissance de Marzouk fait écho, en effet, à celui des autres interlocuteurs interrogés. Loin d'impliquer un sentiment de renoncement, comme l'atteste l'emploi systématique des possessifs endogroupaux (nous, notre et nôtre), ces mises en discours sont, au contraire, l'expression plus polyphonique que dialogique de l'inquiétude d'une disparition définitive. Elles ne peuvent s'entendre qu'en termes d'appel d'urgence pour secourir ces biens immatériels en danger de disparition justement.

Loin de livrer tous les secrets du devenir des pratiques proverbiales dans l'espace social kabyle actuel, et avec elles l'ensemble du patrimoine immatériel de cet espace culturel et linguistique, les échanges réalisés à ce sujet sont en concordance avec ce que nous constatons depuis au moins une décennie : ce devenir est incertain. Sans l'engagement des pouvoirs publics pour redynamiser socialement ces pratiques dans le contexte urbain plurilingue, en voie de généralisation, il est en effet peu probable que la défense des militants puisse atténuer les effets négatifs sur le maintien de ces formes orales standardisées des mutations socioéconomiques et sociopolitiques dans lesquelles est engagé l'espace kabyle. 


\section{BIBLIOGRAPHIE}

AIT HAMOU ALI Rabiha, «Construction interlocutive de représentations du français dans des échanges entre des lycéens et leurs parents à Tizi-Ouzou ", Synergies Algérie, nº 20, 2013, p. 67-81. AIT HAMOU ALI Rabiha, « Discours de parents d'élèves tizi-ouziens à propos des langues à l'école et dans le giron familial ", Les cahiers du SLADD, $\mathrm{n}^{\circ}$ 7, 2015, p. 45-62.

AIT HAMOU ALI Rabiha, « Rupture dans la transmission de prénoms kabyles : propos de témoinsporteurs », dans Sini Chérif (dir.), Les langues dans l'espace familial algérien, Oran, Centre de recherche en anthropologie sociale et culturelle, 2013, p. 37-52.

AUROUX Sylvain, La révolution technologique de la grammatisation : introduction à l'histoire des sciences du langage, Liège, Mardaga, 1994.

AUTHIER-REVUZ Jacqueline, « Hétérogénéité montrée et hétérogénéité constitutive : éléments pour une approche de l'autre dans le discours », Documentation et recherche en linguistique allemande contemporaine, $\mathrm{n}^{\circ} 26,1982$, p. 91-151.

BRES Jacques, « Savoir de quoi on parle : dialogue, dialogal, dialogique ; dialogisme, polyphonie... », dans Bres Jacques et al. (dir.), Dialogisme et polyphonie : approches linguistiques, Bruxelles, De Boeck-Duculot, 2005, p. 47-62.

DÉTRIE Catherine, SIBLOT Paul, VERINE Bertrand, Termes et concepts pour l'analyse du discours : une approche praxématique, Paris, Honoré Champion, 2001.

GOODY Jack, Entre l'oralité et l'écriture, Paris, PUF, 1994.

Jolles André, Formes simples, Paris, Éditions du Seuil, 1972.

MAMMERI Mouloud, Culture savante, culture vécue, Alger, Tala, 1991.

MEIRIEU Phillipe, « Quelle éducation pour faire face aux défis d'aujourd'hui ? », bulletin $\mathrm{n}^{\circ} 1 \mathrm{de}$ l'Institut pour la promotion du lien social, 2018, n. p.

MELLAK Djillali, «L'oralité au Maghreb : la mémoire sans cesse proférée », Dialogue méditerranéen, $\mathrm{n}^{\circ} 5,2013, \mathrm{p} .77-84$.

MONTANDON Alain, «Formes brèves et microrécits », Les cahiers de Framespa, éd. numérique, $\mathrm{n}^{\circ} 14$, 2013. [URL :https://journals.openedition.org/framespa/2481]

RABATEL Alain, « La dialogisation au cœur du couple polyphonie/dialogisme chez Bakhtine », Revue romane, vol. XLI, $\mathrm{n}^{\circ}$ 1, 2006, p. 55-80.

SINI Chérif, « La famille nucléaire kabyle : enjeu et moteur des mutations sociolinguistiques en cours dans la région de Tizi-Ouzou? », Les cahiers du SLADD, nº 9, 2017, p. 313-334.

SINI Chérif, « La promotion du berbère en Algérie : de la prise de conscience intellectuelle au projet de société citoyenne », Cahier d'études africaines, n 219, 2015, p. 445-465.

SINI Chérif, « La question de la graphie pour la langue kabyle », Mots : les langages du politique, $\mathrm{n}^{\circ} 110,2016$, p. 142-153.

SINI Chérif, « Les procédés traditionnels d'attribution de prénoms à l'épreuve des mutations socioculturelles à Tizi-Ouzou », Les cahiers du SLADD, nº 8, 2015, p. 179-199. 
SINI Chérif, « Paroles de parents kabylophones tizi-ouzouèens à propos des langues à faire acquérir à leurs enfants », dans Laroussi Foued, Liénard Fabien (dir.), Plurilinguisme, politiques linguistiques et éducation : quels éclairages pour Mayotte?, Mont-Saint-Aignan, Presses universitaires de Rouen et du Havre, 2011, p. 449-464.

\section{NOTES}

1. Par «formes orales standardisées ", J. Goody désigne les proverbes, les adages, les dictons mais aussi les devinettes, les berceuses et autres contes, légendes, chants de moisson, de jouissance, de célébration funèbre, etc., rythmant la vie dans les sociétés sans écriture.

2. C. Sini, «La famille nucléaire kabyle: enjeu et moteur des mutations sociolinguistiques en cours dans la région de Tizi-Ouzou ? », p. 313.

3. J. Authier-Revuz, «Hétérogénéité montrée et hétérogénéité constitutive : éléments pour une approche de l'autre dans le discours ", p. 91.

4. A. Rabatel, «La dialogisation au cœur du couple polyphonie/dialogisme chez Bakhtine ».

5. J. Bres, "Savoir de quoi on parle: dialogue, dialogal, dialogique; dialogisme, polyphonie... ».

6. $Y$ compris en analyse conversationnelle.

7. A. Montandon, « Formes brèves et microrécits ».

8. A. Jolles, Formes simples, p. 7.

9. D. Mellak, «L'oralité au Maghreb : la mémoire sans cesse proférée », p. 77.

10. J. Goody, Entre l'oralité et l'écriture.

11. C. Sini, «La promotion du berbère en Algérie: de la prise de conscience intellectuelle au projet de société citoyenne »; C. Sini, « La question de la graphie pour la langue kabyle ».

12. M. Mammeri, Culture savante, culture vécue, p. 64-74.

13. Ibid.

14. J. Goody, Entre l'oralité et l'écriture.

15. R. Ait Hamou Ali, «Rupture dans la transmission de prénoms kabyles: propos de témoins-porteurs ".

16. L'arabe et le français menacent le kabyle traditionnel dans son espace familial même, y compris dans les zones les plus isolées géographiquement.

17. S. Auroux, La révolution technologique de la grammatisation : introduction à l'histoire des sciences du langage.

18. Après sa promotion au statut de "langue également nationale" lors de l'amendement constitutionnel d'avril 2002, la langue amazighe est admise comme seconde langue officielle en Algérie avec la révision constitutionnelle de janvier 2016.

19. Projet domicilié au Laboratoire d'aménagement et d'enseignement de la langue amazighe de l'université Mouloud-Mammeri de Tizi-Ouzou (Algérie).

20. C. Détrie, P. Siblot, B. Verine, Termes et concepts pour l'analyse du discours: une approche praxématique. 
21. CRASC, Oran (Algérie).

22. Nous disons bien de Kabylie et non en Kabylie, car cette transmission concerne aussi cette langue en dehors justement de cet espace sociogéographique.

23. C. Sini, «Les procédés traditionnels d'attribution de prénoms à l'épreuve des mutations socioculturelles à Tizi-Ouzou ».

24. $\mathrm{E}$ = enquêtrice; $\mathrm{F}=$ Farida, employée de banque, la cinquantaine et mère d'Aldjia dite Sabrina et de Hend dit Juba. Entretien entamé en kabyle et réalisé en alternance avec le français.

25. Indications générales sur les modalités d'entretien: / pause; // pause moyenne; /// pause longue ; : allongement vocalique ; \# inaudible.

26. En famille nucléaire, sans l'aide habituelle de la famille traditionnelle.

27. R. Ait Hamou Ali, «Construction interlocutive de représentations du français dans des échanges entre des lycéens et leurs parents à Tizi-Ouzou »; R. Ait Hamou Ali, "Discours de parents d'élèves tizi-ouziens à propos des langues à l'école et dans le giron familial ».

28. Chef-lieu du département du même nom et principale ville kabyle, à une centaine de kilomètres au sud-est d'Alger.

29. $M$ = Malika, la cinquantaine, enseignante dans le secondaire.

30. $R=$ Razika, infirmière de $30-40$ ans (version traduite du kabyle).

31. C. Sini, «Paroles de parents tizi-ouzouèens à propos des langues à faire acquérir à leurs enfants ».

32. $\mathrm{T}$ = Tahar, médecin, la quarantaine passée.

33. D. Mellak, «L'oralité au Maghreb : la mémoire sans cesse proférée », p. 77.

34. P. Meirieu, «Quelle éducation pour faire face aux défis d'aujourd'hui ?»

35. Chevauchement.

\section{RÉSUMÉS}

À partir d'observations directes et de mises en discours sollicitées en situation d'intersubjectivités et analysées selon la praxématique en combinaison avec la conception sociale de la langue, l'ensemble ci-après explicite le rapport entre la modernité et la fragilisation dans la chaîne de transmission des proverbes kabyles et de la langue du même nom. Cette fragilisation semble se situer dans le passage du mode d'organisation familiale traditionnelle/large à celui de la famille moderne/nucléaire qui coïncide avec l'urbanisation et l'accès de la femme à l'activité salariale en dehors du foyer familial, impliquant la mise des enfants dans des établissements de la petite enfance pour apprendre l'arabe ou le français. Cette double rupture discrètement encouragée, jusqu'au début de ce siècle, par la politique culturelle du pays semble conduire vers l'extinction de ces proverbes malgré l'éveil des défenseurs politiques du kabyle et de la langue amazighe (la langue berbère) en général. 


\section{AUTEUR}

\section{RABIHA AIT HAMOU ALI}

Enseignante-chercheure en français à l'Université Mouloud Mammeri de Tizi Ouzou, Algérie, associée au Centre de recherche en anthropologie sociale et culturelle (CRASC) 


\title{
Le Psaume 104 : témoin des aléas de la transmission d'un savoir à Jérusalem dans l'Antiquité
}

\author{
Stéphanie Anthonioz
}

1 Le livre des Psaumes appartient à la section des Ketouvim ou «Écrits» de la Bible hébraïque, qu'il ouvre. Il comprend cent cinquante compositions, de thèmes et de formes diverses, de longueurs variables. En hébreu, il a reçu le nom de tehillîm, pluriel de tehillah, qui signifie «louange ». Alors qu'on ne trouve ce terme que dans le titre du Ps 145 (v. 1), l'interprétation de l'ouvrage comme tel est cependant justifiée par le fait que, si la première partie est dominée par la supplication, le ton change progressivement pour faire place à la louange exclusivement. Pourquoi alors les «louanges » sont-elles devenues «psaumes»? Le grec apporte la réponse, puisque "psaume» dérive du psaltérion qui désigne l'instrument à cordes avec lequel on accompagne le chant. Même si théoriquement seul le mizmôr hébreu est accompagné de l'instrument, la traduction grecque de la Septante a généralisé l'usage du mot pour l'appliquer à l'ensemble des compositions. On voit déjà à travers ces quelques remarques concernant le titre l'impact de la transmission et de la réception de ce livre.

2 Si le livre offre une certaine unité d'ensemble, à cause des quelques arguments formels comme les doxologies, il n'en reste pas moins qu'il réunit des pièces fort différentes, des prières collectives avec des prières individuelles, des récits d'histoire nationale, voire de l'histoire des origines, avec des récits personnels parfois intimes. La diversité des textes mis ensemble ne fait aucun doute. La dimension rituelle des différentes pièces, si elle a existé, a été gommée manifestement au fil de la mise ensemble des compositions, qui répond parfois à l'exigence d'une collection, comme celles d'Asaf (73-83) et de Coré $(42-49 ; 84-85.87-88)$. Et même les collections dites de David présentent peu d'éléments communs sinon leur rattachement à la figure royale (3-41; 51-72). Ainsi, le psautier apparaît au mieux sous l'habit d'une anthologie : est-elle alors liturgique au moment de sa composition ou bien l'est-elle devenue au fil de ses relectures et de son autorité consacrée ? Il ne fait pas de doute que les Psaumes représentent une composition originale et unique mais, loin de refléter la prière de 
l'Israël ancien, ils reflètent plutôt le travail des scribes de la communauté de Jérusalem, occupés à la transmission des compositions et des collections ${ }^{1}$. D'ailleurs, les témoins anciens montrent des différences importantes tant dans le nombre de compositions que dans la forme.

3 Cette contribution a pour objet d'explorer la transmission de ce "livre " particulier dans l'Antiquité en s'appuyant sur un psaume témoin, connu aujourd'hui sous le numéro 104. Cette exploration permettra d'étudier la manière dont les scribes œuvraient. Quels éléments étaient jugés dignes d'être transmis et, par contrepoint, quels éléments étaient omis? Ces éléments omis étaient-ils volontairement perdus ou un dommage collatéral à l'entreprise de transmission? Les scribes avaient-ils recours à telle ou telle pratique en vue d'assurer la juste transmission ou l'interprétation de ces compositions, de manière singulière mais également en tant que collection?

4 La première partie de cette étude vise à présenter les témoins hébraïques anciens du Ps 104, à mesurer les variantes, à caractériser les techniques des scribes. La seconde partie revient, en amont de la composition, sur les traditions égyptiennes et plus particulièrement amarniennes du Ps 104, et s'interroge : une telle transmission est-elle envisageable entre les capitales Amarna et Jérusalem? Avant d'aborder une étude plus détaillée, la question de la structure du psaume se posera, car comment comparer ce que l'on comprend mal? Enfin, une étude détaillée du psaume en ses traditions permettra d'éclairer les pratiques des scribes, au-delà des influences qui restent controversées.

\section{Les témoins hébraïques anciens du Ps 104}

Diversement attesté à Qumrân par les manuscrits - 110Psa $(104,1-6.21-35)$; $4 \mathrm{QPs}^{\mathrm{d}}$ (104,1-5.8-11.14-15.22-25.33-35); 4QPs ${ }^{\mathrm{e}}(104,1-3.20-22) ; 4 \mathrm{QPs}^{1}$ (104,3-5.11-12); 2QPs (104,6.8-9.11-12) - , le psaume que nous appelons aujourd'hui 104 n'apparaît pas dans un ordre fixe (entre 103 et 105 donc). Reprenons brièvement chacun de ces témoins. $11 \mathrm{QPs}^{\mathrm{a}}$, fragment $\mathrm{E}$, contient les restes de trois colonnes et les portions des Psaumes suivants : $118,24-29$; 104,1-6 dans la colonne i ; 104,22-35 et 147,1-2 dans la colonne ii et 147,18-20 ainsi que 105,1-113. Le texte hébreu préservé dans la première colonne est très proche du texte massorétique ou TM (v. 1-6). On note les variantes suivantes : le psaume est précédé de la mention «à/de David»; le tétragramme est écrit en caractères paléohébraïques et suivi du nom divin sous la forme «notre Dieu » (1. 7) et non « mon Dieu »; en 104,4 l'accord du substantif « feu » se fait au féminin (1. 10) non au masculin (cf. $4 \mathrm{QPs}^{\mathrm{d}}$ et $4 \mathrm{QPs} \mathrm{P}^{\mathrm{l}}$ ), ce qui reste d'ailleurs grammaticalement correct.

Le texte hébreu est extrêmement bien préservé dans la deuxième colonne (v. 21-35). Du coup, le nombre des variantes est aussi plus important mais leur teneur sans conséquence majeure. Ainsi, outre les questions d'orthographe, on peut noter la forme verbale en 104,22 qui est dotée d'un waw (comme en 104,28.29.30.31) tandis que la forme nominale "leur tanière» est suffixée plus lourdement (comme $4 \mathrm{QPs} \mathrm{e}^{\mathrm{e}}$, cf. Jr 21,13; Jb 37,8). Le début du verset 25 (1. 4) est amputé du démonstratif. Par contre, la seconde phrase nominale se voit complétée d'un adverbe: "là beaucoup se meuvent ", et la troisième phrase note une variante de construction. Au verset 27, 1.7, on peut noter l'ajout du complément: "afin de leur donner leur nourriture ». De manière plus intéressante, manque dans le fragment qumranien, 1.8, le stique entier «tu caches ta face, ils se troublent» $(104,29)$. Intéressante aussi la variante "ton 
souffle » au lieu de «leur souffle » (104,30). Les variantes qui suivent sont de l'ordre de la construction, de la syntaxe et de l'orthographe. La copie, œuvre des scribes, n'admet ici qu'une liberté d'orthographe et de syntaxe donc. Plus intéressante l'absence d'un stique ou la variante, peut-être théologique, sur le "souffle ", même s'il est difficile d'interpréter en l'état ces différences. S'agit-il d'une liberté d'interprétation, d'une correction théologique ou simplement d'une erreur de copie? Cette analyse peut être poursuivie sur l'ensemble des manuscrits et des fragments : les types de variantes sont les mêmes.

$74 \mathrm{QPs}^{\mathrm{d}}$ préserve de manière fragmentaire des portions des Ps 106 (48 ?); 147 (1-4.13-17.20) et 104 (1-5.8-11.14-15.22-25.33-35)4. Dans la colonne ii (Ps 147,13-17.20; 104,1-5), le titre mentionnant David est apparemment absent (contrairement à 11QPs ${ }^{a}$ ). En 104,1, 1.11, le nom divin peut être reconstruit comme "Yhwh Yhwh Die[u] » (à comparer donc aux variantes du TM et de $\left.11 \mathrm{QPs}^{\mathrm{a}}\right)$. La dernière forme verbale du verset est un inaccompli «tu te revêts", alors que le TM présente l'accompli. Les variantes suivantes concernent la syntaxe, le nombre et l'accord, enfin l'orthographe. Il en est de même pour la colonne iii (Ps 104,8-11.14-15) plus fragmentaire et la colonne iv (Ps 104,22-25).

$4 \mathrm{QPs} \mathrm{e}^{\mathrm{e}}$ préserve sur les fragments xiv, $\mathrm{xv}$-Xvi les portions du Ps 118,29 suivi directement de $104,1-3$ puis $20-22^{5}$. Le texte est trop fragmentaire et, outre des questions d'orthographe, ne présente pas de variante majeure. Le nom divin au verset 1 n'est pas écrit en caractères paléo-hébreux mais carrés. L'espace permet de restituer ou du moins de supposer la mention introductive «à/de David».

$4 Q \mathrm{Ps}^{1}$ préserve sur les colonnes $i$ et ii les versets $3-5$ puis $11-12^{6}$. En Ps $104,4,1.9-10$, on peut noter les singuliers alors que le pluriel est attesté dans le TM, $11 \mathrm{QPs}^{\mathrm{a}}$ et $4 \mathrm{QPs}{ }^{\mathrm{d}}$, et en Ps 104,5, 1.11-12, une variante orthographique et une variante syntaxique.

2QPs est constitué de deux fragments seulement couvrant les portions des Ps 103,2-11 et 104,6-11'. On note ainsi en 104,8, 1.2 l'ajout d'un mot.

11 L'ensemble des témoins pointe ainsi vers une même conclusion concernant les pratiques de la copie. L'arcane du texte demeure alors que sa place dans la collection n'est pas fixe. L'attribution à David n'est pas généralisée, ni d'ailleurs l'écriture du nom divin. Varient des formes orthographiques, morphologiques, grammaticales ou syntaxiques. Ces écarts sont en général sans conséquence sur le sens ou la compréhension du texte. On peut penser que, pour les scribes, ces variantes relèvent de la technique de la copie et de son intention. Elles sont à comparer à celles qui ont été mises en lumière depuis longtemps dans le monde cunéiforme ${ }^{8}$. Les variantes majeures, celles qui changent la compréhension du texte, apparaissent plus souvent dans les restructurations et les ajouts que dans le détail. Mais ces variantes ne sont pas ici assez importantes pour juger de la liberté des scribes à faire œuvre d'interprétation ou de réinterprétation lorsqu'ils copient. Ils ne s'arrogent aucun droit manifestement dans la copie du psaume qui semble dès lors une composition "arrêtée ». Je voudrais comparer ces résultats aux conclusions de Dominique Charpin au sujet de la lecture et de l'écriture en Mésopotamie et, plus particulièrement, au sujet du travail de copie massif qui se développe dans les capitales assyriennes au I ${ }^{\text {er }}$ millénaire av. n. è. :

«On doit ajouter qu'il n'existait chez les scribes mésopotamiens aucun sentiment comparable à la "bibliophilie" moderne: lorsqu'ils découvraient une tablette ancienne intéressante, ils en recopiaient le contenu, mais ne se souciaient guère de l'original. [...] Ce qui compte, c'est bien le texte non le manuscrit ${ }^{9}$. » 
Ce constat prouve certainement le poids de la tradition et de la transmission orale même quand le support écrit est devenu nécessaire. Cette pratique orale de l'écrit, pourrait-on dire, permet de mieux comprendre la fluidité des textes et la nature des variantes orthographiques, grammaticales, syntaxiques, plus rarement lexicales, sémantiques ou idéo-théologiques. Ce constat n'empêche pas de s'interroger sur les sources à partir desquelles les scribes ont œuvré pour produire une composition unique et originale malgré des variantes typiques donc de l'œuvre de copie.

\section{Les aléas de la transmission : le Grand Hymne à Aton}

Le Ps 104 est célèbre pour sa proximité thématique et idéologique avec un hymne au dieu égyptien Aton. Le Grand Hymne à Aton se lit, disposé en treize colonnes, dans l'embrasure de la porte de la tombe $n^{\circ} 25$ à Amarna, aménagée pour Aÿ, personnage de l'entourage du roi Akhenaton/Aménophis IV (c. 1350 av. n. è.), dont l'épouse Tiyi fut la nourrice principale de la reine Néfertiti ${ }^{10}$. La structure du texte laisse supposer une métrique bien établie, texte liturgique, destiné à être récité, voire peut-être même chanté, lors des cérémonies du culte dans les temples de la nouvelle capitale Akhetaton. L'hymne s'adresse au dieu Rê-Horakhty, en premier lieu, dont Aton comme astre vivant est la manifestation, ainsi qu'au pharaon et à son épouse. Aussi la louange divine se faitelle éloge de la famille royale. Le Grand Hymne n'est connu que dans une seule version ${ }^{11}$ dont la compréhension n'est pas définitive. Les parallèles avec le Ps 104 ont été soulignés depuis longtemps, de nature littéraire, ou plutôt thématique ${ }^{12}$. La question de la dépendance s'est alors posée, souvent affirmée dans un sens (ou dans l'autre ${ }^{13}$ ), parfois très nuancée ${ }^{14}$, plus rarement, au contraire infirmée ${ }^{15}$. De fait, une simple comparaison invite à mesurer la distance d'un texte à l'autre (tabl. 1, 2).

Tabl. 1. - Grand Hymne à Aton et Psaume 104 : comparaison.

\begin{tabular}{|c|c|}
\hline Grand Hymne à Aton, colonnes 2-3 & Psaume 104,1-2 \\
\hline $\begin{array}{l}\text { Ton apparition est parfaite dans l'horizon du ciel, ô } \\
\text { Aton vivant, qui inities la vie, car tu es brillant dans } \\
\text { l'horizon oriental. } \\
\text { C'est de ta perfection que tu as rempli toute la terre, } \\
\text { car tu es beau et grand, resplendissant et éminent au- } \\
\text { dessus de toute la terre. } \\
\text { Tes rayons embrassent les terres jusqu'aux confins } \\
\text { de tout ce que tu as créé, car tu es le soleil. } \\
\text { Tu atteins jusqu'à leurs confins afin de les soumettre } \\
\text { à ton fils bien-aimé, car tu es éloigné. } \\
\text { Tes rayons sont sur le pays et tu es dans les regards, } \\
\text { [mais] on ne connaît pas [?] tes cheminements. }\end{array}$ & $\begin{array}{l}\text { Bénis le Seigneur, ô mon âme! } \\
\text { Seigneur mon Dieu, tu es si grand! } \\
\text { Vêtu de splendeur et d'éclat, drapé de } \\
\text { lumière comme d'un manteau, tu déploies } \\
\text { les cieux comme une tenture. }\end{array}$ \\
\hline
\end{tabular}

D'après C. Obsomer, «À propos de deux passages du Grand Hymne à Aton (colonnes 2-3 et 6-7) », p. 11.

Tabl. 2. - Grand Hymne à Aton et Psaume 104 : comparaison. 
[Toi] qui produis les semences dans les femmes, qui transformes le fluide en êtres humains, [toi] qui vivifies le fils dans le ventre de sa mère, qui l'apaises en cessant ses larmes, [toi qui es] une nourrice dans la gent féminine, qui donnes le souffle pour vivifier tout être qu'un père engendre, lorsque celui-ci sort du ventre pour respirer, le jour de sa naissance, tu lui ouvres sa bouche entièrement et tu pourvois à ses besoins.

Tu envoies ton souffle, ils sont créés, et tu renouvelles la surface du sol.

D'après C. Obsomer, «À propos de deux passages du Grand Hymne à Aton (colonnes 2-3 et 6-7) 》, p. 18.

14 L'ensemble des auteurs bien sûr invite à mesurer les distances idéologiques ${ }^{16}$. Il n'en reste pas moins que les séquences thématiques qui peuvent être comparées n'ont cessé d'être réaffirmées : la présentation du dieu universel, le coucher du soleil avec le repos de l'homme et la liberté des bêtes du désert, le lever du soleil avec l'activité de l'homme, la vie heureuse des animaux marins et terrestres, la divinité source du souffle et de la vie, la sagesse divine qui a tout créé et veille sur tout. La notion de dépendance reste ainsi ancrée dans la recherche.

Si le Grand Hymne à Aton est une pièce unique d'époque amarnienne, il faut alors imaginer une voie de transmission complexe via Canaan ou la Phénicie, comme le montre d'ailleurs la présence de motifs levantins tel le Léviathan : le Ps 104 n'en serait pas moins un témoin de la réception de la religion amarnienne à Jérusalem plusieurs siècles après. Il devient donc nécessaire d'introduire les notions de tradition mais aussi de mémoire et c'est précisément dans ce sens que les travaux de Jan Assmann invitent à réfléchir ${ }^{17}$. Mais peut-être est-ce la pratique scribale qui fausse la reconnaissance des jeux d'influence? C'est l'hypothèse volontiers défendue par Sirje Reichmann pour qui le Ps 104 comme aussi Pr 22 sont des traductions partielles d'originaux égyptiens : peu importe les formulations variantes si les thèmes sont comparables. Les différences sont irrémédiablement la conséquence de toute traduction ${ }^{18}$. Pourtant, on peut se demander si une correspondance thématique - puisque la comparaison religieuse a ses limites est suffisante pour justifier la notion d'emprunt ou de dépendance. Mes travaux me conduisent à penser que l'argument thématique n'est pas suffisant. De plus, l'analyse du Ps 104 démontre une telle maitrise de diverses traditions qu'il serait dommage de le réduire à une seule dépendance.

\section{La structure du psaume : quelle cohérence?}

Regardons le Ps 104 plus en détail. Notons d'abord que la structure générale est difficile à saisir et qu'elle reste débattue : le psaume joue d'associations et de corrélations à répétition. Selon Jean-Luc Vesco, le Ps 104 se présente comme un grand diptyque 1-18 19-35 avec les correspondances suivantes :

-1b-4 - 19-23 : Yhwh vêtu de lumière et créateur des cieux a mis en œuvre la Lune et le Soleil pour régler les temps, le jour et la nuit ;

-5-13-24-30: Yhwh a fondé solidement la terre et contrôlé les eaux qu'il a mises à disposition ;

-13-18 - 31-35b : Yhwh arrose les montagnes et rassasie la terre. Il est cause de réjouissances. parfois : $5-9 ; 10-13 ; 12-18 ; 19-24 ; 23-32 ; 31-35^{19}$. Cette complexité structurelle avait 
déjà été soulignée mais avec des nuances par Pierre Auffret ${ }^{20}$. Sans doute Bernard Renaud offre-t-il une structure plus simple qui permet d'envisager l'ensemble dans une dimension ternaire : cieux (Ps 104,1-4), terre (5-24) et mer (25-26) ${ }^{21}$. Mais il faut avouer que les travaux de Jean-Luc Vesco et Pierre Auffret permettent de mieux rendre la complexité et la richesse du texte. Le système des inclusions qui le structurent en différentes zones concentriques, les mots conducteurs que l'on retrouve au fil de la lecture, enfin les mots crochets sont autant d'outils poétiques et stratégiques pour dire la création.

18 La complexité structurelle permet de repérer les thèmes et on en vient ainsi à une analyse plus substantielle. Or, dans le détail, des traditions autres que celles liées à la religion amarnienne se font jour, en particulier le récit sacerdotal de la création (Gn 1), ne serait-ce que parce que l'on y trouve le même ordre d'apparition des éléments du cosmos : la lumière (Ps 104,1-2a/Gn 1,3-5), le firmament (Ps 104,2b-4/Gn 1,6-8), la terre/ les eaux (Ps 104,5-9/Gn 1,9-10), la végétation (Ps 104,10-18/Gn 1,11-13), l'alternance jour/nuit (Ps 104,19-23/Gn 1,14-19), les animaux marins (Ps 104,25-26/Gn 1,20-22), le don de nourriture (Ps 104,27-28/Gn 1,25-30)22. Aussi les scribes qui œuvrent à Jérusalem paraissent maîtriser un ensemble plus vaste de sources et déjà considérer certaines comme faisant autorité tout en travaillant à leur réinterprétation. Il est alors nécessaire d'analyser les rapports entre le Ps 104 et le récit sacerdotal de la création: cette analyse montre en réalité que des sources diverses sont convoquées au sujet de la création.

\section{Les aléas de la transmission : diversité et richesse des traditions de la création}

On peut ainsi proposer de partir de la comparaison du Ps 104 et du récit sacerdotal de la création en Gn 1 selon l'ordre des jours de la création. Tout l'enjeu est de montrer comment cette réappropriation, si elle est vraie, en dévoile bien d'autres, des traditions plus ou moins bien attestées en l'état.

20 Après l'invitation à la bénédiction (Ps 104,1), le psaume s'ouvre au verset 2 sur le «jour 1 » du récit sacerdotal (Gn 1,3-5): la lumière. Or celle-ci n'est pas créée, contrairement à Gn 1,3-5, elle apparaît comme un « manteau » dont la divinité se revêt. Aussi le milieu originel, le tohu wavohu, milieu aqueux et ténébreux, est-il absent. La lumière l'emporte dès les origines ${ }^{23}$. Noter que l'expression «éclat et magnificence " $(104,1)$ pour nommer la grandeur divine est commune à d'autres psaumes (Ps 21,6 ; 96,$6 ; 111,3 ; 1$ Ch 16,27 .

21 Le verset 2 introduit le « jour 2 » (Gn 1,6-8). Les cieux sont étendus comme un rideau ou une tente : c'est la divinité qui les « étend ». L'image d'étendre les cieux est commune au deuxième livre d'Isaïe (Is 40,$22 ; 42,5 ; 44,24 ; 45,12 ; 51,13$; voir aussi Jr 10,12; 51,15). Il s'agit donc non pas tant d'un motif sacerdotal de la création que d'un motif prophétique qui n'est pas sans un ancrage dans le livre de l'Exode. Car le verbe est celui-là même du salut opéré en Égypte, lorsque Moïse, en « étendant » sa main sur les eaux, les sépare et fait apparaître le sec sur lequel les fils d'Israël pourront cheminer vers la liberté $(\mathrm{Ex} 14,16)$. La composition tout en épousant la structure du récit sacerdotal convoque donc des traditions scripturaires autres. Des sources que les 
scribes maîtrisent et qu'ils réutilisent manifestement assez librement dans leur composition.

Le verset 3 développe le " jour 2 » et la séparation des eaux d'en haut et des eaux d'en bas (Gn 1,6-8). Si la représentation du cosmos est commune, le vocabulaire est loin cependant du sacerdotal et place est faite au mode de création architectural et aux images mythologisantes: la divinité charpente les cieux pour retenir les eaux d'en haut, elle y installe ses chambres hautes pour rassembler les eaux, d'où elle pourra par la suite abreuver les montagnes (cf. 104,13).

La divinité se promène sur les ailes du vent (cf. Ps 18,11 et 68,5 ; Ha 3,8.15; Is 19,1; Dn 7,13; Dt 33,26). Ce n'est donc pas le souffle/vent de la divinité qui balaye les eaux (Gn 1,2), c'est elle qui chevauche les vents. Ici d'autres traditions antiques sont puisées, Baal n'est-il pas le "chevaucheur des nuées » dans les sources d'Ougarit ${ }^{24}$ ? L'image maitresse de cette section est bien la cosmologie et la séparation des eaux qui permet à l'air, à l'atmosphère, de prendre place entre le ciel des eaux et la terre. La divinité qui réside dans l'atmosphère comme dans le ciel fait alors penser au dieu Baal certes, mais également au dieu mésopotamien Enlil, "seigneur de l'air», dont c'est la fonction cosmologique de séparer le ciel et la terre.

Après le firmament, c'est la terre qui est créée au verset 5 . Le « jour 3 » de la création sacerdotale (Gn 1,9-13) commence à se déployer. Mais, contrairement à Gn 1,9, la terre n'apparaît pas, rendue visible par le rassemblement des eaux d'en bas, elle est fondée, fixée sur ses bases. Ce motif de création est ailleurs fréquent particulièrement dans les Psaumes (Ps 24,$2 ; 78,69 ; 89,12 ; 102,26 ; \mathrm{Jb} 38,4-6$ et au sujet de la stabilité de la terre cf. Ps 60,$4 ; 82,5 ; 93,1 ; 96,10)$. Il correspond à la même cosmologie antique de la séparation des eaux d'en haut et d'en bas : la terre doit être fixée pour ne pas dériver. Dans la mythologie mésopotamienne, la terre est parfois retenue par des pieux d'amarrage ou des cordes. L'image aura donc été, en quelque sorte, évincée du récit sacerdotal. De plus, en Gn 1,10-11, l'apparition de la terre amène avec elle la séparation de la mer, mais aussi la végétation de la terre : la terre une fois créée a en elle-même de quoi se perpétuer. Or la séparation des eaux d'en bas dans le Ps 104,6-9 ne suit pas une ligne de démarcation horizontale mais poursuit le mouvement vertical: alors que l'abîme recouvre encore la terre comme un vêtement, les montagnes pointent leur sommet tandis que les eaux sont maintenues au-dessus d'elles. Ce ne sont pas verdure et végétation mais les montagnes qui émergent. La place des montagnes apparaît assez significative, puisque après les occurrences de la «terre» au nombre de sept (104,5.9.13.14.24.32.35), les « montagnes » en comptabilisent six (104,6.8.10.13.18.32). Or les montagnes sont le dernier point de séparation du ciel et de la terre dans la cosmologie que l'on connaît en Mésopotamie : c'est pour cette raison que les temples sont appelés souvent « mont » ou « montagne » saint(e). Ils ont pour fonction de relier ciel et terre et de permettre l'harmonie cosmique entre les mondes d'en haut et d'en bas, des dieux et des hommes. Inversement, les montagnes sont absentes de la création sacerdotale, ce qui manifeste une rupture par rapport aux sources mésopotamiennes connues.

$\mathrm{Au}$ verset 7, la séparation des eaux se poursuit ou plutôt elles se mettent en fuite à la menace de Yhwh, au bruit de son tonnerre. L'image se retrouve dans le Ps 77,17-19 ainsi qu'en Job 38,8-11. Mais puisque le psalmiste est familier de la tradition de relecture du Deutéro-Isaïe, il n'est pas impossible ici qu'il offre sa propre relecture de l'Exode : la fuite des eaux devient alors une allusion à la fuite des Égyptiens (Ex 14,25-27), ce que 
l'on retrouve dans le psaume exodique $114,3-5^{25}$. Les eaux sont vaincues comme l'ennemi le fut et, ainsi que le proclame le verset 9 , elles ne pourront plus ni traverser ni revenir pour recouvrir la terre. Au cœur de cette structure concentrique laissant émerger la terre (104,5-9), le verset 8 décrit le mouvement vertical continué : les montagnes s'élèvent tandis que les vallées descendent au lieu de leur fondation. Ce « lieu » rappelle le lieu unique du rassemblement des eaux de la mer en Gn 1,9-10. Quoi qu'il en soit des diverses traditions convoquées, le fil conducteur reste la représentation cosmologique et la progressive séparation du monde originel qui permet à la création de s'épanouir. D'ailleurs, on notera que les verbes ayant la divinité pour sujet sont toujours soit à l'accompli $(104,1.5 .6 .8 .9)$, soit au participe $(104,2.3 .4)$. Aussi l'action de la création est-elle située non seulement dans le temps de l'origine mais également au-delà du temps, dans la stabilité et la pérennité.

La création terrestre se poursuit maintenant avec la distribution des eaux délimitées et maitrisées $(104,10-13)$. Ce sont les sources qui coulent dans les vallées au cœur des montagnes, qui abreuvent "toutes les bêtes des champs", qui étanchent la soif des onagres. Près d'elles, «les oiseaux du ciel» demeurent pour donner de la voix. Cette section se termine au verset 13 avec l'image des montagnes, mais cette fois ce ne sont pas elles qui abreuvent les vallées mais elles qui sont abreuvées par les chambres hautes divines. Le jour 3 se poursuit dans l'abondance: «des fruits de tes œuvres la terre est rassasiée». Ce jour 3 du psaume n'a, comme on l'a dit, pas encore fait apparaître la végétation qui survient juste après (104,14-18), mais il est clair déjà que les animaux sont vivants et que leur création n'est pas l'objet de ce développement. Dans le récit sacerdotal, les oiseaux sont créés avec les monstres marins et les poissons au jour 5 (Gn 1,20-21). Les autres bêtes terrestres au jour 6 avec l'homme (Gn 1,24-26). Si la végétation n'est pas encore créée alors que les bêtes vivent déjà, il faut remarquer que « les fruits » sont nommés mais renvoient aux œuvres divines.

27 Avec le verset 14 apparaît la végétation. C'est la divinité qui fait germer verdure et herbage pour les bêtes et au service de l'homme. Ici encore l'œuvre de création du jour 6 sacerdotal, bêtes et hommes, est présupposée. Ce qui est mis en valeur c'est l'organisation de la nature au service du vivant. Cette section faisant place à la végétation se termine à nouveau sur l'image des montagnes, non pas abreuvant ou abreuvées, mais refuge pour la création (104,14-18).

On le voit, la maîtrise de scribes permet de rassembler une diversité de traditions sur la création. À travers cette diversité, c'est le motif de la séparation originelle qui est revisité et dont la conséquence est l'abondance des eaux bien maîtrisées. La symbolique de la montagne ne fait aucun doute à ce sujet ainsi que le recours à l'accompli pour les verbes, qui disparaît d'ailleurs définitivement après le verset 19. L'intention est donc tout autre que dans le récit sacerdotal.

Avec le verset 19 commence le « jour 4 » : la création des luminaires, lune et soleil, pour les rythmes et les temps. Là encore, la relecture est surprenante, car les temps marqués sont au service de la création et, la nuit, "toutes les bêtes des forêts " sortent et fourmillent à la recherche de la nourriture que Dieu/El leur donne avant de retourner se coucher avec le jour tandis que l'homme, lui, se lève pour aller à son ouvrage jusqu'au soir (104,20-23). Les versets 19-20 forment une véritable césure et les verbes sont maintenant à l'inaccompli lorsque la divinité Yhwh est sujet : l'instauration des saisons et des fêtes permet donc de sortir du temps originel de la création pour entrer dans le temps quotidien, celui des rythmes, humain et animal. Ce jour 4 et cette section 
(104,19-24) se clôturent sur une louange des œuvres divines, pour chanter cette fois leur nombre et leur sagesse (v. 24, cf. v. 13).

Avec le verset 25 commence le « jour 5 », la grande mer est alors nommée, parce que les bêtes petites et grandes y fourmillent sans nombre. Là encore, ces dernières ne sont pas créées mais la mer existe pour elles. La mer existe aussi pour la navigation et pour Léviathan que la divinité a façonné pour «jouer» avec lui. C'est d'une part la providence universelle de Yhwh qui est mise en valeur et, par ailleurs, l'ordre de la création, puisque Yhwh le maîtrise. Difficile de ne pas mettre en relation cet ordre divin avec celui de Job 38-41: Béhémoth et Léviathan ne sont-ils pas loués, œuvres premières et merveilleuses du créateur? Cette référence soulève donc la question du mal qui est occultée dans le récit sacerdotal - de toute façon, tous les jugements divins prononcés sont bons - et la réponse du psaume ne tarde pas dans la finale : les pécheurs disparaîtront de la terre et les méchants ne seront plus $(104,35)$. On notera que c'est toujours en fonction d'un système des eaux contrôlées que la création se déploie.

$31 \mathrm{Au}$ " jour 6 ", le souffle de Yhwh et son pouvoir vital font l'objet de la dernière section du psaume qui met en scène la fragilité humaine (104,29-32). On notera la touche finale concernant les montagnes, premières choses apparues dans l'ordre de la création, qui viennent clore la relecture psalmique pour réaffirmer leur soumission parfaite ou plutôt la maîtrise parfaite de Yhwh sur et dans toutes ses œuvres. Point d'image et de ressemblance ici mais un immense hommage au vivant dans lequel Yhwh ne peut lui aussi que se réjouir !

$\mathrm{Au}$ terme de cette analyse littéraire, il apparaît clairement qu'au-delà de la séparation «temps originel/temps continué » (v. 1-19/20-32) trois grandes thématiques se dessinent, formant une triple boucle, les œuvres de Yhwh (104,13.24.31), les vivants $(104,11.20 .25)$ et le rassasiement de la création $(104,13.16 .28)$. Ces trois grandes spirales viennent s'ajouter aux structures simples ou complexes analysées plus haut. Elles résument en elles-mêmes toute l'idéologie du psaume : ce n'est pas tant l'acte créateur qui est loué que l'ordre et l'organisation de la création au service du vivant. Cette lecture originale du thème de la création s'inscrit dans une représentation cosmique qui n'en est pas moins d'une grande antiquité, puisque déjà à Sumer à la fin du $\mathrm{IV}^{\mathrm{e}}$ millénaire av. $\mathrm{n}$. è. on connaît la séparation progressive des eaux pour laisser place à la vie, leur maîtrise par un système complexe de collecte et de redistribution, l'eau restant le cadre de toute vie, une eau d'abondance! Et les références mythologiques ne sont pas évincées. Les scribes s'inscrivent donc dans des traditions qu'ils réinventent.

Du point de vue des traditions scripturaires, ils ont recours à différentes sources concernant la création qui ne sont donc pas exclusivement celle du récit sacerdotal à l'ouverture du livre de la Genèse. On reconnaît, en dehors des parallèles égyptiens, mésopotamiens et cananéens, des références précises, le livre de l'Exode relu par le Deutéro-Isaïe, Job. Les scribes puisent aussi dans un réservoir d'expressions psalmiques. Ils ne craignent pas non plus des parallèles avec la littérature sapientiale, comme un monde créé en sagesse (v. 24, cf. Pr 3,19), dans l'harmonie mais aussi dans l'attente du châtiment des méchants (v. 35, cf. Ps 1; 37) ${ }^{26}$. Manifestement le Ps 104 se révèle être, beaucoup plus que le témoin exclusif d'une tradition, une composition qui manifeste la maîtrise des sources et d'un ensemble vaste de traditions locales, 
régionales et internationales. Mais la composition implique la maîtrise et le maniement des sources, non leurs références précises. L'acte d'écriture est un acte de réécriture : les traditions se perdent ainsi comme elles s'enrichissent dans leur transmission.

$\mathrm{Au}$ terme de cette étude, il apparaît que le Ps 104 est un excellent témoin de la transmission des Psaumes que l'on peut situer dans la bibliothèque de Jérusalem à l'époque du Second Temple. Non seulement les pratiques des scribes mettent en lumière les aléas d'une transmission "orale", alors même que le support écrit est devenu nécessaire. Mais, surtout, elles mettent en évidence la richesse et la diversité des sources et des traditions qui se cachent derrière l'œuvre de composition, autant de sources perdues certes, mais sauvées aussi par la technique et la pratique des scribes à composer et à réinventer.

\section{BIBLIOGRAPHIE}

ASSMANN Jan, « Mono-, pan-, and cosmotheism : thinking the "One" in Egyptian theology ", Orient, vol. XXXIII, 1998, p. 130-149.

AUFFRET Pierre, « Note sur la structure littéraire du Psaume 104 et ses incidences pour une comparaison avec l'hymne à Aton et Genèse 1 ", Revue des sciences religieuses, vol. LVI, $\mathrm{n}^{\circ} 2,1982$, p. 73-82.

BAILLET Maurice et al., Les petites grottes de Qumrân. Exploration de la falaise : les grottes 2Q, 3Q, 5Q, 6Q, $7 Q$ à 10Q, Oxford, Clarendon Press, 1962.

BERLIN Adele, " The wisdom of creation in Psalm 104 », dans Troxel Ronald L., Friebel Kelvin G., Magary Dennis R., Fox Michael V. (dir.), Seeking out the wisdom of the Ancients : essays offered to honor Michael V. Fox on the occasion of his sixty-fifth birthday, Winona Lake, Eisenbrauns, 2005, p. 71-83.

CANNUYER Christian, « La religion d'Akhénaton : monothéisme ou autre chose ? Histoire et actualité d'un débat égyptologique ", dans Lebrun René, De Vos Julien, Van Quickelberghe Étienne (dir.), Deus Unicus, Turnhout, Brepols, 2014, p. 77-117.

CHARPIN Dominique, Lire et écrire à Babylone, Paris, Presses universitaires de France, 2008.

CLIFFORD Richard J., « A note on Ps 104: 5-9 », Journal of biblical literature, vol. C, n 1, 1981, p. 87-89. DAY John, «Psalm 104 and Akhenaten's Hymn to the Sun », dans Gillingham Susan (dir.), Jewish and Christian approaches to the Psalms : conflict and convergence, Oxford, Oxford University Press, 2013, p. 211-228.

DIETRICH Manfried, LORETZ Oswald, SANMARTÍN Joaquín, The Cuneiform Alphabetic Texts from Ugarit, Ras Ibn Hani and Other Places, Münster, Ugarit-Verlag, 2013.

GARCÍA MARTínEZ Florentino et al., Qumran Cave 11. II : 11Q2-18 \& 11Q20-31, Oxford, Clarendon Press, 1998.

GRANDET Pierre, Hymnes de la religion d'Aton, Paris, Seuil, 1995. 
HUMBERT Paul, «La relation de Genèse 1 et du Psaume 104 avec la liturgie du Nouvel An israélite », Revue d'histoire et de philosophie religieuses, vol. XV, n 1-2, 1935, p. 1-27.

KEEL Othmar, SCHROER Silvia, Creation : biblical theologies in the context of the ancient Near East, Winona Lake, Eisenbrauns, 2015.

KRÜGER Annette, Das Lob des Schöpfers : Studien zu Sprache, Motivik und Theologie von Psalm 104, Neukirchen-Vluyn, Neukirchener Verlag, 2010.

KRÜGER Thomas, «"Kosmo-theologie” zwischen Mythos und Erfahrung : Psalm 104 im Horizont altorientalischer und alttestamentlicher "Schöpfungs"-Konzepte ", Biblische Notizen, vol. LXVIII, 1993, p. 49-74. Réédité dans Kritische Weisheit: Studien zur weisheitlichen Traditionskritik im Alten Testament, Zürich, Pano Verlag, 1997, p. 91-120.

NAGEL Georges, «À propos des rapports du Psaume 104 avec les textes égyptiens », dans Baumgartner Walter (dir.), Festschrift Alfred Bertholet, Tübingen, J. C. B. Mohr (Paul Siebeck), 1950, p. 395-403.

OBSOMER Claude, «À propos de deux passages du Grand Hymne à Aton (colonnes 2-3 et 6-7) », Babelao, vol. IV, 2015, p. 1-24.

REICHMANN Sirje, Bei Übernahme Korrektur? Aufnahme und Wandlung ägyptischer Tradition im Alten Testament anhand der Beispiele Proverbia 22-24 und Psalm 104, Münster, Ugarit-Verlag, 2016.

RENAUD Bernard, «La structure du Psaume 104 et ses implications théologiques », Revue des sciences religieuses, vol. LV, no 1, 1981, p. 1-30.

RENAUD Bernard, « Note sur le Psaume 104 : réponse à P. Auffret », Revue des sciences religieuses, vol. LVI, nº 2, 1982, p. 83-89.

SKEHAN Patrick W. et al., Qumran Cave 4. XI : Psalms to chronicles, Oxford, Clarendon Press, 2000.

TIGAY Jeffrey H., The evolution of the Gilgamesh Epic, Philadelphia, University of Pennsylvania Press, 1982.

UEHLINGER Christoph, «Leviathan und die Schiffe in Ps 104,25-26 », Biblica, vol. LXXI, n 4, 1990 , p. 499-526.

ULRICH Eugene C. et al., The biblical Qumran scrolls: transcriptions and textual variants, Leyde, Brill, 2010

VEsco Jean-Luc, Le psautier de David, t. II, Paris, Éditions du Cerf, 2006.

\section{NOTES}

1. S. Anthonioz, "Continuités et porosités culturelles et religieuses: les prières de Mésopotamie et les Psaumes bibliques", communication donnée lors du colloque international «Continuités et porosités culturelles et religieuse en Mésopotamie, de l'Antiquité à nos jours », (musée du Louvre-Lens, 13-14 janvier 2017).

2. E.C. Ulrich et al., The biblical Qumran scrolls: transcriptions and textual variants, p. 666-670.

3. F. García Martínez et al., Qumran Cave 11. II: 11Q2-18 \& 11Q20-31, p. 29-36.

4. P. W. Skehan et al., Qumran Cave 4. XI: Psalms to chronicles, p. 63-71.

5. Ibid., p. 81 . 
6. Ibid., p. 128-129.

7. M. Baillet et al., Les petites grottes de Qumrân. Exploration de la falaise : les grottes 2Q, 3Q, $5 Q, 6 Q, 7 Q$ à $10 Q$, p. 69-71.

8. J. H. Tigay, The evolution of the Gilgamesh Epic, p. 72.

9. D. Charpin, Lire et écrire à Babylone, p. 212.

10. Voir récemment C. Obsomer, «À propos de deux passages du Grand Hymne à Aton (colonnes 2-3 et 6-7)». Une traduction complète en français est proposée par P. Grandet, Hymnes de la religion d'Aton.

11. Cette version n'est attestée intégralement que dans la tombe de Aÿ, mais la tombe de Mây en présente le début. Pour cette raison, il s'agit probablement d'un texte connu. Voir C. Obsomer, «À propos de deux passages du Grand Hymne à Aton (colonnes 2-3 et 6-7) », p. 20.

12. J.-L. Vesco, Le psautier de David, p. 965. Voir encore T. Krüger, « "Kosmo-theologie” zwischen Mythos und Erfahrung: Psalm 104 im Horisont altorientalischer und alttestamentlicher "Schöpfungs"-Konzepte ».

13. Par exemple, $\mathrm{O}$. Keel, S. Schroer, Creation: biblical theologies in the context of the ancient Near East, p. 127-132 ; J. Day, « Psalm 104 and Akhenaten's Hymn to the Sun »; G. Nagel, « À propos des rapports du Psaume 104 avec les textes égyptiens ».

14. A. Krüger, Das Lob des Schöpfers: Studien zu Sprache, Motivik und Theologie von Psalm 104, p. 421.

15. C. Uehlinger, « Leviathan und die Schiffe in Ps 104, 25-26».

16. J.-L. Vesco, Le psautier de David, p. 966. Voir encore T. Krüger, " "Kosmo-theologie” zwischen Mythos und Erfahrung: Psalm 104 im Horizont altorientalischer und alttestamentlicher "Schöpfungs"-Konzepte », qui différencie la " cosmo-théologie » qui est aussi une "théologie du temple» à l'œuvre dans le psaume de la cosmologie amarnienne ou « cosmo-théisme ». Sur la religion amarnienne, voir C. Cannuyer, « La religion d'Akhénaton: monothéisme ou autre chose? Histoire et actualité d'un débat égyptologique ».

17. J. Assmann, "Mono-, pan-, and cosmotheism: thinking the "One" in Egyptian theology $»$.

18. S. Reichmann, Bei Übernahme Korrektur? Aufnahme und Wandlung ägyptischer Tradition im Alten Testament anhand der Beispiele Proverbia 22-24 und Psalm 104.

19. Voir dans le détail J.-L. Vesco, Le psautier de David, p. 957-958.

20. P. Auffret, « Note sur la structure littéraire du Psaume 104 et ses incidences pour une comparaison avec l'hymne à Aton et Genèse 1 », p. 75.

21. B. Renaud, "Note sur le Psaume 104: réponse à P. Auffret »; B. Renaud, "La structure du Psaume 104 et ses implications théologiques». C'est également la structure retenue par T. Krüger, " "Kosmo-theologie" zwischen Mythos und Erfahrung : Psalm 104 im Horizont altorientalischer und alttestamentlicher "Schöpfungs"Konzepte »; O. Keel, S. Schroer, Creation: biblical theologies in the context of the ancient Near East, p. 130.

22. P. Auffret, « Note sur la structure littéraire du Psaume 104 et ses incidences pour une comparaison avec l'hymne à Aton et Genèse 1 "; B. Renaud, "Note sur le Psaume 104 : réponse à P. Auffret »; B. Renaud, «La structure du Psaume 104 et ses 
implications théologiques »; P. Humbert, "La relation de Genèse 1 et du Psaume 104 avec la liturgie du Nouvel An israélite ».

23. Cependant, la terre plus loin est dite avoir été recouverte de l'abîme comme d'un habit $(104,6)$.

24. Voir par exemple M. Dietrich, O. Loretz, J. Sanmartín, The Cuneiform Alphabetic Texts from Ugarit, Ras Ibn Hani and Other Places, 1.2 iv 28'-29'.

25. R. J. Clifford, «A Note on Ps 104:5-9».

26. A. Berlin, « The wisdom of creation in Psalm $104 »$, p. 71.

\section{RÉSUMÉS}

Cette contribution a pour objet d'explorer la transmission du Psautier dans l'Antiquité en s'appuyant sur un psaume témoin, connu aujourd'hui sous le numéro 104. L'étude des témoins de Qumrân, du Grand Hymne à Aton et d'autres traditions antiques et scripturaires sur la création permettra de montrer la manière dont les scribes œuvraient. Quels éléments étaient jugés dignes d'être transmis et, par contrepoint, quels éléments étaient omis? Ces éléments omis étaient-ils volontairement perdus ou un dommage collatéral à l'entreprise de transmission? Les scribes avaient-ils recours à telle ou telle pratique en vue d'assurer la juste transmission ou l'interprétation de ces compositions, de manière singulière mais également en tant que collection?

\section{AUTEUR}

\section{STÉPHANIE ANTHONIOZ}

Professeur à l'université catholique de Lille, membre de l'équipe Mondes sémitiques du laboratoire Orient et Méditerranée (UMR 8167), membre de la section Histoire et archéologie des civilisations antiques du CTHS 


\title{
Les questions de transmission
} posées par les associations mémorielles dans les dispositifs muséographiques

\author{
Malika Bordes-Boudellal
}

1 L'élaboration de deux projets muséographiques liés à des conflits, autour de la Retirada ${ }^{1}$ à Septfonds en Tarn-et-Garonne d'une part, et de la Résistance et la déportation en Haute-Savoie de l'autre, a mis en évidence un problème de transmission des connaissances portées jusqu'alors par les témoins directs. La rupture de transmission due à la quasi-disparition de ces témoins est venue interroger la place à accorder aux nouveaux interlocuteurs associatifs, positionnés comme les garants actifs et légitimes $\mathrm{du}$ « devoir de mémoire » dont ils se revendiquent.

\section{Mettre la guerre en musée pour transmettre l'histoire et la mémoire}

2 Ces dernières années, le renouveau des musées liés aux guerres et conflits, ou la création de nouveaux dispositifs muséographiques, se sont opérés concomitamment à un renouvellement des membres des associations mémorielles. Pourtant, la place qui est accordée à ces associations, leur fonction traditionnelle de transmission de témoignages destinés aux jeunes générations a connu peu de changement. Dans le même temps, les historiens, les chercheurs, les enseignants, les conservateurs, puis les nouveaux intervenants que sont les muséographes, les scénographes, les médiateurs, ont fait évoluer leurs pratiques professionnelles, en accord avec l'actualisation de la connaissance scientifique, de la demande sociale et des publics. Dès lors, se pose la question du risque de décalage entre la place de ces associations mémorielles, généralement positionnées aux côtés des maîtres d'ouvrage publics, et les autres acteurs de l'histoire et de sa transmission. Or, la prise en compte des messages et 
valeurs portés par ces associations prend tout son sens à la lumière des conflits actuels, et bien plus encore dans la question qui émerge actuellement de la place à donner à la mémoire, l'expérience, l'émotion, que des thérapeutes comme Boris Cyrulnik éclairent et défendent. Dès lors, comment aborder ces transmissions mémorielles, en interaction avec la transmission de l'histoire et non en opposition? Plusieurs expériences muséographiques ont nourri cette réflexion et permettent à présent de soumettre quelques évolutions questionnant cette forme de transmission.

\section{Des musées pour des publics : de la réparation à la transmission}

3 Le choix délibéré de restreindre cette approche à notre cadre muséographique professionnel limite volontairement le contenu de cette analyse et mise en perspective ; elle a été formalisée pour répondre aux besoins d'une pratique concrète appelée par des réalisations de dispositifs muséographiques. Il s'avère nécessaire en préalable de qualifier ce que nous entendons par dispositifs muséographiques. Ces dernières années, l'évolution des musées liés à des conflits, et tout particulièrement à la Grande guerre², l'ouverture de lieux de mémoire sous la forme de centres d'interprétation ${ }^{3}$, de parcours mémoire ou encore de réalisations multimédia ont remis le sujet des témoignages à l'ordre du jour. Parallèlement, la question des publics et tout particulièrement des jeunes et des visiteurs étrangers, ciblés par les actions de transmission, est devenue un paramètre de professionnalisme, et parfois un gage de réussite pour les institutions. Plus que jamais, collections d'objets témoins, documents d'archives, iconographies ont été sublimés, tout en étant restaurés, étudiés, valorisés et ces démarches validées par des conseils scientifiques, impliquant de multiples disciplines, et parfois des spécialistes étrangers. La scénographie de ces musées est venue rajouter la dimension esthétique, auparavant marquée d'une dramaturgie de reconstitution des scènes encore présentes dans les mémoires.

C'est à cet endroit de la fiabilité muséographique qu'est venue se poser la question des témoignages et le rôle des associations mémorielles. En effet, jusqu'à ces dernières années, la présence de certains témoins des conflits - en grande majorité des victimes atteintes physiquement et psychiquement -, était intégrée à un certain nombre de visites, notamment pour incarner auprès des jeunes la réalité des conflits, leurs conséquences, et ce qui était prôné comme la responsabilité du devoir de mémoire. Or, si de rares témoins sont encore vivants, la grande majorité a aujourd'hui disparu. La valeur, l'impact émotionnel, le contact avec le réel, et surtout la légitimité de ces témoignages ont constitué une constante majeure de la mémoire des deux épisodes dont il est ici question ici, à savoir l'exil massif de réfugiés vers la France, lors de la guerre d'Espagne, et la Résistance lors de la Seconde Guerre mondiale.

Concernant le premier cas analysé, ces rares témoins directs de la guerre d'Espagne et de l'exil ont des souvenirs d'autant plus précis de leur vécu qu'ils étaient jeunes à l'époque. C'est le cas de ceux qui, en France, ont été internés dans des camps, séparés de leur famille, maltraités, et qui ont pourtant réussi à se construire une vie ici, marquée cependant par un impossible retour, ou alors dans des conditions souvent douloureuses. Les témoins de ce terrible conflit, dans lequel la France n'a pas joué le rôle que les victimes du franquisme auraient attendu, en ont été profondément et durablement marqués, pour plusieurs générations. Ils ont pourtant dû rester en France, 
héritiers, dans de nombreux cas, de la mémoire des engagements politiques contradictoires au sein de cette guerre, qui fut à la fois guerre civile, conflit européen et prémisse du conflit mondial, par l'engagement des pays alliés au franquisme, Allemagne et Italie, puis le rôle joué par l'URSS de Staline.

Aujourd'hui, les associations mémorielles sont composées de témoins de deuxième et troisième génération, qui expriment encore les courants pluriels composant le Front républicain, unis pour s'opposer au coup d'État franquiste de juillet 19364. Par la suite, se sont ajoutés les épisodes de poursuite de la lutte antifranquiste après 1939, celle des guérilleros engagés aux côtés des Résistants français durant la Seconde Guerre mondiale, engagement contre le fascisme qui, pour plus de 5000 Espagnols marqués du triangle bleu des apatrides, s'est dramatiquement terminé dans le camp de concentration de Mauthausen (Autriche). Les femmes ne furent pas épargnées, dirigées vers le camp de Ravensbrück (Allemagne).

7 Ces associations, dont les membres sont Français en grande majorité, sont présentes sur de nombreux territoires, conduisent des actions dans différents domaines, patrimoniaux, culturels, sociaux, parfois en lien avec des milieux universitaires et pédagogiques. Les commémorations constituent à la fois des temps de souvenirs partagés, de cohésion sociale et d'expression des divergences politiques et mémorielles précédemment citées. Aujourd'hui, dans le territoire du sud-ouest concerné par le dispositif muséographique, un collectif national d'associations de 14 membres $^{5}$ est présent, ainsi que les représentants locaux d'un autre collectif national, composé d'anciens guérilleros $\mathrm{FFI}^{6}$ et FTP, alliés des Résistants français. Engagés comme frères d'armes, ils avaient espéré que le combat contre le fascisme déboucherait sur une victoire en Espagne, qui n'eut pas lieu; le rôle des guérilleros ${ }^{7}$ dans la Libération de la France a tardé à être reconnu ${ }^{8}$. L'absence de récit partagé et apaisé concernant la guerre d'Espagne maintient de fait ces clivages historiques et mémoriels en Espagne et jusqu'en France.

\section{Le cas du camp d'internement de Septfonds}

8 Dans le cas du projet muséographique de la commune de Septfonds, conçu sous la forme d'un centre d'interprétation et de promenades de mémoire, plusieurs situations se sont présentées impliquant des associations mémorielles. La première s'est caractérisée par l'absence d'association organisée et agissant in situ et de façon permanente, aux côtés des acteurs publics, portant la mémoire du camp de Judes, un camp d'internement édifié en 1939 et qui reçut jusqu'à 18000 réfugiés espagnols. La deuxième était la présence, dans un lieu emblématique et historique, la gare de Borredon par où arrivaient les réfugiés, d'une association d'anciens guérilleros, portant un message fortement victimaire et opposé à la démarche municipale. Cette gare est ouverte au public et l'association y accueille des visiteurs. La troisième situation était celle d'une première période durant laquelle différents représentants d'associations à vocation nationale étaient présents, mais le projet muséographique n'existait pas encore. Les autres associations mémorielles liées au camp d'internement - victimes polonaises, juives, communistes, résistantes - ne constituent pas une expression mémorielle permanente: elles sont uniquement présentes lors des commémorations annuelles du 8 mai. 
9 Le projet à vocation historique et muséographique a d'emblée pris en considération la réalité des différents acteurs, du plus silencieux au plus revendicatif, tout en suivant les préconisations et directives d'un conseil scientifique, dirigé par Geneviève DreyfusArmand et une association à vocation historique et scientifique, "Présence Manuel Azaña ", présidée par l'historien Jean-Pierre Amalric. Les Archives départementales du Tarn-et-Garonne étaient étroitement associées au projet. La réalisation muséographique s'est structurée autour de contenus en capacité de servir une première étape de patrimonialisation, à savoir une réappropriation de cet épisode de l'histoire par les habitants et les personnes concernées par les mémoires liées au camp. Ce projet muséographique a, sans conteste, révélé le manque de travaux historiques publiés et diffusés ${ }^{9}$, des oublis et des silences, et un contexte mémoriel conflictuel exacerbé par cette réalisation en cours.

10 La Maison des mémoires de Septfonds est en très grande partie dédiée à l'évocation de l'ancien camp d'internement implanté sur la commune en 1939, pour y enfermer ceux qui furent frappés du nom d'indésirables ${ }^{10}$. L'absence d'associations mémorielles directement et fortement impliquées dans le projet muséographique ne pouvait cependant occulter ou faire abstraction d'une réalité, même externe et hostile. Ainsi, la gare de Borredon a été mentionnée sur un des parcours de visite comme lieu de mémoire lié au camp, porteur d'un autre discours mémoriel.

11 C'est en confrontant cette situation et ces réflexions sur les offres à présenter aux visiteurs et aux médiateurs (comme les enseignants) à l'autre situation muséographique décrite plus loin, que ce sujet s'est précisé et clarifié. Un dispositif muséographique ou interprétatif réunit, dans son montage, une équipe qui porte le projet - généralement une collectivité et ses partenaires institutionnels -, et une équipe de compétences muséographiques encadrée par un conseil ou des référents scientifiques. L'objectif poursuivi étant de faire connaitre l'histoire pour expliquer et valoriser les éléments constitutifs d'un patrimoine partagé, la communauté d'acteurs impliqués ou associés est par essence en accord de fond sur les messages transmis et les contenus élaborés les traduisant. Tout opposant à ces valeurs et principes ne pouvait de fait trouver sens à cette démarche de projet fondée sur la transmission de savoirs avérés, attestés par les témoignages croisés, les archives, et la vérification des données. Ainsi, dès sa conception, le dispositif muséographique s'est attaché à anticiper sur les interventions et collaborations comme avec "Présence Manuel Azaña», mais également sur les contradictions et contestations attendues d'autres associations mémorielles.

\section{Le projet de musée de la Résistance et de la déportation de Haute-Savoie}

La seconde situation qui a nourri cette réflexion est un projet de Musée de la Résistance et de la Déportation, porté par une collectivité, le département de Haute-Savoie, une équipe de solides compétences et un conseil scientifique rigoureux. Gil Emprin a consacré un article très éclairant à ces liens entre associations des Glières et historiographie ${ }^{11}$. Pour mémoire, ce musée, fondé à Bonneville par des anciens de l'Armée secrète, a été donné au Conseil départemental par l'Amicale des Anciens Combattants de la Résistance (ANARC) qui s'est retrouvée dépositaire de collections d'objets de privés. La Haute-Savoie est le département français emblématique de la 
Résistance, dont témoigne l'épisode des maquisards du plateau des Glières ${ }^{12}$, tenu par l'Armée secrète, et aujourd'hui la nécropole nationale de Morette, avec ses 105 tombes, dont neuf renfermant les dépouilles de combattants espagnols. Ces combattants espagnols, entraînés depuis des années de lutte dans la guerre d'Espagne, s'étaient échappés des compagnies de travailleurs étrangers (CTE), dans lesquelles ils avaient été enrôlés comme appui de main-d'œuvre.

13 Le site des Glières, visité par le général De Gaulle en 1944, marqué de la célèbre devise "Vivre libre ou mourir ", accueille les visiteurs par un dispositif d'interprétation et de mémoire, mais surtout par une œuvre d'art, la célèbre sculpture d'Émile Gilioli, inaugurée par André Malraux en 1973. Le site de Morette, près de Thônes, est aussi doté d'un espace d'accueil et d'interprétation, aux côtés du Mémorial départemental de la Déportation créé en 1965 par l'Association des Déportés, Internés et Familles de disparus de Haute-Savoie et de la nécropole nationale des Glières, classée au titre des Monuments historiques. Là, dans un ancien chalet d'alpage datant de 1794, faisant office de Musée départemental de la Résistance, sont présentées des collections témoins, prises en charge par une association mémorielle. Jusqu'à ces derniers temps, aucune démarche muséographique professionnelle n'a été mise en œuvre pour gérer ces collections, ce musée assurant ses missions de «musée tombeau ${ }^{13}$ ». Ces sites incarnent l'héroïsme français, jusqu'au mythe parfois, au point qu'ils soulèvent aujourd'hui des questions chez des historiens de la Résistance.

14 Autour de ce projet se trouvait un très grand nombre d'associations mémorielles, positionnées aux côtés des instances politiques et disposant ainsi du pouvoir de décision. La position des associations mémorielles était légitimée par ces dons de collections muséographiques et par le devoir de transmission aux jeunes générations au titre du « devoir de mémoire », puis par celui de la commémoration.

Là comme ailleurs, la confrontation entre l'histoire et la mémoire avait marqué ce projet muséographique depuis de longues années, alors que plusieurs historiens avaient plus récemment conduit des études sur le sujet et que des ethnologues avaient mené un important travail de recueil de témoignages. Parallèlement, et durant les mêmes années, d'autres personnes ou associations donnaient leurs versions des faits, parfois en décalage ou contradiction avec le récit historique élaboré avec exigence, le dernier en date étant la synthèse élaborée par Fabrice Grenard pour le compte du Conseil départemental en 2016.

16 Au cours de l'étude de programmation muséographique, les élus donnaient place et parole aux associations, d'une part pour honorer légitimement le don des collections, d'autre part pour donner la possibilité à ces membres associatifs de décider des fonctions et choix de transmission. Il s'est agi de l'Amicale des Anciens Combattants de la Résistance (ANACR), les Amis de la Fondation pour la Mémoire de la Déportation (AFMD 74), la Fédération Nationale des Déportés et Internés Résistants et Patriotes (FNDIRP), le Comité Haut-Savoyard des Associations de Mémoire de la Résistance et de la Déportation (CRD 74) et l'Association des Glières pour la mémoire de la Résistance, présidée par le général Jean-René Bachelet. Auparavant, le travail historique avait été construit par étapes, en même temps que le projet scientifique et culturel du musée, et le travail complexe sur les collections d'objets témoins de guerres et situations de conflits était poursuivi, avec toutes les précautions qu'exige leur état, le besoin de documentation et recherche de sens. À titre d'exemple, un seul objet, comme une paire de skis ou un vélo, présentait un caractère polysémique que seuls des professionnels 
pouvaient conduire par documentation et contextualisation. C'est précisément sur ce sujet de la conservation et la connaissance des collections que cette réflexion s'est avérée indispensable, dans le processus de transmission matérielle et immatérielle, constitutif de ce type de musées. De nombreuses associations mémorielles ont réuni et sauvé d'importantes collections d'objets liés aux guerres; la valeur patrimoniale et mémorielle qu'elles leur conféraient relevait du seul statut de témoins d'un épisode qu'ils avaient vécu ou connu, ce qui n'était plus le cas pour leurs descendants, ou les autres membres associatifs. Aujourd'hui, au regard des contraintes et du besoin de la transmission, ces collections exigent, car il n'a pas toujours été fait, un très important travail d'identification, de documentation, de conservation, de restauration, de contextualisation, avant d'envisager une véritable transmission de ces informations essentielles.

Beaucoup de ces collections d'objets sont en très mauvais état ; certains d'entre eux ne pourront jamais être réellement étudiés, d'autres ont pris une unique valeur marchande (militaria) dans les milieux de collectionneurs, aidés en cela par les ventes sur internet, les salons de collectionneurs et les incessantes commémorations qui maintiennent un marché dynamique des "objets et documents revivifiés", au détriment de la transmission muséographique publique. Il ne s'agit pas obligatoirement d'un constat ou d'un jugement négatif, car cette situation traduit la persistance de la valeur sociale et mémorielle de ces objets et documents, mais force est de constater que l'intérêt pour ces objets entretient également des nostalgies plus discutables, bien éloignées du désir d'histoire ou de mémoire.

18 L'analyse de ces deux expériences muséographiques et l'observation d'autres cas similaires ont permis de conforter l'intérêt de cette problématique. Celle-ci a été éclairée d'une part par les récents programmes de recherche lancés autour de la mémoire des attentats de Paris par l'historien Denis Peschanski, responsable du programme 13-Novembre, d'autre part des situations rapportées par l'actualité autour de la mémoire des traumatismes des populations migrantes et notamment des enfants, rappelés par Boris Cyrulnik dans ses nombreux ouvrages. En effet, la mémoire récente ou en construction des populations traumatisées par des faits de guerre, d'attentats, de violence, de migrations forcées, nous semblait être en capacité, sinon de résoudre ces questions de transmission, mais tout au moins de les interroger sur de nouveaux registres. Imaginer les musées de demain, consacrés à ces faits de guerre, de conflits, de migrations, et leurs conséquences, permet de porter un regard rétrospectif sur la question des témoins. Par témoins, nous entendons en tout premier lieu les récits collectés auprès des personnes, toutes les formes de documentations matérielles et immatérielles (qui seront les sources de travaux des historiens de demain), mais aussi tous les objets du quotidien (armes, cuillères, bijoux, papiers et photos personnelles, couvertures, livres, symboles religieux, jouets, etc.). La réussite de la grande collecte lancée autour de la Première Guerre mondiale atteste de cet intérêt pour les supports d'histoire et de mémoire détenues par les familles et les milieux privés.

\section{La transmission mémorielle s'enrichit de nouvelles disciplines}

19 Ce sont, après les intervenants de la première urgence de survie, les professionnels de la psychologie, de la psychiatrie, des neurosciences, des sciences cognitives, aux côtés 
des sciences sociales et humaines, et bien d'autres disciplines, qui détiennent sans aucun doute les principales clés de compréhension de la place actuelle des associations mémorielles des conflits passés. Des études comparatives avec d'autres pays enrichiraient ces réflexions, au-delà de la seule question de la transmission des conflits par les dispositifs muséographiques; toutefois, des exemples de traitement ont été observés dans des musées ${ }^{14}$, des lieux de mémoire avec vocation de centre d'interprétation (sans objets) et de mémorial ${ }^{15}$, ou lors d'expositions temporaires. Des démarches ont été identifiées en Suisse ${ }^{16}$ et en Belgique ${ }^{17}$.

Les objets, les documents ou les témoignages qui accompagnent ces objets assurent la fonction, auprès des visiteurs, de transmetteur de sens, de faits, de fonctions, d'émotions ou de sensations, puis d'adhésion, de question, de rejet ou de révolte parfois. Aujourd'hui, les techniques scénographiques permettent, grâce à l'éclairage et aux ambiances sonores et visuelles, de renforcer le message, de le diriger davantage vers la transmission historique, que vers la seule mise en vitrine qui prévalait auparavant. Le mannequin porteur du vêtement rayé de déporté est en cours de disparition, les objets sont traités et restaurés, les armes sont moins nombreuses dans les vitrines, l'iconographie n'est plus la même, les témoignages sont anciens, ou ne sont pas... Car si les témoins directs ont quasiment tous disparu, qu'en est-il des témoins indirects silencieux ? Les femmes, les enfants, les personnes âgées, les amis proches, les voisins, en résumé tous ceux qui ne sont pas dans les présentations muséographiques, ceux qui n'ont pas été pris en photo, ceux à qui personne n'a demandé de témoigner, ceux qui se sont tus et ont laissé leur entourage et leur descendance dans ce silence ? Qui sont tous ces héritiers de témoins de seconde et troisième génération, qui sont ces transmetteurs actifs de la mémoire des disparus, des victimes, des oubliés, souvent des proches, même sans lien de famille? Ce sont eux aussi qui se font les défenseurs d'une transmission "authentique ", les autres étant parfois soupçonnés ou accusés de "ne rien comprendre " à leurs légitimes propos ou revendications, de "ne pas l'avoir vécu », de ne pas savoir réellement ce qui s'est passé, de rappeler ce que les « historiens ignorent et ne comprendront jamais ».

21 Ce que nous pouvons entendre de ces récits lancinants, tantôt plaidoiries, tantôt accusations, ce sont des souffrances transmises. La plupart des récits personnels ne sont pas écrits dans les livres, les douleurs ne sont pas toujours entendues. Les associations mémorielles actuelles deviennent dès lors les dépositaires de ces mémoires sourdes mais criantes, palliant parfois l'absence de reconnaissance de ces souffrances banalisées, celle des gens ordinaires. Toutefois, c'est aussi au côté de ces anonymes qu'entre dans le débat la dernière catégorie des protagonistes de ces mémoires de conflits, les militaires et belligérants, armés. Au cours de la guerre d'Espagne et dans les combats de la Résistance, de nombreux civils ont porté les armes qu'on ne trouve pas toujours parmi les trophées de famille. Les armes les plus meurtrières ne se trouvent pas dans des musées, comme les bombes qui détruisirent la ville de Guernica ou harcelèrent le maquis des Glières. Comment dès lors aborder cette question de l'objet qui donne la mort, sans récit tronqué et sans mise en vitrine glorifiée? 


\section{Les associations mémorielles et le champ exploré des « valeurs »} les objets-témoins en liens avec l'ensemble des protagonistes, comme certains musées l'ont pratiqué avec les témoins directs, mais comment procéder avec les associations de témoins actuels?

Comment dès lors procéder, pour améliorer, faire évoluer ou tout simplement revoir des discours sur ces transmissions muséales de guerres et de conflits? Doit-on maintenir la mise à l'écart des associations mémorielles, doit-on accepter qu'elles se substituent aux historiens ou qu'elles soient positionnées dans un propos forcément conflictuel ou imposé par le pouvoir politique? Quelle part peuvent-elles assurer dans les fonctions de transmission des conflits, dès lors qu'elles n'ont plus légitimité à témoigner de ce qui s'est réellement passé ?

Pour enclencher avec plus de pertinence et d'anticipation ces dispositifs muséographiques en mutation ou à venir, il semble qu'il faille interroger trois grands pôles d'intervenants, dont le rôle serait d'accompagner les maîtres d'ouvrage publics : les archivistes et historiens, les spécialistes des conflits et connaisseurs (psychologues, psychiatres, anthropologues...) de la " chose militaire » (stratégie, armement...) et enfin les associations désireuses d'assurer une transmission mémorielle. Les équipes de compétences muséographiques internes et externes en charge des collections, devraient disposer de la possibilité d'aborder chaque évolution ou élaboration de dispositif muséographique par la sollicitation de ces acteurs auxquels s'ajoutent d'évidence les créateurs et les artistes. La pluralité des intervenants présente la difficulté de la concertation ${ }^{18}$ et de sa durée, voire de la conciliation, mais offre la garantie d'un équilibre histoire/mémoire/muséographie en tant que discipline de la transmission, dans une perspective évolutive. La dynamique d'un tel processus évoque les questions soulevées par Paul Ricœur autour du deuil, et du travail collaboratif de construction de la narration mémorielle ${ }^{19}$. C'est certainement dans les disciplines nouvellement mobilisées, au-delà de la philosophie ou de l'anthropologie par exemple, que la question des témoins associatifs (individuels) et associations mémorielles (collectifs) pourrait être repositionnée pour relire, actualiser et imaginer les nouveaux dispositifs muséographiques.

Le visiteur d'un musée de société ne pourrait accepter d'erreur d'attribution, d'usage ou de fonction d'un objet qui lui est présenté ; comment serait-il possible d'imaginer un visiteur observant un objet comme une arme, sortie de son contexte d'utilisation et des éventuels effets sur des êtres humains? Si les historiens et spécialistes de la transmission de savoirs techniques sont mobilisés pour contextualiser cet objet, pourquoi ne pas inclure, avec les précautions de méthode qui s'imposent, l'autre volet de la contextualisation anthropologique ou psychologique, que le témoin peut produire et transmettre comme la peur ou la fascination ou le désir de désarmement? Ainsi, l'intégration de ces expressions émotionnelles est en capacité de venir enrichir les offres didactiques et pédagogiques, aux côtés ou en complément de la transmission des savoirs historiques des conflits. Il est en effet une transmission que chaque dispositif muséographique gagne à proposer, c'est celle des valeurs que de grands noms de la Résistance ou survivants de la déportation, comme Lucie et Raymond Aubrac, Simone Veil, Germaine Tillon et tant d'autres, comme les artistes et poètes tels Pablo Picasso ou 
Antonio Machado ont portées. Courage, humanisme, engagement, prise de risque ont conduit la vie de ces grands personnages comme celles de milliers de personnes demeurées anonymes. De nombreux membres d'associations mémorielles sont très attachés à défendre et transmettre ces valeurs intemporelles: il importe donc de prévoir des cadres d'interventions pour ces transmissions et leurs modalités, y compris en intégrant les objets, les documents, les témoignages d'un parcours muséographique qui donne place à cette expression.

Le rôle social de ces musées est sans conteste conforté par ces fonctions de transmission citoyenne, incarnées par les valeurs portées par le Conseil national de la Résistance, les Droits de l'homme, ou les actions en faveur de la paix. Les nouveaux dispositifs muséographiques des musées d'histoire et de société permettent des rencontres différentes des musées d'art et n'imposent ni la contemplation ni le silence. Un niveau de discours vivant, incarné par des membres de ces associations mémorielles, des descendants de témoins des conflits ou des victimes récentes de conflits, pourraient se voir confier un rôle de transmetteurs que des grands-parents, arrière-grands-parents mais aussi des cousins, s'ils étaient encore présents, pourraient assurer. Leur discours serait alors à concevoir dans une nouvelle fonction de transmission qui soit un enrichissement mémoriel et cognitif.

\section{Les jeunes deviennent à leur tour passeurs de mémoire}

L'éclairage du neuropsychiatre Boris Cyrulnik propose des pistes par son analyse :

«Ce qui est traumatisant pour ceux qui ont vécu cela, et plus encore pour la première génération d'après, devient intéressant pour les petits-enfants ou les arrière-petits-enfants. La distance affective prise par les arrière-petits-enfants peut rendre captivant, étonnant, un évènement qui s'est déroulé soixante ans plus tôt, c'est-à-dire trois générations ${ }^{20}$.

Par ailleurs, la création artistique a constitué un champ d'expression de très grande efficience: peintures, sculptures, littérature, poésie, chant, musique, ont exprimé, sublimé, et transmis le sensible et l'émotion. Le concept de résilience est venu expliquer et aider à l'écoute et au mieux-être, au mieux-vivre de victimes indirectes, voire très éloignées des temps de conflits. Les deuils demeurent parfois impossibles pour de nombreuses raisons : absence des corps, absence de réparation matérielle ou symbolique, absence d'histoire et de récit partagés. Ce sont tous ces champs de transmission qu'il paraît important d'investir afin de conférer une juste place à ces associations mémorielles, qui viennent rappeler, aux côtés de nouvelles démarches pluridisciplinaires, que le temps des vitrines sans expression émotionnelle et psychique est sans doute révolu. Des associations veulent transmettre ces savoirs, ce nouveau champ doit être clairement pris en considération et renouvelé dans ses expressions muséographiques, parce que le musée d'art ou de société constitue une des institutions culturelles emblématiques de nos sociétés et que, selon l'anthropologue David Berliner, « la transmission contribue nécessairement à la perpétuation du culturel ${ }^{21}$ » qui précise que " exposer la chaîne de la transmission, c'est se donner les moyens de retracer ce processus complexe et ses médiations multiples ». Il permet ainsi d'éclairer la manière dont les nouvelles expressions muséographiques peuvent tirer enseignement de certaines expériences, comme celle de ces jeunes ${ }^{22}$ passeurs d'histoire en direction 
d'autres jeunes. Il s'agit en effet d'élaborer des discours de transmission mémorielle qui ne cèdent ni à la tentation victimaire ni à une compassion émotionnelle excessive. De plus, ces récits créatifs ne pourront s'insérer ni dans le champ figé de la commémoration, ni dans celui de l'indéterminé devoir de mémoire.

C'est au côté de cette rigueur que pourront trouver place des messages plus réparateurs et apaisés, dont le cadre aura été prévu par et avec des professionnels de plusieurs disciplines, sans ambiguïté pour les publics, parfois venus seulement vivre une expérience touristique. C'est aussi en écoutant et observant les victimes actuelles de conflits et d'exil que peuvent évoluer les relations des musées avec les associations mémorielles régénérées ou inexorablement dissoutes dans le temps.

\section{BIBLIOGRAPHIE}

AMALRIC Jean-Pierre et DREYFUS-ARMAND Geneviève (éd.), La guerre d'Espagne et la France, actes des Journées Manuel Azaña (Montauban, 7 et 8 novembre 2013), Toulouse, Framespa, 2013.

BERLINER David, « Anthropologie et transmission », Terrain, n 55, septembre 2010, p. 4-19.

BOURSIER Jean-Yves, Musées de guerre et mémoriaux, Paris, éditions des sciences de l'Homme, 2005.

CENDOYA-LAFLEUR Jessica, LAVOREL Marie et DAVALLON Jean, « Patrimonialiser la mémoire de la guerre au musée : entre Histoire et témoignage ", dans Tardy Cécile et Dodebei Vera (dir.), Mémoire et nouveaux patrimoines, éd. numérique, Marseille,

[URL : http://books.openedition.org/oep/457]

CYRULNIK Boris, Entretien avec Denis Peschanski, Mémoire et traumatisme : l'individu et la fabrique des grands récits, Bry-sur-Marne, INA, 2012 (Les entretiens de Médiamorphoses).

DREYFUS-ARMAND Geneviève et MARTINEZ-MALER Odette, L'Espagne, passion française, 1936-1975, guerres, exils, solidarités, Paris, Les Arènes, 2015.

DREYFUS-ARMAND Geneviève, L'exil des républicains espagnols en France : de la Guerre civile à la mort de Franco, Paris, Albin Michel, 1999.

EMPRIN Gil, « Les associations d'anciens résistants et l'écriture de l'Histoire : Glières, une historiographie sous tutelle ? ", dans Douzou Laurent (dir.), Faire l'histoire de la Résistance, PUR, 2010.

GRENARD Fabrice, Guerre, occupation, collaboration et Résistance en Haute-Savoie (1939-1945), manuscrit rédigé dans le cadre d'une enquête commandée par le Conseil départemental de Haute-Savoie (2015)

HERANGAT de Zoé, « Réhabiliter leur mémoire? Représentations des victimes de la Guerre Civile et du franquisme dans les musées d'Espagne », Nuevo Mundo Mundos Nuevos, éd. numérique, 
Questions du temps présent

[URL : http://journals.openedition.org/nuevomundo/67836]

MOULINIÉ Véronique, « L'exode et les camps pour pays. Les descendants de républicains espagnols en France ", Ethnologie française, vol. 43, n 1, 2013, p. 31-41.

TODOROV Tzvetan, Les abus de la mémoire, Paris, Arléa, 2004.

\section{NOTES}

1. Évènement lié à la guerre d'Espagne, désignant l'exil massif de Catalogne de près de 500000 réfugiés vers la France.

2. Voir le très emblématique Musée de Meaux.

3. Lieu d'exposition présentant peu ou pas d'objets, organisé autour d'un discours explicatif, didactique, pédagogique, aujourd'hui équipé de dispositifs multimédias.

4. Élue en février 1936, la Seconde république espagnole, présidée par Manuel Azaña, fonde le socle de ce Frente popular (Front populaire) composé des anarchistes de la CNT, des socialistes majoritaires du syndicat UGT et les deux courants communistes dont le POUM antistalinien.

5. Les associations membres de ce collectif: IRIS - Mémoire d'Espagne Toulouse, ASEREF (Montpellier), Ateneo republicano du Limousin, Ay Carmela Bordeaux, Memoria andando (Decazeville), MER 47 (Agen), MHRE 89 (Yonne), MER Pau, MERR 32, Présence Manuel Azaña (Montauban), Terre de Fraternité (Saint-Girons), Terres de Mémoires et de luttes (Oloron Sainte-Marie), NO PASARAN (Frontignan).

6. Il s'agit de l'amicale des Anciens Guérilleros en France - AAGEF - FFI.

7. Ce fut le cas de José Antonio Alonso Alcalde, le commandant Robert, FFI, qui sortait du camp d'internement de Septfonds.

8. Anne Hidalgo, maire de Paris, les a honorés en 2017, lors du 14 juillet.

9. Les archives restées dans l'ancien camp d'internement ont été détruites en 1945, au moment de son démantèlement.

10. Cf. lois Daladier de 1938.

11. G. Emprin, « Les associations d'anciens résistants et l'écriture de l'Histoire : Glières, une historiographie sous tutelle?», p. 187-199.

12. Soldats allemands et miliciens français alliés à la Gestapo s'y sont opposés à 465 maquisards, dont 59 Espagnols; 149 perdent la vie lors des affrontements du 26 mars 1944. Ce plateau avait reçu d'importants parachutages venant d'Angleterre, de la France Libre.

13. Décrit par Pierrane Gausset, « Du musée tombeau au musée livre d'histoire », Musées de guerre et mémoriaux ».

14. Comme musée international de la Croix-Rouge et du Croissant-Rouge à Genève, le CERCIL à Orléans, le CHRD à Lyon, le Musée de la résistance et de la déportation de Toulouse, le Musée de la paix de Guernica, le Musée de la Jonquera...

15. Mémorial de Rivesaltes, le Mémorial de la Shoah, Camp des Milles, Oradour-surGlane, Mailhé en Touraine... 
16. Une initiative unique de la CICAD (Coordination Intercommunautaire contre l'antisémitisme et la diffamation) est à l'origine de la rencontre entre des enfants de nazis et de déportés.

17. Projet TRANSMEMO, projet interdisciplinaire, mené par des historiens et des chercheurs en sciences sociales et cognitives, auprès de familles ayant vécu la Seconde Guerre mondiale.

18. Comme l'expérience du Musée de la Résistance et de la Déportation en Isère (MRDI) exposée dans l'article de Jessica Cendoya-Lafleur, Marie Lavorel et Jean Davallon, "Patrimonialiser la mémoire de la guerre au musée : entre Histoire et témoignage ».

19. P. Ricœur, La mémoire, l'histoire, l'oubli.

20. B. Cyrulnik, Entretien avec Denis Peschanski, Mémoire et traumatisme: l'individu et la fabrique des grands récits.

21. D. Berliner, « Anthropologie et transmission ».

22. Expérience conduite dans la cadre du Concours national de la Résistance et de la Déportation (CNRD) par les élèves de 3ème du collège Joliot-Curie de Stains, relatée dans l'émission «La Fabrique de l'histoire", France Culture, 16 janvier 2018: une odyssée pédagogique sur l'univers concentrationnaire (Buchenwald).

\section{RÉSUMÉS}

L'élaboration de deux projets muséographiques liés à des conflits récents, autour de la Retirada d'une part et de la Résistance de l'autre, a mis en exergue un problème de transmission mémorielle. La rupture de transmission due à la disparition des témoins directs a imposé la recherche d'une place à assigner à d'autres acteurs de deuxième et troisième génération. Quel rôle accorder en particulier aux associations mémorielles, parfois puissantes et appuyées par le politique, face aux historiens dont elles contestent souvent le travail et la légitimité ? Force est de constater que la prise en considération des transmissions mémorielles pourrait venir éclairer les séquelles des conflits actuels. Comment garantir les conditions les mieux adaptées à cette transmission par la médiation du sensible et de l'émotion (deuil, résilience, fictions), incontournable, notamment en direction des jeunes publics?

\section{AUTEUR}

\section{MALIKA BORDES-BOUDELLAL}

Ethno-muséographe consultante et formatrice culture, Société de BORDA (Dax) 


\title{
Femmes au cœur d'une transmission : le cas de la kafala dans le contexte migratoire français
}

\author{
Noria Boukhobza
}

En Algérie, comme dans les autres pays du Maghreb, en vertu de la loi musulmane, la kafala, accueil légal que l'on pourrait assimiler à une adoption qui n'en est pas une - on y reviendra - consiste en une délégation de l'autorité parentale. Il ne s'agit donc pas d'une institution de filiation mais d'une simple tutelle. Cette dernière, plutôt confirmée par le code de la famille, est décrite ainsi: c'est «l'engagement de prendre bénévolement en charge l'entretien, l'éducation et la protection d'un enfant mineur, au même titre que le ferait un père pour son fils ». La formule "un père pour son fils » s'inscrit d'abord dans une filiation patrilinéaire et masque la réalité : en l'occurrence le fait de prendre une fille, ce que nous développerons plus loin. Les statuts de chacun donnent lieu à un vocabulaire spécifique : le kafil c'est le tuteur, le protecteur, et le makfoul, l'enfant sous tutelle. La kafala a été essentiellement étudiée jusqu'ici à travers le prisme juridique, en vue de mieux saisir les processus de recueil d'enfants dans un contexte migratoire donnant lieu ou pas à une adoption simple ou plénière. En ce domaine, l'ouvrage récent d'anthropologie d'Émilie Barraud, centré sur les adoptions par des Français issus de l'immigration maghrébine d'enfants abandonnés au Maghreb, apporte un éclairage neuf ${ }^{1}$. Le placement familial par kafala y apparaît comme une solution privilégiée par les politiques publiques concernant des couples stériles désireux d'adopter un enfant de même origine. Son enquête de terrain multisituée (Maroc, Tunisie, Algérie) permet de mieux saisir les enjeux inhérents à la question de l'adoption dans les pays du Maghreb et son impact dans la société française. En resserrant son propos sur les démarches institutionnelles qui mobilisent plusieurs acteurs entre ici et là-bas - juges, responsables de pouponnière, assistantes sociales, etc. -, l'auteure nous donne à voir la complexité de cette kafala. Cette dernière, en effet, se présente sous plusieurs formes en fonction de la situation de départ de l'enfant :

«Si celui-ci est abandonné et que sa situation de filiation est totalement inconnue

(né sous $\mathrm{X}$, exposé et trouvé) ou bien partiellement connue (reconnaissance 
maternelle, abandon tardif), la kafala est dans ce cas préférentiellement

judiciaire ${ }^{2} . "$

2 En outre, si l'enfant n'est pas abandonné et de filiation connue, la kafala est confiée à un membre de sa famille en vertu d'un acte dressé par des notaires ou des juges et il s'agit alors d'une kafala dite notariale.

3 J'aimerais rappeler en quelques lignes les travaux qui m'ont conduit à revisiter sous un angle différent les questions de parenté pour les populations d'origine maghrébine. En centrant au départ mes recherches sur la transmission mère-fille ${ }^{3}$, j'avais noté que certaines de mes informatrices élevaient en France les enfants d'une autre femme. Mes interlocutrices comme Aïcha, Zineb, Luisa que j'avais suivies longtemps ont fini par me parler ouvertement, des années plus tard, de leur ancienne pratique: prendre un enfant de là-bas. C'est à ce moment-là que j'ai pu constater à quel point les circulations entre ici et là-bas sont étroitement liées aux femmes et interrogent de fait les stratégies mises en œuvre pour ce faire. En effet, peu de travaux abordent la question des circulations d'enfants intrafamiliales entre la France et le Maghreb. Je me propose dans cet article d'aborder les circulations d'enfants et de mettre en valeur ces dimensions en examinant le contexte migratoire français alors que les travaux conduits aujourd'hui en traitent dans le pays d'origine ${ }^{4}$. Par ailleurs, reprendre à plusieurs années de distance des parcours de vie de famille et des récits de vie de femmes me permettra de mettre en lumière les manières de donner et recevoir des enfants de la parenté proche originaire du Maghreb et plus particulièrement d'Algérie, mais aussi de suivre le parcours d'enfants adoptés comme Karima, Fatima et Leila.

4 La kafala d'ordre familial permet de rendre visible une ancienne pratique de circulation d'enfant de famille en famille. Elle est fondée sur un contrat oral, le premier don c'est la parole, une parole fondée sur "l'honneur » qui engage, le nif, une valeur essentielle dans les pays du Maghreb ${ }^{5}$.

5 Le travail ethnographique que je présente ici révèle la prégnance de pratiques culturelles héritées de la société d'origine, leur perpétuation, mais aussi leur réinterprétation qui ne va pas sans conflits. La circulation d'enfants entre ici et là-bas se révèle être un bon pôle d'observation de ces mouvements et des " recompositions » familiales qu'ils engendrent. Donner son enfant à un parent proche pour qu'il soit élevé dans un contexte migratoire soulève en effet plusieurs interrogations. Comment l'enfant peut-il passer la frontière? Quelles sont les personnes aptes à recevoir des enfants? De nos jours, comment s'organise et s'accompagne leur circulation dans la parenté élargie entre deux territoires nationaux ${ }^{6}$ ?

6 Ces transferts se font selon des modalités complexes et des temporalités qui invitent à repenser ces usages coutumiers et révèlent des formes de manipulations, de transactions voire d'instrumentalisations que je tenterai de mettre en lumière à partir de quelques situations singulières. C'est donc dans l'intimité du cercle restreint de la parenté que je propose de donner à voir le parcours de ces enfants marqué par différentes étapes.

\section{Enfant du péché (aw-lad lahram)}

7 D'après les données recueillies sur mon terrain - une population d'origine maghrébine implantée à Clermont-Ferrand et à Toulouse -, les récits des familles que j'ai rencontrées font apparaître des situations complexes qui interrogent tout 
particulièrement les pratiques coutumières existant dans le pays d'origine. Déjà dans les années 1960 dans le quartier de Madière à Clermont-Ferrand, où je partageais le quotidien de familles maghrébines, des rumeurs circulaient à propos de femmes jalousant celles qui avaient une importante progéniture. En effet, la valeur accordée à la fécondité y était essentielle, et on murmurait aussi que ces "femmes envieuses", selon le discours commun qui associe le désir d'enfant à toutes même à celles qui sont déjà mères, optaient pour une solution connue de toutes: celle d'aller chercher un enfant sur le point d'être abandonné dans leur pays d'origine. Il s'agissait souvent d'un aw-lad lahram ("enfant du péché ») conçu hors mariage par une jeune femme voire une jeune fille, et stigmatisée comme immorale et pratiquant une sexualité illégitime ${ }^{7}$. Même si cela se disait sous le sceau du secret, l'histoire était connue et finissait toujours par être révélée spontanément par les autres enfants au principal intéressé («tu es adopté », « ce n'est pas ta vraie mère ») ou au sein même des familles (" tu n'es pas mon frère », «tu n'es pas ma sœur, mes parents t'ont recueilli », et cela pouvait aller dans certains cas jusqu'à : « tu es la honte de la famille »). Pourtant, à l'intérieur de la fratrie, même si frères et sœurs n'appartenaient pas à la même filiation comme on va le voir, tous portaient le même patronyme. Écoutons Leila, 40 ans :

« Tu sais, lorsque l'on m'a recueillie toute petite, j'étais destinée à mourir, ma mère adoptive m'a sauvé. Mes frères qui ne sont pas mes frères de sang me disent toujours avec méchanceté que je suis "l'enfant du fond du couloir". Au début, je ne comprenais pas cette expression. C'est en grandissant que j'ai saisi le sens et j'avoue que je ne suis pas fière d'être issue d'une relation brève et sans amour, conçue en bas d'un immeuble, sans que mon géniteur ait été identifié. »

Cet enfant aw-lad lahram ou "enfant du couloir", promis parfois à la mort, était donc en quelque sorte sauvé par ce l'on pourrait appeler « une adoption cachée», selon le terme utilisé. Dans la première partie de son ouvrage, Émilie Barraud relate des cas d'adoptions intrafamiliales qui s'opèrent dans le pays d'origine, elle met en lumière ces pratiques informelles d'adoption se déroulant à l'abri des regards. Néanmoins, elle ne fait pas état de cette pratique dans le contexte migratoire, ce que je vais développer maintenant ${ }^{8}$. Comment sont organisées les circulations de ces enfants afin que les unes puissent se laver de la honte, les autres, les « envieuses », accroître leur progéniture ? Dans tous les cas, les dons, les adoptions, les abandons relèvent du féminin, les choses se passent entre elles. Les femmes qui en ont la maitrise et assurent la gestion de ces enfants détiennent la parole sur ces situations-là et ce sont aussi elles qui le révèlent. Aïcha, âgée de 75 ans, raconte l'histoire de Zineb, âgée aujourd'hui de 68 ans, mère de trois enfants, deux garçons et une fille, et nous permet d'illustrer de manière concrète ce premier cas de figure.

\section{Toujours plus d'enfants...}

«Zineb part quelques mois en Algérie dans sa ville dans l'intention de ramener un enfant de là-bas. Aussitôt, elle est mise en relation avec une voisine du même quartier qui cherchait à se débarrasser d'un enfant de l'hachouma, de la "honte", c'est comme cela qu'on le dit. Elle voulait sauver l'honneur de sa fille. Très vite, avec l'aide de quelques femmes du voisinage, elles organisent "une fête de naissance" - pour annoncer l'arrivée du bébé, une petite.»

9 En partageant un repas et en participant à ce rituel, "le rituel du sborr ", effectué normalement au septième jour d'un enfant et au cours duquel on nomme le nouveauné, les voisins en toute connaissance de cause ont contribué à une mise en scène et sont 
devenus les témoins de cette fausse filiation. Déclaré à la mairie de Sétif par la nouvelle mère sous le nom de XXX, le bébé est inscrit dans le livret de famille, et y figure comme quatrième enfant de la fratrie. Plus tard, Zineb se procurera un autre enfant, de sexe masculin cette fois-ci. Une de ses voisines, issue de son quartier en France, facilitera la réalisation de son désir car l'une de ses sœurs travaillant à la maternité de l'hôpital d'Alger s'occupait d'y faire accoucher discrètement des jeunes filles dans cette situation. Un garçon naît et les femmes concernées, voisine et sœur, s'activent pour accélérer des démarches administratives effectuées en l'absence de la future mère adoptive. Le nouveau-né sera ramené en France par la voisine de Zineb.

10 Notons que les stratégies dont a usé Zineb ont permis aux enfants d'être inscrits sur le livret de famille et de ce fait d'hériter du nom de famille du père, ce qui les a rendus légitimes aux yeux de l'administration française. Par contre, cette légitimité reste de façade dans le quartier, les voisins de Zineb, pour la plupart d'origine algérienne, n'étaient pas dupes et rappelaient en permanence l'histoire de ces transactions. De là résulte une tension qui peut conduire de l'intégration au rejet si l'enfant ne donne pas satisfaction. On attend en effet de lui qu'il réussisse d'abord scolairement et ensuite socialement. D'une certaine manière, il doit «rendre » ce qui lui a été donné 9 . S'il réussit, les liens se consolident, en revanche, ils tendent à se défaire face à une situation précaire et donnent lieu à des conflits voire à des rejets à l'intérieur des familles. En effet, c'est plus particulièrement face à des bouleversements, comme le mariage, l'héritage, que leur position et leur identité sont redéfinies au sein de la parenté élargie. Ces conflits et ces rejets questionnent alors la place des unes et des autres et les liens qui les unissent à cette personne.

11 Ainsi, Leila, qui avait été recueillie et inscrite dans le livret de famille dans les années 1960, ayant été condamnée et incarcérée, fut sommée par ses frères et sœurs de se défaire de leur nom de famille. Ils voulaient porter l'affaire au tribunal mais leur mère leur fit prendre conscience qu'ils allaient mettre au jour un autre délit : celui d'avoir inscrit l'enfant d'une autre dans le livret de famille. Ce cas illustre bien la forme la plus coutumière: on s'arrange entre femmes et, au bout d'un certain temps, on découvre que l'on n'a plus les moyens de légaliser cette situation. Par ailleurs, cette « adoption cachée » vécue en France entre les années 1960 et 1980 n'est plus possible aujourd'hui.

12 Une deuxième forme d'accueil que l'on qualifie de temporaire a existé entre ici et là-bas permettant aux enfants de conserver leur filiation d'origine. On se trouve là face à des formes de circulations que les ethnologues ont déjà rencontrées sur des terrains

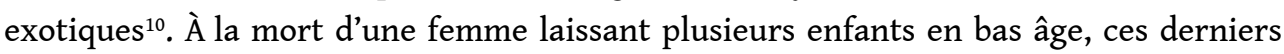
étaient confiés à la grand-mère maternelle, ou bien la stérilité d'un couple déclenchait la possibilité d'avoir un enfant de la parenté. Cet arrangement entre les membres de la famille ne modifiait pas la configuration de la parenté élargie puisque l'enfant continuait à appartenir à celle-ci même dans la migration. Dans ce cas, il s'agit d'opérer un rééquilibrage des ensembles familiaux par le fait "de donner des parents aux orphelins et donner des enfants à des couples stériles ${ }^{11}$ ». En Algérie, dans les années 1970, les adoptions de ce type étaient quasi invisibles, relevaient du domaine privé et ne donnaient pas lieu à une déclaration auprès des différentes institutions. Nous allons voir, dans le cas qui suit, que c'est du côté des hommes que se décide le don de l'enfant. 


\section{Ils font enfanter leurs femmes pour leur sœur}

13 Voici Luisa, âgée aujourd'hui de 75 ans, et Hamed, de 79 ans, un couple qui s'installe en France en 1965. Mariés depuis quelques années, ils ne peuvent pas avoir d'enfants sans pour autant chercher à savoir d'où vient leur stérilité. Les jeunes frères de Luisa se marient à leur tour et commencent à engendrer. Comme Luisa est l'aînée de sa fratrie, son premier frère promet de lui donner un enfant, ce qu'il fait à la troisième grossesse de sa femme en dépit du désaccord de cette dernière qui pourtant ne peut empêcher le don de la fille qui vient au monde, décision masculine dans ce cas. Elle lui choisit pourtant un prénom et le lui donne avant que sa belle-sœur en prenne possession, affirmant ainsi sa position. Sept ans plus tard, c'est au tour du second frère de faire concevoir sa femme et de donner son quatrième enfant à sœur aînée. Un garçon naît mais, cette fois-ci, c'est Luisa qui lui donnera son prénom. La voilà maintenant dotée de deux enfants en vertu de la règle coutumière qui ordonne le don d'enfant selon la position des hommes dans la fratrie ${ }^{12}$. Cette façon commune de procéder, dont j'ai rencontré plusieurs occurrences, s'effectue du côté maternel et c'est aussi un frère qui donne un enfant à sa sœur. Autour de la pratique s'articulent donc d'autres enjeux comme celui de la nature des liens qui unissent un frère à une sœur. Les frères, en décidant ainsi du sort des enfants avant leur naissance, en faisant enfanter leurs femmes pour leur sœur, s'instituent alors comme géniteurs de l'enfant de leur sœur et se mettent en position de faire couple avec elle. Ce que l'on peut apparenter à un inceste symbolique du deuxième type ${ }^{13}$.

Qu'en est-il si l'on se place maintenant du côté du père adoptif? Il garde une place visible et devient le tuteur légal, aux yeux du groupe et des frères de Luisa. Quels vont être les destins des deux enfants, cousin et cousine dans la parenté biologique, frère et sœur dans la parenté adoptive? Comment cela va-t-il se passer une fois qu'ils connaîtront la vérité et seront en âge de se marier?

La fille va devoir se défaire de l'histoire de sa famille d'origine, c'est-à-dire d'un pays, d'un lieu, d'une place dans la fratrie. Frère et sœur d'adoption, cousin et cousine de filiation constituent cette nouvelle famille portant le même patronyme. Comme l'a souligné Agnès Fine :

«L'anthropologie nous rappelle avec force que les systèmes de filiation sont des constructions culturelles qui brodent à partir de quelques invariants, entre autres la reproduction sexuée, en fondant la filiation sur le sexe de l'un des deux parents, de sorte que les enfants peuvent ne dépendre que d'une lignée en l'occurrence dans les cas qui nous concernent celle de leur père - filiation patrilinéaire ${ }^{14}$.

Les voyages réguliers en Algérie vont lever très rapidement le voile sur l'identité de l'adopté. Écoutons Karima, 39 ans :

«C'est à l'âge de 8 ans que j'ai su que ma vraie mère vivait en Algérie, moi je l'appelais tante, tu sais, c'est dans le cadre des fêtes en Algérie où les gens médisent, surtout les femmes, elles te disent un jour : "Tu sais, elle c'est ta vraie mère et eux ce sont tes frères et tes sœurs, alors tu dois l'appeler maman et celle qui t'élève c'est ta tante." "

17 En Algérie, en effet, il est du devoir des femmes de rappeler en permanence cette transaction et cette filiation d'origine alors que les mères adoptives vivant en France préfèrent ne pas révéler la vérité. Ainsi on qualifie de « vraie » mère la femme qui a mis au monde l'enfant adopté, et l'on a recours à la technique des empreintes génétiques pour identifier le « vrai » père d'un enfant ${ }^{15}$. Pourtant la mère adoptive n'a ni enfanté, 
ni adopté au sens juridique français du terme, elle a uniquement recueilli légalement. Une fois Karima devenue adolescente, face à la complexité des démarches administratives, mère et fille ont pu parler et ont pu accepter pleinement la situation car, comme le dit Karima «la mère qui élève, c'est elle qui donne le cœur ». Ainsi, au nom des soins et de l'éducation, elle reconnaît sa tutrice comme sa mère légitime et la nomme maman. En conséquence, elle continue à voir dans sa mère biologique une tante et, dans ses frères et sœurs, des cousins et des cousines. Dans ce contexte migratoire, Karima reconstruit sa propre histoire familiale. Ayant accepté pour elle-même cette révélation et la considérant comme légitime, Karima apprendra à son frère, alors âgé de 15 ans, qu'il a été lui aussi adopté.

De manière très paradoxale, cette adoption discrète, acceptée par tous et permettant aux enfants d'être intégrés à leur nouvelle famille, peut cependant entraîner des écarts, des ruptures. La législation a tenté de contrôler ces venues en France car, dans le contexte migratoire, ce mode de circulation revêt une autre signification, celle de contourner le processus légal, alors que la réalité est tout autre et correspond comme nous allons voir à un système beaucoup plus complexe. Dans le pays d'origine, le passage d'un enfant d'une maison à une autre fondé sur « la parole donnée " perdure, les cas singuliers que nous avons évoqués montrent que le passage s'est opéré aussi d'un territoire à un autre. Néanmoins, je remarque que ces adoptions quasi invisibles permettent aussi de choisir le sexe de l'enfant, et que ce dernier le plus souvent est féminin.

Suzanne Lallemand l'avait bien noté elle aussi sur son terrain : « Le garçon reste et la fille part». Les garçons sont plus souvent maintenus au sein du lignage paternel et, lorsqu'ils circulent, c'est pour apporter leur force de travail. La circulation des filles est plus complexe : captées par leur groupe agnatique, elles sont le plus souvent confiées à la tante paternelle ${ }^{16}$. Sur notre terrain, l'Algérie et la France, ce sont aussi ces tantes, ayant un statut de veuve ou de femme divorcée, qui accueillent des fillettes de la parenté du côté patrilinéaire.

20 Josiane Massard avait souligné que, dans la société malaise, des femmes ayant déjà eu des enfants peuvent en recevoir et devenir leur tutrice légale. Cela renforce l'image d'une maternité réussie et d'un « savoir-faire » valorisé par le groupe. Nous pouvons en déduire que toutes les femmes ne peuvent pas recevoir et que l'acte de donner appartient d'abord au père :

" Il confie à qui il désire ou bien il refuse à qui le lui réclame ${ }^{17}$. »

\section{Femmes ménopausées : des mères de substitution}

Depuis quelques années, éducateurs et travailleurs sociaux s'interrogent sur les liens qui unissent des femmes âgées d'origine maghrébine vivant en France et de jeunes enfants et plus particulièrement des petites filles venant du Maghreb. Il s'agit de saisir sous quelles formes elles sont présentes sur le territoire français. Face aux différents conflits que rencontrent des mères adoptantes avec ces enfants devenues adolescentes, les assistantes sociales tentent de comprendre le bien-fondé de ce couple femme/ enfant qui s'apparente à une famille monoparentale en dehors des schémas habituels ${ }^{18}$.

Pour les acteurs sociaux, il est difficile de décrypter ces modes d'organisation familiale qui peuvent même susciter des interrogations, voire de la méfiance : quelle est la responsabilité de ces tutrices? Par qui la décision de confier ces enfants a-t-elle été 
prise? Les fillettes sous couvert d'adoption ne sont-elles pas l'objet d'une transaction matrimoniale? Comment les parents biologiques ont-ils pu abandonner leurs enfants pour un autre pays? Pourquoi des femmes seules âgées de plus de 55 ans ont-elles pu avoir cette délégation de l'autorité parentale dans ce contexte migratoire?

Dans un précédent travail, j'ai déjà abordé le cas d'une femme que je nommerai ici Aïcha, élevée par sa tante paternelle. Son histoire singulière sera le fil conducteur de cette partie car elle donne à voir les formes complexes des circulations confrontées à des temporalités différentes. Reprenons brièvement son histoire: originaire d'un village des hauts plateaux de Saïda, seule fille de la famille, elle a cinq frères. Toute jeune, elle perd son père. Sa mère décide alors de revenir dans sa famille pour gagner de l'argent, mais elle ne peut éduquer l'ensemble de ses enfants. Aïcha nous raconte :

«Quand j'étais petite j'avais une santé fragile et je causais beaucoup de soucis à ma maman et elle priait chaque soir le "bon Dieu" pour lui donner la force de nous élever. Un jour, ma tante Saïda, veuve, qui vivait seule à la campagne, lui propose de prendre mon frère et moi. Ma mère ne voulait pas se séparer du dernier, mais moi elle m'a donné à ma tante, je n'avais que 4 ans, ma mère lui a dit ceci : "Si tu la sauves, elle est à toi." Ensuite ma mère adoptive m'a raconté qu'avant mon départ pour le petit village on m'a fait boire de l'eau magique afin que j'oublie le visage de ma vraie mère. En vivant avec ma tante paternelle, elle a pris soin de moi et j'ai été élevée comme une fille unique ${ }^{19}$. »

Nous observons ici que c'est la mort du père et la nouvelle situation de la mère sans ressources et sans mari qui déclenche cette circulation du côté paternel.

Suivi sur la longue durée, le cas d'Aïcha, née en Algérie en 1940, nous éclaire à la fois sur les anciennes pratiques coutumières dans le pays d'origine et sur leur maintien dans un contexte migratoire. Aïcha a d'abord été donnée à sa tante paternelle à l'âge de 4 ans et élevée à l'écart de ses frères, loin de sa mère biologique. La parole donnée avait ainsi scellé son destin. On lui avait donné de l'eau magique pour qu'elle puisse oublier sa vraie mère et en retour s'attacher à la nouvelle. Dans le pays d'origine, cette pratique coutumière locale avait retrouvé toute sa force. En effet, elle découvrit l'existence de sa mère biologique très tardivement, vers l'âge de 18 ans au moment de son mariage. Son union avec un homme venant de France l'avait éloignée malgré elle de ses deux mères. Installée en France dans les années 1960, Aïcha, dans les années qui suivirent, donna naissance à dix enfants.

À la fin des années 1970, son mari avait été sollicité par le chef de «sa zaouïa ${ }^{20}$ » qui lui avait demandé d'accueillir son fil âgé de 9 mois, de santé fragile. En dépit du désaccord d'Aïcha, son mari ramena l'enfant d'Algérie à la maison pour le soigner et l'élever. Aucun acte n'avait été rédigé pour permettre sa venue si ce n'est ici encore « la parole donnée ». On se trouve là dans la situation d'un prêt d'enfant temporaire, ce que Josiane Massard traduit par l'expression "donner une part », puisque c'est juste une période de la vie de l'enfant qui est concernée ${ }^{21}$. Ce qui m'intéresse du point de vue d'Aïcha, c'est que ce premier prêt va inaugurer une série de prêts ultérieurs comme si, ainsi que le dit Suzanne Lallemand, « le fait d'avoir été adopté par une personne semble parfois ouvrir une sorte de créance sur la lignée de l'individu pris en charge ${ }^{22} »$.

27 À la fin de l'année 1985, Aïcha se retrouvant veuve est directement sollicitée par son oncle maternel qui lui donne sa dernière fille âgée de 2 ans afin qu'elle puisse être élevée en France. Mais entre-temps, la législation ayant changé en Algérie, une démarche administrative et juridique devait être entreprise. En l'absence d'Aïcha, une kafala fut donc rédigée qui la désigna comme tutrice légale. Cette décision la plaça 
malgré elle dans une situation délicate. Elle devait convaincre ses propres enfants et plus particulièrement sa fille aînée de son nouveau rôle de tutrice. Cette dernière s'opposa vivement à cette entreprise et cela eut pour conséquence d'interrompre les démarches nécessaires à la venue de la petite fille. frère, père de neuf enfants, voulut lui donner le huitième pour qu'il puisse avoir un avenir. Brahim était «l'enfant choisi » pour partir en France... Comme il était âgé de 7 ans au moment de la rédaction de l'acte, le juge émit des réserves et mentionna qu'il était trop grand pour s'insérer dans une nouvelle famille. Il était plutôt souhaitable de prendre un enfant de moins de 3 ans pour lui donner toutes les chances de s'adapter et surtout pour obtenir le visa nécessaire pour entrer en France. Un revirement de situation s'opéra alors dans le bureau de l'administration et le père décida de donner sa dernière fille âgée de 2 ans et demi comme un cadeau pour sa sœur. La mère mise devant le fait accompli accepta ce changement. Elle reconnaîtra plus tard qu'elle ne voulait pas se séparer de sa petite dernière, alors qu'elle souhaitait fortement le départ de son fils. Le document fut donc modifié et rectifié au profit de la plus jeune enfant de la fratrie en 1996. L'acte de recueil mentionne les éléments suivants :

" Madame X Aïcha qui a déclaré qu'elle est musulmane, saine d'esprit et de corps et apte à prendre des décisions légales et souhaite prendre en charge la nommée " $\mathrm{X}$ Fatima" et ce pour son éducation et son entretien et son adoption à l'instar du père envers sa fille légitime. »

La tante paternelle justifiera ce revirement par une image, l'émotion ressentie : «À la naissance de la petite, j'avais eu une montée de lait. » Elle interprétera cette émotion comme un signe du destin. Elle souhaitait secrètement prendre une fille, et le temps lui avait donné raison. Elle vécut cela comme une véritable naissance, c'était bien sa propre fille. Cette montée de lait est venue marquer à ses yeux la reconnaissance légitime du lien « maternel » qui l'unissait à sa nièce, fille de son frère.

\section{Filiation symbolique}

Les rituels de détachement et d'attachement de l'enfant, véritables rites de passage dont la fonction est de permettre la séparation avec la mère biologique et de mettre en place un lien affectif avec la "mère de substitution », se font selon plusieurs manières. Nous l'avons déjà mentionné, c'est bien au moyen de l'eau « magique » que l'on tente de nouer le destin de la fillette à sa tante paternelle ${ }^{23}$. La « montée de lait » était une autre façon pour Aïcha de signifier qu'elle se positionnait en tant que mère nourricière et de marquer par là une filiation. Cette expression liée au corps révèle la capacité pour ces mères adoptantes de s'inscrire dans un nouveau registre biologique. Elles sont toutes ménopausées au moment de recevoir un enfant, cette démarche modifie de fait leur statut et les replace de manière symbolique dans une fonction de génitrice, ce qui du coup les écarte de leur rôle de grand-mère.

31 L'histoire singulière d'Aïcha donne à voir les formes complexes des circulations confrontées à des temporalités différentes. Le fait qu'une femme reçoive par ailleurs la fille de son frère crée une cellule familiale au féminin. Les filles sont réputées plus faciles à élever que les garçons et le fait que le nom, jusqu'à une date récente, soit l'objet d'une transmission patrilinéaire n'est peut-être pas étranger à cette préférence. Cette prise en charge interroge aussi les statuts féminins en présence : les femmes au 
Maghreb sont amenées à perdre leur nom lorsqu'elles se marient, paradoxalement, elles le reprennent lorsqu'elles accueillent et élèvent un enfant du côté paternel. Ce qui permet à ces mères de substitution de se réinscrire dans leur famille d'origine, puis de rejouer, au fil des étapes de l'éducation qu'elles donneront à leur nouvelle fille, les temps forts de leur rôle de mère, renforçant son appartenance à la famille.

Notons aussi que ces enfants de la parenté par leurs circulations régulières continuent à tisser un lien entre ici et là-bas. En portant le même nom de famille, marqueur d'une identité patrilinéaire, ils permettent ainsi la participation de la parenté élargie résidant dans le pays d'origine. Des temps forts vont rituellement inscrire l'enfant dans le lignage, comme la fête d'anniversaire. Les préparatifs de cette cérémonie pour la septième année de la fillette nécessitent des manipulations du corps, comme l'habillage de la petite fille en petite mariée. Un moment lui aussi considéré comme un rite de passage, qui l'intègre d'abord dans le groupe des enfants, puis l'inscrit dans la culture musulmane, avec la récitation de la Fatiha, premier verset du Coran. La mise en image de ce rite, à travers les photos qui circulent, permet le passage non seulement d'un statut à un autre, d'une famille à une autre, mais aussi du pays d'immigration au pays d'origine. Porter les parures de sa tante paternelle scelle alors son destin en tant que possible future bru. Mes travaux antérieurs ont évoqué cette pratique qui prend place au soir de la nuit du destin, vingt-septième jour du Ramadan. Par cet habillage - qui a lieu pour le cinquième ou septième anniversaire de la fillette -, qui préfigure celui des noces, on enseigne à la fillette les valeurs traditionnelles et cultuelles. Le port des bijoux de la famille n'est-il pas le début de la constitution de la dot assurée par la mère adoptive et les femmes du lignage ${ }^{24}$ ? Ce temps d'initiation associé à un voyage renforce le lien entre Aïcha et Fatima, la petite fille, et c'est bien au moyen de la transmission des premiers bijoux et des cadeaux que le rite d'attachement se consolide.

\section{Fille de famille (bent famillia)}

33 J'ai pu constater que Fatima, qui était appelée uniquement par son prénom, avait du mal à nommer sa tante, appelée " mémé " par ses petits-enfants du même âge qu'elle, et yoma par ses propres enfants. Face à ce flottement au fil des années, la mère adoptive, malgré son désir d'être nommée "maman" par sa nièce, fut appelée «remti» («tante») selon sa place initiale. À l'intérieur de la fratrie, les termes d'adresse qui concernaient la petite fille étaient étroitement liés aux statuts familiaux des uns et des autres. Par exemple, pour les filles encore célibataires n'ayant pas eu d'enfant, elle était perçue comme la petite sœur, pour celles qui étaient déjà mères, elle devenait la cousine. C'était la même chose pour les garçons devenus pères. En revanche, les fils célibataires qui demeuraient encore à la maison, étant considérés comme des époux potentiels, maintenaient avec elle un écart nécessaire. Je ne traiterai pas dans le cadre de cet article de l'éducation que reçoivent les petites filles adoptées, mais elles ont été bien étudiées par des ethnologues comme Josiane Massard ou Suzanne Lallemand. Le système entraînant des confusions possibles à un moment donné, il faut remettre de l'ordre pour permettre des alliances selon les règles coutumières.

$34 \mathrm{Au}$ fil des années, des échecs liés à cette configuration familiale apparaissent. Des ruptures, des failles se révèlent dans les étapes de la socialisation de Fatima. Tout d'abord, à l'extérieur et plus particulièrement à l'école, on renvoie en permanence 
l'enfant à son origine, en l'interrogeant sur ses parents biologiques. Les différentes fêtes civiles - fête des Mères, des Pères - sont des moments cruciaux qui révèlent une situation complexe où l'enfant doit s'expliquer, sur laquelle il doit mettre des mots. Puis, au sein de la famille, les attentes et les aspirations qu'elle a suscitées au départ disparaissent à la préadolescence qu'elle vit difficilement. On lui prêtait toutes les qualités, celle d'une bent famillia, c'est-à-dire d'une fille de famille, en se montrant indocile et insolente, elle entraîne peu à peu son rejet de la cellule familiale et la nécessité de trouver une solution dans un cercle plus large.

\section{Kafala complexe pour une adoption simple}

Face aux difficultés grandissantes que rencontre la tante avec sa nièce, un relais temporaire est mis en place dans le contexte migratoire qui déclenche une nouvelle circulation. Comme Fatima a une sœur aînée qui habite dans la même ville, on la lui confie temporairement. La mise en place de passation des pouvoirs de la délégation d'autorité continue à maintenir l'enfant dans le lignage allié. Je tiens à signaler ici que pour d'autres situations semblables à celle-ci, en l'absence d'un membre de la famille, c'est l'institution qui prend le relais et place l'enfant dans un foyer ${ }^{25}$.

Comme nous pouvons le constater, la circulation se poursuit soit dans la parenté de l'enfant soit dans une institution. Fatima qui maintenant habite chez sa sœur, mère de trois enfants, occupe désormais au sein de cette nouvelle famille une nouvelle place : de nièce elle est devenue tante. Le provisoire étant devenu durable, Fatima ne souhaita plus revenir chez Aïcha. Une démarche juridique eut donc lieu sous l'impulsion de la sœur aînée qui mentionnait que la tante était trop âgée pour s'occuper de l'adolescente. Une telle démarche fut entérinée par l'administration française qui officialisa le transfert. Que devenait alors Aïcha, la tutrice légalisée par les documents algériens ? Si la sœur aînée a pu hériter en France de la délégation d'autorité pour sa jeune sœur, cette délégation est-elle reconnue dans le pays d'origine?

Côté français, la tante, en formalisant cette kafala auprès du tribunal en 1998, a réalisé une adoption simple. Or l'enfant ne vit plus avec elle depuis l'âge de 12 ans, puisqu'elle a été placée chez sa sœur aînée par un juge pour enfants. Aïcha perd du coup la délégation parentale. En revanche, côté algérien, l'enfant est toujours sous la tutelle de sa tante car l'enfant lui a été donné à elle. Aïcha, jusqu'à la majorité de sa nièce, doit par exemple se déplacer au consulat d'Algérie pour donner les autorisations permettant à sa nièce de circuler entre les deux pays.

38 Face à l'échec de cette prise en charge, les langues se délient: les enfants d'Aïcha n'étaient pas favorables à la mise en place de cette kafala qui est devenue une affaire de famille entre ici et là-bas. Partenaires impliqués malgré eux dans cette histoire, ils ne comprennent pas aujourd'hui encore ces formes de circulation. Socialisés en France, ils rejoignent les discours dominants concernant l'éducation des enfants. C'est-à-dire qu'un enfant doit être élevé par ses parents biologiques. Leur " modernité » les éloigne des pratiques coutumières qu'ils associent à l'Algérie et qui n'appartiennent pas à leur histoire familiale. Cependant, ils acceptent l'entreprise de leur mère née et socialisée dans le pays d'origine. Pourtant Fatima s'est mariée selon la coutume et elle est devenue mère d'une petite fille depuis peu. 
position sociale forte associée à une grande proximité parentale dans le processus adoptif. Cette proximité s'articule surtout autour du nom de famille des femmes qui permet ainsi de fluidifier les passages à la frontière. Ce circuit répétitif de dons effectués sur trois générations du côté paternel renforce le lignage du côté des femmes.

Le regard rétrospectif sur la façon dont les enfants sont captés et les manipulations dont ils font l'objet de la part des femmes preneuses de filles m'ont permis dans un premier temps de mettre en perspective les différentes manières de faire circuler un enfant entre ici et là-bas. Ces situations rendent compte d'expériences singulières, soumises au fil des temps à des rebondissements imprévus, et invitent à repenser dans ce contexte les représentations sociales souvent stéréotypées de la famille d'origine maghrébine d'aujourd'hui qui s'opposent à ces nouvelles configurations familiales, celles d'une monoparentalité générationnelle se construisant de femme à femme ${ }^{26}$. Ces pratiques coutumières conjuguées au féminin se perpétuent et cimentent les liens entre la France et l'Algérie. Les relations se nouent alors au moment du don, perdurent entre ici et là-bas et révèlent la complexité de l'assimilation des valeurs dans un contexte de double appartenance culturelle.

41 Force est de constater que les manipulations et les transactions qu'opèrent ces femmes âgées dans ce contexte migratoire pour obtenir un enfant à un âge où elles ne procréent plus interrogent de fait la place et les statuts de chacun. L'acte de la kafala fait donc passer du côté masculin ces femmes ménopausées preneuses d'enfant. Ce qui est mis en avant, c'est le fait que l'enfant doit être élevé dans un foyer musulman, c'est la condition essentielle. Cette double filiation entre ici et là-bas rend alors licite sa circulation. Rendre compte de la mise en œuvre de ces kafalas familiales qui se déroulent à l'abri des regards peut aussi conduire à s'interroger sur le devenir de ces jeunes dans la société française. De kafala en kafala, cette pratique qui se transmet de génération en génération, entre ici et là-bas, par l'entremise des femmes, assure à ces dernières un prestige et un pouvoir qu'elles tentent de maintenir en dépit des changements en continuant à jouer de la marge de manœuvre que leur permet l'écart juridique entre leur société d'origine et la société d'accueil.

\section{BIBLIOGRAPHIE}

BARRAUD Émilie, L'adoption entre France et Maghreb : de terre et de sang, Éditions Non Lieu, 2013.

BоUкновZA Noria, Les femmes dans l'ombre du jour : histoires d'une famille entre l'Algérie et la France, Cahors, L'Hydre, 2002.

воUкновZA Noria, «Les filles naissent après les garçons : représentations sociales des populations d'origine maghrébine en France ", Revue européenne des migrations internationales, vol. XXI, $\mathrm{n}^{\circ} 1$, 2005, p. 227-242. 
FINE Agnès, « Des retrouvailles peu ordinaires », postface dans Martre-Micaleff Dominique, Mon enfant en terre lointaine : une adoption ouverte, Toulouse, Privat, 2009, p. 61-89.

HÉRITIER Françoise, Les deux sœurs et leur mère : anthropologie de l'inceste, Paris, Odile Jacob, 1993.

LALLEMAND Suzanne, «L'adoption des enfants chez les Kotokoli du Togo », Anthropologie et sociétés, vol. IV, $\mathrm{n}^{\circ} 2,1980$, p. 19-37.

LALLEMAND Suzanne, La circulation des enfants en société traditionnelle : prêt, don, échange, Paris, L'Harmattan, 1993.

MASSARD Josiane, « Le don d'enfants dans la société malaise », L'homme, t. XXIII, n 3, 1983, p. 101-114.

MERNISSI Fatima, Sexe, idéologie, islam, Paris, Tierce, 1983.

MOUTASSEM-MIMOUNI Badra, Naissances et abandons en Algérie, Paris, Karthala, 2001.

VASSAS Claudine, «Le corps à la lettre ou les quatre femmes de Jacob », L'homme, $\mathrm{n}^{\circ} 160,2001$, p. 11-40.

ZERDOUMI Nefissa, Enfants d'hier : l'éducation de l'enfant en milieu traditionnel algérien, Paris, F. Maspero, 1982.

\section{NOTES}

1. É. Barraud, L'adoption entre France et Maghreb: de terre et de sang.

2. Ibid.

3. N. Boukhobza, Les femmes dans l'ombre du jour : histoires d'une famille entre l'Algérie et la France.

4. B. Moutassem-Mimouni, Naissances et abandons en Algérie.

5. Une parole donnée telle qu'elle est définie dans les travaux concernant les populations du Maghreb (N. Zerdoumi, Enfants d'hier: l'éducation de l'enfant en milieu traditionnel algérien).

6. Une étude sur la population étrangère de Limoges révèle ces formes de circulations dans la parenté élargie. C'est en 1999 qu'a été constatée une augmentation significative de l'arrivée d'enfants sous kafalas sur le territoire de Limoges. Entre 2000 et 2006, les enfants représentent entre 13 et $25 \%$ de l'ensemble de regroupement familial soit 299 enfants répertoriés (F. Messica, C. Younes, "La situation des enfants mineurs légalement recueillis par acte kafala dans l'agglomération de Limoges »).

7. F. Mernissi, Sexe, idéologie, islam.

8. É. Barraud, L'adoption entre France et Maghreb : de terre et de sang.

9. S. Lallemand, La circulation des enfants en société traditionnelle : prêt, don, échange.

10. S. Lallemand, «L'adoption des enfants chez les Kotokoli du Togo » ; J. Massard, « Le don d'enfants dans la société malaise ».

11. S. Lallemand, «L'adoption des enfants chez les Kotokoli du Togo ».

12. Claudine Vassas, à partir du texte biblique de la Genèse, a analysé un exemple de cette pratique: deux sœurs mariées à un même homme et désireuses d'avoir des enfants, l'une parce qu'elle est stérile, l'autre pour accroître sa progéniture, font 
enfanter leurs servantes pour elles (C. Vassas, «Le corps à la lettre ou les quatre femmes de Jacob»).

13. Ce cas singulier renvoie aux travaux de Françoise Héritier sur l'anthropologie de l'inceste. À côté des relations entre père et fille, entre mère et fils, entre frères et sœurs, il existe un inceste du "deuxième type " qui concerne en particulier les consanguins de même sexe partageant un même partenaire, une mère et sa fille, ou encore deux sœurs (F. Héritier, Les deux sœurs et leur mère : anthropologie de l'inceste).

14. A. Fine, « Des retrouvailles peu ordinaires ».

15. Ibid.

16. Il faut noter que pour les Kotokoli, une population étudiée par Suzanne Lallemand, "la fillette est accueillie par sa tante paternelle et le mari de celle-ci, c'est un patrilignage étranger qui l'héberge, elle s'inscrit donc dans un lignage allié et elle est utilisée comme un trait d'union entre le groupe et les autres ensembles familiaux ", S. Lallemand, «L'adoption des enfants chez les Kotokoli du Togo ».

17. Idem.

18. La recherche-action menée sur Limoges avait pour objectif de dégager des propositions pour mieux accompagner ces enfants sur le plan éducatif et social. «Certains interlocuteurs ne s'autorisent aucun jugement de valeur, mais s'interrogent sur les moyens de préserver au mieux l'intérêt des enfants, d'autres, ce sont les plus nombreux, ont eu une perception négative de cette institution qualifiée par certains de "tribale" ou tout simplement de "filière clandestine" " (F. Messica, C. Younes, "La situation des enfants mineurs légalement recueillis par acte kafala dans l'agglomération de Limoges »).

19. N. Boukhobza, Les femmes dans l'ombre du jour : histoires d'une famille entre l'Algérie et la France, p. 28.

20. La zaouïa est une fondation religieuse qui a pour vocation de célébrer les commémorations destinées à un saint patron, de recevoir des dons. La zaouïa qu'honore le mari d'Aïcha a pour coutume de recevoir les filles ânées d'une fratrie pour être élevées dans le groupe et en retour les adeptes de cette confrérie reçoivent leurs bénédictions, N. Boukhobza, Les femmes dans l'ombre du jour : histoires d'une famille entre l'Algérie et la France, p. 25.

21. Les travaux de Josiane Massard sur la circulation des enfants en Malaisie montrent que des familles ont recueilli des enfants de manière temporaire pour leur permettre d'acquérir les forces nécessaires à l'amélioration de leur santé.

22. S. Lallemand, «L'adoption des enfants chez les Kotokoli du Togo », p. 24.

23. Dans d'autres sociétés comme chez les Kotokoli, le transfert intrafamilial est marqué par une métaphore qu'utilise la personne qui donne son enfant. Cette expression se résume ainsi : «c'est pour qu'il [la personne adoptante] lui donne de l'eau à boire », S. Lallemand, "L'adoption des enfants chez les Kotokoli du Togo ».

24. N. Boukhobza, Les femmes dans l'ombre du jour : histoires d'une famille entre l'Algérie et la France.

25. F. Messica, C. Younes, «La situation des enfants mineurs légalement recueillis par acte kafala dans l'agglomération de Limoges ».

26. N. Boukhobza, «Les filles naissent après les garçons : représentations sociales des populations d'origine maghrébine en France ». 


\section{RÉSUMÉS}

C'est dans une nouvelle perspective que cet article aborde, dans le contexte migratoire français, les manières de donner et de recevoir des enfants de la parenté proche originaire d'Algérie. Ces transferts se matérialisent aujourd'hui par un acte écrit, la kafala. Ces circulations fondées sur la parole donnée sont un bon pôle d'observation de ces mouvements et des "recompositions " familiales qu'ils engendrent selon des modalités complexes confrontées à des temporalités différentes. Ces situations rendent compte d'expériences singulières, et invitent à repenser les définitions figées de la famille maghrébine d'aujourd'hui qui s'opposent à ces nouvelles configurations, celles d'une monoparentalité générationnelle se construisant de femme à femme. Cette pratique, qui se transmet de génération en génération par l'entremise des femmes, assure à ces dernières un prestige et un pouvoir qu'elles tentent de maintenir en continuant à jouer de la marge de manœuvre que leur permet l'écart juridique entre leur société d'origine et la société d'accueil.

\section{AUTEUR}

\section{NORIA BOUKHOBZA}

Maîtresse de conférences en ethnologie à l'École supérieure du professorat et de l'éducation de Midi-Pyrénées, université Toulouse - Jean-Jaurès, membre permanente du Laboratoire interdisciplinaire solidarités, sociétés, territoires (LISST-CAS, CNRS/UTM/EHESS) 


\title{
Transmission du savoir-faire et ordre généalogique dans la danse Odissi à Bhubaneswar (Inde)
}

\author{
Barbara Čurda
}

1 La danse Odissi fait partie des huit formes de danse que le gouvernement de l'Inde a déclarées «classiques » depuis l'indépendance du pays en 1947. Ces pratiques, destinées à des spectacles sur scène, jouissent d'un haut statut culturel et sont considérées comme étant représentatives des identités des États indiens dans lesquels elles se sont développées ${ }^{1}$. Aussi, même si l'Odissi, qui est de manière prépondérante un phénomène urbain, est pratiquée dans plusieurs grandes métropoles indiennes, du point de vue de nombreux pratiquants, la pratiquer sans tisser de liens à l'État d'Orissa (rebaptisé Odisha en 2011 par le gouvernement indien dans un effort d'indianiser les noms de lieux ${ }^{2}$ ) est inimaginable. La capitale de l'Orissa, Bhubaneswar, est le haut lieu des pratiques d'Odissi. Mais il faut noter que la transmission de cette danse est à ce jour très peu institutionnalisée. S'il existe bien quelques institutions affiliées au système d'enseignement supérieur gouvernemental dans lesquelles il est possible d'entreprendre une formation en Odissi débouchant sur l'obtention d'un diplôme officiellement reconnu, ces formations-là ne sont pas valorisées par les pratiquants. Ceux-ci préfèrent se rendre dans les multiples écoles privées dirigées par des maîtres d'Odissi, dont une grande partie est implantée à Bhubaneswar. Parmi elles, certaines jouissent d'une notoriété plus ou moins importante. Même les organismes de promotion des pratiques de la scène du gouvernement central considèrent les enseignants qui dirigent ces écoles comme les interlocuteurs les plus adaptés pour toute question relative à cette danse.

Du point de vue des pratiquants, les premiers choix effectués par le novice désireux d'apprendre la danse ont un impact important sur l'acquisition du savoir-faire : ces derniers affirment en effet qu'acquérir une expertise en Odissi n'est possible qu'en se rendant auprès d'un transmetteur particulièrement doué. En outre, ils considèrent qu'il existe trois styles d'Odissi, créés dans les années 1950 par trois maîtres aujourd'hui décédés. Ainsi, jusqu'à ce jour, être danseur implique d'appartenir à une de ces lignées. 
Par ailleurs, alors que le système scolaire indien adopte le même vocabulaire que le système éducatif européen, la transmission des pratiques musicales et dansées s'appuie sur un concept vernaculaire de la relation de transmission, le guru-sisya-paramparā, terme que l'on peut traduire par succession (paramparā) de maitres (guru) et de disciples (śisya). Aussi, la première question que se voit poser toute personne qui déclare pratiquer la danse Odissi est : « Qui est ton guru?»

Dans la première moitié des années 1990, j'avais entrepris d'apprendre l'Odissi auprès d'un maître à Bhubaneswar ${ }^{3}$, que j'avais sélectionné dans le respect de ces critères, à la suite d'une recommandation par une danseuse de renom. Il appartenait à la deuxième génération de maîtres et, si sa notoriété n'avait pas encore atteint le grand public, il bénéficiait d'une appréciation grandissante dans les réseaux culturels. À cette époque, mon dessein était d'atteindre le niveau d'expertise le plus élevé possible, et mon mentor, ainsi que les autres pratiquants autour de moi, me faisaient entendre que, pour arriver à danser à peu près correctement, il était nécessaire de s'entraîner sans trêve plusieurs heures par jour pendant plusieurs années - d'ailleurs, dans son école, on s'entraînait aussi le dimanche. Six ans de pratique étaient considérés comme un minimum absolu pour pouvoir commencer à penser qu'on maîtrisait un peu la danse.

Selon ces indications, il suffirait donc, pour acquérir le savoir-faire de la danse, de choisir un maître talentueux et de s'entraîner avec assiduité sur le long terme. Un observateur extérieur conclura peut-être même qu'après s'être soumis à ce processus les pratiquants acquièrent la capacité de transmettre à leur tour la danse. Mais plusieurs constructions discursives locales coexistent avec celles que nous venons de mentionner, qui contredisent une telle conception. Selon celles-ci, l'identité des apprenants joue un rôle prépondérant pour déterminer le type de compétences que ces derniers peuvent acquérir. Ainsi, dans les réseaux de la danse Odissi à Bhubaneswar, une affirmation commune est que « seules les filles oriyas peuvent danser l'Odissi ». Et simultanément, une idée commune très répandue est que les transmetteurs de ces pratiques sont de toute façon des hommes oriyas. Ceci semble indiquer que les femmes oriyas, seraient à la fois plus aptes que quiconque à pratiquer la danse, et particulièrement inaptes à la transmettre. Et que les hommes, bien que dépositaires d'un savoir-faire fréquemment représenté comme ancestral, seraient cependant moins versés que les femmes dans la pratique dansée. Comment se fait-il que le processus de transmission de la danse débouche sur ces différenciations en fonction des caractéristiques identitaires des apprenants? Faut-il supposer que les hommes et les femmes acquièrent effectivement, au cours de leur apprentissage de la danse, des compétences et savoir-faire distincts? Ou cette répartition des rôles s'explique-t-elle plutôt par des écarts dans la reconnaissance des expertises en fonction des caractéristiques identitaires des pratiquants? Afin d'élucider ce point, il importe d'examiner quelles relations s'établissent dans le cadre des pratiques de danse Odissi entre savoir-faire et ordre social. Ceux-ci sont inexorablement emmêlés, imbriqués, ou présentent-ils au contraire l'un vis-à-vis de l'autre un certain degré d'indépendance? Cette question s'apparente bien à celle posée par Robert Cresswell, qui va, dans ce qui suit, guider nos interrogations :

« Le technique est-il dans le social ou face à lui ${ }^{4}$ ? » 


\section{Un ordre social régissant les réseaux de la danse}

5 Il ne fait aucun doute que si la généalogie de l'odissi attribue la légitimité en matière de transmission à des hommes originaires de l'État d'Orissa, alors qu'elle fait apparaître la pratique de la scène comme une activité féminine, liée de façon moins catégorique à l'appartenance régionale - de nombreuses femmes appréhendées comme interprètes sont en effet originaires d'autres États de l'Inde -, ceci est l'indice d'un équilibre bien particulier des rapports de pouvoir au sein des réseaux de la danse. Les discours des danseurs représentent en outre massivement les maîtres comme étant des hommes issus de milieux ruraux, jouissant de peu de prestige social, et présentant un niveau d'éducation institutionnelle particulièrement bas, et font apparaître les interprètes comme étant des femmes appartenant aux plus hautes sphères de la société. Si ces représentations ont quelque chose de caricatural, j'ai cependant constaté au cours de mes recherches qu'il existe concrètement des différences marquées dans les appartenances socioculturelles des pratiquants masculins et féminins de l'odissi: la majorité des hommes sont originaires de milieux ruraux de l'Orissa, et clament volontiers faire partie des classes populaires. Les femmes que l'on rencontre dans les écoles de danse à Bhubaneswar présentent des profils nettement plus variés que celui exposé plus haut, mais sont clairement issues de milieux urbains, et notamment de milieux urbains de l'Orissa ${ }^{5}$ Bien que parmi elles se trouvent celles qui ont à leur actif des carrières brillantes - appartiennent réellement à des milieux d'élite, la plupart considèrent, quelle que soit leur appartenance régionale, qu'elles bénéficient d'une supériorité sociale au moins relative face aux hommes, et font volontiers référence pour entériner cette idée à leur niveau plus élevé d'éducation formelle. Les femmes issues d'autres États indiens font partie des écoles locales par intermittence, car elles effectuent souvent leur formation au cours de séjours plus ou moins longs en Orissa, pour retourner développer leur activité dans les grandes métropoles.

6 Cette division structurelle n'implique pas que les femmes soient vues comme des interprètes et les hommes comme des transmetteurs. Une explication au fait que les hommes se voient comme transmetteurs est à trouver dans un ordre social qui n'est pas du tout particulier aux réseaux de la danse, et qui soumet les femmes des couches de la population se réclamant de la religion hindoue à une "éthique de domesticité6". Effectivement, les pratiques associées à l'hindouisme prescrivent aux individus des chemins de vie, et ceux-ci imposent aux femmes de s'engager dans des carrières domestiques, et aux hommes de veiller au bien-être matériel de leurs familles ${ }^{7}$. Dans ces considérations, les pratiques de danse occupent peu de place. Mais il peut apparaître acceptable qu'un homme fasse une carrière en danse lorsque cette occupation constitue un moyen de subsistance suffisamment bon pour qu'il remplisse son devoir social de pourvoyeur, alors que dans le cas des femmes, à partir du mariage, non seulement l'activité dansée est en contradiction avec les responsabilités qui leur sont attribuées, mais, en outre, elle est communément jugée inconvenante pour une épouse. Dans les conceptions communes siège ainsi une contradiction: d'une part, les individus soulignent que si de nombreuses femmes pratiquent la danse Odissi, c'est grâce à la popularité croissante que la forme a connue depuis les années 1950. De l'autre, le présupposé général dans les réseaux de la danse est que celles-ci devront interrompre leur carrière lorsqu'elles quitteront leur famille biologique pour se marier, 
alors que les hommes qui viennent apprendre l'Odissi seraient destinés à devenir enseignants et savoir-faire.

7 Revenons à notre questionnement sur les imbrications entre ordre social et pratiques corporelles : s'agit-il, dans le cas particulier des pratiques de danse Odissi en Orissa, « de deux domaines face à face (éventuellement côte à côte) ou d'une intrication totale des techniques et de la culture dans un seamless web ${ }^{8}$ ?». Remarquons qu'il n'est pas facile pour des individus issus d'autres contextes géographiques et socioculturels qui se rendent en Orissa pour apprendre l'Odissi de ne pas se soumettre aux codes dominants de la société locale. Lorsque, dans les années 1990, j'avais intégré l'école de danse de mon maître, assumer la présence dans son école d'une femme étrangère comportait pour lui le risque non négligeable d'altérer ses relations avec les gens de son quartier. Le tissu social dans la ville de Bhubaneswar était tel que les voisins exerçaient sur les individus un contrôle social soutenu, et mon cas était d'autant plus sensible que j'étais en situation de transgression des normes sociales parce que le lieu que j'habitais comprenait une entrée séparée. La règle veut en effet que les allées et venues des femmes non mariées soient constamment encadrées, et j'avais la possibilité d'échapper à cette surveillance. Or mon maître considérait que toute altération de ma réputation se répercuterait obligatoirement sur lui, et se sentait de ce fait fortement concerné par mes agissements.

8 Il faut noter que si je m'étais rendue dans les mêmes lieux en poursuivant d'autres activités que la danse, ou si j'avais habité dans d'autres quartiers, en faisant d'autres choix de fréquentations, ma présence en tant que femme célibataire vivant seule aurait posé des questions analogues aux individus entrant en contact avec moi - en témoigne le fait qu'il était difficile de trouver un propriétaire qui accepte de louer un logement à une femme seule. Dans une certaine mesure, ces faits apparaissent donc tout à fait extérieurs à la pratique dansée ou, en tout cas, il n'est pas indispensable pour exécuter des mouvements de danse de se soumettre à des règles de conduite particulières. D'ailleurs, selon des rumeurs qui circulent à Bhubaneswar, au fil des décennies, plusieurs danseuses qui s'étaient rendues en Orissa pour apprendre l'Odissi auraient mis en œuvre toutes sortes de stratagèmes pour mener, dans les moments où elles ne s'entraînaient pas, la vie « dévergondée » qui leur était interdite par leurs maîtres - or ceci ne les a pas empêchées de devenir, plus tard, des danseuses célèbres.

9 Toutefois, il est intéressant de noter que ces danseuses non oriyas sont souvent l'objet de médisances de la part de pratiquants de l'Orissa. Aussi les injonctions que m'adressaient mon maître ainsi que d'autres personnes qui fréquentaient son école ne gravitaient-elles pas simplement autour de la question de savoir si je prenais soin de demeurer, comme cela était de mise pour une jeune femme d'Orissa, à l'intérieur de mon logement. J'étais constamment invitée, par diverses personnes de l'école, à apprendre à parler la langue locale, à manger le riz local, à apprécier sans réserve tout ce qui contribuait à construire un savoir-être oriya. Parfois, ces injonctions s'attaquaient directement à ma personne. Ainsi, dans ma première année, je me fis dire par une danseuse :

«Il ne faut pas que tu ries si fort. Les filles oriyas ne rient pas fort comme ça!»

10 Et elle rajouta qu'étant donné que je désirais «être oriya », il était adéquat que je me conduise comme une Oriya, reliant ainsi discursivement le fait d'être oriya à celui d'être danseuse Odissi. 
11 Une fraction importante des pratiquants de danse Odissi à Bhubaneswar attribue donc beaucoup d'importance au fait d'adhérer dans la vie quotidienne à une certaine conception de l'être oriya, qui implique aussi une conception spécifique de la féminité. De nombreuses pratiques corporelles font la promotion de ce que Robert Layton appelle « une théorie de l'être ${ }^{9}$ ». De ce point de vue, ce rapprochement entre pratiques dansées et codes de conduite valorisés par un groupe de personnes spécifique ne constitue donc pas une surprise. Il est toutefois important, si nous voulons comprendre la transmission de la danse, de documenter de quelles manières ces éléments sont interconnectés dans des cas particuliers.

\section{Le déroulement des entraînements}

12 Dans le cadre d'un terrain effectué en connexion avec ma recherche doctorale en $2009^{10}$, j'ai porté une attention particulière au déroulement des entraînements de danse dans les écoles de la ville de Bhubaneswar. Si chaque école a des spécificités, on retrouve néanmoins un certain nombre de traits communs dans leur fonctionnement. L'un d'eux est l'existence d'un entraînement quotidien matinal pour les hommes et les femmes se destinant à une pratique de danse qu'ils qualifient de "professionnelle ${ }^{11}$ ». L'on s'attend aussi à ce que ces séances soient dirigées par les maîtres, alors qu'il est habituel que les cours pour enfants ne le soient pas, et que les maittres puissent demander à certains de leurs disciples de donner, à d'autres moments, des cours à des personnes plus ou moins novices, afin qu'ils travaillent sur des aspects de la pratique dansée qui ne sont pas abordés dans les séances collectives du matin - et qui concernent fréquemment l'apprentissage de nouvelles chorégraphies, ou l'affinement de la gestuelle.

Les données ethnographiques mentionnées dans ce qui suit sont extraites des observations de ces séances matinales dans une école de la ville de Bhubaneswar dirigée par un maître d'Odissi considéré localement, au moment du terrain, comme un des maîtres de troisième génération les plus dynamiques et prometteurs, et que j'appelle appelons Aditya ${ }^{12}$. La fonction principale que remplissent les entraînements matinaux aux yeux des danseurs est de leur permettre d'acquérir ou de maintenir la forme physique nécessaire pour danser dans un spectacle - d'ailleurs, dès qu'ils passent une journée sans s'entraîner, ils considèrent être capables d'en observer les effets néfastes sur leur pratique. La danse Odissi s'effectue majoritairement dans des positions de plié, et demande donc une importante force physique qu'on ne maintient qu'en pratiquant régulièrement sur le long terme. Par ailleurs, la répétition quotidienne des gestes permet d'incorporer la fluidité caractéristique des mouvements de l'Odissi. Une des activités centrales lors de ces séances est la répétition de pas de danse et de chorégraphies déjà apprises, qui sont mémorisés durablement dans ce processus. À cet effet, les danseurs et danseuses se placent par rangées dans la salle et font tous face à une même direction, dans laquelle se situerait le public au moment d'un spectacle. Lors des entraînements, c'est souvent le maître qui se positionne à cet endroit en spectateur des pratiques. C'est à lui qu'incombe alors l'accompagnement sonore et rythmique : il scande des ukutas (syllabes mnémoniques correspondant aux sons produits sur un instrument de percussion), joue sur l'instrument de percussion utilisé en danse Odissi, le pakhavj ou mardala, ou encore bat la mesure avec un instrument constitué de deux pièces en bois frappées l'une sur l'autre, le kathi. 
Cependant, parfois, l'entraînement se déroule au son de la musique enregistrée émanant d'un lecteur CD.

14 En entretien, plusieurs danseuses de niveaux d'expertise divers m'ont dit qu'il était très difficile de s'entraîner seules chez elles. Elles avaient besoin, pour réussir à s'y astreindre, de la coercition créée par la présence d'une figure d'autorité. La présence du maître est ainsi importante même dans les situations - tout à fait fréquentes - dans lesquelles il se contente, assis sur le sol face aux danseurs, de les regarder s'entraîner. Les danseurs apprécient toutefois les séances dans lesquelles il s'implique, et ne manquent pas, entre eux, de commenter comment s'est passée la matinée. Un cours dans lequel ils ont répété de nombreux pas et de nombreuses chorégraphies est un bon cours, et, lorsque les efforts fournis ne leur paraissent pas assez importants, ils s'en plaignent et se traitent de paresseux! Le maître joue ainsi, indépendamment de la manière par laquelle il s'implique - et bien que, en toute apparence, les danseurs soient parfaitement en mesure de mener à bien leur séance de manière autonome -, un rôle capital dans la continuité des entraînements.

\section{Les discours en action dans les séances de transmission}

15 Ce que le maître discute dans les moments d'entraînement peut à première vue apparaître aléatoire. Pourtant, des thèmes particuliers se dégagent de ses interventions et, souvent, ceux-ci n'ont pas trait à l'action corporelle. Parmi ses préoccupations, mentionnons le thème des relations amoureuses de certaines danseuses Odissi non oriyas résidant dans un autre État de l'Inde, celui de la cuisine oriya et celui de la cuisine du Sud de l'Inde. Il les évoque sans forcément préciser explicitement son point de vue sur le sujet. Or ces sujets sont loin d'être neutres. Les relations amoureuses, par exemple, sont une transgression: dans les milieux hindous à Bhubaneswar, il est de coutume que les mariages des individus soient arrangés par leurs familles. Pour les danseurs et danseuses présents, dont la majorité ne sont pas encore mariés, il serait fortement inconvenant d'affirmer en public qu'ils ont une relation amoureuse. Et pourtant, c'est dans ce contexte-là qu'Aditya relève, comme si cela n'avait pas d'importance, le fait qu'une danseuse Odissi, non mariée bien qu'elle frise la quarantaine, qui n'est pas d'Orissa et vit dans un autre État indien, aurait eu une liaison. À d'autres moments, Aditya, sans quitter la salle de danse, donne à voix haute, en plein dans la séance d'entraînement, des instructions à un des disciples qui vivent dans l'école afin qu'il prépare des plats oriyas :

«Coupe des épinards, un oignon, coupe un bon oignon, quand tu l'auras coupé tu

viendras me le dire, après on fera du dalma ${ }^{13}$. »

Certes, les séances se terminent généralement aux alentours de 13 heures et, la préparation de la cuisine prenant beaucoup de temps, il apparaît utile de s'en préoccuper avant la fin de l'entraînement. Toutefois, le maître pourrait donner ses instructions discrètement, à voix basse - et au contraire, il les théâtralise devant les danseurs.

17 Si cette gestion particulière des séances d'entraînement confère " un sens que la danse et la vie ne sont pas séparées ${ }^{14}$ ", il est à noter que, par l'introduction de ces thèmes dans le déroulement des entraînements matinaux, Aditya crée, insidieusement, des frontières entre ce qui est de l'Orissa et ce qui ne l'est pas. Bien qu'il ne se prononce 
pas, dans plusieurs des moments que nous venons de citer, sur son appréciation personnelle de ce qu'il évoque, les danseurs dans la salle savent à quoi s'en tenir. En effet, lorsqu'en entretien avec une des danseuses j'évoque le fait qu'il s'enquiert de la préparation des plats du Sud de l'Inde, elle répond spontanément que le maitre fait ceci parce qu'il «les déteste ${ }^{15}$ ». D'ailleurs, Aditya affiche ouvertement sa passion pour l'Orissa: lors d'une entrevue, il affirmera qu'il désire qu'à chacune de ses réincarnations ${ }^{16}$ il renaisse en tant que danseur Odissi, et ce, insistera-t-il, en Orissa ${ }^{17}$.

Les aspects de l'activité du maître dans la salle d'entraînement décrits plus haut semblent à première vue tout à fait détachés de la danse : en effet, l'exécution des mouvements de danse peut tout à fait avoir lieu sans cette théâtralisation de l'identité oriya. Toutefois, le simple fait qu'ils se déroulent dans ce contexte spatio-temporel les relie à la danse. Par ailleurs, l'activité verbale du maître est conditionnée par l'action corporelle : elle se produit, avant tout, dans les moments où les danseurs s'arrêtent de pratiquer. Et, interrogé sur ces intermèdes discursifs, Aditya me dit :

«[...] Je connais la technique [...]. Donc je sais où [...] leur donner du repos, tu comprends ${ }^{18}$ ?»

19 Choisir le moment pour arrêter la pratique, introduire quelques échanges qui permettent aux danseurs de souffler avant de reprendre de plus belle leurs efforts, ce sont bien là des gestes qu'Aditya considère faire partie de son activité de pédagogue. Le fait d'introduire des moments de pause fait donc bien partie des gestes immédiatement nécessaires à l'entraînement. Qu'en est-il des contenus idéologiques qui sont au centre de ses verbalisations ? Il est utile de rappeler que la préoccupation avec l'identité oriya apparaît bien comme un élément fortement mis en valeur par les pratiquants de l'Odissi. Aditya, en choisissant de l'évoquer, participe activement à réactualiser ce thème de prédilection des danseurs Odissi. Et, simultanément, il l'impose à ses disciples. Car, en effet, par le fait d'avoir, dans leur désir d'apprendre cette danse, rejoint cette école, ceux-ci se voient confrontés à la nécessité de se plier à l'ordre social et aux règles de conduite qui sont à l'œuvre dans la salle de danse. L'ordre social et moral qui sous-tend les verbalisations du maître et la pratique corporelle sont donc inexorablement liés sur le lieu même des situations de transmission. Cette mise en relation constitue-t-elle une situation de côte à côte? Ou s'agit-il plutôt d'une imbrication?

Tournons-nous, afin de pouvoir examiner ce point, vers l'analyse d'un moment de l'entraînement au cours duquel les verbalisations du maitre coïncident avec l'action corporelle des danseurs. C'est le cas lorsqu'un matin, celui-ci n'a pas recours à la musique enregistrée, et déambule, sans se presser, le visage détendu, frappant le rythme avec son kathi et accompagnant de manière intermittente ces frappes d'un comptage vocal, s'arrêtant de temps à autre devant un danseur ou une danseuse, entre les rangs des danseurs qui sont en train d'effectuer une série d'exercices et de pas. Parfois, il intègre de courtes consignes dans son comptage, en les scandant rythmiquement pour ne pas interrompre l'entraînement. C'est ainsi qu'à un moment il se retrouve à l'arrière de la salle, où plusieurs femmes exécutent, côte à côte, un pas de danse. Aditya se dirige vers l'une d'entre elles en la regardant de face, et lance, sans s'arrêter de frapper : «Le corps droit! » Puis il tourne autour d'elle et arrive au fond de la salle, où il s'arrête entre deux autres danseuses, positionné cette fois-ci derrière elles. Toutes deux effectuent à cet instant le même pas que les autres danseurs, mais elles ont inversé la droite et la gauche. Aditya le fait remarquer à la première d'entre 
elles. Sa voisine, Ratna, se rend alors compte de son erreur et s'arrête d'un air gêné. À ce point, le maître se tourne face à elle et soulève son kathi au-dessus de son épaule, comme s'il s'apprêtait à la frapper. Il interrompt toutefois son geste et, se tournant vers la prochaine danseuse, lui dit que Ratna est une ādibāsi - une fille de la forêt, une «tribale ». À ce moment les danseurs font une pause, et le maitre reste quelques instants devant les deux voisines de Ratna, auxquelles il raconte avec amusement que cette dernière, originaire d'une région de l'Orissa comportant une forte proportion de population classifiée comme "tribale" par le gouvernement indien, effectuerait les danses de cette population-là. Les deux femmes rient. Il en est de même pour Ratna lorsque Aditya retourne quelques secondes plus tard vers elle, engageant une discussion en lui demandant où est son village.

21 Lorsque, plus tard, je discute avec Ratna du déroulement des entraînements et lui présente la vidéo de ce moment particulier, celle-ci affirme que le maître la " corrige ", et est donc impliqué dans son activité pédagogique ${ }^{19}$. Pourtant, les verbalisations du maître ne mentionnent aucun des mouvements de Ratna. Elles concernent uniquement son identité sociale. Non pas que Ratna fasse partie des ādibāsī, une fraction stigmatisée de la population indienne. Elle est, au contraire, la fille d'un homme distingué, directeur du département mécanique de la Steel Authority of India dans la ville de Bolani. Mais la partie de l'Orissa dans laquelle elle a grandi comprend une forte proportion de population officiellement répertoriée comme «tribale ». Ainsi, la boutade du maître constitue une inversion de son statut social effectif. En ayant recours à ce procédé, Aditya, dont le statut social est nettement inférieur à celui de la danseuse, rétablit la position hiérarchique qu'il occupe en tant que maitre, simultanément, par la tonalité humoristique de l'échange, il prend en compte la supériorité sociale de sa disciple. D'autres témoignages, ainsi que mes observations, confirment que le maître a recours à des procédés similaires dans ses interactions avec d'autres femmes bénéficiant d'un statut social comparable à celui de Ratna. Et il est notable que les danseuses interprètent ces échanges, qui impliquent des termes dévalorisants, comme autant de marques spéciales d'affection de la part du maître à leur encontre. Celui-ci ne met pas en cause, de leur point de vue, la qualité de leur prestation dansée. Enfin, il est important de relever que cette manière d'agir constitue aux yeux de Ratna un acte pédagogique, visant à lui permettre de se perfectionner.

22 Il faut rappeler, à ce sujet, que les verbalisations ont lieu au moment même où elle danse, et qu'avant d'avoir recours à l'assignation identitaire, le maître réagit corporellement, en s'approchant d'elle, et en faisant mine de la frapper, à l'erreur qu'elle effectue dans l'exécution de son pas. La communication se joue alors à plusieurs niveaux : elle est constituée d'actions corporelles qui placent le geste dansé au centre des préoccupations. Et elle est constituée des verbalisations du maitre, qui ne font pas du tout référence au geste dansé, mais impliquent le statut social de la danseuse, constituant ainsi un rappel des asymétries contradictoires inhérentes à cette relation particulière de maître à disciple. Cette métacommunication ${ }^{20}$ permet donc dans ce moment que les situations sociales du maître et de la danseuse, la hiérarchie de la relation maître-disciple et l'exécution du geste dansé se jouent dans le même instant.

23 Ainsi, en associant l'identité de Ratna à son activité dansée, Aditya relie le geste technique à l'ordre social qui régit les réseaux de danse Odissi, et donc à sa généalogie. En effet, ce mode d'action n'est pas accidentel ; l'analyse approfondie de la pédagogie du maitre exposée dans mon travail doctoral montre que, dans son enseignement, le 
recours à l'assignation identitaire et sa mise en relation avec l'exécution de la danse par ses disciples est une performance routinière.

Cette activité est complexe: selon mes observations, et d'après les affirmations des danseurs, elle varie notamment en fonction du sexe et du statut du - ou de la - disciple auquel il s'adresse. Dans l'exemple cité en amont, l'intervention du maitre est appréhendée, malgré le contenu du verbe adressé à Ratna, comme constituant une " plaisanterie ». Elle est, en outre, suivie d'un moment de détente. À une autre occasion, les remontrances qu'il prononce à l'encontre d'un danseur ne paraissent pas ludiques, ou ne débouchent pas sur un moment de pause, mais rajoutent au contraire à la tension physique des corps, qui s'astreignent à effectuer les gestes difficiles de la danse, une tension psychologique. À ce moment, Aditya réaffirme son autorité avec fermeté face à ce garçon dont la position sociale est comparable à la sienne, en contraste avec ce qu'il laissait entrevoir lors de son interaction avec Ratna. Ses interventions ont donc une double efficacité, car elles lui permettent de gérer les relations qu'il entretient avec chacun de ses apprenants, de leur assigner, dans le déroulement même des entrainements, une place spécifique dans la hiérarchie de l'école, tout en les incitant à augmenter leur effort physique, ou au contraire à faire une pause. Or, elles s'appuient bien sur l'ordre social à l'œuvre au sein des réseaux de l'Odissi. Dans les séances de transmission, la pratique de la danse, la hiérarchie de la relation maître-disciple et les représentations que les pratiquants ont de leur microcosme sont donc amenés à exister dans, et par, les diverses actions des danseurs. Ceux-ci s'initient ainsi simultanément à la danse et aux codes d'interaction en cours dans les réseaux de l'odissi. De plus, dans l'espace de la salle de danse se transmet une philosophie de l'être qui tend vers une reproduction de l'ordre dominant au sein des réseaux de cette danse. Aussi, dans les discours des pratiquants, la qualité du geste dansé des pratiquants et le jugement porté sur leur personne apparaissent volontiers confondus.

Le fait que l'identité oriya et l'ordre généalogique de la communauté des danseurs soient ainsi réactivés au sein du cours de danse ne nous paraît par ailleurs pas constituer une anomie, vu l'importance que les pratiquants leur attribuent. Par ces procédés, ils veillent à ce que la transmission de la danse ne se réduise pas à l'apprentissage de ses gestes, et porte au contraire ce qui est à leurs yeux l'esprit de la danse vers les nouvelles générations. Il est certain que cet équilibre est fragile, car il est constamment renégocié dans les situations de transmission. Or nous avons indiqué ailleurs que les fortes asymétries qui régissent le microcosme des pratiquants ne sont pas unanimement acceptées, mais font au contraire l'objet de contestations aussi bien du côté des hommes que des femmes ${ }^{21}$. Dans quelle mesure ces contestataires développent-ils d'autres conceptions de ce qui rend la pratique de l'odissi si spéciale à leurs yeux? Un examen du déroulement de séances de transmission dirigées par certaines de ces personnes pourrait permettre d'élargir notre compréhension de la transmission de cette danse. 


\section{BIBLIOGRAPHIE}

CRESSWELL Robert, « Geste technique, fait social total : le technique est-il dans le social ou face à lui ? ", Techniques \& culture, éd. numérique, $\mathrm{n}^{\circ}$ 40, 2003.

[URL : http://tc.revues.org/1576]

ČURDA Barbara, « Enjeux identitaires, relationnels et esthétiques de la transmission de la danse Odissi en Inde : le cas d'une école émergente à Bhubaneswar dans l'État d'Orissa », thèse de doctorat en anthropologie des dynamiques sociales et culturelles, Clermont-Ferrand, Université Blaise-Pascal - Clermont-Ferrand II, 2013.

ČURDA Barbara, «L'Odissi en Orissa contemporaine : stratégies individuelles, contraintes, genre ", mémoire de maîtrise de sociologie, Toulouse, université Toulouse - Le Mirail, 2002.

ČURDA Barbara, « La divinité Jagannatha préfère-t-elle les traditionnalistes ou les innovateurs de la danse Odissi ? », dans Fratagnoli Federica, Lassibille Mahalia (dir.), Danser contemporain : circulations et politiques de création : gestes croisés d'Afrique et d'Asie du Sud, Montpellier, Éditions Deuxième Époque, 2018, p. 51-79.

LAYTON Robert, « Art and agency : a reassessment », Journal of the Royal Anthropological Institute, vol. IX, nº 3, 2003, p. 447-464.

MENON Usha, Women, wellbeing, and the ethics of domesticity in an Odia Hindu temple town, Heidelberg/ New York/Dordrecht/Londres, Springer India, 2013.

PRICKETT Stacey, « Guru or teacher? Shishya or student? Pedagogic shifts in South Asian dance training in India and Britain », South Asia research, vol. XXVII, n 1, 2007, p. 25-41.

RUESCH Jurgen, BATESON Gregory, Communication: the social matrix of psychiatry, New York, W. W. Norton \& Company, 1951.

\section{NOTES}

1. Pour un compte rendu détaillé du développement de l'Odissi, voir B. Čurda, « Enjeux identitaires, relationnels et esthétiques de la transmission de la danse Odissi en Inde : le cas d'une école émergente à Bhubaneswar dans l'État d'Orissa ».

2. Les terrains de recherche étant antérieurs à ce changement, j'utilise l'ancien nom de l'État dans cet article.

3. Ce parcours de pratiquante précède mon implication avec l'odissi dans une perspective de recherche.

4. R. Cresswell, «Geste technique, fait social total : le technique est-il dans le social ou face à lui ? ».

5. B. Čurda, «L'Odissi en Orissa contemporaine : stratégies individuelles, contraintes, genre ».

6. U. Menon, Women, wellbeing, and the ethics of domesticity in an Odia Hindu temple town.

7. Usha Menon (ibid.) décrit en détail les différentes phases de vie et les responsabilités qui leur sont liées en s'appuyant sur le cas particulier des modes de sociabilité à l'œuvre dans la vieille ville de Bhubaneswar. 
8. R. Cresswell, «Geste technique, fait social total : le technique est-il dans le social ou face à lui ? », p. 15.

9. R. Layton, «Art and agency: a reassessment », p. 449.

10. Je ne relève ici que quelques moments des situations de transmission en question, décrites de manière détaillée dans ma thèse (B.Čurda, "Enjeux identitaires, relationnels et esthétiques de la transmission de la danse Odissi en Inde : le cas d'une école émergente à Bhubaneswar dans l'État d'Orissa »).

11. Il n'existe pas, au sein des pratiques de danse Odissi à Bhubaneswar, de concept de pratique amateur. Mais les cours pour les enfants ont généralement lieu moins souvent et à d'autres moments que ceux destinés aux personnes aspirant à faire de la danse une occupation centrale.

12. Pour préserver l'anonymat de mes interlocuteurs, j'ai employé des noms fictifs.

13. Le dalma est un des plats populaires de la cuisine oriya.

14. " a sense that dance and life are not separate » (S. Prickett, « Guru or teacher? Shishya or student? Pedagogic shifts in South Asian dance training in India and Britain », p. 30).

15. Entretien avec Ratna, 19 octobre 2009.

16. Selon la religion hindoue, les individus se réincarnent après leur mort.

17. Entretien avec Aditya, 11 octobre 2009.

18. Entretien avec Aditya, 11 octobre 2009.

19. Entretien avec Ratna, 19 octobre 2009.

20. J. Ruesch, G. Bateson, Communication : the social matrix of psychiatry.

21. B. Čurda, «La divinité Jagannatha préfère-t-elle les traditionalistes ou les innovateurs de la danse Odissi?».

\section{RÉSUMÉS}

L'Odissi, officiellement considérée par le gouvernement de l'Inde comme la danse « classique » de l'État d'Orissa (rebaptisé Odisha en 2011), présente de fortes asymétries dans sa généalogie puisqu'elle reconnaît des pratiquants masculins comme étant les transmetteurs légitimes de la danse et assigne aux femmes des positions d'interprètes. Quelles sont les relations entre cet ordre social et les pratiques dansées ? Cet article fournit des éléments de réponse à cette question. Dans un premier temps, il expose, à partir d'observations effectuées dans la ville de Bhubaneswar, capitale de l'État dans laquelle les pratiques de cette danse se déploient avec dynamisme, l'importance que les pratiquants de danse Odissi accordent aux modes de sociabilité locaux. Ensuite, il examine de manière détaillée le déroulement de situations de transmission dans une école de danse de cette ville, et met en exergue les procédés par lesquels un maître relie, au cours des entraînements, l'ordre idéologique et social qui apparaît central dans les représentations de la danse aux identités de ses disciples et à la pratique corporelle. 
AUTEUR

BARBARA ČURDA

Docteure en anthropologie de la danse, associée au laboratoire ACTÉ (EA 4281, Université Clermont-Auvergne) 


\title{
Les savoirs perdus de l'ancienne Polynésie
}

\author{
Véronique Dorbe-Larcade
}

\section{Une conscience malheureuse}

1 La Polynésie française d'aujourd'hui n'est qu'une fraction, héritée de l'époque coloniale, de la vaste aire de culture des Maoris ${ }^{1}$. Cette zone du Pacifique sud est la dernière de la planète à avoir été explorée par les Européens. À la fin du XVIII siècle, on y a trouvé un ailleurs, antérieur et meilleur dans une certaine mesure, puisqu'il s'agissait d'un monde radicalement autre qui, jusqu'au contact, ne connaissait ni le fer, ni l'écriture. La transmission du savoir, pivot de la continuité d'une culture ${ }^{2}$, s'y effectuait donc oralement seulement et uniquement. Or cette transmission a été interrompue.

2 Si Tahiti et les îles du Pacifique sont le lieu d'un surinvestissement imaginaire et pratiquement fantasmatique ${ }^{3}$, elles sont aussi le lieu d'une conscience malheureuse, celle de la disparition du savoir d'avant. Ce que résume le titre du livre de Victor Segalen qui s'y rapporte: Les Immémoriaux $x^{4}$. Des malaises et des blocages profonds toujours sensibles dans la Polynésie contemporaine ${ }^{5}$ en tirent leur origine ${ }^{6}$.

3 Mais si perte il y a bien eu, jusqu'à quel point et de quelle manière la rupture avec les savoirs anciens s'est-elle produite? La transmission des savoirs implique trois grands éléments qui interagissent fortement les uns sur les autres: des contenus informatifs, des agents de communication et des moments ou des circonstances variées et variables de relation ${ }^{7}$. Dans cette perspective, le développement qui suit interrogera tour à tour les notions de disparition et de déperdition pour envisager enfin et cependant de la possibilité d'une sauvegarde. 


\section{Une disparition}

4 L'explorateur George Vancouver (1757-1798), vétéran des voyages de Cook, atteste, en 1791, des transformations spectaculaires :

«Nous ne leur vîmes plus que peu d'instruments de pierre et d'os [...] pour peu qu'ils reçoivent encore des draps de fabrique d'Europe, la culture de la plante dont ils tirent les vêtements [référence à l'étoffe à base d'écorce ou tapa utilisée avant l'arrivée des Européens] et qui, aujourd'hui, est extrêmement négligée, sera totalement abandonnée ${ }^{8}$. "

5 De toute évidence la disparition des savoirs matériels anciens, à Tahiti, frappa par sa rapidité. Il en alla de même pour les savoirs immatériels. Ainsi les deux premiers Polynésiens à s'être embarqués sur des navires européens, Ahutoru/Poutavéry (avec Bougainville en 1768) puis Tupaia (sur l'Endeavour de James Cook, lors de son premier voyage dans le Pacifique en $1769^{\circ}$ ), avant d'avoir pu vraiment expliquer leur religion et leur société, succombèrent à des pathologies contre lesquelles leurs organismes n'étaient pas prémunis, préfigurant les effets généralisés du choc microbien qui résulta du contact. Si une transmission des savoirs d'avant le contact des Polynésiens aux Européens a pu ainsi être empêchée, cette transmission entre Polynésiens et donc de Polynésiens à Polynésiens en fut encore davantage affectée.

6 Les effets des épidémies consécutives au contact ont été gradués. Ils ont été brutaux immédiatement et leur effet dévastateur a été ressenti à long terme ${ }^{10}$. Pour repérer, chronologiquement, la disparition des savoirs d'avant le contact, il faut certainement penser en termes de générations autant qu'à l'appui de dates et d'événements ${ }^{11}$. Pour la transmission orale, une relation clé existe entre grands-parents et petits-enfants, à cause de la disponibilité cognitive des plus jeunes et de la disponibilité fonctionnelle des plus âgés ${ }^{12}$. Ce lien qui court-circuite la génération des parents est d'ailleurs formalisé, en matière successorale, dans la société polynésienne (un petit-fils hérite directement du titre de son grand-père, par exemple). En cas d'épidémie, les petits et les vieillards fragilisés par leur âge sont particulièrement menacés et leur disparition en nombre met évidemment en péril le processus de transmission transgénérationnel. La syphilis a frappé très vite au moment du contact et peu après, mais l'on sait qu'à Tahiti une épidémie de coqueluche a été particulièrement virulente en $1853^{13}$ et, de même, la grippe espagnole en 1918 a décimé les anciens et les plus petits dans la population de l'île ${ }^{14}$. Des moments de crise de la transmission des savoirs sont certainement intervenus au-delà du seul moment du contact.

7 Quelqu'un qui avait 15 ans en 1767, c'est-à-dire au moment de l'arrivée à Tahiti de Samuel Wallis et donc des premiers Européens, était âgé de 45 ans en 1797, lorsque le Duff, amenant les premiers missionnaires de la Société des missions de Londres (London Missionary Society ou LMS) mouilla dans la baie de Matavai. Sachant qu'entre le troisième voyage de James Cook et le premier séjour du capitaine Bligh dans l'île dix années s'écoulèrent sans qu'aucun navire européen ne fasse escale, cette génération resta très en prise avec les façons et les principes de l'avant-contact. Des jeunes d'à peu près 15 ans en 1797 étaient pleinement à même de recevoir l'enseignement des quinquagénaires d'alors. Ils arrivèrent eux-mêmes vers la cinquantaine - à l'âge d'être non seulement parents mais même grand parents - en 1827. Les années 1830 constituèrent ainsi un seuil avant que ne disparaissent les derniers témoins de l'époque $\mathrm{du}$ contact. Les adolescents avec lesquels ont pu vivre ceux-ci atteignirent eux-mêmes 
le seuil de la vieillesse en 1857. Ceux qui avaient 15 ans en 1857 eurent 45 ans en 1887 . Dès lors, les années 1890 ont pu à leur tour correspondre à une phase critique. Les jeunes qui fréquentèrent les personnes âgées du milieu des années 1880 abordèrent la cinquantaine en 1917, donc à l'époque de la Première Guerre mondiale qui retentit fort en Polynésie.

Le ressenti d'une crise dans la transmission des savoirs d'avant le contact est bien illustré par le cas de Maré. Ce dernier, convaincu que ses connaissances (légendes, chants, cosmogonies et généalogies) se trouvaient en passe d'être définitivement perdues, s'appliqua à transcrire ce qu'il avait appris oralement. Cette conversion alla de pair avec son propre ralliement au régime du protectorat établi à partir de $1843^{15}$.

Edmond de Bovis témoigne, lui aussi, de la crise de la transmission de la période 1830-1840 :

«[Les] vieillards dont les plus instruits ne sont plus : le vieux prêtre Taaroa, mort en 1844, presque dans mes bras à Vairao ; Pati, ancien grand prêtre, mort en 1852 à Moorea, trois jours après la dernière dictée que je reçus de lui ; le vieux prince Mai de Borabora, le ministre Auriro et beaucoup d'autres [.... ${ }^{16}$ »

10 Ces propos alarmistes font écho à ceux d'autres Français, participants des expéditions de Duperrey et Freycinet (1822-1825) et de Dumont d'Urville (1826-1829) qui dénoncent le rôle néfaste et destructeur de l'ancienne civilisation polynésienne joué par les missionnaires britanniques, alors qu'il s'agit de justifier l'intervention de la France dans les îles du Pacifique sud ${ }^{17}$. Enfin, effectués à l'initiative de Polynésiens, nouveaux convertis au christianisme, eurent parfois lieu des autodafés, manifestation spectaculaire du rejet des idoles des Anciens ${ }^{18}$. Globalement, une dévalorisation des savoirs d'autrefois était alors d'actualité.

11 La pénibilité du travail que l'absence de fer imposait aux Polynésiens y contribua certainement dans le domaine technique ${ }^{19}$. L'atteste la manière dont, plusieurs années avant que les Européens ne parvinssent à Rarotonga, les habitants reçurent la nouvelle du passage aux îles de la Société d'« une race entièrement différente [...] tout à fait blanche et qui s'appelait Tute ou Cook». Ces étrangers avaient des navires « immensément grands » qui ne chaviraient pas quoiqu'ils n'aient pas de balancier... Ils possédaient «des choses aiguisées avec lesquelles ils pouvaient couper [des arbres] avec la plus grande facilité20 $»$.

Dans le domaine religieux, il est rapporté qu'à Huahine, l'une des îles de la Société, avant le contact, un culte était voué à Hiro, dieu des voleurs. L'usage voulait qu'un objet volé lui fût aussitôt offert comme action de grâce. Lors du troisième voyage de Cook, des outils du bord furent dérobés et déposés, selon la coutume, au marae de Hiro. Une grande assemblée eut lieu ensuite pour décider de ce que l'on en ferait. Une distribution équitable du butin parmi les habitants s'avérait impossible. Aussi le grand prêtre déclara qu'il fallait que, comme des légumes, ces outils se reproduisent. Donc, on défricha un petit champ et on "planta " la scie, la hache, les ciseaux et les nombreux clous. On fit des prières et des invocations à Hiro. Mais il n'y eut pas de récolte et la rouille rendit les outils inutiles. On en conclut à l'évidence de l'impuissance du dieu et l'évangélisation de Huahine en fut facilitée ${ }^{21}$.

13 Néanmoins, au XIX ${ }^{e}$ siècle, l'écrit, mode privilégié de transmission du côté européen, présente une certaine fragilité. Par contre, l'« archivage » purement oral peut s'avérer fiable et durable. On a pu ainsi vérifier, en Polynésie, l'exactitude d'informations, remontant à vingt-cinq générations avant 1900 et relevant exclusivement d'une 
transmission de bouche-à-oreille sur une très longue période ${ }^{22}$. Par contre, couchée sur le papier, l'œuvre de John M. Orsmond (1784-1856) faillit disparaitre à jamais. De surcroît, à ses activités de missionnaire ${ }^{23}$, - il fut l'un des premiers évangélisateurs britanniques de l'archipel de la Société, maitrisant parfaitement le reo tahiti - il s'était employé à recueillir la mémoire de la religion païenne désormais pratiquement abandonnée : ainsi, entre 1822 et 1834, le chant de la création de l'île de Raiatea. En l'absence, alors, de possibilités de reprographie, ces documents furent rassemblés sous la forme d'un volumineux manuscrit dont n'existait qu'une seule version. Or, acheminé en France, ce recueil fut catastrophiquement perdu, lors d'un incendie vers $1850^{24}$. Toutefois cette masse d'informations ne disparut pas complètement. Teuira Henry (1847-1915), petite-fille du révérend, travailla tout au long de sa carrière d'enseignante à rassembler, à compléter et à reprendre les notes et les brouillons de son grand-père, à partir desquels elle rédigea Tahiti aux temps anciens, publié pour la première fois à Honolulu, en anglais, en 1928. Un livre qui constitue, à présent, la somme de référence majeure sur la société et la culture tahitiennes d'avant le contact ${ }^{25}$, même s'il ne faut pas exclure des déformations à cause du double prisme par lequel sont passées les données qu'il présente, d'une part de ce qu'a compris et retenu (ou non) le grand-père, puis, d'autre part, de ce qu'a compris et retenu (ou non) ensuite la petite-fille; tous deux, à coup sûr, compétents et honnêtes, mais forcément conditionnés par leurs préoccupations et celles de leur époque.

\section{Une déperdition}

14 Si l'oralité est un mode de transmission éprouvé, il y a, de fait, une transmutation qualitative de ce qui est transmis. Aussi mieux vaudrait parler de déperdition que de disparition, peut-être. La notion de tradition, de par son ambivalence, est intéressante à considérer : elle implique l'ensemble des savoirs anciens, mais elle s'applique aussi et surtout à certains champs de connaissance bien particuliers, très pratiques et fortement utilitaires ${ }^{26}$.

15 Mapuhi a Tekuraveke (1850-1913) le révèle. Métis, de mère polynésienne et de père anglais ou américain, il était originaire de Takaroa dans l'archipel des Tuamotu où il passa l'essentiel de son existence. Son instruction était assez sommaire ${ }^{27}$ mais il avait des connaissances nautiques peu communes, maitrisant le régime des vents, les courants de la haute mer et l'orientation sur les étoiles et le soleil, naviguant dans la continuité des grands navigateurs polynésiens d'avant l'arrivée des Européens ${ }^{28}$. Le savoir de Mapuhi a certes fait l'objet d'une reconnaissance, mais de la part d'un administrateur colonial qui a forcé les usages établis. En effet, Charles Marcadé, ancien lieutenant de vaisseau, alors qu'il était résident aux Tuamotu ${ }^{29}$, accorda un brevet de maitre au petit cabotage à Mapuhi - largement ignorant des principes techniques et scientifiques européens en matière de navigation. Il avait, en effet, pu éprouver luimême le savoir de ce dernier, à l'occasion d'un voyage de Papeete à Hikueru ${ }^{30}$. Cependant, les compétences de Mapuhi n'allaient pas sans susciter un certain scepticisme. En témoigne le propos d'un marin participant au même voyage apparemment qui mit ses exploits sur le seul compte de l'habitude et d'une grande familiarité avec les particularités de l'archipel ${ }^{31}$.

À l'appui de ce cas, la tradition est marquée d'une certaine connotation péjorative : un savoir dégradé ou déphasé par rapport à la norme établie qui se trouve, par ailleurs, 
être d'origine européenne, dans le cadre colonial d'actualité alors. La tradition s'apparente, ainsi, à un savoir dissident et non institutionnel, en tout cas. Un savoir reconnu communautairement et non scientifiquement ${ }^{32}$.

17 La complexité de la nature de la tradition est bien vérifiée en matière de pratiques de santé. La notoriété d'un personnage comme Tiurai (1835-1918), qualifié de guérisseur par l'administration et la bonne société de son temps, témoigne d'un recours important par la population polynésienne à des soins qui ne relèvent ni des soignants ni des procédures de santé relevant de la science à l'européenne ${ }^{33}$. Il incarne clairement une alternative - sinon une forme de résistance - à l'autorité coloniale française et à ses représentants. Tiurai fut régulièrement l'objet de poursuites judiciaires par les deux médecins civils d'alors à Tahiti, en particulier celui de Papeete. Mais il était systématiquement relaxé, car il déjouait les questions de l'interprète en faisant des jeux de mots tahitiens : ainsi «traiter» en reo tahiti veut dire aussi «saler». Si bien que Tiurai affirmait qu'il ne "traitait» pas puisque cela ne concernait que la viande des porcs $^{34}$. Il défendait l'idée que ce qui venait d'Europe et des Européens était mauvais pour les Tahitiens et que leurs maladies en résultaient. Tiurai mourut effectivement, à 80 ans, lors de la terrible épidémie de grippe espagnole qui décima Tahiti en $1918^{35}$. Ce qui rappelle certains éléments de la Mamaia, un mouvement religieux syncrétique combinant des références chrétiennes et une inspiration néopaïenne dans la continuité de la religion de l'avant-contact. Ses derniers adeptes sont morts de la variole au début des années 1840 parce qu'ils refusaient la médecine des nouveaux venus européens et, en particulier, la vaccination ${ }^{36}$.

18 Issu d'une grande famille aristocratique, Tiurai était bien porteur d'un savoir hérité des Anciens. Mais il avait, en propre, de véritables compétences médicales et d'indéniables résultats à son actif. Par exemple, en ce qui concerne des affections cutanées consécutives à la consommation de conserves, pendant les restrictions de ravitaillement en produits frais, à cause du blocage de la passe de Papeete, durant la Grande Guerre ${ }^{37}$. Ce que proposait Tiurai à ses patients s'apparentait à des traitements de type homéopathique. Lui-même avouait, avec beaucoup de franchise, qu'il improvisait dans sa pratique et qu'il manipulait en quelque sorte le savoir des Anciens en fonction du but thérapeutique visé. Ainsi, pour éviter une intervention chirurgicale qu'il jugeait dangereuse, Tiurai parvint à traiter un malade atteint d'un abcès à la gorge en prétendant recourir à des procédés traditionnels pour obtenir, de fait, la résolution en douceur du problème ${ }^{38}$. Il est moins opportun de s'interroger sur l'authenticité ou l'inauthenticité de la tradition que de souligner d'abord et avant la ductilité de celle-ci.

\section{La possibilité de la sauvegarde}

19 Les années 1920 ont été celles d'un sauvetage, vécu comment urgent, du patrimoine culturel du Pacifique. Le Bishop Museum de Honolulu, fondé en 1889 par le banquier Charles Bishop ${ }^{39}$, joua un rôle majeur. À l'origine conçu pour la conservation des regalia de la dynastie Kamehameha (à laquelle appartenait l'épouse de Charles Bishop, Bernice Pauahi), il se transforma, après la Première Guerre mondiale, lorsque Herbert Gregory en devint responsable. Désormais, la priorité fut donnée à la vie et aux gens ordinaires dont les coutumes et pratiques tombaient en désuétude, alors que s'intensifiait la mondialisation (ouverture du canal de Panama en 1914) ${ }^{40}$. 
20 L'archipel des Marquises s'imposa comme terrain d'enquête. Dans cette colonie française, intégrée à l'ensemble administratif colonial des EFO (Établissements français l'Océanie, il ne restait que 3000 personnes au début des années 1920 alors que sa population avant le contact avec les Européens s'élevait probablement à 80000 habitants $^{41}$. Le Bishop Museum diligenta donc, entre septembre 1920 et juin 1921, l'archéologue Ralph Linton et un couple d'ethnographes, Edward et Willowdean Handy. Sur place, deux hommes les aidèrent à trouver des informateurs et servirent d'interprètes : Guillaume Le Bronnec (1884-1968), un Breton, ancien employé de magasin à Paris, parti à l'aventure en Océanie pour finalement s'établir à Hiva Oa, l'une des îles de l'archipel des Marquises ${ }^{42}$, et Henry Lie, un Norvégien, né en 1889, ancien déserteur d'un navire de coprah et établi, lui aussi, à Hiva $\mathrm{Oa}^{43}$.

21 L'évidence d'une transmission genrée, distillée dans le temps et pas forcément verbale s'impose. D'autant plus que ces deux hommes clés pour les Américains étaient tous deux mariés à des Marquisiennes : Tihia Pii a Nuanua pour le premier et Rosina Wolher, de Ua Pu, pour le second. C'est à celles-ci que revient la responsabilité de la capacité d'information et de la compétence de terrain de ces derniers ${ }^{44}$.

Dans les premiers fascicules de la fameuse série des Bulletins du Bishop Museum publiant, à partir de $1922^{45}$, les résultats de cette enquête, les Handy s'appliquèrent à reproduire les termes polynésiens spécialisés ainsi que des dessins et des photographies aussi précis et exhaustifs que possible, à cause du constat établi de la disparition presque totale de toutes les anciennes techniques. Or présentement ces travaux sont totalement intégrés aux supports qui servent de référence pour la mise en valeur et la perpétuation d'un patrimoine typique ${ }^{46}$. Donc même détournée, il y a transmission des savoirs anciens et établissement d'une certaine continuité.

Mais a contrario la communication peut être refusée et des phénomènes de rétention existent. Disparu dernièrement, l'activiste John Doom l'a rapporté dans ses mémoires. Des anciens de sa connaissance, dit-il, avaient en leur possession des écrits (dits Puta tupuna) retraçant l'histoire de leur famille et de leur terre. Mais ils ont préféré se faire enterrer avec ces manuscrits et donc assurer leur perte plutôt que de les transmettre à des rejetons qu'ils en jugeaient indignes ${ }^{47}$. L'existence voire la présence d'émetteurs et de récepteurs ne suffit pas donc forcément à la transmission ${ }^{48}$. Nullement automatique, elle implique une interaction dont l'entente et la confiance sont des composantes majeures. C'est ce qu'illustre le cas d'Ariitaimai

Elle était issue du prestigieux lignage tahitien des Teva dont la défaite avait permis à la dynastie Pomare de devenir l'unique détentrice d'une souveraineté de type monarchique, en rupture avec l'avant-contact, où coexistaient plusieurs arii entre lesquels s'établissaient des rapports de force fluctuants ${ }^{49}$. Héritière des biens et de la mémoire des siens, elle avait épousé Alexandre Salmon, homme d'affaires prospère d'origine écossaise, qui devint, grâce à elle, grand propriétaire foncier. Elle fascina surtout l'Américain Henry Adams, issu d'une lignée présidentielle et membre de l'université d'Harvard qui séjourna à Tahiti de janvier à juin 1891 :

«Elle est une pure indigène et ne parle aucune langue étrangère. Elle a 68 ans et refuse de s'asseoir à table avec nous, mais s'assied sur le sol à l'ancienne manière indigène, et c'est vraiment un grand personnage. Pendant les soirées, nous nous couchions sur les nattes autour d'elle et elle nous parlait de l'ancien peuple de Tahiti, qui était bien plus intéressant que celui d'aujourd'hui. Elle nous racontait aussi de longues légendes indigènes $[. . .]^{50}$. » 
Ce qui avait lieu surtout à Tautira, dans la presqu'île de Tahiti, lieu retiré et préservé à l'opposé de la ville coloniale et occidentalisée de Papeete ${ }^{51}$.

Néanmoins, les Memoirs of Arii Taimai publiés sous la plume d'Henry Adams qui en résultèrent doivent beaucoup à la contribution de la reine Marau Taaroa. Fille d'Ariitaimai, elle était retournée vivre chez elle, après quelques mois seulement de vie commune avec son époux Pomare $\mathrm{V}$, dernier roi de Tahiti qui céda ses droits de souverain à la France, rendant possible l'intégration de Tahiti et des îles à l'empire colonial français. Ce texte d'Henry Adams ne circula qu'en version anglaise jusqu'à la seconde moitié du $\mathrm{xx}^{\mathrm{e}}$ siècle ${ }^{52}$ de façon assez conforme aux sympathies probritanniques marquées d'Ariitaimai et de Marau. L'appui apporté à Henry Adams par la reine Marau se prolongea ainsi par l'accueil chaleureux qu'elle réserva aux Handy, vers $1923^{53}$. Le fait qu'elle transmette directement - et du côté de la France - ne s'imposa que tardivement. Le traumatisme des ravages de la grippe espagnole de 1918 l'incita à le faire :

«[... Alors disparurent] les derniers vieillards qui retenaient encore quelque chose de nos antiques légendes et en voyant se lever une nouvelle génération à laquelle personne ne serait plus capable de transmettre [...] je conçus le projet de fixer ce qui pouvait être sauvegardé54.»

Du coup, en 1922, Marau acheva une histoire des Teva ${ }^{55}$. Cette source comme la parole de Marau Taaroa peinèrent à être reconnues du côté français. Celle-ci fut ainsi extrêmement déçue de ne pas avoir la présidence de la Société des études océaniennes, société savante à but historique principalement, fondée sous l'égide des autorités françaises et reconstituée en 1919 : elle ne l'intégra pas avant $1926^{56}$. Mais pour autant, l'unanimité ne s'est pas faite. James Lyle Young, homme d'affaires et érudit irlandais établi à Tahiti, écrit ainsi le 30 juin 1921 :

«La prédominance des Teva [...] n'est qu'une fiction, une invention de Marau, l'épouse divorcée du dernier roi Pomare [... qui] désirait exalter le peuple de Papara et la famille de sa mère aux dépens de la famille Pomare, en partie par mépris de cette dernière et en partie pour appuyer les revendications de la famille Salmon concernant les terres du district de Papara ${ }^{57}$. 》

Au temps de l'établissement du protectorat français, on avait de même reproché à Maré de fausser les généalogies afin de légitimer la concentration monarchique de l'autorité au profit des Pomare ${ }^{58}$. Mais ces réserves suggèrent surtout la nature collective et sociétale des savoirs du passé : il ne peut y avoir réellement transmission de la part d'un détenteur de la tradition sans acceptation du contenu et adhésion de la part des récepteurs de cette tradition ${ }^{59}$. C'est bien leur ultime critère de validité.

\section{BIBLIOGRAPHIE}

ADAMS Henry, Mémoires d'Arii Taimai, Paris, Musée de l’Homme, 1964.

AUDRAN H., « Moeava, le grand “Kaito Paumotu” ", Bulletin de la Société des études océaniennes, $n^{\circ} 248,1917$, p. 19-28. 
BABADZAN Alain, «L'invention des traditions et le nationalisme ", Journal de la Société des océanistes, $\mathrm{n}^{\circ} 109,1999$, p. 13-35.

BERLINER David, « Anthropologie et transmission », Terrain, n 55, 2010, p. 4-19.

BLAIS Hélène, Voyages au Grand Océan : géographies du Pacifique et colonisation (1815-1845), Paris, Comité des travaux historiques et scientifiques, 2005.

BoUgAINVILLE Louis-Antoine de, Voyage autour du monde, Bideaux Michel, Faessel Sonia (éd.), Paris, Presses de l'université Paris-Sorbonne, 2001.

BOUlay Roger, ABSALON Patrick (dir.), Rencontres en Polynésie: Victor Segalen et l'exotisme, cat. exp. (Daoulas, abbaye de Daoulas, 2011), Paris, Somogy, 2011.

BOVIS Edmond de, État de la société tahitienne à l'arrivée des Européens, Papeete, Société des études océaniennes, 1978.

CAILlOT Eugène, Histoire de la Polynésie orientale, Paris, E. Leroux, 1910.

Carnet Puta 2 tenete, [sur la bataille de Fei Pi en 1815], éd. numérique, [s. 1.], [s. n.], [s. d.]. [URL : http://www.tenete-tahiti.org/pdf/Puta_2.pdf]

cook James, The journals of Captain James Cook on his voyages of discovery, I, The voyage of the Endeavour (1768-1771), Beaglehole John Cawte (éd.), Cambridge, University Press, 1955.

DANIELSSON Bengt, Tahiti autrefois, Papeete, Hibiscus, 1982.

DENOON Donald (dir.), The Cambridge history of the Pacific Islanders, Cambridge, Cambridge University Press, 2004 (1999).

Di GIoRgio-teAmotuaitau Josiane, Fa'ati'a mai ia Tai'arapu ! Grandeur et déclin des Teva i tai, Mahina, Association Tā'atira'a Parau, 2016.

Doom John Taroanui, Mémoires d'une vie partagée, Papeete, Haere Po, 2016.

DOUGLAS Bronwen, Science, voyages and encounters in Oceania (1511-1850), Basingstoke, Palgrave Macmillan, 2014.

DRIESSEN Hank, «Tupa'ia : the trials and tribulations of a Polynesian priest », dans Herda Phyllis, Reilly Michael, Hilliard David (dir.), Vision and reality in Pacific religion, Canberra, Pandanus Books, 2005, p. 66-86.

EMORY Kenneth P., " The Tahitian account of creation by Mare », The journal of the Polynesian Society, vol. XLVII, $\mathrm{n}^{\circ} 2$ (186), 1938, p. 45-63.

FINNEY Ben, « Myth, experiment, and the reinvention of Polynesian voyaging ", American anthropologist, vol. XCIII, $\mathrm{n}^{\circ}$ 2, 1991, p. 383-404.

GASCOIGNE John, Encountering the Pacific in the Age of the Enlightenment, Cambridge, Cambridge University Press, 2014.

GRAND Simone, Tahu'a, tohunga, kahuna : le monde polynésien des soins traditionnels, Pirae, Au Vent des îles, 2007.

GUNSON Neil, WHITE Ralph Gardner, « An account of the Mamaia or visionary heresy of Tahiti (1826-1841) », Bulletin de la Société des études océaniennes, t. XII, 1963 (1962), p. 143-144.

HANDY Willowdean Chatterson, Forever the land of men : an account of a visit to the Marquesas Islands, New York, Dodd Mead, 1965.

HANDY Willowdean Chatterson, Handcrafts of Society Islands, New York, Kraus Reprint, 1971 (1927). 
HANDY Willowdean Chatterson, Tattooing in the Marquesas, New York, Kraus Reprint 1971 (1922). HENRY Teuira, Tahiti aux temps anciens, Paris, Musée de l'Homme, 1951 (1928).

HERMEL A., « Lettre au sujet de Tiurai », Bulletin de la Société des études océaniennes, nº 248, 1917, p. 195.

HOBSBAWM Eric, RANGER Terence (dir.), The invention of tradition, Cambridge, Cambridge University Press, 1983.

HUETZ DE LEMPS Christian, Le paradis de l'Amérique : Hawaï, de James Cook à Barack Obama, Paris, Véndémiaire, 2017.

KAHANE Joyce D., "State funding for the Bishop Museum ", report $n^{\circ} 2$, Honolulu, Legislative Reference Bureau, 1988.[URL :https://lrb.hawaii.gov/wp-content/uploads/ 1988_StateFundingForTheBishopMuseum.pdf] KROEPELIEN Bjarne, Tuimata, Papeete, Haere Po, 2009.

LAGAYETTE Pierre, « Mémoires et "Mémoires" : Marau Taaroa et l'historiographie de Tahiti ", Journal de la Société des océanistes, t. XXVIII, nº 34, 1972, p. 49-65.

LAUX Claire, Le Pacifique aux XVIII et XIX ${ }^{e}$ siècles, une confrontation franco-britannique : enjeu colonial et rivalité géopolitique (1763-1914), Paris, Karthala, 2011.

LAVONDÈS Henri, OLLIER Marie, « L'écrit des dits perdus : l'invention des origines dans Les Immémoriaux de Victor Segalen », Journal de la Société des océanistes, n 106, 1998, p. 113.

LESSON René-Primevère, Voyage autour du monde, vol. II, Bruxelles, [s. n.], 1838.

LINTON Ralph, Le fondement culturel de la personnalité, Paris, Dunod, Coll. Sciences de l'éducation, 1977 (1945). Éd. numérique réalisée par Jean-Marie Tremblay, [URL :http:// www.anthropomada.com/bibliotheque/Ralph-LINTON.pdf], p. 59.

MARAU TAAROA, Mémoires de Marau Taaroa, dernière reine de Tahiti, éd. numérique, Paris, Société des océanistes, 2013 (1971)

[URL : https://books.openedition.org/sdo/227]

Natira'a : le tressage, un lien entre passé et présent, cat. exp. (Punaauia, Musée de Tahiti et des îles), Punaauia, Musée de Tahiti et des îles, 2000.

No hea mai matou? Destins d'objets polynésiens, cat. exp. (Punaauia, Musée de Tahiti et des îles), Punaauia, Musée de Tahiti et des îles, 2007.

NORDENSKIÖLD Erland, « Nécrologie de Karl von den Steinen », Journal de la Société des américanistes, t. XXII, nº 1, 1930, p. 220-227.

O'REILLY Patrick, TEISSIER Raoul, Tahitiens : répertoire biographique de la Polynésie française, Paris, Musée de l'Homme, 1975

PÉTARD Paul, Quelques plantes utiles de Polynésie française et raau tahiti, Papeete, Éditions Haere Po, 2019, (1986).

PICHEVIN Bernard, Généalogies et histoire de Tahiti et des îles de la Société: de prestigieuses lignées d'arii, Pirae, Au Vent des îles, 2013.

QUATREFAGES Armand de, Les Polynésiens et leurs migrations, Paris, A. Bertrand, 1866.

RALLU Jean-Louis, Les populations océaniennes aux XIX $X^{e} X^{e}$ siècles, Paris, Institut national d'études démographiques/Presses universitaires de France, 1990. 
RIGo Bernard, Les lieux-dits d'un malentendu culturel, Pirae, Au Vent des îles, 2004.

SALMOND Anne, Aphrodite's Island: the European discovery of Tahiti, Berkeley, University of California Press, 2009.

SAURA Bruno, «Quand la voix devient la lettre : les anciens manuscrits autochtones (puta tupuna) de Polynésie française ", Journal de la Société des océanistes, n 126-127, 2008, p. 293-309.

SAURA Bruno, Tahiti Ma'ohi : culture, identité, religion et nationalisme en Polynésie française, Pirae, Au Vent des Îles, 2008.

SCEMLA Jean-Jo, Le voyage en Polynésie : anthologie des voyageurs occidentaux de Cook à Segalen, Paris, R. Laffont, 1994.

TCHERKÉZOFF Serge, Polynésie/Mélanésie : l'invention française des "races » et des régions de l'Océanie (XVI ${ }^{e}$-XIX ${ }^{e}$ siècle), Pirae, Au Vent des îles, 2008.

VANCOUVER George, Voyages de découvertes à l'océan Pacifique du Nord et autour du monde, exécuté pendant les années 1790, 1791, 1792, 1793, 1794, 1795, par le capitaine Vancouver, Paris, [s. n.], 1802.

WALKER Orsmond, «Tiurai, le guérisseur », Bulletin de la Société des études océaniennes, n 10, 1925, p. 3-35.

\section{NOTES}

1. S. Tcherkézoff, Polynésie/Mélanésie: l'invention française des "races" et des régions de l'Océanie (XVI ${ }^{e}$-XIXe siècle), p. 208, 229, 315.

2. R. Linton, Le fondement culturel de la personnalité.

3. H. Blais, Voyages au Grand Océan: géographies du Pacifique et colonisation (1815-1845), p. 12 ; J. Gascoigne, Encountering the Pacific in the Age of the Enlightenment, p. 147.

4. R. Boulay, P. Absalon (dir.), Rencontres en Polynésie : Victor Segalen et l'exotisme, p. 72-74, 96-97; H. Lavondès, M. Ollier, « L'écrit des dits perdus : l'invention des origines dans Les Immémoriaux de Victor Segalen ».

5. B. Rigo, Les lieux-dits d'un malentendu culturel, p. 213.

6. B. Saura, Tahiti Ma'ohi : culture, identité, religion et nationalisme.

7. D. Berliner, « Anthropologie et transmission », p. 11-13.

8. G. Vancouver, Voyages de découvertes à l'océan Pacifique du Nord et autour du monde, exécuté pendant les années 1790, 1791, 1792, 1793, 1794, 1795, par le capitaine Vancouver, cité dans J.-J. Scemla, Le voyage en Polynésie: anthologie de voyageurs occidentaux de Cook à Segalen, p. 409.

9. J. Cook, The journals of Captain James Cook on his voyages of discovery, I, 1, p. 117. Tupaia apprit à dessiner, selon les méthodes européennes, pour compléter les explications qu'il donnait à James Cook et à Joseph Banks (A. Salmond, Aphrodite's Island: the European discovery of Tahiti, p. 175-176).

10. J.-L. Rallu, Les populations océaniennes aux XIX et $X X^{e}$ siècles, p. 17, 218-219, 335 ;

D. Denoon (dir.), The Cambridge history of the Pacific Islanders, p. 113.

11. D. Berliner, « Anthropologie et transmission », p. 14-16. 
12. B. Pichevin, Généalogies et histoire de Tahiti et des îles de la Société: de prestigieuses lignées d'arii, p. 260.

13. L'histoire démographique : planches 73-74 : www.horizon.documentation.ird.fr/exldoc/pleins_textes/divers16-08/38895.pdf

14. B. Kroepelien, Tuimata, p. 241.

15. P. O'Reilly, R. Teissier, Tahitiens: répertoire biographique de la Polynésie française, p. 371 ; B. Pichevin, Généalogies et histoire de Tahiti et des îles de la Société: de prestigieuses lignées d'arii, p. 39-41 ; K. P. Emory, «The Tahitian account of creation by Mare ».

16. E. de Bovis, État de la société tahitienne à l'arrivée des Européens, p. 18.

17. B. Douglas, Science, voyages and encounters in Oceania (1511-1850), p. 166-170, 174, 176.

18. Paradoxalement, le sauvetage de ces objets et des savoirs dont ils relevaient a pu revenir alors à des missionnaires (No hea mai matou? Destins d'objets polynésiens, p. 17, $55)$.

19. L.-A. de Bougainville, Voyage autour du monde, p. 232.

20. H. Driessen, «Tupa'ia : the trials and tribulations of a Polynesian priest ».

21. E. de Bovis, État de la société tahitienne à l'arrivée des Européens, p. 22-23.

22. B. Pichevin, Généalogies et histoire de Tahiti et des îles de la Société: de prestigieuses lignées d'arii, p. 263.

23. R.-P. Lesson, Voyage autour du monde, p.176-186; E. Caillot, Histoire de la Polynésie orientale, p. 217, 283 ; C. Laux, Le Pacifique aux XVIII et XIX siècles, une confrontation francobritannique : enjeu colonial et rivalité géopolitique (1763-1914), p. 247.

24. A. de Quatrefages, Les Polynésiens et leurs migrations, p. 57, p. 182.

25. T. Henry, Tahiti aux temps anciens, p. 12-14.

26. D. Berliner, « Anthropologie et transmission », p. 7.

27. P. O'Reilly, R. Teissier, Tahitiens: répertoire biographique de la Polynésie française, p. 364-365.

28. H. Audran, « Moeava, le grand "Kaito Paumotu" ».

29. Décision du 31 mars 1908 : lexpol.cloud.pf/LexpolAfficheTexte.php?texte= 422982 .

30. Cité dans P. O’Reilly, R. Teissier, Tahitiens: répertoire biographique de la Polynésie française, p. 364-365.

31. Ibid.

32. La tradition s'est trouvée, par contre, fortement réhabilitée avec, en 1976, l'entreprise d'archéologie expérimentale de Ben Finney et l'expédition réussie de l'Hokule'a (B. Finney "Myth, experiment, and the reinvention of Polynesian voyaging $»$ ).

33. S. Grand, Tahu'a, tohunga, kahuna: le monde polynésien des soins traditionnels, p. 125-152, 195 ; O. Walker, «Tiurai, le guérisseur »; A. Hermel, «Lettre au sujet de Tiurai ».

34. S. Grand, Tahu'a, tohunga, kahuna : le monde polynésien des soins traditionnels, p. 151.

35. Ibid., p. 152.

36. N. Gunson, R. G. White, «An account of the Mamaia or visionary heresy of Tahiti (1826-1841) ». 
37. P. Pétard, Quelques plantes utiles et raau tahiti; S. Grand, Tahu'a, tohunga, kahuna: le monde polynésien des soins traditionnels, p. 131.

38. O. Walker, « Tiurai, le guérisseur ».

39. C. Huetz de Lemps, Le paradis de l'Amérique: Hawaï, de James Cook à Barack Obama, p. 166-169, 247-249, 249-257.

40. J. D. Kahane, «State funding for the Bishop Museum ».

41. E. Nordenskiöld, « Nécrologie de Karl von den Steinen ».

42. P. O'Reilly, R. Teissier, Tahitiens: répertoire biographique de la Polynésie française, p. 323-324.

43. Ibid., p. 345.

44. W. C. Handy, Forever the land of men: an account of a visit to the Marquesas Islands; P. O’Reilly, R. Teissier, Tahitiens : répertoire biographique de la Polynésie française, p. 324, 345.

45. W. C. Handy, Tattooing in the Marquesas, suivi par quatre autres brochures signées par les Handy, sur la musique (1925), les jeux de ficelle (1925), les légendes (1930) et la société préeuropéenne des Marquises (1923), et la cinquième sur l'archéologie par Ralph Linton (1925).

46. W. C. Handy, Handcrafts of Society Islands, p. 56 ; Natira'a : le tressage, un lien entre passé et présent.

47. J. T. Doom, Mémoires d'une vie partagée, p. 73; B. Saura, «Quand la voix devient la lettre : les anciens manuscrits autochtones (puta tupuna) de Polynésie française ».

48. D. Berliner, «Anthropologie et transmission », p. 13-16.

49. Carnet Puta 2 tenete; J. Di Giorgio-Teamotuaitau, Fa'ati'a mai ia Tai'arapu! Grandeur et déclin des Teva i tai.

50. Cité dans H. Adams, Mémoires d'Arii Taimai, p. 9.

51. P. Lagayette, "Mémoires et "Mémoires": Marau Taaroa et l'historiographie de Tahiti ».

52. H. Adams, Mémoires d'Arii Taimai, p. 15-16.

53. Ces enquêtes étaient largement ignorées du côté francophone. Seul un résumé assez sommaire et réducteur en fut donné dans Les îles Marquises du $\mathrm{D}^{\mathrm{r}}$ Rollin, ouvrage publié en 1932 (B. Danielsson, Tahiti autrefois, p. 42).

54. S. Grand, Tahu'a, tohunga, kahuna: le monde polynésien des soins traditionnels, p. 153 ;

B. Kroepelien, Tuimata, p. 259-268.

55. Marau Taaroa, Mémoires de Marau Taaroa, dernière reine de Tahiti, 2013 (1971), p. 25-26.

56. P. O'Reilly, R. Teissier, Tahitiens: répertoire biographique de la Polynésie française, p. 599-600 ; Bulletin de la Société des études océaniennes, nº 15, 1926, p. 109-125.

57. P. Lagayette, "Mémoires et "Mémoires": Marau Taaroa et l'historiographie de Tahiti ».

58. B. Pichevin, Généalogies et histoire de Tahiti et des îles de la Société: de prestigieuses lignées d'arii, p. 39-42. 
59. D. Berliner, «Anthropologie et transmission », p. 13-14 ; E. Hobsbawm, T. Ranger (dir.), The invention of tradition, p. 119 ; A. Babadzan, "L'invention des traditions et le nationalisme $»$.

\section{RÉSUMÉS}

Il y a une conscience malheureuse de la perte irrémédiable des savoirs polynésiens d'avant le contact avec les Européens. Il s'agit de revisiter cette idée reçue. Tout d'abord il convient de mettre en évidence comment et quand la disparition de ces savoirs a été possible pour envisager ensuite quelles transformations ils ont pu subir et considérer dès lors un processus de déperdition. Ce qui conduit à s'interroger, paradoxalement, sur l'éventualité et les modalités, malgré tout, d'une sauvegarde.

\section{AUTEUR}

\section{VÉRONIQUE DORBE-LARCADE}

Maître de conférences HDR en histoire moderne, université de la Polynésie française 


\title{
Le sentiment religieux chez les nomades Mbororo du Tchad : une adhésion opportuniste à l'islam?
}

\author{
Yassine Kervella-Mansaré
}

1 La principale conclusion d'enquêtes anthropologiques menées récemment en Afrique subsaharienne (ouest du continent) est d'y constater un essor du sentiment religieux inspiré par l'islam. Après un millénaire d'influences diffuses et disparates, la fin du $\mathrm{xx}^{\mathrm{e}}$ siècle aurait vu une accélération des adhésions individuelles et groupales. Le phénomène s'expliquerait par une volonté plus ou moins affichée de pallier la faillite morale, politique et économique des États ${ }^{1}$. L'islam apparaitrait à cet égard "non seulement apte à assurer le bien public et à maintenir les identités nationales hors du factionnalisme ou du régionalisme, mais à redéfinir aussi de facto la nature même des espaces publics ouest-africains ${ }^{2} »$.

Dans le cadre de cette courte étude, il s'agit de s'écarter des centres urbanisés pour examiner la situation des nomades Mbororo qui, en Afrique subsaharienne, accueillent l'islam, ou le refusent, sans avoir, et pour cause, une pratique de l'espace public, du moins quand on le conçoit comme un lieu de cohabitation multiethnique, multiconfessionnelle, multipolitique, où s'élaborent aussi des compromis citoyens, au sens où s'y rechercherait un minimum consensuel pour vivre ensemble, précisément malgré les différences ethniques, confessionnelles ou politiques. Les analyses publiées sur les effets des débats menés dans cet espace n'ont pour eux aucun sens. La question se pose d'ailleurs de savoir s'ils ne sont pas marginalisés par les chercheurs qu'intéresse actuellement la « globalisation » islamique.

\section{Repères méthodologiques}

Une enquête de terrain menée de septembre 2012 à mai 2013 auprès de plusieurs groupes Mbororo du Tchad, aussi bien dans le Baguirmi, le Kanem que le Mayo-Kebbi, permet de dégager quelques propositions simples sur l'importance très relative du 
sentiment religieux islamique en leur sein. Au-delà des impressions subjectives, se discerne notamment l'impossibilité de leur appliquer la plupart des catégories interprétatives employées dans les études sur les phénomènes urbains.

4 A fortiori, il ne peut être question chez eux de « remoralisation de l'espace public ${ }^{3}$ » et encore moins " d'alternative civilisationnelle au modèle occidental ${ }^{4}$ ». Leur style de vie les maintient en dehors des enjeux de cette nature. Éleveurs itinérants de bovins, encore largement endogames et structurés autour de chefferies qui échappent aux appareils hiérarchiques des États, c'est à peine si l'on peut les intégrer à une problématique de «l'islam noir », supposé caractéristique de l'islam au sud du Sahara, par contraste avec «l'islam blanc» au nord, puisque l'image qu'ils conçoivent d'euxmêmes n'est ni blanche ni noire, ni même intermédiaire. Comme les autres Peuls d'ailleurs, ils estiment être à part. Au physique comme au mental, ils s'attribuent des distinctions qui rendent inappropriées les constructions théoriques autour d'une bipolarisation.

5 Le phénomène de migration se comprend la plupart du temps dans une sorte de dialectique entre un dehors et un dedans. Le migrant quitte un lieu (ex : émigrer) pour pénétrer un autre (in: immigrer). Dans ce cas, la zone entre ces deux lieux, celle qui permet le voyage, ne lui paraît pas digne d'intérêt; il la passe, la dépasse souvent à la hâte, en limitant les arrêts. Dans le cas d'un migrant existentiel, si j'ose dire, d'un nomade qui bouge tout le temps, c'est au contraire cette zone qui lui est familière. Le dehors d'un lieu habité est son dedans. Pour le Mbororo, telle est la brousse, la savane, la vaste étendue de terre écrasée par le soleil. C'est là qu'il mène son troupeau, qu'il en découvre la subsistance; c'est là qu'il construit son système symbolique et sa propre métaphysique, sans églises ni mosquées, sans synagogues, sans temples ou autres bâtiments de culte. Aussi bien, n'est-ce pas la façon dont une pratique religieuse exportée se transforme dans un ou plusieurs lieux d'importation qui est à étudier ici, mais plutôt la façon dont une pratique religieuse en constante mobilité est captée (capturée ?) par une autre sédentaire pour qu'elle s'y laisse absorber ou manœuvrer.

6 Le Mbororo n'est pas dans la position du migrant qui passe de la campagne à la ville ni d'une ville à une autre, dans le même pays ou à l'étranger. Il n'est pas confronté au besoin de réinscrire ses croyances dans un contexte socialement différent de celui qu'il aurait quitté. En effet, parce que naturels, encore sauvages, la caractéristique des espaces qu'il parcourt est d'être socialement neutres. Soumis au cycle des saisons sèches et pluvieuses indépendamment de sa volonté, il ne lui impose aucune transformation durable. En outre, les interactions avec autrui, c'est-à-dire avec des groupes porteurs d'une autre culture que la sienne, y sont peu fréquentes, discontinues et souvent bornées aux échanges économiques minimaux (troc épisodique, achat de denrées, de vêtements, négociation pour s'abreuver à un puits). Dans cet environnement, où qu'il soit, même après la traversée d'une frontière, il n'est donc jamais déraciné car jamais enraciné.

7 En tout état de cause, la situation actuelle des Mbororo invite à examiner à la fois leurs choix collectifs quand ils sont en déplacement avec leurs troupeaux, et leurs choix individuels quand certains décident d'abandonner provisoirement ou définitivement leur communauté pour séjourner dans une agglomération citadine et se livrer à une activité différente de l'élevage. Migrer en groupe, se sédentariser individuellement, voilà deux possibilités qui impliquent des stratégies différentes pouvant influer sur les pratiques religieuses. De plus, il arrive qu'au sein d'une même communauté, un partage 
se réalise en fonction des âges. Tandis que les jeunes continuent à nomadiser, les anciens s'établissent dans un village, voire le construisent eux-mêmes pour ne plus jamais le quitter. La religion trouve alors, là aussi, deux manières de s'exprimer.

8 Sans doute faut-il d'emblée affronter une difficulté. Comme tous les Peuls, les Mbororo veillent à définir leur personnalité ethnique en évoquant un code de conduite qui leur est particulier: le pulaaku. La littérature ethnologique abonde en allusions plus ou moins appuyées à l'efficience de ce code. Sa caractéristique est d'être présenté comme hérité d'une lointaine tradition, voire selon la légende depuis l'apparition du Peul sur la terre, et de fournir ainsi les principes guidant n'importe quel engagement individuel ou collectif. Mettant en valeur les sentiments de patience, de respect d'autrui et de soimême, de conciliation, d'humilité, de générosité, d'adaptation réfléchie aux circonstances parfois compliquées, le pulaaku est donc à la fois une éthique et une ontologie. Il manifeste à la fois ce que le Peul fait et ce qu'il est. Or, en examinant la plupart des prescriptions qu'il dicte, on s'aperçoit qu'elles n'ont vraiment de sens que dans une société d'élevage pastoral bovin: un collectif d'humains s'occupe quotidiennement d'un collectif de bovidés.

9 Ne plus avoir de rapports directs avec un troupeau en mobilité, même de modeste amplitude, a pour conséquence de fragiliser le pulaaku et de faire perdre au Peul, dont le Mbororo, la personnalité distinctive à laquelle il tient. L'éloignement d'individus hors du groupe ou le retrait de l'activité pastorale sont perçus comme des menaces. Partant, la pratique migratoire ainsi vécue apparaît non pas comme une occasion de reconfigurer ou recomposer un ensemble de croyances et de pratiques, mais au contraire comme la condition de leur conservation.

Cette difficulté peut se formuler autrement. Lorsqu'un jeune Mbororo quitte sa famille pour émigrer dans une ville plus ou moins lointaine, les anciens confient leur pessimisme. Ils lui prédisent un oubli du pulaaku et du même coup de sa fierté peule. Lorsqu'un jeune reste dans sa famille et participe activement à aux soins du troupeau, tandis que des anciens se fixent quelque part pour adopter une vie sédentaire, il considère que les mêmes ont tendance à oublier le pulaaku puisqu'ils ne sont donc plus emportés dans le mouvement des troupeaux. Or, dès qu'on aborde précisément la question religieuse, on s'aperçoit que les anciens sont volontiers enclins à manifester leur adhésion à l'islam, du moins dans les communautés étudiées ici, tandis que dans les deux cas, les jeunes y sont plutôt indifférents ou désintéressés.

\section{Perpétuels migrants}

11 Les Peuls n'auraient jamais cessé de migrer, ils seraient des perpétuels campeursdécampeurs. Leur origine exacte est méconnue. Nul ne sait de façon exacte et indubitable où ils ont commencé à se manifester comme une population autonome, peut-être au bord du Nil, peut-être ailleurs. On est seulement sûr de deux choses. La première est que, depuis la plus haute Antiquité, ils ont déjà l'élevage de bovins en activité principale, voire exclusive, ce que leurs mythes et légendes répètent d'ailleurs à satiété. La seconde est qu'ils se sont établis au cours du premier millénaire de notre ère au cœur de l'actuel Sénégal, après quoi ils ont essaimé dans de nombreux pays de l'Afrique de l'Ouest et du Centre, au point de former aujourd'hui une sorte d'archipel, selon l'heureuse expression de Jean Schmitz ${ }^{5}$ reprise par Jean Boutrais ${ }^{6}$. 
12 Migrer appelle des haltes parfois longues sur un territoire d'accueil, et quand il s'agit d'en repartir ce n'est pas automatiquement tout le monde qui s'y met. Des fractionnements de populations peuvent se produire, suivis de dispersions. En tout cas, la tradition peule, quels que soient les groupes qui la revendiquent aujourd'hui, renvoie à l'image d'une communauté unique qui se serait donc segmentée de siècle en siècle. Pour ce qui concerne les Mbororo, ils semblent avoir alterné des phases de sédentarisation sur des lieux d'hivernage puis de nomadisme les poussant vers de nouveaux horizons, de l'ouest vers l'est. Tel est le cas de plusieurs informateurs rencontrés au fil de l'enquête, qui déclarent que leurs familles ont vécu au Mali, au Niger, au Nigeria, au Cameroun, au Tchad, en Centrafrique, au Soudan, et quelquesunes tenteraient même actuellement des incursions en Éthiopie.

Avec eux, la question religieuse peut être abordée de différents biais. Tantôt, il s'agit de caractériser, dans les traditions qu'ils revendiquent, les usages inspirés par une croyance en des forces ou des puissances invisibles, ces usages qualifiés pour aller vite de fétichistes ou animistes. Tantôt, il s'agit d'évoquer directement leur éventuelle adhésion à l'islam et la valeur qu'il lui prête. Eux-mêmes font spontanément la distinction, d'ailleurs, et souvent pour souligner les interdits prononcés par l'islam contre ces usages traditionnels, ce qui ne signifie pas qu'ils les approuvent, mais ce qui manifeste chez eux le sentiment d'avoir, pour le moins, à composer avec une religion d'importation.

Mbororo appartenant à un groupe de Wewefe, Amadou Abdoulaye, âgé de trente-cinq ans environ, dont la famille est originaire du Niger, du moins aussi loin que remonte sa mémoire, présente le cas de sa propre génération de la manière suivante :

«Quand nous étions petits, nous voyions nos parents prier, mais ils ne nous apprenaient pas comment prier. Nous savions que c'était l'islam, que nous étions nés musulmans, et c'était tout. Nous respectons ça. Mais nous ne pratiquons pas beaucoup la religion. Nous aimons beaucoup nous amuser, il faut grandir pour aimer la prière, n'est-ce pas? Il faut arriver à l'âge de quarante à cinquante ans, c'est à ce moment qu'on réfléchit à ça ${ }^{7}$. "

À peu de variantes près, ce propos est exprimé par la plupart des jeunes Mbororo ayant accepté un entretien. Dans leur bouche, s'amuser ne signifie pas automatiquement ou uniquement se divertir. Comme ils s'en expliquent en fournissant divers exemples, il ne s'agit pas seulement de se livrer à des jeux ou des fêtes, mais aussi de prendre plaisir à vivre entre soi sans se préoccuper d'une discipline dictée de l'extérieur. Celle du pulaaku suffit amplement à garantir le bon ordre de leur société. Ils veillent d'ailleurs à préciser qu'elle s'impose, elle, depuis la prime enfance, qu'il ne leur vient pas à l'esprit d'y manquer, que c'est leur honneur d'en appliquer chaque jour les règles.

Sans autre commentaire, on pourrait croire avoir affaire à une jeunesse affichant une sorte de désaffection récente à l'égard du religieux, alors que leurs parents auraient été autrefois quant à eux plus scrupuleux, ayant peut-être de leur côté su associer dans leur propre jeunesse à la fois l'islam et le pulaaku. Il n'en est rien, la distinction en tranches d'âge est en réalité opératoire à n'importe quelle époque, au sens où les vieux d'aujourd'hui agissaient et réagissaient hier comme leurs propres enfants devenus adultes. Selon qu'il a vingt ans ou selon qu'il en a soixante, le Mbororo ne s'affirme pas musulman de la même manière, loin de là.

17 Quelques-uns décrivent les dispositions qu'ils prennent lorsque, entre deux hivernages, ils guident leurs troupeaux vers de lointains pâturages. Ils ne prient pas, ils marchent, 
ils se reposent, ils installent leurs huttes près de points d'eau, ils dispensent leurs soins aux animaux. La plupart du temps, s'ils n'envisagent pas d'occuper un site privilégié comme lieu de retour périodique, site où pourrait s'ériger un village, ils vont et viennent avec leurs familles au complet. Quand un vieux meurt, il est enterré dans un linceul, en présence des hommes, les femmes étant laissées au campement, et sans les prières qu'on entend chez les musulmans de la ville. Car personne ne les connaît, ces prières.

18 Les perpétuels migrants sont économes des moyens dont ils disposent, tant matériels qu'intellectuels. Ils ne s'encombrent pas. Le strict nécessaire, au plus léger, constitue leurs bagages. Tout le monde contribue à la vie domestique organisée autour du troupeau. Ce sont des familles ou des groupes de familles qui forment l'unité nomade. Donc, pas d'école coranique qui pourrait guider les apprentissages simultanés de la langue arabe et des préceptes de la foi. Pour communiquer, ils ont leur langue maternelle, le fulfulde, et elle leur suffit amplement. Dès cinq ou six ans, les garçons commencent à suivre leurs aînés pour découvrir les techniques du bouvier, tandis que les filles contribuent auprès de leurs mères aux tâches ménagères. Mais alors, est-ce signifier que l'on peut être musulman sans avoir les rudiments de l'islam?

Remontons de quelques décennies en arrière. Comme le montrait Marguerite Dupire au cours des années 1960, l'islamisation des Mbororo est inégale selon les groupes ${ }^{8}$. Elle semble en tout cas postérieure à celle d'autres Peuls, comme ceux du Fouta-Djalon guinéen ou de l'Adamaoua camerounais. On remarquera, en outre, que certaines de leurs migrations s'expliquent par la fuite devant les pressions exercées sur eux au $\mathrm{xx}^{\mathrm{e}}$ siècle, quand un jihad était engagé par ces autres Peuls pour tenter l'instauration d'une hégémonie sur les populations du Sahel. Quoi qu'il en soit, de nos jours, ils sont majoritairement entrés dans le giron de l'islam, mais ce qu'ils en disent autorise à penser que leur adhésion est largement conditionnelle. Ne serait-ce pas, au bout du compte, pour faciliter la continuation de leur migration dans des pays où, en effet, la référence musulmane est devenue un atout?

Les motifs ou mobiles qui poussent un individu à adopter une foi religieuse sont si variés qu'il est impossible d'en dresser une nomenclature exhaustive. On peut noter cependant que chez les Mbororo, ainsi que chez les autres Peuls rencontrés au fil de l'enquête (notamment des Fellata), le mimétisme est fréquemment invoqué. On est musulman plus par imitation que par conviction. En l'absence d'école coranique et de lettrés au sein de l'unité nomade, on se contente de reproduire des stéréotypes. Partant, je suggère d'articuler deux séries de considérations, la première relative au formalisme de l'expression religieuse, la seconde relative aux négociations qu'un système religieux doit engager avec un environnement socioculturel pour s'y faire admettre.

\section{Le culte des apparences}

S'intéressant aux Peuls du Cameroun, Philip Burnham observe ceci :

«Pour montrer sa fidélité religieuse, il suffit de faire semblant d'exécuter les cinq prières quotidiennes et, puisque ces prières peuvent être dites de manière inaudible, il n'est possible à personne de vérifier si l'individu récite vraiment les versets coraniques ${ }^{9}$. 
l'islam dans les pays d'Afrique où il est déjà bien ancré, et il l'est effectivement là où les Peuls se sont dispersés, signifie, pour les catégories d'entre eux qui y ont été longtemps réfractaires, le moyen de faciliter leur acceptation dans les terres qu'ils parcourent, et qui sont donc de plus en plus contrôlées par et pour les sédentaires. Le «comme » ne requiert pas un quelconque raisonnement, une quelconque théorie de ce qu'on imite. On le vérifie sans peine quand, de façon plus générale, on demande aux informateurs pourquoi ils veulent perpétuer leurs traditions, leurs coutumes et a fortiori le pulaaku. gestes sont à combiner afin de prouver à l'environnement humain qui les attend qu'on en a compris les règles de coexistence. Dans le cas de la religion, une chose est ce qui s'éprouve dans l'intimité d'une conscience singulière, autre chose est ce qui est manifesté par un comportement ritualisé.

Tandis que le pulaaku est si profondément intériorisé que les définitions qui en sont données insistent précisément sur l'importance de quelques sentiments à entretenir à chaque seconde de l'existence (voir plus haut), la foi islamique semble pour la plupart des informateurs une affaire de mise en scène très ponctuelle à des moments choisis de la journée (prières), voire seulement de l'année (Maouloud, Tabaski, Aïd-el-Kebîr). Dans son principe, une telle ritualisation n'a en soi rien d'original puisqu'elle est flagrante sous diverses formes dans les autres religions. Son effet est de fournir aux yeux d'un public les signes visibles d'une intégration à son espace. Ceci nous ramène certes à la notion d'espace public. Encore faut-il ajouter que, avant tout débat, et on pourrait ajouter : en excluant tout débat qui pourrait contrarier le déroulement de la cérémonie, l'objectif est bel et bien de communier, au sens où une union commune est à assurer et réassurer en actes prédéfinis et en paroles convenues. Dans ce cas, la question de la sincérité est tout à fait secondaire.

On peut émettre l'hypothèse que les Mbororo ayant accepté l'islamisation l'ont fait sous la pression d'autres populations islamisées avant eux, pour la raison fort pragmatique de pouvoir continuer à évoluer librement dans les milieux nécessaires à leur nomadisme. Car ces milieux, aussi naturels soient-ils, sont de toute façon bordés ou parsemés de zones villageoises ou citadines occupées par des sédentaires et ce sont eux qui ont développé des structures de contrôle territorial sans cesse plus extensives, jusqu'aux frontières nationales. Avant la colonisation, on sait combien certains Peuls eux-mêmes ont œuvré à la formation d'empires (Fouta-Toro, Fouta-Djalon, Macina, Sokoto, Adamaoua) accordant à l'islam une fonction politico-religieuse primordiale.

Pour limiter les risques d'exclusion, de subjugation ou de minoration, n'est-il pas avantageux d'adopter les usages dominants de ceux qui détiennent les moyens de contrôle ? Les problématiques actuelles autour de l'assimilation et de l'intégration dans les sociétés occidentales connaissant d'importants flux migratoires appellent la même question. Lorsque, étranger à un espace habité, on se propose d'y voyager ou de s'y installer, s'impose la nécessité d'en adopter les règles préétablies, lesquels ne sont évidemment pas toutes inscrites dans les textes de lois (règles implicites sur l'habillement, sur la politesse, etc.). Comme je l'ai indiqué plus haut, cela n'empêche pas de négocier, de rechercher d'éventuels accommodements, et l'on verra tout de suite des exemples pour les Mbororo ; mais la première règle est bien de «faire comme » les autochtones. 
Ils répondent en effet "parce que c'est comme ça ", parce qu'ils veulent faire comme leurs parents qui eux-mêmes ont fait comme leurs propres parents et ainsi de suite. En tout cas, le « comme » travaille davantage sur les apparences que sur le ressenti.

Doit-on en déduire que la foi est fragile dans ce contexte, voire inexistante? Je me garderai bien d'émettre une opinion sur ce point. L'investigation ethnologique s'arrête là où commence celle de la psychologie. Disons seulement qu'il est toujours possible à un Mbororo de superposer le nom d'une divinité de son panthéon patrimonial à celui d'une divinité d'importation. La confusion des deux amène à reporter la croyance en l'une vers l'autre. Auquel cas, la foi est plus ou moins intense selon les capacités émotionnelles de l'individu.

Mais, passons au second point. Puisque l'adhésion au modèle religieux musulman est loin d'être inconditionnelle chez les Mbororo, puisqu'elle n'est acceptée qu'au moyen d'une négociation implicite ou explicite, dont l'objet est de maintenir au fondement de leur personnalité ethnique les valeurs traditionnelles qui ne doivent rien à l'islam, demandons-nous comment s'opèrent les concessions réciproques.

\section{Une négociation paradoxale}

Sauf une rigidité d'intégrisme qui le bloque, le mécanisme d'une négociation est de concilier des points de vue a priori divergents. L'histoire des religions en général et celle de l'islam en particulier sont jalonnées de négociations plus ou moins spontanées, plus ou moins réfléchies. Dans le cas des Peuls, plusieurs exemples en fournissent une bonne illustration. Contentons-nous d'en citer deux, empruntés à deux époques différentes séparées par plus d'un siècle d'intervalle.

En 1893, voyageant dans le Fouta-Djalon, Ernest Noirot observe des séances de lecture semi-publique du Coran. Dans un village où réside un Almamy (à la fois chef de guerre et gardien de la foi), des lettrés s'efforcent de dégager le sens exact de passages qui les ont marqués.

"Trois ou quatre fois par semaine, une réunion de savants corrige le Coran.

L'Almamy est censé avoir le livre type tel que Dieu l'a soufflé à Mohamed. Les savants du village apportent leurs livres, l'Almamy lit à haute voix et les autres suivent. Quand une sentence échappe à leur sens, ils la suppriment pour la remplacer par une autre plus appropriée à leurs besoins. Aussi le Coran a-t-il été fortement modifié par les Peulhs ${ }^{10}$.»

31 L'exercice n'est évidemment pas inspiré par un désir plus ou moins gratuit de pure spéculation intellectuelle. Il s'agit souvent de rechercher des solutions à des problèmes pratiques.

En 2009, présentant le fonctionnement d'une juridiction musulmane de proximité au Burkina-Faso, précisément à Todiam où résident des Peuls, Maud Saint-Lary observe, à peu de chose près, la même scène. Les causes jugées le sont souvent au travers d'un arrangement avec les normes islamiques, afin de tenir compte de la coutume et du droit positif dispensé dans les tribunaux proprement dits. D'un côté, il est impossible d'ignorer les droits et devoirs de la citoyenneté, tels qu'ils sont définis dans le cadre des dispositifs de l'État; d'un autre côté, force est également de tenir compte de la tradition, de la coutume. Et Saint-Lary de mettre l'accent sur une notion inventée par ces juristes peuls pour fonder leurs sentences : le sulufu. 
«Ce mot fulanisé est tiré du terme arabe suhl exprimant l'idée de paix et de réconciliation dans le droit et la pratique islamiques. L'objectif premier du sulufu, que l'on peut traduire par "arrangement" est de préserver l'entente, au besoin en s'écartant un peu de la Loi rendue plus souple ${ }^{11}$. »

En d'autres termes, l'islam se laisse adapter aux cultures dans lesquelles il s'immisce. Mais, effet en retour, il cherche aussi à les plier à son cadre. Ce double mouvement s'observe dans les domaines majeurs des existences quotidiennes, là où les enjeux symboliques sont particulièrement visibles. C'est donc le cas quand les " cinq piliers " sont concernés, mais aussi quand il s'agit de codifier les principales modalités d'une organisation sociale (rapports entre genres, entre générations, entre familles, entre autorités, etc.). Comme les contradictions ne sont pas rares, les conflits de valeurs, leur solution réclame des compromis instables.

D'un point de vue général, on peut dire qu'un discours importé au sein d'une société qui n'en est pas à l'origine s'adresse à des hommes déjà possesseurs de normes régulatrices. La tentation est alors de les inférioriser, de les considérer comme encore proches de la nature (d'où les préjugés sur le fétichisme, l'animisme, le paganisme). Mais, dans l'impossibilité de leur imposer une mutation radicale et immédiate, il faut malgré tout composer, accommoder, risquer le syncrétisme sur certains points, jouer avec les apparences surtout quand la religion est en connivence avec la politique. Telle est la nécessité de négociation, où l'on renonce de façon temporaire ou définitive à des aspects de l'une ou l'autre culture pour tenter de rendre les deux compatibles. La compatibilité ne signifie pas alors une fusion, mais au moins la neutralisation des litiges potentiels pour faciliter le vivre ensemble. Ceci reste valable, bien entendu, dans le cas où ce sont plusieurs religions qui investissent la même société.

La caractéristique des Mbororo islamisés est d'échapper à cette situation sur le mode paradoxal. J'ai signalé plus haut la distinction qu'ils font eux-mêmes entre les conduites qu'ils adoptent jusqu'à l'âge de quarante-cinquante ans et après. Jusqu'à cet âge, ils se préoccupent fort peu de l'expression de la foi et, si l'on se fie à leurs témoignages, ils semblent bien ne pas se soucier non plus d'entretenir cette foi dans l'intimité de leur conscience. Ni extérieurement ni intérieurement, le sentiment religieux ne semble requérir une quelconque attention de leur part. Après cet âge, en revanche, la tendance est d'entrer, apparemment, dans un style de vie où l'on commence à prier et à rechercher dans le Coran des raisons de croire au dieu de l'islam. De fait, ce partage est tout simplement créé par un changement d'activités sociales, avec passage de la mobilité en brousse (le dehors) à l'immobilité au village (le dedans).

La plupart du temps, les jeunes courent la brousse avec leurs troupeaux, sans que rien ni personne ne leur rappelle les recommandations de l'islam. S'ils y songent quelquefois, c'est donc plutôt à l'occasion de haltes près de lieux habités où des musulmans exercent un pouvoir local. Tant qu'ils sont vigoureux, hommes et femmes vivent plutôt dans le respect du pulaaku. Les vieux, dont les forces déclinent, s'ils n'ont pas obligation à continuer le nomadisme, cherchent à se sédentariser quelque part, dans un village connu de longue date ou construit par eux, et c'est alors qu'ils adoptent les rites les plus ostensibles de l'islam et profèrent des discours d'apparente ferveur. Cette mutation se constate d'ailleurs dans l'image donnée de soi. Tandis que les jeunes portent des cheveux longs tressés, des habits colorés et participent activement à toutes les fêtes en s'ornant de riches parures, les vieux se coupent les cheveux, se retirent des fêtes et deviennent assez austères dans leur habillement. Bien sûr, un tel contraste 
s'observe dans d'autres sociétés, mais il convient d'insister ici sur la matérialité des contextes. La brousse n'est pas le village, le dehors n'est pas le dedans.

Le paradoxe vient de ce que ce sont les jeunes qui estiment les plus à même de garantir la pérennisation du pulaaku, en tant que code essentiellement fondé pour réglementer la vie pastorale, moyennent quoi le besoin de négocier avec l'islam n'est guère ressenti par eux, tandis que les vieux, fort de leur expérience passée, s'estiment au contraire fondés à négocier et, dans ce mouvement, à réclamer des jeunes des concessions qu'ils ne sont pas enclins à faire. L'appartenance à une même communauté, où les liens de parentés sont forts, où le respect dû aux anciens est constamment affirmé, n'implique pas automatiquement une attitude uniforme des individus.

Pour cette raison, la transmission culturelle d'âge en âge ne suit pas le mouvement que l'on croit habituel. Ce n'est pas le prédécesseur dans le temps (l'ancien) qui est reconnu porteur des valeurs du Pulaaku. Sans perdre à son égard la notion d'obéissance, voire de piété filiale, tout se passe tacitement comme s'il était disqualifié. Parce qu'il est sédentarisé et n'a plus de rapport constant à la brousse, au bétail, parce qu'il n'est plus impliqué dans les longues transhumances qui imposent des relations quasi organiques à la nature, il n'est plus, pour ainsi dire, dans les conditions pragmatiques favorables. C'est le jeune, fort de sa vigueur, qui s'estime le mieux placé pour entretenir en quelque sorte l'héritage du passé.

Insistons sur cette idée qu'il s'agit moins d'un conflit de générations, comme on peut en décrire beaucoup ailleurs, que d'une opposition entre deux modes d'existence. Selon qu'on est dedans ou dehors, on n'est pas affronté aux mêmes besoins ni aux mêmes moyens de les satisfaire. Si tant est que cette formule simpliste soit acceptable, la dualité est celle d'une culture dont le lieu de constitution est la nature, d'un côté, et d'une autre culture dont le lieu de constitution est un espace fortement domestiqué, d'un autre côté. Pour maîtriser les déplacements au dehors, mieux vaut savoir décrypter les signes de la faune et de la flore, voire du minéral. Pour bien maîtriser une installation au-dedans, mieux vaut savoir décrypter les signes qui y sont tracés par la main des hommes.

40 On perçoit bien l'ampleur du paradoxe quand les Mbororo interrogés, qu'ils soient jeunes ou vieux, distinguent eux-mêmes trois termes, et non deux: la brousse, le village, la ville. En brousse, ils constituent donc une unité mobile essentiellement structurée par des liens familiaux, l'homogénéité sociale y est à son maximum. Au village, c'est la partie la plus âgée des familles qui demeure, en cohabitant éventuellement avec des sédentaires d'autres origines. En ville, les familles sont éclatées, les cohabitations sont multiethniques, la dimension imposée est celle de l'hétérogénéité.

41 Bien sûr, si la jeunesse est fonctionnellement destinée à la brousse, comme on vient de le voir, c'est chez elle aussi que des individualités répondent volontiers à la tentation de la ville. Dès lors, entre ces deux milieux, les anciens s'estiment les mieux placés pour défendre à leur manière les valeurs de l'islam. La ville présente à leurs yeux le danger de faire perdre en même temps le sens du pulaaku et celui de la religion islamique. Mais, interrogeons les jeunes concernés par la migration en ville. S'il est vrai qu'ils manifestent peu de ferveur envers l'islam, ils répètent avoir conservé le souci de la tradition véhiculée par le pulaaku.

Cela est flagrant quand il s'agit de se regrouper en ville par affinités pour former une communauté entre soi. Ils mettent alors en avant non le fait d'être musulmans mais 
celui d'être Peuls. Mbororo ou fils d'une autre ethnie, c'est d'abord l'appartenance à la vaste diaspora peule qui les motive. Telle est en tout cas l'opinion convergente de plusieurs informateurs, entre vingt et trente-cinq ans, venus à N'Djaména pour exercer des petits métiers dont celui de commerçant au marché central, près de la grande mosquée. Peuls d'abord, pourrait-on dire. Ainsi, ils atténuent leurs distinctions intraethniques (Wewebe, Wodaabe, Wouilla, Fellata, entre autres) pour s'attacher à celle plus enveloppante et, quant à elle non négociable, de Poullo (Peul). Ils sont venus dans la capitale tchadienne pour des raisons principalement économiques: trouver un emploi rémunérateur, car le métier de bouvier connaît des crises récurrentes. Pour autant, ils ne renoncent pas à définir le modèle du pastoralisme actif dans la brousse comme un idéal fondateur de leur personnalité. Ils s'en inspirent quand l'entretien porte à évoquer des questions aussi diverses que la naissance d'un enfant, le mariage, la solidarité familiale, le rythme des saisons, le rapport au bétail, etc. À chaque fois, ils se réfèrent au vécu de la brousse, allant d'ailleurs jusqu'à ajouter que l'usage de certains appareils technologiques modernes, comme le téléphone mobile et ce qu'il suppose désormais en équipements Internet, y trouve une application aussi banale qu'en ville, ce qui est une manière pour eux de signifier que tradition et modernité ne s'excluent pas, de toute façon. Les objets nomades conviennent parfaitement aux hommes nomades.

C'est vers des villages ou des faibles agglomérations, et vers la tranche d'âge des anciens, qu'on doit se tourner pour obtenir l'information la moins lacunaire sur le rôle de l'islam dans la société mbororo. L'enquête nous ayant conduite de Dourbali (Baguirmi) à Gourneïda (Mayo Kebbi) et à Guitté (Kanem) porte à conclure que le paradoxe se maintient justement dans les condamnations plus ou moins vigoureuses que certains anciens, notamment ceux qui détiennent un pouvoir de laamiido (chef de communauté) et souvent simultanément de chef de canton (découpage administratif), prononcent contre des pratiques traditionnelles pourtant acceptées voire encouragées par le pulaaku. Pour être à la fois bon musulman et bon Mbororo, il faudrait les abolir, les oublier. Sauf que cela fait des décennies qu'on s'y exerce, et qu'elles durent malgré tout.

\section{De quelques censures manquées}

Les Mbororo fournissent de nombreux exemples de pratiques traditionnelles qui, sous la pression réprobatrice de l'islam, auraient tendance à disparaitre. En faire ici le recensement serait déborder du cadre assigné à cet article. Attardons-nous seulement sur deux, le soro et le hiirde sukaaku, qui sont en plusieurs points prototypiques de celles qu'il s'agirait de censurer, mais qui perdurent dans plusieurs communautés.

Le soro est une cérémonie organisée entre membres de deux groupes familiaux différents, sans liens agnatiques, afin de mettre en compétition des jeunes hommes se bastonnant à tour de rôle. En brousse, dans un décor de bûcher enflammé à la nuit tombée et à proximité duquel se sont rassemblés les membres de ces groupes, son déroulement est le suivant. Après avoir ingurgité des boissons destinées à atténuer les douleurs, un jeune homme s'avance devant les spectateurs, lève les bras au ciel et offre sa poitrine au coup d'un rival préalablement choisi dans une le groupe opposé. Deux ou trois coups lui sont alors violemment portés, parfois plus. Il doit y résister avec fermeté, sans manifester aucun signe de peur ni de souffrance. Selon sa capacité à 
rester impassible, il attire l'admiration des jeunes femmes présentes, et l'attention particulière que l'une ou l'autre lui montre ostensiblement peut être un prélude à une relation sexuelle. Au cours d'une même soirée, plusieurs affrontements ont lieu. Une autre fois, car la réciproque doit toujours être assurée, ce sont les frappeurs qui deviennent à leur tour frappés.

La justification qui en est donnée est qu'un jeune garçon apprend ainsi le courage, la vaillance, la fierté et même l'honneur. Sous le regard de tous, il en fournit la preuve. Ensuite, retiré dans l'obscurité de la nuit, il en est récompensé par les faveurs d'une compagne. Mais, interrogés sur l'importance qu'ils accordent aujourd'hui à ce genre de pratique, les anciens protestent de son inutilité et même de sa nocivité. Outre qu'elle peut provoquer des blessures graves, et même quelquefois la mort, elle inspire également dans certaines familles des rancœurs, des rancunes préjudiciables à la bonne entente entre les communautés en cause. Et les anciens de se féliciter, donc, que l'islam réclame son abandon. Sauf que les administrations coloniales cherchaient aussi, en leur temps, à les proscrire, d'une part, et que la liste des localités tchadiennes où elle subsiste, quand des Mbororo s'y attardent, est suffisamment importante (plus d'une dizaine) pour qu'on doute sur l'imminence d'une extinction.

Le hiirde sukaaku est plus pacifique. En soirée (d'où le nom de hiirde), une jeunesse adulte (sukaaku) propose de se rassembler à l'écart des parents afin de rivaliser dans un concours de chants. Souvent, l'objet des chants est de vanter les qualités de l'être aimé. Filles ou garçons engagent une sorte de compétition dont la finalité est que des couples soient autorisés à s'éloigner du groupe pour concrétiser charnellement une séduction ainsi manifestée. Plusieurs garçons peuvent convoiter la même fille; de même plusieurs filles peuvent convoiter le même garçon. C'est alors l'occasion de révéler quelques jalousies, mais le principe est de pouvoir nouer une relation avec l'approbation générale.

On devine ici ce qui peut inspirer la censure. Comme à l'issue d'un soro, une liberté sexuelle aussi ouvertement pratiquée, sans que soit invoqué un projet de mariage, car les histoires d'une nuit ne sont pas toujours promises à fidélité, heurte la sensibilité du religieux qui se réfère au Coran. Voilà pourquoi une censure est souhaitée, et parfois réussie dans certaines communautés mbororo actuelles, mais bien plus chez les sédentarisés que chez ceux restés nomades. Quoiqu'ils en aient eux-mêmes apprécié les effets dans leur propre jeunesse, les anciens défendent l'idée que les mœurs doivent évoluer. Encore faut-il ajouter que les jeunes qui persistent à organiser un hiirde, comme des Mbororo Wewebe ayant l'occasion de séjourner quelques semaines à Dourbali entre deux grandes transhumances, perçoivent aussi dans la morale prônée par l'islam des positions rétrogrades, passéistes dont ils ne veulent pas. Si bien que, à choisir entre ce que le pulaaku autorise et ce que l'islam interdit, ils font vite leur choix.

Au fil des échanges sur le statut de la femme dans la société mbororo, il est difficile d'évaluer la portée des arguments quand, dans la bouche d'informateurs revendiquant leur appartenance à l'islam, ils prônent une émancipation. Cette émancipation est presque toujours pensée en opposition à la tradition, car elle consiste à dire qu'il faut abandonner les usages infériorisant la femme dans de nombreuses circonstances (possession limitée du bétail, marginalisation lors d'un héritage, soumission au mari pour la plupart des décisions concernant le ménage, etc.). Du coup, ils attribuent à l'islam la vertu d'inciter au progrès. Mais ce point de vue ne fait évidemment pas consensus, loin de là. Certains jeunes nomades, même ceux qui sont devenus citadins et 
qui affichent une adhésion apparente à l'islam, y perçoivent des inconvénients encore plus redoutables que ceux de leur tradition.

Gomerou Harou, qui exerce à la fois les responsabilités de katchala (chef du troupeau en transhumance) et de laamiido au sein de son groupe de Wodaabe, écarte la religion de sa conception d'une union contractée entre un homme et une femme.

«Quand on trouve une femme qui nous plait, et quand la femme est d'accord, on la prend et on part. Si c'est un mariage entre un Bodaado et une Wouilla ou une autre Peule, on peut faire une fête, mais entre Wodaabe et Wodaabe on prend la femme et c'est tout ${ }^{12}$.»

51 Pour la forme, l'accord des familles est sollicité. Cependant, il n'est pas question d'en référer à un marabout ou un imam qui, de toute façon, n'accompagne pas les unités nomades. C'est en ville qu'ils résident. Là aussi, bien entendu, on peut se marier. Mais, quand rien ne les oblige, les Mbororo sont tous d'accord pour répéter que leur préférence va au « mariage de brousse ».

En allant plus à fond dans le questionnement, on s'aperçoit que la notion de compatibilité culturelle est en réalité à double application. Il ne s'agit pas seulement de tenter l'accord entre au moins deux systèmes, mais aussi d'accepter à l'intérieur de chacun les écarts par rapport à ses propres normes. La négociation porte aussi sur les contradictions entre la théorie et la pratique, entre l'idéal et le concret, entre ce que la raison propose et ce que les circonstances imposent. Sur certains points du dogme religieux islamique, le Mbororo sait ce qu'il conviendrait de faire, mais il ne le fait pas, et n'en conçoit aucune gêne. Cela ne vaut pas que pour lui, bien entendu. Mais, pour en rester à son cas, on comprend aisément comment il peut entrer dans le culte des apparences sans renoncer le moins du monde à ce que l'islam juge en mauvaise part.

Cela étant, peut-on considérer que ce sont les différences d'adaptation au schéma normatif interne d'une religion qui expliquent les hiérarchies voulues par des groupes (communautés, sociétés) s'estimant plus orthodoxes que d'autres, plus avancés, plus ancrés dans la foi ? Au Cameroun, une association de Mbororo a été fondée en 1987 par des jeunes citadins anglophones de confession musulmane, sous l'acronyme de Mboscuda (Mbororo Social and Cultural Development Association), afin de "réformer », selon leur propre terme, leur société d'origine. Les actions entreprises jusqu'à ce jour sont présentées comme une lutte contre des pratiques culturelles « négatives " au profit d'une adhésion prétendue moins superficielle à l'islam. Un site Web a été créé qui insiste sur ce que cette religion apporte à l'amélioration de certaines conditions de $v^{i} e^{13}$. Alors, se perçoit en effet une tendance à dévaloriser le Mbororo encore impliqué dans les grandes migrations pastorales. Mais il n'est pas sûr qu'un tel militantisme soit aussi progressiste qu'il voudrait l'être. Il consiste en effet à opposer une vérité soi-disant universelle à une pluralité d'erreurs prétendues archaïques par cette même vérité. Or, tant que la preuve du contraire n'est pas administrée, le postulat de cette vérité juge de tout demeure un acte purement idéologique.

Que s'agit-il de transmettre ? La technique de l'élevage, la connaissance de la nature, de ses bienfaits et de ses pièges, le sentiment d'appartenance à une société humaine solidaire qui cultive sa distinction des autres sociétés de son environnement, les règles explicites ou implicites qui régissent les rapports entre les personnes d'une même 
famille, d'un même clan, et ainsi de proche en proche jusqu'à considérer l'ensemble de la communauté peule répartie sur plusieurs territoires. L'éducation donnée dans l'enfance s'en charge, puis les apprentissages de l'adolescence. Et il ne vient à personne de nier le rôle capital des parents. Mais au cœur de la transmission est le Pulaaku qui détermine une manière d'être et de faire dans un contexte de pastoralisme nomade, si bien que ce contexte participe aussi de la transmission. Il définit le lieu de son efficience.

Les anciens Mbororo sédentarisés dans un village ne vivent plus dans ce contexte. Ils en ont le souvenir, ils en ont perdu la pratique assidue et continue. C'est pourquoi, sans leur manquer de déférence, les jeunes qui s'y maintiennent estiment pour leur part être les meilleurs garants de la préservation des valeurs traditionnelles. Ce sont eux, pensent-ils qui en assurent la sauvegarde. Leur adhésion à la religion islamique reste superficielle. Ils s'en accommodent plus qu'ils se l'approprient.

\section{BIBLIOGRAPHIE}

BOUTRAIS Jean, « Pour une nouvelle cartographie des Peuls », Cahiers d'études africaines, vol. XXXIV, $\mathrm{n}^{\text {os }} 133-135,1994$, p. $137-146$.

BURNHAM Philip, « L'ethnie, la religion et l'État : le rôle des Peuls dans la vie politique et sociale du Nord-Cameroun », Journal des africanistes, t. LXI, fasc. 1, 1991, p. 73-102.

DUPIRE Marguerite, Organisation sociale des Peuls : étude d'ethnographie comparée, Paris, Plon, 1970. DUPIRE Marguerite, Peuls nomades : étude descriptive des Wodaabe du Sahel nigérien, Paris, Institut d'ethnologie, 1962.

HOLDER Gilles (dir.), L'islam, nouvel espace public en Afrique, Paris, Karthala, 2009.

NOIROT Ernest, À travers le Fouta-Diallon et le Bambouc (Soudan occidental), Paris, Flammarion, 1893.

SAINT-LARY Maud, « Autonomie politique et diffusion de normes morales dans l'espace public burkinabé : l'exemple d'une juridiction musulmane de proximité », dans Holder Gilles (dir.), L'islam, nouvel espace public en Afrique, éd. numérique, Paris, Karthala, 2009, [URL :

halshs-01742641]

ScHMITZ Jean, « Les Peul : islam, pastoralisme et fluctuations du peuplement », Cahiers des sciences humaines, $\mathrm{n}^{\circ} 26$ (4), 1990, p. 499-504.

\section{NOTES}

1. G. Holder (dir.), L'islam, nouvel espace public en Afrique, p. 16.

2. Ibid.

3. Ibid., p. 12.

4. Ibid., p. 8. 
5. J. Schmitz, « Les Peul : islam, pastoralisme et fluctuations du peuplement », p. 499.

6. J. Boutrais, « Pour une nouvelle cartographie des Peuls », p. 140.

7. Entretien du 25 octobre 2012, N’Djaména.

8. M. Dupire, Peuls nomades: étude descriptive des Wodaabe du Sahel nigérien, passim; M. Dupire, Organisation sociale des Peuls : étude d'ethnographie comparée, passim.

9. P. Burnham, «L'ethnie, la religion et l'État: le rôle des Peuls dans la vie politique et sociale du Nord-Cameroun », p. 80.

10. E. Noirot, À travers le Fouta-Diallon et le Bambouc (Soudan occidental), p. 145.

11. M. Saint-Lary, "Autonomie politique et diffusion de normes morales dans l'espace public burkinabé : l'exemple d'une juridiction musulmane de proximité », p. 209.

12. Entretien du 8 décembre 2012, Guitté.

13. Site internet de Mboscuda (Mbororo Social and Cultural Development Association), rubrique «Domains of intervention », puis «Islam and development » (http:// www.mboscuda.org).

\section{RÉSUMÉS}

Les Mbororo sont des Peuls nomades dispersés sur plusieurs pays, entre le Mali et le Soudan. Éleveurs de bœufs, ils sont sans cesse à la recherche de nouveaux pâturages pour leurs troupeaux. Actuellement, ils sont en majorité musulmans. Cependant, leur adhésion à l'islam semble peu profonde et revêtir un caractère d'opportunisme. Il s'agit pour eux d'adopter la pratique religieuse devenue dominante dans les pays où ils enchaînent leurs déplacements. Leurs rapports avec les populations autochtones s'en trouvent facilités. Ainsi, l'étude de leur cas conduit à poser le problème des migrations autrement que dans les contextes ordinairement abordés par la recherche. Il ne s'agit pas de voir dans quelles conditions un migrant transplanté dans un autre lieu que celui de sa communauté d'origine y importe sa religion souvent pour la pratiquer en compagnie d'autres migrants éventuellement de communautés différentes, mais plutôt comment et pourquoi une communauté homogène de migrants accepte ou refuse une religion extérieure, au risque (ou pas) d'avoir à modifier ses traditions séculaires.

\section{AUTEUR}

\section{YASSINE KERVELLA-MANSARÉ}

Docteure en anthropologie, chargée de cours, chercheure associée au Centre de recherche bretonne et celtique et au Laboratoire d'études et de recherches en sociologie à l'université de Bretagne occidentale (Brest) 


\title{
Empire, paix et vérité : la résistance des savoirs dans l'Europe de la Renaissance (1500-1540)
}

\author{
Laureano Lopez
}

1 Les rapports entre le savoir et le pouvoir façonnent, d'après nous, une réalité aussi politique que savante. Nous proposons une approche des savoirs de la Renaissance à travers l'analyse de l'idée de paix présente chez Érasme, Thomas More, et J. L. Vives ${ }^{1}$. Nous pensons que ces rapports entre le savoir et le pouvoir vont rendre possible une nouvelle vérité politique en quelque sorte reliée à cette notion de paix. Notre but est donc de voir comment s'est opéré ce transfert des connaissances d'une vérité, pour ainsi dire, de la grammaire, d'une vérité attachée aux mots, propre à l'émergence des sciences humaines, à une vérité politique, c'est-à-dire à une vérité qui n'est plus celle des mots, qui ne serait d'ailleurs plus frappée par la philologie et retrouvée par la traduction, et qui proviendrait non pas nécessairement de la tradition, mais du pouvoir, en constituant, par contre, l'émergence d'un différent regard sur la question. À notre avis, cette nouvelle vérité concernerait plutôt l'action, dans la mesure où elle garderait seulement sa valeur dans le « sens unique » de l'action du gouvernement ${ }^{2}$.

Nous comprenons qu'à l'heure de l'Europe des nations et de la réforme, le transfert des savoirs d'une époque vers une autre gagne un intérêt quant à l'organisation des connaissances ${ }^{3}$. À notre avis, ce rapport entre le pouvoir et l'humanisme conditionnerait la valeur de vérité du politique en organisant enfin un système de certitudes plus ou moins rationnelles. En premier lieu, nous aborderons l'État dans l'ensemble de ces rapports, ancré dans la réalité politique au $\mathrm{xVI}^{\mathrm{e}}$ siècle : en particulier l'ordre du pouvoir dans la Chrétienté. Nous nous intéressons ici au cadre politique de l'Europe pré-moderne et à l'essor du pouvoir politique et religieux dans la mesure où il frappe les limites d'un espace de vie, d'un espace conçu comme communauté de foi, mais d'un espace également déchiré par la guerre. Nous pensons que cette communauté s'expliquerait dans la tension entre territoires en s'organisant principalement à travers la dispute entre l'Empire et l'Église ${ }^{4}$. Voici le premier axe de notre article. Dans un second mouvement, nous prêterons un intérêt renouvelé à l'humanisme chrétien en 
tant que vecteur majeur de la transmission des savoirs. Sur ce point, nous discuterons les discours d'Érasme, de Thomas More, et de Juan Luis Vives sur la paix ${ }^{5}$. Il nous semble que ces trois maitres-penseurs de l'humanisme chrétien ont quelque chose à dire de l'Empire et de la Réforme. En suivant les leçons de Michel Foucault et Giorgio Agamben, nous aborderons en guise de conclusion - les conséquences historiques du transfert de ces vérités relatives à la paix et aux pratiques du pouvoir par l'État afin de repérer le comportement de l'humanisme et de l'érasmisme ${ }^{6}$. Nous pensons que ce dernier s'est démarqué de l'Empire et de la Réforme pour configurer une «voie moyenne » pour la transmission des idées. Pour nous, cette troisième voie favoriserait l'émergence d'une "volonté de paix » qui aurait vivement déterminé l'histoire du début du siècle au concile de Trente comme forme de résistance caractérisée par la revendication de la paix. La riposte savante à la crise politique et de conscience européenne entre 1500 et 1540 se révélerait donc capitale vis-à-vis du pouvoir, mais aussi auprès du savoir, mais d'un savoir que nous comprenons comme résistance : voici la troisième hypothèse de notre contribution.

\section{La réalité politique de l'Europe chrétienne vers 1500}

3 L'Europe de 1500 rayonne dans un éclair d'authenticité. Nous en découvrons les progrès dans la science et dans les arts. On assiste au triomphe d'une beauté aussi antique que véritable. De même, nous pouvons apprécier le développement des sciences positives, l'émergence de l'imprimerie et la diffusion de l'humanisme, la vulgarisation du savoir, l'essor du commerce et de l'économie monde, comme l'appelait Fernand Braudel ${ }^{7}$. La Renaissance instaure une nouvelle perspective sur les affaires de l'homme. La Renaissance développe un regard sur le monde, une certaine manière de voir ${ }^{8}$. Nous assistons aussi à une sorte, pour ainsi dire, "d'élargissement de l'attitude spirituelle ", floraison de la devotio moderna dont les résultats - que nous allons présenter - se réunissent dans la figure d'Érasme, de More et de Vives. Tout cet éclat mystique de rénovation coïncide avec un élan intellectuel qui pousse les esprits savants sur les formes de l'Antiquité et rompt, en quelque sorte, avec la tradition. Les polémiques propres aux humanistes $d u \mathrm{xVI}^{\mathrm{e}}$ siècle se concentrent sur la rhétorique de Cicéron, la restauration de la foi véritable, et la question du pouvoir politique ${ }^{9}$. Depuis les sphères de l'humanisme se produisent en ce moment le remplacement d'Aristote et la récupération de Platon, ce qui provoquera des conséquences dans le cadre de la morale, de la philosophie et de la politique.

En ce qui concerne le pouvoir, François I $^{\mathrm{er}}$ accède au trône de France en 1515. En 1517, Charles de Gand prend le trône en Espagne et s'érige en empereur des Romains deux ans plus tard. Parallèlement, le pape et Luther fomentent l'un contre l'autre une crise qui ne laissera personne indifférent. En Angleterre, quelques années plus tard, Henri VIII frappera aussi l'establishment de l'orthodoxie romaine suite à l'affaire de son divorce. Or, toutes ces disputes provoquent une sorte d'accélération des temps en politique qui ferait éclater le problème sur l'art de gouverner ${ }^{10}$. À ce moment, l'Italie devient la plaque tournante de la politique internationale ${ }^{11}$. Trois vagues de guerres à caractère international, dans lesquelles les volte-face sont d'ailleurs à l'ordre du jour, déferlent sur son sol. Les tensions politiques internationales se concentrent alors sur l'axe Naples-Milan, attirant une sanglante confrontation entre François $\mathrm{I}^{\mathrm{er}}$, roi des Français, et Charles Quint, empereur d'Allemagne ${ }^{12}$. Nous trouvons également un 
deuxième axe problématique entre Luther et le pape, à partir de 1517, qui mêlait les questions de la foi à la réforme du pouvoir temporel ; ensuite, une troisième discorde émerge et occupe la totalité de la dispute symbolique quand l'empire de Charles Quint s'oppose à la réalité politique de l'Église ${ }^{13}$. Il ne faut pas non plus négliger, pour terminer, la confrontation idéologique entre l'empire chrétien et l'Empire ottoman de Soliman le Magnifique. Dans tous les cas, les confrontations européennes du XvI ${ }^{e}$ siècle révèlent le visage politique des disputes religieuses et la transcendance religieuse des comportements politiques: il nous semble qu'il s'est produit un choc entre deux sphères relatives au pouvoir qui cristallise d'une manière formelle l'opposition entre l'Empire et l'Église. Dans ce sens, nous pouvons parler d'une explosion de l'art de gouverner comme problème: comme problème savant, religieux et politique ${ }^{14}$. Les affaires de la foi sont apparemment concernées par les intrigues, souvent politiques, du pouvoir ${ }^{15}$.

5 Comme l'expliquait d'ailleurs Michel Foucault dans ses cours au Collège de France, le problème du gouvernement éclate $a u \mathrm{XVI}^{\mathrm{e}}$ siècle, et c'est depuis ce moment que l'on assiste à la prolifération de traités qui ne sont plus des Relox de Princes, qui n'indiquent plus aux princes ce qu'il faut faire ou comment agir à chaque instant, à chaque heure, mais des textes qui s'inscrivent, en partie, sur la voie de la science politique ${ }^{16}$. Depuis le conseil au prince à l'art de gouverner et ensuite à la science politique, il s'est produit alors une évolution théorique que nous ne pouvons pas négliger. Le problème se déclinerait ainsi selon la triade suivante: comment se gouverner soi-même, ce qui implique un retour des questions propres au stoïcisme ; comment être gouverné, ce qui indique la question des âmes, et qui évoque ce conflit dont nous parlions précédemment, concernant la pastorale catholique et protestante dans la tension non assimilée de la réforme; et comment gouverner les autres, qui indique, en effet, la question de l'éducation des plus jeunes et qu'on assimile normalement à la naissance de la pédagogie telle qu'elle apparaît au $\mathrm{xvI}^{\mathrm{e}}$ siècle $^{17}$. Les trois questions sur le gouvernement posées par Michel Foucault coexistent tout au long de l'élaboration de deux processus : d'une part, la création de l'État moderne, premièrement sous la forme organique de l'État territorial, et ensuite comme État-nation, s'agissant, dans les deux cas, de la fin du féodalisme politique et morale. Voici qu'on parle à ce propos d'une inversion des dynamiques pour affronter une concentration étatique; et de l'autre, l'impact de la réforme sur le sol de l'Europe. Comme l'écrivait d'ailleurs Michel Foucault :

«Comment être gouverné, par qui, jusqu'à quel point, à quelles fins, par quelles méthodes ${ }^{18}$.»

Or, dans ce contexte, l'empire semble être l'agent qui se trouve dans la mêlée de toutes les polémiques. Son organisation territoriale frappe les nouveaux Temps modernes. Dans l'empire de Charles Quint, nous pouvons repérer l'ancien idéal de romanité s'inspirant de l'Empire romain comme dominus mundi ${ }^{19}$. Nous pouvons accepter d'emblée que pendant le $\mathrm{VI}^{\mathrm{e}}$ siècle aurait eu lieu une transition de la forme de ce savoir relatif à la domination vers un nouveau modèle entendu comme universitas christiana. Cela s'expliquerait d'emblée à partir de l'introduction du christianisme dans les structures de l'empire romain. Or, la pax romana du temps d'Auguste deviendrait une pax christiana et ensuite elle se voudrait représentée devant le monde comme pax universalis, comme en fait le proposait Dante dans son traité De Monarchia ${ }^{20}$. Cet ordre répond à la forme de l'empire et à l'hégémonie de l'empereur devant le pape. La nouvelle conception de l'empire éveille aussi au $\mathrm{xvI}^{\mathrm{e}}$ siècle une nouvelle idée de paix 
qui défend l'autorité de l'empire devant l'Église. La question donc sur la conduite que nous venons de poser paraît trouver ici une réponse. Gouverner, c'est conduire à son salut selon la vérité. À la ratio pastoralis de l'Église s'oppose désormais à la ratio gouvernamentoria, nouvelle rationalité du souverain ${ }^{21}$.

7 Mais que peut-on entendre par «gouverner » selon la pastorale? Dans De Regno, Saint Thomas d'Aquin établissait que le roi c'était « celui qui gouverne le peuple d'une seule cité et d'une seule province, et cela en vue du bien commun ${ }^{22} »$. Nous comprenons en conséquence que chez Saint Thomas le roi gouverne selon un modèle, celui de Dieu sur la terre. Afin de bien gouverner, le roi devrait seulement imiter la nature et gouverner comme Dieu. Il y a ici, comme l'affirme Foucault, une première analogie avec Dieu. Ensuite, une deuxième analogie avec la nature, car, selon la doctrine thomiste, dans le monde tous les êtres vivants sont exposés aux limitations de leur nature, laquelle régit leur parcours dans le monde tout en déterminant leur force vitale. Et la seule façon de faire que les hommes soient mués par un réel désir d'œuvrer pour le bien commun et non pour l'intérêt personnel, c'est par le biais de l'autorité du roi ${ }^{23}$. Saint Thomas établi une troisième analogie avec le berger, d'après laquelle, la finalité de la vie ne serait pas d'être riche, ni de tendre vers le bonheur, ni de favoriser la bonne santé du corps. Les thomistes postulaient le primat de la félicité éternelle, entendue comme jouissance de Dieu. Comme l'indiquait aussi Michel Foucault, la fonction royale "doit être de procurer le bien commun de la multitude suivant une méthode qui soit capable de lui faire obtenir la béatitude céleste ${ }^{24} »$. Depuis le thomisme et la scolastique, le roi gouverne selon une triple analogie: Dieu, nature, berger. Gouverner selon la ratio pastoralis implique en conséquence l'établissement d'une sorte d'économie portant sur le salut, économie qui porte aussi sur l'obéissance et qui dérive également sur la véritée $^{25}$. Autrement dit, le monde serait soumis à une économie du salut car, comme l'exposait Michel Foucault, les choses de ce monde sembleraient faites pour l'homme tandis que l'homme ne serait pas fait pour ce monde. Gouverner le monde pastoralement voulait dire d'abord «que le monde était soumis à toute une économie de l'obéissance : pour se faire obéir sur le monde, Dieu dépliait toute une panoplie de signes, de prodiges, de merveilles et monstruosités » qui menaçaient aussitôt qu'elles promettaient le salut ${ }^{26}$. Gouverner pastoralement impliquerait ensuite l'articulation d'une économie de la vérité, "de vérité enseignée d'une part, de vérité cachée et extraite de l'autre ", qui admet l'existence de la vérité, pouvant être appréhendée sous la forme du renvoi de l'une à l'autre, c'est-à-dire de la ressemblance et de l'analogie.

$8 \mathrm{Au}$ début $\mathrm{du} \mathrm{XVI} \mathrm{e}^{\mathrm{e}}$ siècle, les circonstances tant historiques que savantes vont briser d'abord ce continuum dans l'ordre de la cosmologie, en amorçant ensuite une crise de l'art de gouverner dans laquelle s'inscriront les humanistes, particulièrement les érasmistes, ceux qui offriront une sortie cohérente aux problèmes de la civilisation européenne. Dans ce contexte, la question sur l'art de gouverner va se poser autrement. Ainsi, le roi sera censé agir différemment par rapport à ses ouailles, de même le père de famille avec ses enfants ou le berger et son troupeau. C'est-à-dire, gouverner et être souverain n'indiqueront désormais plus la même chose. Devant les conflits et les enjeux envisagés par l'Occident chrétien, la faction des érasmistes, notamment More, Érasme et Vives, vont conduire cette question relative à l'art de gouverner parallèlement au débat sur la guerre, la paix, le bon gouvernement et le bien commun. En ce qui concerne l'essor du pacifisme au cours du $\mathrm{xvI}^{\mathrm{e}}$ siècle, l'érasmisme contribuera à favoriser l'émergence de cette nouvelle rationalité politique devant l'Église, la Réforme 
et l'Empire ottoman. Nous allons aborder par la suite l'apport de cette rationalité depuis l'humanisme, notamment à propos de l'art de gouverner, la guerre et la paix et le bien commun.

\section{Thomas More, J. L. Vives et Érasme dans l'essor de la rationalité politique}

Entre 1515 et 1526 vont paraître les ouvrages fondamentaux qui permettront d'interpréter les disputes de la Chrétienté depuis un humanisme moralisant et politisé. La nature de ces textes porte sur une controverse et amorce une réflexion sur le pouvoir. Il s'agit de l'Utopie de Thomas More, l'édition des Adagiorum chiliades (1515), l'Institution du prince chrétien (1516) et la Querela Pacis (1517) d'Érasme, et De Europae dissidiis et república (1526) de Luis Vives. L'essor de la pensée politique, pour ainsi dire, d'Érasme émerge dans l'Enchiridion militis christiani (1504) et progresse dans les pages de l'éloge de la folie (1511). Ce renouveau des textes critiques vis-à-vis de l'art de gouverner est conditionné par le virage dans le discours d'Érasme, qui, à partir de 1515 s'implique ouvertement dans la critique du pouvoir depuis le discours de renouvellement de la spiritualité. Les Adagiorum chiliades de 1515, the utopian editions, comme l'avait appelé M. M. Phillips, inclut des innovations pertinentes sur la situation politique de l'Europe ${ }^{27}$. Il nous semble que les trois humanistes partagent un même intérêt et une même réflexion sur l'art de gouverner, sur le bien et sur la paix. Les trois auteurs représentent cette voie d'écartement par rapport à la ratio pastoralis sans pour autant annoncer la raison d'État. En conséquence, ils n'érigeront pas une nouvelle rationalité politique, mais un principe qui cherchera à restaurer et récupérer une vérité sous la forme du bon prince chrétien. Deux idées nous ont semblé organiser la pensée politique de ces trois humanistes : le principe du bien commun et le maintien du statu quo.

Dans ce cadre, le souverain devrait adopter les mesures appropriées afin de défendre les limites et les frontières, ainsi que les richesses de la communauté. Cela veut dire qu'il y a un savoir, celui du bouléforos comme le dit Érasme dans une lettre à Paul Voltz, qui doit agir auprès du pouvoir pour accompagner et conseiller le prince. Nous trouvons ce thème relatif au conseil dans l'Institutio et la Querela, mais aussi dans l'Utopie, où Raphaël Hythlodée s'exprime en ces termes sur le conseil au prince. Le savoir du conseiller doit impérativement s'incliner devant le bien pour garantir le bon gouvernement. Ainsi, le roi ne doit point gouverner pour lui seul, mais en bénéfice de son peuple. Il existe un pacte tacite entre le souverain et les assujettis, qui ne seront plus censés obéir au roi si celui-ci ne respecte pas le pacte pour le bien commun. Or, le prince, modèle idéal de gouvernement, doit agir selon la loi naturelle, la loi de dieu, c'est-à-dire d'une façon exemplaire, car le but dernier est l'unité de la res publica chrétienne, laquelle est conçue par Érasme comme corps mystique. Au travers de cette métaphore du corps, l'humaniste de Rotterdam nous montrera le lien entre l'unité et la concorde, entre l'hégémonie, entendue comme puissance politique suffisante pour diriger, et la concorde, assimilant cette dernière à la paix. Autant dans la société que dans l'homme, l'idéal sera celui de rassembler la paix ultime de la vérité chrétienne et la vérité essentielle du pouvoir, laquelle, pour les humanistes, ne consiste pas à la violence, mais dans le savoir.

11 Dans l'Utopie, Raphaël Hythlodée dénonce la décadence dans laquelle le monde est plongé et revendique un ordre de paix fondé sur le statu quo et le bon gouvernement. 
Comme il l'affirme dans le même ouvrage, « les princes dédient beaucoup plus de temps à agrandir leurs domaines, avec raison ou bien sans elle, qu'à bien gouverner selon la paix leurs territoires ». Mais Hythlodée s'oppose aussi à la paix telle qu'elle est recherchée par François I ${ }^{\mathrm{er}}$, car, dit-il, le monarque la considère comme surveillance et contrôle :

«Ils pensaient que le bonheur du pays consiste à avoir une armée toujours prête à se battre. »

Pour Hythlodée, en parlant de François $\mathrm{I}^{\mathrm{er}}$, ce n'est point possible de demeurer en bon conseiller tout en siégeant auprès d'un roi pour qui la politique consiste principalement à la recherche d'une hégémonie territoriale. Thomas More dénonce dans son travail les traits de la politique du roi de France, prêt à contrôler Milan, sans pour autant manifester une moindre ambition pour Naples, l'Italie, la Flandre, le Brabant et la Bourgogne. Dans l'Utopie, nous remarquons une défense de la paix à travers le discours de Raphaël Hythlodée ; un discours qui nous paraît d'ailleurs bien distinct de celui sur la victoire issue d'une guerre, l'hégémonie territoriale, et le contrôle des populations. En revanche, dans l'Utopie prévalent le bien commun et le statu quo. Or, la leçon de Thomas More, comme celle d'Érasme, défend l'existence d'un pacte entre le roi et la république $^{28}$. Comme l'affirme ensuite Hythlodée :

"Si je montrais que les sujets choisissent un roi, non pour lui, mais pour euxmêmes, afin de vivre heureux, en sécurité, à l'abri des injures, grâce à ses efforts et à sa sollicitude ; que le roi par conséquent doit s'occuper plutôt du bonheur de son peuple que du sien propre, exactement comme le rôle du berger est de nourrir ses moutons avant de penser à lui-même, si toutefois il est un vrai pasteur ?29 "

13 Selon le discours de l'Utopie, la mesure de la communauté est déterminée par les ressources qui garantissent le bien commun et un idéal particulier de vie qualifiée. Or, la mesure de la communauté déterminera les exigences de l'autorité. Thomas More n'arrive pas à postuler un principe de victoire et de conquête, bien qu'il reconnaisse la possibilité d'amorcer une guerre au nom du bien commun selon la loi naturelle, laquelle remplace désormais la jurisprudence. Nous reconnaissons sur ce point tout un savoir qui se transmettrait aux marges des lois et de la justice. Dans ce sens, la loi naturelle semble plutôt une loi morale :

«Leurs lois sont peu nombreuses : il n'en faut guère avec une telle Constitution. Ils désapprouvent vivement chez les autres peuples les volumes sans nombre qui ne suffisent pas à l'interprétation des leurs, car ils voient une suprême iniquité à tenir les hommes liés par des lois trop nombreuses pour que personne ne puisse jamais les lire d'un bout à l'autre, et trop obscures pour que le premier venu puisse les comprendre ${ }^{30}$.»

14 En même temps, les habitants d'Utopia n'ont absolument pas besoin des traités de paix, car ils comptent sur une loi naturelle qui reflète la nature morale de l'âme. Thomas More reconnaît que la finalité ultime de la vie est la contemplation de la vérité de l'être, qui n'est rien d'autre que la nature divine. La guerre semble alors seulement possible quand elle admet un caractère défensif. Elle pourrait être moralement acceptée dans trois situations : pour se défendre, pour défendre ses amis, par pitié des voisins, pour les libérer du tyran et de l'injustice :

«Mais ils ne s'y résolvent pas volontiers, à moins que ce ne soit pour défendre leurs frontières, ou encore pour repousser des ennemis qui auraient envahi un pays allié, ou enfin par pitié envers un peuple tyrannisé - et c'est pour l'amour de l'humanité qu'ils agissent dans ce cas - qu'ils libèrent par la force du joug de son tyran et de 
son état de servitude. Ils interviennent aussi au bénéfice de leurs amis, non

seulement pour les défendre, mais aussi pour venger des injures commises ${ }^{31}$. ” inquiétudes centrales. Cette perfection équivaudrait à l'état de nature ${ }^{32}$. Si la guerre existe, elle est le fait sans doute, d'une décadence du corps social en tant que communauté politique. Dans le Dulce Bellum inexpertis, l'humaniste de Rotterdam attribue le malheur de l'occident aux leçons d'un Aristote lu depuis le thomisme, excessivement scolastique, et qui facilita en même temps «l'adaptation de la doctrine évangélique aux lois impériales ${ }^{33} »$. La critique d'Érasme porte sur la réglementation des rapports entre chrétiens à partir du droit civil romain, car ce dernier légitimerait à son avis l'usure, et le droit privé, en refusant la force par la force, et acceptant la possibilité d'une guerre juste. C'est à ce moment qu'il considère que l'homme s'écarte du véritable christianisme en intégrant cette sorte d'utilitarisme morale, cette éthique mondaine qui reconnaît le droit de guerre. L'opposition sur ce point est claire. Pour les humanistes, les seuls combats étant acceptés sont contre la concupiscence, l'argent et l'ambition. Il peut paraître évident qu'ils refusent les arguments de la guerre juste, contre la croisade, et contre les Turcs. Car à leurs yeux, les seules armes s'incarnent dans l'exemplarité et la force des mots.

Érasme intègre la maxime de Cicéron : mieux vaut une paix injuste que la plus juste des guerres. Dans ce sens, le primat de la paix, même en étant injuste, gouverne dans sa pensée; même s'il estime possible dans le bellum de conduire une guerre défensive, au nom seulement du bien commun. Concernant la guerre religieuse, Érasme la refuse aussi. L'auteur des Adages prône la conversion des âmes de ses ennemis par le biais de l'exemplarité. D'ailleurs, dans la Querela Pacis - et c'est la paix en personne qui parle, comme parlait aussi la folie dans l'Encomium Moriae - Érasme explique pourquoi la guerre est contraire au message de l'Évangile. De son avis, une guerre ne peut jamais être juste, comme il l'explique aussi dans le Dulce Bellum inexpertis :

« $\mathrm{Si}$, en pesant sur les plateaux de la balance les avantages et les désavantages, vous découvrez qu'une paix injuste vaut beaucoup plus qu'une guerre juste, pourquoi préférez-vous courir la chance de $\mathrm{Mars}^{34}$ ?»

17 Toute guerre entre les membres d'un même corps sera toujours une guerre fratricide, une guerre civile. La doctrine d'Érasme nous rappelle que Platon, par exemple, refusait aussi d'utiliser le terme bellum pour faire référence à la guerre entre les Grecs. Or, entre les membres d'un même corps il ne peut pas y avoir de guerre, mais dissension, stasis voici le terme que Luis Vives utilisera dans De Europae dissidiis et República pour faire référence aux problèmes de l'Europe. Érasme à la fin de la querela dit :

«[contre les Turcs] si un amour mutuel ne peut les rassembler, qu'un ennemi commun, du moins, les unisse ; et, puisque la véritable concorde est absente, qu'une coalition, bonne ou mauvaise, du moins les lie ${ }^{35}$. »

Et ensuite :

«C'est souvent l'intérêt privé des princes, alors que les raisons d'entreprendre une guerre devraient être éminemment des raisons d'intérêt public ${ }^{36}$."

19 Le pacifisme de Luis Vives n'est pas moins engagé que celui de More et Érasme. Il représente, en fait, l'image du pacifiste intégral. Dans De Europae dissidiis et República, ce dernier analyse l'état de la chrétienté et dénonce dans des termes de guerre civile toute guerre entre chrétiens. Il annonce d'ailleurs la possibilité de concevoir l'Europe moderne comme une terre de paix, et refuse le destin tragique qui divise et piétine l'Europe. Vives élabore en outre une formule politique basée sur l'équilibre des forces 
et l'arbitrage, qui concernait d'abord Henri VIII d'Angleterre et ensuite Charles V. Dans le contexte des guerres d'Italie, Vives soutient entre 1525 et 1529 une paix européenne ou une alliance entre les princes chrétiens, car seulement la paix peut garantir la restauration des savoirs qu'il prônera plus tard dans De Disciplinis (1530) et dans De veritate fidei christianae (1540). Nous pensons que l'humaniste de Bruges contribue aussi à transmettre ce savoir sur la paix relative au pouvoir, selon lequel toute guerre entre Européens est d'ailleurs considérée comme une guerre civile.

Comme l'écrivait Michel Foucault dans La volonté de savoir, " là où il y a un pouvoir, il existe une résistance ${ }^{37}$ ». Il nous semble que durant les premières décades du $\mathrm{XVI}^{\mathrm{e}}$ siècle, les humanistes autour d'Érasme partagent un savoir contraire au discours dominant, qui s'opposera à la moderne théorie du droit élaborée depuis la scolastique. La pensée des trois humanistes que nous avons présentée dialogue avec les problèmes de leur époque tout en tissant un fil rouge critique vis-à-vis de l'autorité, de l'hégémonie et du pouvoir. Ils auront tenté, peut-être en vain, de transmettre un message de paix qui s'oppose à la conquête. La force de ces idées pousse la pensée à chercher l'équilibre, à défendre le bien commun, tout en développant un savoir qui se dévoile finalement comme le seul pouvoir véritable. Dans ce sens, la transmission et la défense de la paix deviendraient un acte subversif, même révolutionnaire. Dans un séminaire tenu à l'université de Princeton à propos de la guerre civile, Giorgio Agamben exposait dans l'ordre de l'opposition mentionnée, que dans la constitution d'Athènes, d'Aristote, s'exposaient les effets de la loi de Solon en temps de guerre ${ }^{38}$. Le Stagirite expliquait que pendant la guerre civile seraient châtiés ceux qui n'auraient pas pris les armes. L'Athénien défendait la perte de droits civiques. D'après les Grecs, ceux qui ne s'engageaient pas dans la défense de la cité seraient frappés d'atimie. Comme écrivait Aristote :

«Celui qui, quand la cité se trouve dans une guerre civile (stasiazouses tes poleos) ne prend pas les armes (me thetai ta hopla) par l'un de deux parties sera frappé d'infamie (atimon enai) et sera exclu de la politique (tes poleos me metechein) ${ }^{39}$. »

Cicéron reprendra l'expression « atimon enai » conçue comme une infamie par Aristote dans les Lettres à Atticus ${ }^{40}$. Dans ces lettres, il traduira "atimon enai " par "capite sanxit » tout en évoquant le " capitis diminutio » qui correspondrait à l'atimie grecque, à la perte de droits civils et par ailleurs, à l'exclusion du citoyen de la sphère politique. En revanche, dans le contexte de la guerre de Rome, Cicéron transmettra à Atticus les mots suivants :

«J'en demande pardon à Solon votre compatriote, et je pense, aussi le mien; mais je repousse sa loi de mort contre ceux qui ne prennent pas parti dans les guerres civiles, et, à moins d'arrêt contraire de votre bouche, je m'en vais avec mes enfants. Quant à ma neutralité, nulle incertitude ${ }^{41}$. »

Pour conclure, il nous semble que l'évocation des voies et des transferts des connaissances à l'époque de la Renaissance concerne le territoire des humanités et plus particulièrement, celui des intellectuels, écrivains et traducteurs. L'humanisme "récupéré» rétablit les mots dans la mesure où il accomplirait une tâche de restauration des textes, et de leurs sens associés. Il reprend le savoir du passé, un certain savoir qui apparaîtrait désormais comme porteur d'une vérité déterminée par l'espace, le lieu et le temps. La détresse du philologue paraît donc vouée à la 
transmission du savoir, s'amorçant d'abord comme relais des connaissances, pour ensuite se découvrir, dans les trois cas que nous avons exposé, comme dissidence politique. Le travail de l'écriture, de l'exégèse et de l'interprétation apparaîtrait ainsi différemment: nous le voyons maintenant comme un travail politique. En somme, entre le savoir et le pouvoir, l'érasmisme inscrit un nouveau discours qui bannit la guerre, qui s'oppose à l'autorité conquérante des empires et qui d'une certaine façon fait aussi acte de résistance. Devant la figure toute puissante des princes, il nous a semblé que les érasmistes défendaient un savoir déterminé et concrétisé par un discours que nous connaissons depuis le temps de Cicéron, à l'heure où le pacifisme se profile depuis les marges propres à la neutralité et l'infamie.

\section{BIBLIOGRAPHIE}

ADAMS Robert P., The Better Part of Valor: More, Erasmus, Colet and Vives on Humanism, War, and Peace, 1496-1535, Seattle, University of Washington Press, 1962.

AGAMBEN Giorgio, Homo Sacer. Le pouvoir souverain et la vie nue, Paris, Seuil, 1997.

AGAMBEN Giorgio, La guerre civile. Pour une théorie politique de la stasis, traduction de Joël Gayraud, Paris, Éditions points, 2015.

Aquin, Saint Thomas, De regno, dans Opera omnia, t. 42, Rome, 1979, p. 449-471.

Aquin, Saint Thomas, Du royaume, traduit par M. Martín-Cottier, Paris, Egloff, 1946.

BATAILLON Marcel, «Érasme et la chancellerie impériale », Bulletin Hispanique, 1924, t. XXVI, p. 27-34.

BATAILLON Marcel, « Du nouveau sur J. L. Vives », Bulletin Hispanique, 1930, t. XXXII, p. 97-113.

BORN Lester K., " The perfect prince: a study in thirteenth and fourteenth century ideal », Speculum, 1928, t. III, p. 470-504.

BORN Lester K., " The specula principum of the Carolingian Renaissance », Revue Belge de Philologie et d'Histoire, 1933, t. XII, p. 583-613.

BORN Lester K., " The perfect prince according to the Latin panegyrist », American Journal of Philology, 1934, t. LV, p. 20-35.

BOSBACH Franz, Monarchia Universalis. Storia di un concetto cardine della politica europea (secoli XVIXVIII), Milano, Vita e pensiero, 1998.

BRAUDEL Fernand, La Méditerranée et le Monde méditerranéen à l'époque de Philippe II, Paris, Armand Colin, 1949.

BRAUDEL Fernand, Civilisation matérielle, économie et capitalisme: $\mathrm{XV}^{e}$-XVIII ${ }^{e}$ siècle. Tome 3, Le temps du monde, Paris, Armand Colin, 1979.

BRAUDEL Fernand, La dynamique du capitalisme, Paris, Flammarion, 1985. 
CHABOD Federico, «Y a-t-il un État de la Renaissance? », FEBVRE Lucien, RENAUDET Augustin et COORNAERT Émile (éd.), actes du Colloque sur la Renaissance, Paris, Vrin, 1958.

CHABOD Federico, De Machiavel à Benedetto Croce, Études présentées par Henri Lapeyre, Genève, Librairie Droz, 1970.

CHAUNU Pierre, Le temps des réformes : histoire religieuse et système de civilisation : la crise de la chrétienté, l'éclatement (1250-1550),Paris, Fayard, 1975.

CROUZET Denis, « Chrétienté et Europe : aperçus sur une sourde interrogation du Xvi siècle », SOUTOU Henri et BÉRENGER Jean (dir.), L'ordre européen du XVI au XXe siècle, actes du colloque de l'Institut de Recherches sur les Civilisations de l'Occident Moderne, 15-16 mai 1996, Paris, Presse Université Sorbonne, 1998, p. 11-55.

CURTIS Catherine, « The Social and Political Thought of Juan Luis Vives : Concord and Counsel in the Christian Commonwealth », FANTAZZI Charles (ed.), A companion to Juan Luis Vives, Leiden/ Boston, Brill, 2008, p. 113-176.

D’AMICo Juan Carlos, «La papauté et le pouvoir temporel dans la translatio imperii, (XIV $\mathrm{XVI}^{\mathrm{e}}$ siècles) ", MORINI Agnès (éds.), Papes et papauté, respect et contestation d'une autorité bifrons, Saint-Étienne, Publications de l'Université de Saint-Étienne, 2013.

Dante, La monarchie, précédé de La modernité de Dante, par Claude Lefort, édition bilingue, traduit par Michèle Gally, Paris, Belin, 1965

DUST Philip C., Three Renaissance Pacifists : Essays in the Theories of Erasmus, More and Vives, American University Studies 23, Series IX History, New York, Peter Lang, 1987.

Érasme, L'Institution du prince chrétien (ou l'art de gouverner), édition de Anne-Marie Greminger, Jean-Christophe Saladin, Paris, Les Belles Lettres, 2016.

Érasme, Plaidoyer pour la paix, traduction de Chantal Labre, Paris, Arléa, 2004.

Érasme, « Dulce bellum inexpertis », dans MARGOLIN J.-C. (éd.), Guerre et paix dans la pensée d'Érasme, introduction, choix des textes, commentaires et notes, Paris, Aubier-Montaigne, 1973.

Érasme, Les adages, édition complète bilingue, sous la direction de Jean-Christophe Saladin, Paris, Les Belles Lettres, 2001.

FANTAZZI Charles, « Vives, More and Erasmus », BUcK August (ed.), Juan Luis Vives, Hamburg, Hauswedell, 1982, p. 165-176.

FEBVRE Lucien, Une question mal posée. Les origines de la Réforme française et le problème général des causes de la Réforme (Extrait de la Revue Historique, t. CLXI), Paris, 1929.

FOUCAULT Michel, Sécurité, territoire, population, Cours au Collège de France (1977-1978), Paris, Gallimard-Seuil, 2003.

Foucault Michel, Naissance de la biopolitique, Cours au Collège de France (1978-1979), Paris, Gallimard-Seuil, 2004.

GALASSO Giuseppe, Carlo V e Spagna imperiale, Studi e ricerche, Roma, Storia e Letteratura, 2006.

MARGoLIN Jean-Claude, « Pour une humanité à la recherche d'elle-même : Érasme et le déclin des idéologies ", Revue des Synthèses, 1987, n 2, p. 261-268.

MESNARD Pierre, L'Essor de la philosophie politique au XVI e siècle, Paris, J. Vrin, 1977.

MESNARD Pierre, La philosophie chrétienne : Éloge de la folie, L'essai sur le libre arbitre. Le cicéronien. La réfutation de Clichtove. Introduction, traduction et notes par Pierre Mesnard, Paris, J. Vrin, 1970. 
MORE Thomas, Utopie, les classiques du matérialisme dialectique, éd. numérique, Parti Communiste Marxiste-Léniniste-Maoïste de France, Mai 2013.

[URL :http://lesmaterialistes.com/files/pdf/PDF-1/L\%27utopie\%20-\%20Thomas\%20More.pdf] NOREÑA Juan Carlos, Juan Luis Vives. Vie et destin d'un humaniste européen, traduit de l'anglais par Olivier et Justine Pédeflous avec la collaboration de Roberto Salazar, Paris, Les Belles Lettres, 2013.

Pocock J. G. A., The Machiavellian Moment. Florentine Political Thought and the Atlantic Republican Tradition, Princeton, Princeton University Press, 1975.

REDONDO Augustin (éd), Le pouvoir monarchique et ses supports idéologiques aux XIV ${ }^{e}-\mathrm{XVII}{ }^{e}$ siècles, Paris, Publications de la Sorbonne Nouvelle, 1990.

SAITTA Armando, Dalla Res Publica Christiana agli Stati Uniti d'Europa, Roma, Storia e Letteratura, 1948.

SKINNER Quentin, The Foundations of modern political Thought, Cambridge, University Press, 1978, (2 vol.).

TALLON Alain, L'Europe au XVI siècle, États et relations internationales, Paris, Presses universitaires de France, 2010.

\section{NOTES}

1. A. Guy, Vives ou l'Humanisme engagé. J.-C. Margolin, "Pour une humanité à la recherche d'elle même : Érasme et le déclin des idéologies ", p. 261-268. R. P. Adams, The Better Part of Valor: More, Erasmus, Colet and Vives on Humanism, War, and Peace, 1496-1535. C. Curtis, « The Social and Political Thought of Juan Luis: Concord and Counsel in the Christian Commonwealth », p. 113-176. P. Dust, Three Renaissance Pacifists: Essays in the Theories of Erasmus, More and Vives. C. Fantazzi, «Vives, More and Erasmus ", p. 165-176.

2. M. Foucault, Sécurité, territoire, population, Cours au Collège de France (1977-1978).

3. P. Chaunu, Le temps des réformes: la crise de la Chrétienté: l'éclatement, (1250-1550). L. Febvre, Une question mal posée. Les origines de la Réforme française et le problème général des causes de la Réforme. J. G. A. Pocock, The Machiavellian Moment. Florentine Political Thought and the Atlantic Republican Tradition. A. Saitta, Dalla Res Publica Christiana agli Stati Uniti d'Europa. Q. Skinner, The Foundations of modern political Thought.

4. D. Crouzet, «Chrétienté et Europe: aperçus sur une sourde interrogation du $\mathrm{XVI}^{\mathrm{e}}$ siècle » p. 11-55. J.-C. D'Amico, « La papauté et le pouvoir temporel dans la translatio imperii, (XIV $-\mathrm{XVI}^{\mathrm{e}}$ siècles)». A. Tallon, L'Europe au $\mathrm{XVI}^{e}$ siècle, États et relations internationales.

5. P. Mesnard, L'Essor de la philosophie politique au XVI siècle. C. Noreña, Juan Luis Vives. Vie et destin d'un humaniste européen. Érasme, L'Institution du prince chrétien (ou l'art de gouverner), Plaidoyer pour la paix. T. More, Utopie.

6. M. Foucault, Naissance de la biopolitique, Cours au Collège de France (1978-1979), Sécurité, territoire, population, Cours au Collège de France (1977-1978). G. Agamben, Homo Sacer. Le pouvoir souverain et la vie nue, La guerre civile. Pour une théorie politique de la stasis. 
7. F. Braudel, La Méditerranée et le Monde méditerranéen à l'époque de Philippe II, La dynamique du capitalisme.

8. A. Tallon, L'Europe de la Renaissance, p. 79.

9. Érasme par exemple, dans son dialogue : De ciceronianis de optimo genere dicendi, aussi dans Institutio principis christiani; De libero arbitrio, ou Moriae encomium. P. Mesnard, La philosophie chrétienne: Éloge de la folie, L'essai sur le libre arbitre. Le cicéronien. La réfutation de Clichtove.

10. M. Foucault, Sécurité, territoire, population, p. 92.

11. A. Tallon, L'Europe au XVI esiècle, États et relations internationales, p. 29.

12. G. Galasso, Carlo V e Spagna imperiale, Studi e ricerche, p. 80-103. F. Chabod, De Machiavel à Benedetto Croce, p. 132-135.

13. G. Galasso, Carlo V e Spagna imperiale, Studi e ricerche, p. 37-49.

14. M. Foucault, Sécurité, territoire, population, p. 92.

15. Ibid.

16. Ibid, p. 94.

17. Ibid, p. 92.

18. Ibid.

19. M. Bataillon, «Érasme et la chancellerie impériale », p. 27-34. F. Bosbach, Monarchia Universalis. Storia di un concetto cardine della politica europea (secoli XVI-XVIII). J.C. D'Amico, «La papauté et le pouvoir temporel dans la translatio imperii, (xIV$\mathrm{XVI}^{\mathrm{e}}$ siècles) ». G. Galasso, Carlo V e Spagna imperiale, Studi e ricerche, p. 49-77.

20. Dante, La monarchie, précédé de La modernité de Dante, p. 180 et ss.

21. M. Foucault, Sécurité, territoire, population, p. 238.

22. Saint Thomas, De regno, dans Opera omnia, p. 449-471, Du royaume. Cité aussi par M. Foucault, Territoire, sécurité, population, p. 238.

23. Ibid, p. 238-239.

24. Ibid.

25. Ibid, p. 240.

26. Ibid.

27. En particulier : Sileni Alcibiadis; Aut regem aut fatuum nasci oportere; Spartam nactus es, hanc orna; Dulce bellum inexpertis; Scarabeus aquilam quaerit. Érasme, Les adages, édition complète bilingue.

28. Thomas More écrit dans l'Utopie: «Si je montrais ensuite que toutes ces ambitions belliqueuses bouleversent les nations, vident les trésors, détruisent les peuples et n'aboutissent, en dépit de quelque succès, à aucun résultat : que le roi s'attache donc au royaume légué par ses ancêtres, qu'il l'embellisse de son mieux et le rende le plus florissant possible; qu'il aime son peuple et s'en fasse aimer; qu'il vive au milieu des siens ; qu'il les gouverne avec douceur et laisse en paix les pays étrangers, étant donné que son domaine actuel est dès à présent assez et trop étendu pour lui - de quelle humeur, mon cher More, pensez-vous que ce discours serait écouté ? ». T. More, Utopie, p. 18.

29. Ibid, p. 19. 
30. «Puisque la prospérité ou la ruine d'un État dépend de la moralité de ses gouvernants, où aurait-on chance de faire un choix plus sage que parmi ceux que nulle cupidité ne saurait détourner de leur devoir? ? Ibid, p. 47.

31. Ibid, p. 49.

32. Le mythe de l'âge d'or passé provenait de l'Antiquité. Il était présent chez plusieurs auteurs classiques comme Hésiode, dans Les travaux et les jours; chez Virgile, Bucoliques (IV, v. 37.), Géorgiques (I, v. 125) ; chez Ovide, Métamorphoses (liv. I, v. 89).

33. Comme l'expliquait Érasme dans l'adage cité : «On en arriva enfin à ce qu'Aristote tout entier fût admis comme partie intégrante de la théologie, et à ce point admis que son autorité fut presque plus sacrée que celle du christ». Érasme, Dulce bellum inexpertis, p. 130.

34. Ibid, p. 140.

35. Érasme, Le plaidoyer pour la paix, p. 81-82.

36. Ibid, p. 82.

37. M. Foucault, La volonté de savoir, p. 125-126.

38. Aristote, Constitution d'Athènes (VIII, 5). G. Agamben, La guerre civile, p. 24.

39. Ibid.

40. Ciceron, Lettres à Atticus, $\mathrm{X}, 1,2$.

41. Ciceron écrit le suivant : legem neglegam, qui capite sanxit, si qui in seditione non alterius utrius partis fuisset, nisi si tu aliter censes; et hinc abero et illim ; sed alterum mihi est certius : nec praeripiam tamen. Ibid.

\section{RÉSUMÉS}

Nous proposons un regard critique depuis l'histoire des idées sur les voies et les relais de transmission des connaissances de l'Europe chrétienne. Notre contribution porte sur l'humanisme, et plus particulièrement, sur les rapports entre le pouvoir établi et les discours pacifistes. Nous comprenons que, à l'heure de l'Europe des nations et de la Réforme, le transfert des savoirs entre une époque et une autre gagne un intérêt quant au système des certitudes et des connaissances. Il nous semble que Érasme, Thomas More et Luis Vives représentent l'émergence d'une « volonté de paix » qui aurait vivement marqué l'histoire du début du siècle au concile de Trente, comme une forme de résistance caractérisée par la revendication de la paix. La riposte savante à la crise politique (et de conscience) européenne entre 1500 et 1540 se révélerait donc capitale vis-à-vis du pouvoir, mais aussi du savoir, d'un savoir entendu comme résistance.

\section{AUTEUR}

\section{LAUREANO LOPEZ}

Professeur certifié d'espagnol, Lili Keller-Rosenberg, Halluin (Nord), docteur en Études romanes, université Paul Valéry - Montpellier III, laboratoire LLACS (langues, littératures, cultures du sud) 


\title{
La transmission des savoirs et
} savoir-faire dans la production semi-industrielle des anches : analyse d'un cas d'étude italien

\author{
Raffaele Pinelli
}

1 L'intervention que nous avons présentée lors du $143^{\mathrm{e}}$ Congrès du Comité des Travaux Historiques et Scientifiques ${ }^{1}$ nous a donné l'opportunité de faire un premier bilan autour de la transmission des savoirs et savoir-faire liés à la facture des anches libres métalliques pour les instruments aérophones mécaniques à soufflet. Un tel sujet, qui s'inscrit dans le cadre des recherches de notre doctorat en ethnomusicologie ${ }^{2}$ autour de l'accordéon diatonique, est né de l'exigence d'enquêter sur tous les aspects qui concernent la facture de cet instrument de musique. Loin d'être encore terminé, le travail d'enquête et d'analyse ici présenté fera l'objet d'approfondissements ultérieurs dans notre thèse doctorale.

2 Si dans sa globalité, tout aérophone mécanique à soufflet, comme la plupart des instruments de musique d'ailleurs, est le résultat de l'assemblage de plusieurs pièces, dans le plan de sa facture, il est l'aboutissement d'un travail complexe réalisé par plusieurs acteurs sociaux dont les tâches, du point de vue macroscopique, sont désormais organisées en filière. Plus précisément, on retrouve quatre catégories productives différentes qui travaillent autour de chaque aérophone mécanique à soufflet. Chacune d'elles gère la transformation de certaines matières premières en pièces finies ou semi-finies, et adopte une organisation de travail particulière, dont les savoirs et savoir-faire sont répartis parmi plusieurs artisans et artisans-ouvriers impliqués dans leur fabrication. Dans ce domaine de travail, où actuellement artisanat et industrie font converger leurs efforts en s'entremêlant, ce sont ces derniers qui sont les dépositaires exclusifs de tous les savoirs et savoir-faire essentiels à l'achèvement d'une ou plusieurs tâches et, en même temps, les seuls qui peuvent en garantir le transfert. 
Dans cet article nous voulons donner notre contribution, notamment autour de ce dernier aspect, en montrant d'une part les aléas liés au manque, total ou partiel, de la transmission des savoirs et savoir-faire dans la facture du dispositif sonore qui est le plus petit, mais aussi probablement le plus important, qu'on retrouve dans ces instruments de musique: les anches libres métalliques. Ce sont les anches qui déterminent le son de tous les aérophones mécaniques à soufflet.

Si du point de vue de l'analyse organologique, les contributions de certains auteurs en ont décrit le rôle dans une perspective d'étude plus globale, en les mettant toujours en relation avec les instruments de musique, il n'y a que peu d'informations publiées en ce qui concerne leur facture et leur milieu de production. Quatre publications ont été retenues pour nos recherches : en 1972 l'acousticien Émile Leipp ${ }^{3}$ écrivit ce qui, depuis 47 ans, est encore le seul essai où les anches libres métalliques pour les accordéons sont examinées par le prisme de l'anatomie, de la physiologie et de l'acoustique; en 1979 c'est l'ethnomusicologue Francesco Giannattasio qui a donné quelques informations sur la facture artisanale des anches en Italie dans son œuvre dédiée à l'accordéon diatonique $^{4}$; en 2005 , le facteur et réparateur d'accordéons, Thierry Benetoux ${ }^{5}$, a écrit un manuel pour l'accordage de ces instruments où il donne des renseignements pour le traitement des anches et leur montage à partir de son expérience directe de travail ; en 2012, Alexander Jouan a publié la troisième édition du livre le plus connu ${ }^{6}$ de Pierre Monichon, quelques années après sa mort, dans lequel sont donnés des renseignements sur l'histoire des anches libres métalliques par rapport à l'histoire des accordéons.

C'est donc à partir de ces informations que nous avons démarré le travail de recherche autour des anches, et d'enquête de terrain dans le DIMROC - District Industriel Multisectoriel de Recanati-Osimo-Castelfidardo ${ }^{7}$. Le district, qui se trouve dans la région italienne des Marches, est lié depuis toujours à la facture d'instruments de musique, et il est mondialement connu en tant qu'épicentre de la production des accordéons depuis le XIX ${ }^{e}$ siècle.

6 En sachant qu'actuellement dans le DIMROC il n'y a que quatre entités de production consacrées à la facture des anches, dont trois caractérisées par une production semiindustrielle (la Voci Armoniche, la Cagnoni et l'Artigiana Voci), et un petit atelier à vocation artisanale (celui de la famille Binci), nous avons décidé méthodologiquement d'en examiner deux : la Voci Armoniche et l'atelier de la famille Binci. Notre intention était avant tout de décrire pour la première fois tous les aspects de la production actuelle des anches et ensuite, par comparaison, d'examiner les similitudes et les différences entre deux types de production, dont une semi-industrielle et l'autre artisanale. En même temps, nous avons étendu l'observation à l'étude diachronique de la facture des anches, en examinant tant l'histoire de la facture dans ses lieux de production, que celle dans le cadre du DIMROC. En abordant ce sujet dans ses axes vertical (c'est-à-dire dans les deux entités de production examinées) et horizontal (en enquêtant sur les rapports entre les facteurs d'anches et d'instruments), l'analyse s'est enfin plongée sur la pratique de travail et l'innovation. La première a été considérée en tant que révélatrice de dynamiques sociales cachées à l'observateur, et la deuxième a été abordée comme un marqueur de la créativité et du progrès des techniques. Dans le cadre de l'étude de la facture des anches, nous avons mené plusieurs enquêtes de terrain in situ et ex situ à partir du 2013. Les enquêtes au sein de l'usine Voci Armoniche et de l'atelier de Binci ont été conduites en parallèle à d'autres recherches dans des archives italiennes, dont notamment l'Archivio Centrale dello Stato (Les Archives 
Centrales de l'État) et les archives de l'ISTAT (l'Institut National de Statistique) à Rome. Ces recherches ont été "imposées" par l'absence de toute forme d'écriture qui concerne les processus de production. Une telle absence s'est en fait manifestée à nos yeux au fur et à mesure lors des enquêtes de terrain dans les usines et les ateliers du DIMROC, en attirant notre attention sur le sujet de la transmission des savoirs et savoirfaire artisanaux. Nous avons donc questionné le rôle des artisans (notamment dans le cas des maitres facteurs d'instruments) et des artisans-ouvriers (employés dans les usines ou dans les ateliers) qui en sont les dépositaires exclusifs. En ce qui concerne la facture des anches, nous avons interrogé aussi bien certains artisans-ouvriers que leurs employeurs.

7 Le cas d'étude ici présenté concerne notamment l'usine Voci Armoniche ${ }^{8}$, dont les portes nous ont été ouvertes par Lorenzo Antonelli, son directeur et notre informateur privilégié. Dans la première partie de cet article on donnera une description de l'anche libre métallique pour les aérophones mécaniques à soufflet et on présentera le contexte de l'enquête; dans la seconde partie nous aborderons les étapes de la transmission orale des savoirs et du savoir-faire dans l'usine; une troisième partie concernera les aléas du manque et/ou de l'interruption de toute transmission et précédera les conclusions.

\section{L'anche libre métallique et les lieux de sa facture}

8 L'anche libre métallique, qui dans le cas des aérophones mécaniques à soufflet est de type hétéroglotte, est un petit dispositif sonore qui se compose essentiellement de trois éléments: le "châssis ", la «lumière " et la "lame "9. Dans ce type d'anche, si le châssis, qu'on appelle aussi «cadre » est l'élément statique, la "lame » est l'élément dynamique. Par rapport à son anatomie, le châssis rectangulaire et en métal, présente deux ouvertures à la fois rectangulaires et symétriques qu'on appelle « lumières ». Les "lames", qui sont des languettes métalliques flexibles, sont disposées chacune de façon asymétrique de chaque côté du châssis et fixées d'un côté sur ce dernier par un rivet métallique. Le son est déterminé par l'oscillation "libre» des languettes qui vibrent dans leurs axes verticaux à travers les deux ouvertures du châssis, et sous l'effet de l'air mis en mouvement par le soufflet de l'instrument de musique, en le tirant et en le poussant ${ }^{10}$. C'est à partir de ce dispositif sonore que les maitres facteurs fabriquent des instruments de musique tels que les accordéons. Massimo Castagnari ${ }^{11}$, maitre facteur d'accordéon diatonique depuis trois générations, nous expliquait lors d'un entretien que pour réaliser un bon aérophone mécanique à soufflet :

«Il faut toujours calculer le volume ${ }^{12}$ des anches qu'on va utiliser avant de commencer la fabrication de l'instrument. Seulement comme ça, on pourra le fabriquer de façon bonne et harmonieuse... »

Le facteur d'instruments ne se charge pas de la facture des anches, ni de celle des soufflets ou des accessoires. Comme nous l'avons dit dans l'introduction, les aérophones mécaniques à soufflet sont l'aboutissement d'un véritable travail d'assemblage d'un nombre variable de plusieurs pièces, qui est réalisé notamment par les maîtres facteurs d'instruments, comme les Castagnari. Dans un accordéon diatonique de petite taille, comme un modèle à 8 basses et à 2 rangées pour la mélodie, on peut en compter plus de $1500^{13}$. 

quatre catégories productives différentes qui sont organisées actuellement en filière, et qui se différencient les unes des autres grâce aux matières premières transformées en pièces finies ou semi-finies: le facteur d'anches transforme les métaux, celui des soufflets s'occupe du papier et du carton, ceux des accessoires du métal, du cuir, du celluloïd et du bois, et le facteur d'instruments fabrique enfin les instruments en se chargeant de leur conception, de la fabrication de plusieurs pièces ainsi que de leur assemblage.

11 Cette répartition de la production, qui est unique dans le panorama actuel de la facture instrumentale, est aussi révélatrice de la préséance d'une spécialisation manufacturière de haut niveau, qui a développé au fil du temps des caractéristiques très particulières. En fait, chacune des catégories productives est à la fois spécialisée dans la transformation de certaines matières premières, et dépositaire de tous les savoirs et savoir-faire qui leur sont liés et qui sont souvent gardés comme de véritables secrets du métier. Ils sont transmis oralement, depuis plus d'un siècle, de génération en génération, dans certains lieux et par des processus particuliers. Les origines de cette organisation de la production diffuse dans le territoire du DIMROC, remontent à la période à cheval entre la première et seconde moitié du XIX siècle et coïncident avec l'industrialisation des Marches. À cet égard, et malgré l'absence de sources fiables, les maitres facteurs d'instruments du district retiennent la date du $1863^{14}$, année de fondation de la première usine d'accordéons diatoniques par Paolo Soprani. Cette usine fut mise en service à Castelfidardo qui, à l'époque, était un petit village au cœur du district ${ }^{15}$ et qui, au fil du temps, s'est affirmée dans l'imaginaire collectif comme "la petite ville des accordéons». Le DIMROC, qui est aussi connu avec l'appellation de "District des instruments musicaux » à cause de la grande concentration de petites usines manufacturières de haut niveau engagées dans la facture de différents types d'instruments de musique, comprend aujourd'hui quatorze petites villes entre les provinces d'Ancône et Macerata ${ }^{16}$. Parmi ces petites villes, il y a Osimo où est installée l'usine Voci Armoniche, qui est actuellement l'une des plus anciennes et des plus importantes usines d'anches au monde.

2013, par l'intermédiaire de Massimo Castagnari, nous avons rencontré son directeur, Lorenzo Antonelli, qui représente la troisième génération d'une famille qui est engagée dans la facture des anches depuis 1935. Les rapports entre les Antonelli et les Castagnari remontent aux années 1960, période au cours de laquelle les Antonelli sont devenus leurs fournisseurs. Ce fut pendant la seconde moitié des années quatrevingt-dix, que Lorenzo Antonelli a commencé son travail en qualité de directeur dans une autre usine d'anches propriété de sa famille, la SIVA (Società Italiana Voci Armoniche), fondée en $1973^{17}$. La SIVA était l'émanation directe d'une autre usine toujours de sa famille, la Fratelli Antonelli, créée en 1935. La Voci Armoniche a été fondée en 2002 grâce à la fusion avec une autre usine d'anches du district, la Salpa de la famille Breccia, fondée en 1946. Une telle fusion, entre deux usines concurrentes, était en fait le seul moyen pour atténuer certaines criticités que les deux partageaient, parmi lesquelles : la relève générationnelle des artisans-ouvriers à l'intérieur et à l'extérieur ${ }^{18}$ de l'usine ; la préservation des savoirs et savoir-faire des artisans-ouvriers, au travers de l'acquisition de toutes les informations s'y référant; l'adaptation et l'ajournement des techniques et de la gestion de la chaîne de production. 


\section{La transmission des savoirs et du savoir-faire}

la plus grande concernait la transmission des savoirs et savoir-faire parmi ses artisansouvriers. Lors de notre premier entretien, L. Antonelli nous montra avec fierté ce qu'il appelait « son livre » : un carnet de notes de son travail en tant que directeur de l'usine. Dans ce carnet, il avait noté minutieusement les moments vécus les plus importants, ses intuitions à vérifier, les résultats obtenus et les objectifs envisagés, ainsi que le témoignage des recherches qu'il avait réalisé autour de la facture des anches dans son usine. Ainsi, il avait essayé de reconstruire l'histoire de sa famille en menant des enquêtes informelles auprès des artisan-ouvriers retraités de son usine. Ce carnet représente donc la première et unique trace écrite de toutes les activités de sa famille autour de la facture des anches, dès la création de la première usine en 1935. concernent notamment le manque total et/ou partiel de transmission orale des savoirs et savoir-faire entre les artisans-ouvriers de la même génération et des générations différentes. C'est pourquoi, nous a-t-il dit, il commença la rédaction de son carnet. nécessitent un nombre adéquat d'artisan-ouvriers spécialisés et hautement qualifiés. Grâce aux informations que nous avons collectées dans plusieurs usines ${ }^{19}$, nous avons noté que les capacités et les compétences requises par chaque artisan-ouvrier, en matière de savoirs et savoir-faire, dépendent en grande partie de deux variables : le temps et l'apprentissage.

16 Le temps peut être entendu comme l'ensemble de certaines activités pratiques répétitives mises en place pour la réalisation de tâches données. L'apprentissage, qui se passe par imprégnation ${ }^{20}$ et/ou par l'intermédiaire d'un artisan-ouvrier dont les capacités ont été reconnues par les commutés des artisans-ouvriers et/ou des maîtres facteurs d'instruments, et que nous appellerons dorénavant "le maître ${ }^{21}$ ", se caractérise par deux étapes différentes.

La première concerne le transfert des savoirs et savoir-faire incorporés par le biais de la transmission orale du maître à l'apprenti. Dans cette étape, qui se passe toujours sous la supervision du maître, si le transfert des savoirs advient par l'intermédiaire du langage, celui du savoir-faire advient par le regard : l'apprenti apprend toutes sortes de techniques et habilités manuelles au travers de la réplique et la répétition des gestes qui lui sont montrés.

Dans le cas où le transfert survient dans des contextes de petites dimensions, comme les foyers domestiques et les ateliers à caractère familial, où l'apprentissage se fait par imprégnation et la transmission des savoirs et savoir-faire est de type vertical dans le même groupe familial (par ex. de père en fils), le maître transfère probablement à l'apprenti tous ses savoirs et savoir-faire. En revanche, quand le transfert a lieu dans un contexte où le rapport entre le maître et l'apprenti est de type horizontal, c'est-à-dire qu'entre eux il n'y a aucun rapport de parenté, on peut observer que certains savoirs et savoir-faire qui concernent différentes étapes de la facture des anches ${ }^{22}$, sont parfois omis par le maître. Dans un tel cas, ce que le maître omet concerne notamment les savoirs et savoir-faire qu'il considère les plus précieux, et qui sont de facto pour luimême de véritables secrets du métier, capables de lui garantir une certaine autorité et 
réputation dans un lieu de travail et/ou dans une communauté. En d'autres termes, ceux-ci constituent pour lui son bien le plus précieux. Tout cela, nous l'avons observé, notamment dans des contextes de plus grandes dimensions telles que les usines, où tant le maître que l'apprenti sont salariés et n'ont, comme on le disait, aucun rapport de parenté entre eux.

Dans ces milieux de travail, au carrefour entre artisanat et industrie, caractérisés par la préséance de nombreux savoirs et savoir-faire techniques traditionnels transmis oralement, nombreux savoirs sont aussi incorporés, voir implicites dans le savoir-faire, et leur transmission peut s'exprimer seulement par une pratique gestuelle qui se fonde sur la répétition. On se réfère notamment à certaines pratiques qui impliquent l'acquisition par l'apprenti de capacités manuelles particulières, qui font partie, comme on le disait, des secrets du maître. Dans ces cas, l'apprenti arrivera à se les approprier uniquement par l'observation directe de son maitre, en les « volant par les yeux ${ }^{23}$ ".

La deuxième étape de l'apprentissage concerne le passage du statut d'apprenti à celui d'artisan (dans le cas d'un emploi indépendant), ou d'artisan-ouvrier (dans le cas d'un employé). Ce passage dépend normalement de l'avis du maître qui a formé l'apprenti de son intention, ou sur mandat de son employeur, et qui juge positivement l'ensemble des savoirs et savoir-faire acquis par l'apprenti. Avant l'arrivée de Lorenzo Antonelli à la direction de l'usine Voci Armoniche, les chefs d'atelier étaient les seuls chargés de la tâche de former les apprentis, comme cela a été toujours le cas dans la pratique de presque toutes les usines du district.

\section{Les aléas du manque ou de l'interruption de la transmission}

21 Dans ce milieu de travail, la survivance de certaines pratiques et processus qui concernent les savoirs et savoir-faire artisanaux est donc liée aux intentions de certains artisans-ouvriers. Il est alors évident que dans un système productif tel que la filière des accordéons du DIMROC, où les domaines de spécialisation productive sont nombreux et multi-niveaux, le manque partiel et/ou l'interruption de toute sorte de transmission entre les artisans-ouvriers représente un aléa tant pour les usines que pour toute la filière elle-même.

Pendant nos recherches dans la Voci Armoniche, nous avons enquêté auprès d'artisanouvriers qui avaient pris le relais de leur père et parfois de leur grand-père. Dans ces cas, les interviewés racontaient avoir reçu une formation à la fois dans le foyer domestique (de type informel) ainsi qu'une autre, une fois employés dans l'usine (de type formel). Quelqu'un parmi eux nous a aussi montré des outils de travail, en nous précisant qu'il s'agissait d'instruments qui étaient à sa famille depuis une ou deux générations, ou encore qu'il les avait reçus par d'autres artisans-ouvriers une fois partis à la retraite. Ces objets sont souvent des pièces uniques faites et/ou modifiées à la main pour l'accomplissement de certaines tâches. Ils représentent symboliquement un héritage partagé parmi plusieurs artisans-ouvriers depuis au moins deux générations, dont la transmission, de main en main, peut être soit de type vertical, soit horizontal. De telles pratiques de création, d'adaptation et de modification, que nous avons notées tant dans la Voci Armoniche, que dans toutes les autres entités de production enquêtées du DIMROC, ne concernent pas uniquement les outils de travail, mais 
concernent aussi certaines machines de travail, comme les meuleuses et les rectifieuses.

Tous les savoirs et savoir-faire techniques qui concernent l'utilisation de ce type d'outils et de machines de travail sont du domaine exclusif des artisans-ouvriers. Dans le cas de la Voci Armoniche, la pratique du passage, voire de la transmission d'outils entre les artisans-ouvriers, n'a jamais fait l'objet de l'attention ni de Lorenzo Antonelli, ni de son père et son grand-père : bien qu'elle fût toujours visible à leurs yeux, ils ne se sont jamais chargés de la gérer. C'est pourquoi, dans le cas où ces outils seraient abandonnés ou remplacés par d'autres présents sur le marché, le risque majeur concerne la disparition des savoirs et savoir-faire qui y sont intrinsèquement liés.

Lors de nos enquêtes dans la Voci Armoniche, nous n'avons trouvé aucune archive ou information détaillée relative à la recherche et développement, aux processus de production et aux projets de chaque type d'anche fabriquée. Pendant un entretien, Lorenzo Antonelli nous a dit que «dans les ateliers personne n'écrit rien. Personne n'a jamais rien écrit». La totalité de ces informations étaient, et sont en partie encore, l'apanage de certains artisans-ouvriers, dont notamment les chefs des trois ateliers de production qui concernent le montage, le meulage et le tranchage. Dans cette organisation du travail, l'efficacité de la chaîne de production dépend donc essentiellement des artisan-ouvriers qui y sont impliqués. À ce sujet, Lorenzo Antonelli nous révéla qu'une fois qu'il avait succédé à son père à la direction de l'usine SIVA, il était obligé de s'en remettre entièrement aux chefs des ateliers pour tout ce qui concernait la production des anches.

Dans certaines usines du DIMROC, les rôles d'administrateur-propriétaire de l'entreprise et d'artisan, correspondent à la même personne. C'est le cas, par exemple, du fabricant d'anches Claudio Binci ou des maitres facteurs d'accordéons diatoniques Castagnari, alors que dans la Voci Armoniche, Lorenzo Antonelli est chargé seulement de la direction de l'usine. N'étant pas un artisan, il n'a jamais reçu une formation pour aucune des spécialisations productives mises en place dans son usine, et donc il ne maitrise pas les savoir-faire des artisans-ouvriers employés dans la production des anches. En revanche, comme on disait, il souhaite en apprendre les savoirs, et son carnet de notes susmentionné en est la preuve.

Si l'absence de l'écriture, en tant que " processus de fixation et ancrage " peut favoriser la perte des savoirs et savoir-faire techniques lors du manque ou de l'interruption de la transmission orale, un autre danger est représenté par leur mauvaise mémorisation et/ ou compréhension par les artisans-ouvriers. Tout ce qui a été alors mal mémorisé et/ou interprété, peut par la suite se manifester dans les processus de mise en place de certaines pratiques manuelles. Lors des enquêtes dans les ateliers de l'usine, nous avons noté que la plupart des artisans-ouvriers mettaient en place certaines pratiques d'une façon qu'on pourrait définir de quasi "automatique ». Après les avoir questionnés, nous avons compris qu'ils reproduisaient de façon mnémonique tous les gestes qu'ils disaient avoir appris par leur maître, sans se poser de questions sur le pourquoi de ces actions. Une fois encouragés, ils nous ont répondu: «on fait comme ça car on l'a toujours fait comme ça, [...] c'est la tradition... ». La réponse, dont la notion de « tradition » ressemble beaucoup plus à une certaine idée d'immuabilité, est révélatrice du danger qui peut arriver lors de la réitération de certaines mauvaises pratiques qui, à leur tour, peuvent se répercuter même sur toute la chaîne de production. À cet égard, Lorenzo Antonelli nous a dit qu'il était censé intervenir régulièrement dans la 
correction ce type d'erreurs dans toutes les étapes de la facture des anches, et cela, dès qu'il est devenu directeur de l'usine.

L'absence de toute forme d'écriture antérieure à l'installation de Lorenzo Antonelli dans la Voci Armoniche a été pour nous révélatrice du manque d'informations quantitatives et qualitatives sur le rapport entre la facture des anches et des instruments de musique. En n'ayant pas trouvé de repère, même dans la littérature scientifique, nous avons mené une enquête dans l'ACS - Arichivio Centrale dello Stato (les Archives Centrales de l'État) à Rome, dont nous avons analysé notamment le corpus de brevets, modèles et marques industriels enregistrés en Italie entre 1855 et 2014. L'enquête a montré que l'innovation dans le secteur productif des anches est depuis toujours de faible intensité. En outre, elle a révélé que la dernière période dans laquelle on peut retrouver quelques inventions et améliorations significatives, est celle à cheval entre les années 1950 et $1960^{24}$. Ces données ont enfin confirmé que le milieu de la facture des anches est caractérisé par une faible innovation tout au long des cinquante dernières années ${ }^{25}$.

L'analyse des processus qui concernent la transmission des savoirs et savoir-faire dans la facture des anches libres métalliques, a permis de plonger le regard dans un milieu de la facture instrumentale particulier qui reste encore peu connu et inexploré par la recherche scientifique. Comme annoncé dans l'avant-propos, le but principal de cet article est de combler au moins en partie l'absence de recherches, notamment dans certaines disciplines telles que l'ethnomusicologie, l'organologie et l'anthropologie des techniques.

L'enquête, qui s'est déroulée autant sur le terrain que dans les archives, a permis d'éclairer certaines dynamiques subjacentes à la facture des anches qui sont cachées de l'extérieur, bien qu'évidentes de l'intérieur du contexte examiné. Ces dynamiques ont toutes un dénominateur commun, qui en est aussi le point d'appui : les savoirs et savoir-faire techniques. Autour de leur conservation et transmission, qui voient les artisans-ouvriers et l'administration de l'usine s'opposer et en même temps concourir ensemble à la réussite de l'entreprise, s'est construite toute une partie de l'histoire récente de ces petits dispositifs sonores.

L'enquête a aussi révélé la préséance d'un certain nombre de problématiques encore présentes dont la transmission des savoirs et savoir-faire en sont encore le pivot, et qui concernent tant les artisans-ouvriers que l'administration de l'usine. Pour ce qui est des artisans-ouvriers on a remarqué : le danger de la perte des savoirs et du savoir-faire techniques lors de l'interruption ou du manque de la transmission orale; les risques liés à la mauvaise transmission des savoirs et du savoir-faire ; le péril de la transmission de certaines pratiques techniques et/ou savoirs erronés qui peuvent se sédimenter dans la réitération gestuelle lors de l'exécution de certaines tâches; la confiance a priori en de nombreuses pratiques de travail transmises oralement qui sont associées, par les artisans-ouvriers, à une idée de tradition qui est proche d'une certaine notion d'immuabilité. Quant à l'administration, on a noté : quelques difficultés à gérer le relais générationnel parmi les artisans-ouvriers impliqués dans la production; les risques qui découlent de l'absence de toute forme d'écriture par rapport aux processus de production et à la formation des artisans-ouvriers; la confiance exclusive donnée à 
certains artisans-ouvriers pour tout ce qui concerne à la fois l'organisation de la chaîne de production et la transmission des savoirs et savoir-faire ; le manque de recherche et d'innovation qui peut déterminer une faible compétitivité.

31 Ce qu'on vient de décrire est constatable dans plusieurs entités de production du DIMROC, alors que le cas de l'usine Voci Armoniche ici examiné représente actuellement une exception. En fait, comme on a montré, Lorenzo Antonelli est en train de changer les rapports entre l'administration et les artisans-ouvriers, et son carnet de notes en est un exemple, mais également son intention de remettre en cause la chaîne opératoire propre à la facture ainsi que le modus operandi des artisans-ouvriers impliqués, pour arriver enfin à la fabrication de nouveaux types d'anches.

En conclusion, nous estimons que l'analyse des processus qui concernent la transmission des savoirs et savoir-faire dans certains milieux de travail tels que celui qu'on vient de décrire, pourrait, si supportée par l'approche émique de terrain, favoriser la compréhension des dynamiques internes subjacentes aux différents acteurs sociaux impliqués dans certains types d'activités, comme celles qui concernent la facture instrumentale.

C'est pour cela que nous considérons l'étude de certaines entités de production semiindustrielles, où oralité et écriture, savoir et savoir-faire, pratiques artisanale et industrielle se mêlent et s'influencent réciproquement, fort stimulante pour d'autres recherches en sciences humaines et sociales visant tant la recherche fondamentale qu'appliquée.

\section{BIBLIOGRAPHIE}

ANGIONI Giulio, «Rubar cogli occhi : fare, imparare e saper fare nelle tecnologie tradizionali », dans Giorgio R. Cadorna (éd.), La trasmissione del sapere : aspetti linguistici e antropologici, Roma, Bugatto Libri, 1989, p. 7-16.

BAGNASCO Arnaldo, Tre Italie : la problematica territoriale dello sviluppo italiano, Bologna, Il Mulino, 1977.

BENETOUX Thierry, L'accordéon et sa diversité sonore, s. l., Édité par Thierry Benetoux, 2005.

CHAmoux Marie-Noëlle, « La transmission des savoir-faire : Un objet pour l'ethnologie des techniques? ", Techniques \& Culture. Revue semestrielle d'anthropologie des techniques, 30 juin 2010, $\mathrm{n}^{\circ}$ 54-55, p. 139-161.

GIANNATTASIO Francesco, L'organetto, Roma, Bulzoni, 1979.

HORNBOSTEL Erich M. von et SACHS Curt, « Classification of Musical Instruments: Translated from the Original German by Anthony Baines and Klaus P. Wachsmann », The Galpin Society Journal, vol. 14, 1961, p. 3-29.

LEIPP Émile, «Éléments d'anatomie, de physiologie et d'acoustique », GAM - Bulletin du Groupe d'Acoustique Musicale, L'accordéon, $\mathrm{n}^{\circ}$ 59, 1972, p. 15-44. 
MONICHON Pierre et JUAN Alexander, L'accordéon, Saint-Amand-Montrond, Éd. Cyrill-Demian, 2012. PINELLI Raffaele, «Quand l'accordéon diatonique nous invite à interroger les méthodes et les objets de l'ethnomusicologie », Cahiers d'ethnomusicologie, vol. 30, 2018, p. 175-189.

PINELLI Raffaele, La renaissance (genèse, évolution et revitalisation) de l'accordéon diatonique (organetto) en France et en Italie (titre provisoire), université Côte d'Azur, università di Roma - La Sapienza, s.l.

SABEL Charles F., « Flexible Specialisation and the Re-emergence of Regional Economies » dans

Post-Fordism: A Reader, Oxford; Cambridge, Mass, Blackwell Pub, 1994, p. 101-156.

\section{NOTES}

1. L'intitulé de l'intervention était: "Dit et non-dit: la transmission de savoirs et savoir-faire dans la facture des anches ».

2. R. Pinelli, La renaissance (genèse, évolution et revitalisation) de l'accordéon diatonique (organetto) en France et en Italie (titre provisoire).

3. E. Leipp, «Éléments d'anatomie, de physiologie et d'acoustique », p. 15-44.

4. F. Giannattasio, L'organetto, Bulzoni, p. 28-32.

5. T. Benetoux, L'accordéon et sa diversité sonore, p. 49-56.

6. P. Monichon et A. Juan, L'accordéon, p. 7-53.

7. En italien, il est appelé DIPROC (Distretto Industriale Plurisettoriale di RecanatiOsimo-Castelfidardo).

8. Pour plus d'informations sur l'usine cf. le site internet www.vociarmoniche.it.

9. En italien, ils s'appellent dans l'ordre : piastrino, luce, voce ou linguetta.

10. Dans la classification des instruments de musique conçue par Erich M. von Hornbostel et Curt Sachs, les accordéons sont inscrits dans la classe 412.132, c'est-àdire celle des instruments qui utilisent des "anches libres en série ", voir un ensemble d'anches dont le nombre est variable. Cf. E. M. von Hornbostel et C. Sachs, Classification of Musical Instruments: Translated from the Original German by Anthony Baines and Klaus P. Wachsmann.

11. Pour plus de renseignements sur la famille des maîtres facteurs d'accordéons diatoniques Castagnari, cf. le site internet www.castagnari.com.

12. Il faut entendre ce mot dans son acception géométrique. Un facteur d'instrument doit préalablement prévoir les dimensions, dont le volume, de l'ensemble des anches qu'il veut utiliser. Ce nombre est variable selon le modèle d'accordéon diatonique, et il peut aussi changer en fonction du musicien qui commande l'instrument: en fait, chaque musicien peut demander un certain nombre de personnalisations aux facteurs d'instruments, y compris celles qui concernent les anches (type, nombre et qualité de l'accordage).

13. Ce chiffre arrondi correspond grosso modo au nombre des pièces du modèle Studio de Castagnari. Pour plus d'informations sur ce modèle d'accordéon diatonique.

14. Cf. F. Giannattasio, L'organetto, p. 46.

15. En ce qui concerne la littérature scientifique ayant étudié les districts industriels dans les perspectives historique, économique et sociologique, cf. A. Bagnasco, Tre Italie: 
la problematica territoriale dello sviluppo italiano; C. F. Sabel, Flexible Specialisation and the Re-emergence of Regional Economies.

16. Pour plus d'informations sur les entreprises et usines des Marches actuellement engagées dans la facture et la réparation des instruments de musique, cf. le report intitulé " Artigiani della musica: imprese e artigianato, export e specializzazioni » réalisé par le Centre d'études de la Confédération italienne de l'artisanat et publié le 03/04/2018, dont le résumé est disponible en ligne à l'adresse suivante: https:// www.confartigianato.it/2018/04/studi-oltre-mille-gli-artigiani-della-musica-imaggiori-mercati-del-made-in-italy-di-strumenti-musicali-sono-stati-uniti-127germania-120-e-francia-80/.

17. La SIVA est toujours active et ses ateliers occupent presque la moitié de la surface du bâtiment où est installée la Voci Armoniche. Contrôlée par la famille Antonelli, la SIVA est spécialisée notamment dans le cisaillage et l'emboutissage à froid de la tôle. Parmi ses principaux secteurs d'activité, il y a la mécanique, l'électromécanique, les électroménagers, l'éclairage et l'automobile. Pour plus de renseignements sur la SIVA, cf. son site internet http://www.sivasrl.net.

18. Dans le cas d'étude analysé ici, les travailleurs à domicile de ce milieu professionnel sont chargés notamment du montage des anches. Même si le recours à ce type d'artisans est en forte baisse, ils sont encore aujourd'hui recrutés par les usines et ateliers du DIMROC pour l'accomplissement de plusieurs tâches.

19. En plus des cas d'Antonelli, de Binci et des Castagnari, au sein du DIMROC, nous avons mené nos enquêtes de terrain dans les usines semi-industrielles de facture des soufflets des familles Galassi, Marconi et Marincioni.

20. Cette notion nous a été inspirée par Marie-Noëlle Chamoux qui l'a utilisée en analysant les modes de transmission des savoir-faire incorporés (transmission par imprégnation et transmission formelle ou informelle par le biais d'un maître) chez les habitants de Cuacuila (Huauchinango, Mexique). Cf. M.-N. Chamoux, La transmission des savoir-faire: Un objet pour l'ethnologie des techniques?.

21. Cette appellation est couramment utilisée par les artisans-ouvriers pour identifier celui qui est reconnu en tant dépositaire de certains savoirs et savoir-faire techniques nécessaires pour accomplir certaines tâches.

22. Actuellement, dans le milieu de la facture des anches, plusieurs étapes sont prévues, dont chacune est caractérisée par des savoirs et savoir-faire particuliers qui impliquent aussi des machines et outils spécifiques. Dans le cas des usines semi-industrielles, tel que la Voci Armoniche, on retrouve au moins dans chaque atelier un artisan-ouvrier chargé de la formation des apprentis, et qui de facto est reconnu en tant que maitre. Du point de vue de l'organisation de la production, on s'attend à ce qu'il connaisse l'ensemble des savoirs et savoir-faire nécessaires pour accomplir toutes les tâches de l'atelier dans lequel il travaille. En d'autres termes, les artisans-ouvriers de l'atelier de montage ne sont pas censés maitriser l'ensemble des savoirs et savoir-faire nécessaires pour travailler dans l'atelier de moulage, etc. En revanche, dans le cas de petits ateliers artisanaux, comme celui de la famille Binci, les six artisans qui y travaillent actuellement ont presque tous appris l'ensemble des savoirs et savoir-faire de la chaîne opératoire qui concerne la facture des anches. 
23. Par rapport aux savoirs traditionnels incorporés dans le savoir-faire ainsi qu'à leur transmission dans certaines cultures traditionnelles, cf. G. Angioni, Rubar cogli occhi: fare, imparare e saper fare nelle tecnologie tradizionali.

24. Sur 766 brevets recensés et relatifs aux aérophones mécaniques à soufflet, ceux qui concernent les anches ne sont que 36. Une partie des résultats obtenus par cette recherche dans les archives a été présentée dans un article que nous avons écrit pour les Cahiers d'ethnomusicologie. Cf. R. Pinelli, «Quand l'accordéon diatonique nous invite à interroger les méthodes et les objets de l'ethnomusicologie », p. 175-189.

25. Actuellement, pour les accordéons diatoniques, chacun des quatre principaux fabricants italiens d'anches en réalise deux ou plusieurs types, dont le nom varie d'une firme à l'autre. Si depuis presque cinquante ans la famille Binci en propose deux (voci a mano et voci tipo a mano), la Voci Armoniche fabrique cinq types différents : tipo $C$, super durall, a mano avional, tipo a mano et a mano. Pour plus de renseignements sur chacun de ces types d'anches, cf. les catalogues dans les sites internet de deux usines aux adresses www.binci.it et www.vociarmoniche.it.

\section{RÉSUMÉS}

L'usine italienne Voci Armoniche (voix harmoniques) est actuellement une des principales dans le monde pour la production des anches métalliques pour les accordéons. Son prestige vient de la grande qualité des anches réalisées par ses artisans-ouvriers hautement spécialisés qui se transmettent oralement de génération en génération savoirs et savoir-faire, depuis environ cent ans. Que se passerait-il si cette transmission était interrompue ou partiellement transférée ? Que peut-on faire pour éviter que de telles connaissances ne soient perdues, menaçant ainsi la vie de l'usine et celle d'un secteur de production tel que celui des instruments de musique aérophones mécaniques à soufflet? En examinant le cas de la Voci Armoniche, l'article veut montrer pour la première fois de l'intérieur, et par le biais de recherches intensives in situ, le scénario qui concerne la transmission de savoirs et savoir-faire artisanaux de la facture instrumentale dans le cadre de la production semi-industrielle.

\section{AUTEUR}

\section{RAFFAELE PINELLI}

Doctorant en ethnomusicologie, université Côte d'Azur de Nice, université de Rome - La Sapienza 


\title{
Les savoirs traditionnels de
} pêcheurs artisanaux à Huanchaco (La Libertad, Pérou) : la problématique de leur transmission et de leur continuité

\author{
Marina Quiñe
}

1 Au Pérou, la pêche représente une activité pratiquée depuis plus de dix mille ans, commençant avec les premières communautés sédentaires côtières qui vivaient de façon presque exclusive de la mer, jusqu'à nos jours, où la pêche a gardé son importance (Rostworowski, 2005).

2 De nos jours, la pêche est la plus importante activité économique liée à l'écosystème marin péruvien (écosystème de Humboldt ou courant de Humboldt). La valeur des produits exportés issus de la pêche au Pérou atteint le milliard de dollars US par année et génère environ cent mille emplois de façon directe et indirecte (PRODUCE, 2017).

La raison pour laquelle cet écosystème est hautement productif est liée à la force et à la persistance de l'upwelling (remontée des eaux profondes de l'Océan sous l'effet du vent). Les eaux profondes et froides sont riches en sels nutritifs et permettent une énorme productivité biologique du phytoplancton et zooplancton. Grâce à cela, l'écosystème peut supporter la pression de la pêcherie industrielle monospécifique la plus importante au monde, celle de l'anchois péruvien Engraulis ringens (Arntz et Valdivia, 1985). Les anchois pêchés permettent la production de farine et d'huile de poisson, nourritures destinées à l'élevage des porcs, volailles et bovins et à l'aquaculture. Cette dernière a une demande en forte augmentation, pour répondre aux besoins de la Chine et de l'Union européenne (Guevara, 2006).

C'est ainsi qu'au Pérou, la pêche industrielle est devenue depuis les années soixante la deuxième activité économique la plus importante en termes de PIB (après l'industrie minière), générant des rentrées en devises pour le pays et d'importants revenus pour 
les industriels et armateurs qui font partie de la Société nationale des Pêcheries du Pérou.

5 Après environ 50 ans d'une activité extractive toujours plus importante, l'impact de la surexploitation de la pêcherie industrielle, jointe à des facteurs de variations cycliques climatiques comme $\mathrm{El} \mathrm{Niño}{ }^{1}$, se répercute directement sur les volumes ramenés par la pêche artisanale - qui diminuent chaque année - et sur les populations animales de l'écosystème marin (oiseaux marins, mammifères marins, poissons carnassiers) (Jahncke, 1998; Tovar, 1993). De plus, la pêche artisanale ne peut pas concurrencer la puissante flotte de pêche industrielle, qui continue de croître, tant en nombre qu'en capacité de pêche, et qui utilise des techniques de pointe en termes d'efficience pour la capture des stocks d'anchois péruviens (Rodríguez, 2002). La pêche artisanale, par contre, s'est maintenue sans changements techniques évidents ces dernières décennies (CPPS, 2002). Elle reste une activité qui s'exerce principalement dans un cadre familial d'économie de subsistance. Elle est conditionnée d'un côté par les variations de l'environnement marin et des ressources; et d'un autre côté par la responsabilité et la volonté marquée par les familles et les communautés d'exercer cette activité (Garcia, 2001).

6 Comme cas d'étude, nous nous intéresserons à la pêche artisanale de Huanchaco, dans le département de La Libertad. Dans cette ville côtière du nord du Pérou, la pêche est réalisée au moyen d'une embarcation singulière et traditionnelle appelée caballito de totora qui signifie « cheval de totora ». Cette activité est devenue une tradition locale et un symbole national.

7 La pêche en caballito de totora se réalise sur une embarcation individuelle fabriquée en roseau à partir d'une plante semi-aquatique appelée totora (Schoenoplectus californicus). El caballito de totora ou balsilla de totora est le plus important attrait spécifique de Huanchaco et incarne également son symbole identitaire. Patrimoine culturel national du Pérou (RD no 648 - INC), il symbolise une des pratiques de pêche les plus singulières au monde, dont l'histoire remonte à cinq mille ans. Son ancienneté a été déterminée grâce à l'étude des vestiges de la céramique des cultures pré-incas qui représentaient déjà la pêche en caballito de totora. Ces études ont été menées par Rafael Larco Hoyle, Hermann Buse de la Guerra, Luis Lumbreras et d'autres archéologues (Larco Hoyle, 1938 ; Tramontana, 2017, Amayo Zevallos, 2020). Le caballito de totora constitue pour Huanchaco un attrait touristique, tant au niveau national qu'international (fig. 1). 
Fig. 1. - Caballito de totora sortant de la mer à Huanchaco.

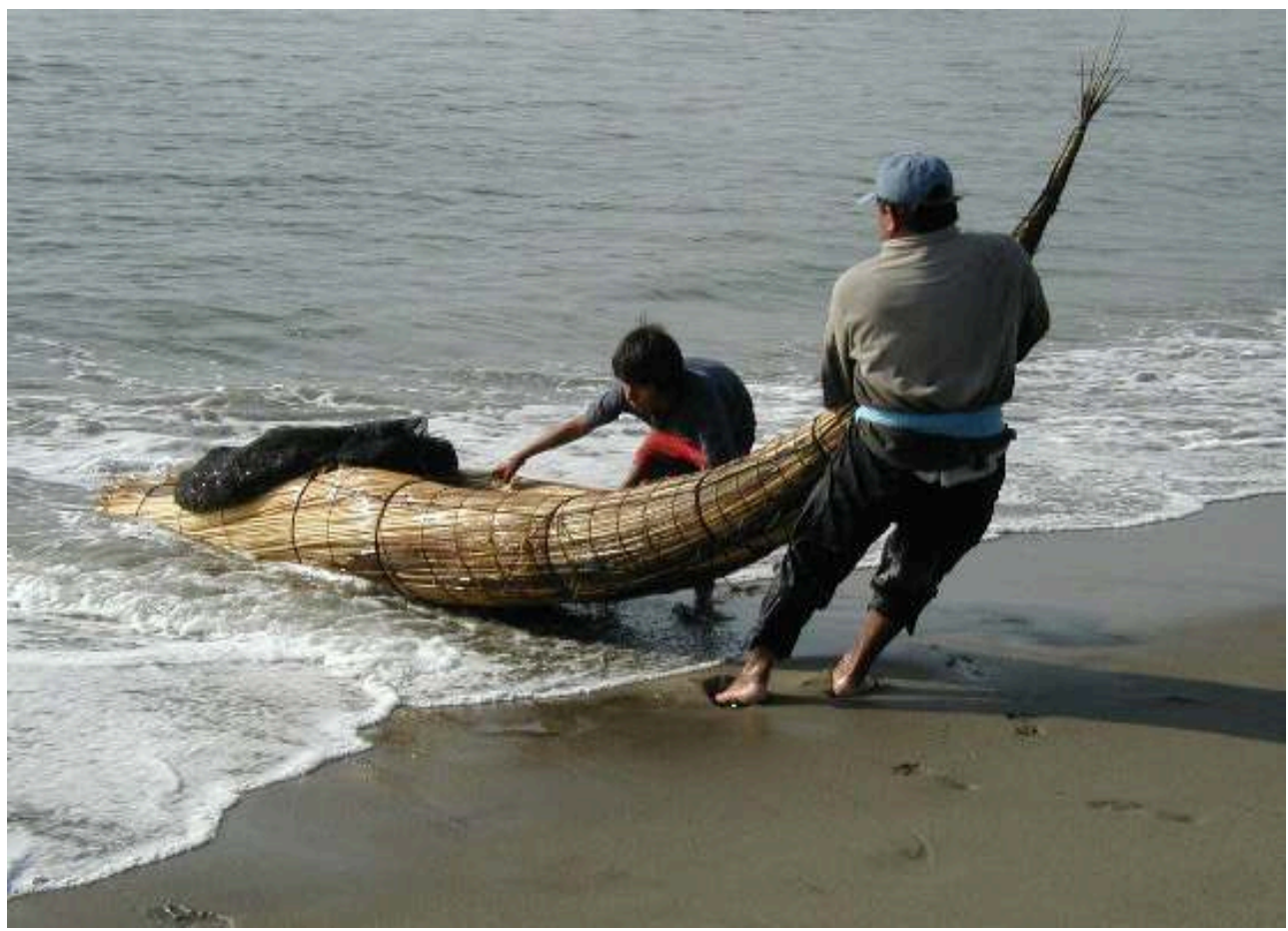

Cliché Marina Quiñe @

8 La pêche, pour le peuple de Huanchaco, n'est donc pas simplement une activité de subsistance, mais est réalisée dans un contexte culturel et identitaire d'héritage familial des savoirs et des savoir-faire. Elle représente un effort continu de garder vivante leur culture, qui remonte à l'époque des peuples précolombiens Mochicas et Chimus (Amayo Zevallos, 2020). Grâce au témoignage qu'ils ont laissé sous forme de céramiques artistiques, on connaît les pratiques traditionnelles que les habitants actuels de la région essaient de transmettre à la jeunesse malgré les difficultés dont souffre la pêche artisanale au Pérou.

\section{Huanchaco et son littoral côtier : importance pour la pêche}

La municipalité de Huanchaco se situe dans le département de La Libertad sur la côte nord du Pérou (0804'34" LS - 7906' $57^{\prime \prime}$ LO). Elle a une surface de $333,9 \mathrm{~km}^{2}$, une population de 68409 habitants avec une densité de $208 \mathrm{hab} . / \mathrm{km}^{2}$. Elle se trouve sur la rive droite de la vallée du fleuve Moche (principale source hydrique de la zone), à $12,6 \mathrm{~km}$ au nord-est de la ville de Trujillo (capitale du département) et à $560 \mathrm{~km}$ de distance de Lima, la capitale du Pérou.

10 L'écosystème marin côtier de Huanchaco est constitué d'eaux froides, typiques du courant de Humboldt, avec une plateforme continentale de grande extension qui garantit une abondance de ressources pour la pêche. Selon les pêcheurs locaux, il y a plusieurs courants à Huanchaco, le plus fort qui va du sud au nord (Humboldt), un autre océanique qui va du large en direction de la côte, et enfin, quand il a du vent, un contre-courant qui va du nord vers le sud. 
11 L'activité de la pêche industrielle le long de la côte de Huanchaco (au-delà de cinq milles marins ${ }^{2}$ ) est assez intense, en raison de son emplacement géographique qui correspond à une des quatre grandes zones d'upwelling et donc de haute productivité halieutique du Pérou, située entre $4-6^{\circ} ; 7-9^{\circ} ; 11-13^{\circ}$ et $14^{\circ}$ latitude sud. (Zuta \& Guillen, 1970).

12 Le fond marin côtier est d'un type sableux-rocheux, soit un substrat optimum pour l'établissement des algues. Cela donne un écosystème de prairie de macroalgues rouges de taille moyenne, dont l'espèce la plus répandue est Chondracanthus chamissoi, connue localement sous le nom de: mococho, cochayuyo ou yuyo (Carbajal et al., 2005). Cette algue est l'espèce-clé de cet écosystème, qui abrite une biodiversité importante, et sert à la fois de zone de pâture pour les poissons herbivores et de lieu de reproduction et de frai pour toutes les espèces de poissons.

13 Par ailleurs, la zone côtière de Huanchaco a un autre écosystème remarquable : les zones humides, dont l'espèce-clé est la totora (Schoenoplectus californicus). On la trouve dans les zones humides tout le long du continent américain, autant côté pacifique qu'atlantique, ainsi que dans les îles (Banack et al, 2004).

14 À Huanchaco, la totora, matière première pour la construction des caballitos, est cultivée. Les zones de culture de cette plante, appelées huachaques ou balsar, se trouvent au nord ouest de Huanchaco à environ $1 \mathrm{~km}$ de l'agglomération actuelle, ils s'étendent sur une aire de 46,73 ha. Il existe environ 200 huachaques sur place (Ñiquen \& Vidal, 1993 ; Banack et al., 2004). Sa proximité par rapport à la mer varie entre 50 et 150 mètres. Un Huachaque ou Balsar, consiste en une dépression artificielle (creusée dans le sol sableux) et qui se remplit petit à petit d'eau souterraine légèrement saumâtre grâce à la proximité de la mer, et qui est utilisée pour cultiver la totora.

\section{Huanchaco et la pêche en caballito de totora : contexte historique}

15 À Huanchaco, on trouve une communauté remarquablement fière et consciente de son histoire et de ses traditions, qui remontent à l'époque des Mochicas ( $\mathrm{II}^{\mathrm{e}}$-VIII ${ }^{\mathrm{e}}$ siècles) et Chimus ( $\mathrm{XII}^{\mathrm{e}}-\mathrm{XVI}^{\mathrm{e}}$ siècles) et dont les traditions se sont enrichies pendant la colonisation espagnole (XVI-XIX ${ }^{\mathrm{e}}$ siècle). De nos jours, certaines de ces traditions n'ont presque pas varié, comme les pratiques de pêche en caballito de totora et la culture de la matière première utilisée dans la construction des bateaux.

Les peuples ayant habité ces côtes dans le passé sont les Mochicas, qui vivaient sur un territoire essentiellement côtier et dont les populations habitant la zone côtière se consacraient exclusivement à la pêche, ce qui a permis un grand développement de techniques de pêche maritime variées (Larco Hoyle, 1938).

Quant aux Chimus 3 , comme les Mochicas, il s'agissait d'un peuple étroitement lié à la mer, d'où venait leur fondateur, le mythique Tacaynamo ${ }^{4}$. La capitale de l'empire Chimu était Chan $\mathrm{Chan}^{5}$, ville composée de dix citadelles fortifiées et qui est entièrement décorée de motifs marins, montrant en cela l'importance de la mer et de la pêche pour ce peuple. De la même façon, à l'intérieur de Chan Chan on peut voir jusqu'à nos jours qu'on cultivait la matière première pour la construction des caballitos, la totora, dans des endroits appelés Huachaques ou Guachaques (Guachák en langue Quingnam ${ }^{6}$ ) ou balsares ou totorales. 

en cherchant de meilleurs endroits pour la pratiquer, a commencé à s'étendre le long de la côte vers le nord et vers le sud depuis leur emplacement d'origine. Cette expansion a permis le développement du troisième empire précolombien le plus important en Amérique du Sud après ceux des Incas et des Wari. Cela a aussi permis, au travers de la continuité et de la transmission de savoirs, l'existence d'un nombre important de communautés pratiquant la pêche en caballito de totora, parmi lesquelles seulement quelques-unes ont perduré jusqu'à nos jours ${ }^{7}$ (Alva Mendo, 2004, citant Walter Diaz Sanchez). Chimor ${ }^{8}$, peuples qui étaient intimement liés à la mer. Dans les expressions du peuple de Huanchaco telles que : "Primero todo ha sido huanchaquero" ${ }^{9}$ ", on se rend compte de sa certitude quant à son lignage et à son origine. Cette attitude de fierté envers leurs racines, de faire toujours remarquer leurs liens avec leur origine, nous est aussi démontrée par l'intérêt croissant des Huanchaqueros pour la généalogie, ils utilisent leur nom de famille ${ }^{10}$ pour construire leurs arbres généalogiques et pour étudier la façon dont ils se sont diversifiés et étendus au niveau local et national. Tout cela participe au contexte identitaire d'un peuple qui continue à pratiquer différentes activités liées à un mode de vie ancestral, parmi lesquelles on trouve la pêche et certains rituels de caractère magico-religieux peu pratiqués de nos jours comme : « $\mathrm{El}$ pago al mar ${ }^{11} »$ (Alva Mendo, 2003).

Dès l'arrivée des Espagnols, l'activité sur la côte péruvienne change pour toujours. Au xvII ${ }^{e}$ siècle, la mer n'est plus exclusivement réservée aux bateaux en roseaux ou aux radeaux des habitants. Les grands bateaux en bois des Espagnols établissent des liaisons commerciales entre leurs colonies, favorisant des échanges de produits comme du blé, du charbon, du vin, du sucre, de l'alcool et des esclaves (Schlüpmann, 1995). Pour favoriser ces échanges commerciaux, ils construisent des ports. À Huanchaco se trouvait ainsi le port le plus important de la région nord de l'époque, celui de Trujillo. Mais comme les conditions d'accès à la frange littorale ne sont pas optimales pour les grandes embarcations, les Espagnols commencent à employer les pêcheurs de Huanchaco, afin de guider les chaloupes lors de la traversée de l'anse (Schlüpmann, 1995). Les pêcheurs font alors aussi du transport pour les Espagnols avec leurs propres caballitos de totora (Diaz, 1968). Ces pêcheurs approvisionnent aussi la ville et les provinces voisines en poissons séchés et autres produits de la mer.

21 Entre les années 1930 et 1950, aux dires des pêcheurs de Huanchaco, il y a eu une activité de pêche très importante, où intervenaient des bateaux à voile et les caballitos de totora. Les vieux pêcheurs huanchaqueros se souviennent encore aujourd'hui de l'époque (qu'ils idéalisent) où ils partaient en bateau à voile pour pêcher en face de Salaverry (200 km environ au nord de Huanchaco) ou jusqu'à Chimbote (150 km environ au sud de Huanchaco), passant entre 10 et 20 jours en mer suivant la pêche, une époque où les poissons étaient presque «des monstres marins » dont la vente rapportait «beaucoup d'argent ».

À partir des années cinquante, a commencé le boom de la pêche d'anchois péruviens. Les bateaux à voile ont été remplacés petit à petit par les bateaux à moteur, mais les caballitos de totora ont continué d'être employés, soit pour aider à décharger les bateaux soit pour pratiquer la pêche dans les zones proches de la côte (Alva Mendo, 2003). 

pêcheurs huanchaqueros qui ont travaillé dans les bateaux de pêche industrielle, pour des durées variables. À la fin de leur contrat, ils rentraient à Huanchaco et reprenaient leurs activités de pêche en caballito.

Ces cinquante dernières années, Huanchaco a expérimenté une croissance rapide qui l'a fait passer d'un humble village de pêcheurs d'un millier d'habitants à une agglomération-cité balnéaire de plus de soixante mille habitants.

\section{La problématique de la pêche en caballito de totora et la perte de savoirs traditionnels}

Différents éléments forment le cadre complexe de la problématique autour de la pratique de la pêche en caballito de totora contemporaine. Ceux-ci ont un impact direct sur la continuité de la transmission ou la perte des savoirs et au maintien de cette tradition de pêche millénaire. Parmi ces éléments, nous nous focaliserons sur trois en particulier :

- la pêche industrielle et son impact sur l'écosystème et la pêche artisanale à l'échelle nationale et régionale ;

- la pêche artisanale en caballito de totora à Huanchaco et son manque de rentabilité : l'impact sur les jeunes et sur l'avenir de la pratique ;

- la surexploitation de l'écosystème de macroalgues côtières à Huanchaco à l'échelle locale.

\section{La pêche industrielle et son impact sur l'écosystème et la pêche artisanale : échelle nationale et régionale}

L'anchois péruvien (Engraulis ringens) est la plus importante ressource marine au Pérou et le matériau de l'industrie de la pêche qui le transforme en farine et huile de poisson. La pêche de cette ressource a démarré dans les années soixante et la production a fortement fluctué ces dernières années : 1,2 Mt. en 1998, 9,2 Mt. en 2000, 8,5 Mt. en 2006, 2,3 Mt. en 2014 et 6 Mt. en 2018. Au début des années soixante-dix, la pêche aux anchois a enregistré le record du tonnage pour une seule espèce pour le monde entier, plus de 12 Mt. (Bertrand et al, 2004 ; Castillo et Mendo, 1987 ; IFFO, 2008 ; FAO, 2018).

Jusqu'en 2006, les quotas étaient appliqués de façon globale au Pérou, c'est-à-dire que la flotte de pêche industrielle essayait, pendant la période d'ouverture de la pêche, de prendre le maximum possible de poissons. La flotte a en quelques années fortement augmenté en nombre et puissance (tonnage et technicité), atteignant les quotas chaque fois plus rapidement. Pour se donner une idée de cette évolution, si en 1986 le quota de pêche établi avait été atteint en 270 jours, dans les années quatre-vingt-dix il a été réduit à environ 200 jours et en 2007 à seulement 50 jours (Paredes et Gutierrez, 2009).

Pour cette raison, la pêche de l'anchois péruvien est devenue une sorte de compétition, où le plus fort, doté de la meilleure technologie de détection des stocks des poissons, réalisait les plus importants bénéfices. L'efficacité atteinte par la flotte de pêche industrielle actuelle est telle que si elle pouvait pêcher pendant 180 jours au lieu de 50 comme en 2007, elle obtiendrait 28 Mt. (Majluf, 2006).

29

L'industrie de la pêche à l'anchois péruvienne compte environ 1300 bateaux de pêche, dont 650 sont des grands bateaux industriels avec une capacité de cale variant de 300 à 
$600 \mathrm{~m}^{3}$. Le reste est constitué d'embarcations appelées Vikingas, bateaux plus petits fabriqués en bois. Environ 93000 personnes sont employées par cette industrie (Sociedad Nacional de Pesquerías, 2018).

La flotte de pêche industrielle surdimensionnée représente un problème autant pour le gouvernement péruvien, qui a de difficultés à contrôler l'extraction, et pour les écologistes qui défendent la biodiversité marine du Pérou, en mettant en cause la durabilité de l'activité dans le temps (Paredes et Gutierrez, 2009). La pêche à l'anchois péruvien impacte tout l'écosystème marin et ses composants trophiques, en diminuant la capacité de soutenir les populations des autres vertébrés comme les oiseaux marins, les otaries à crinière et les poissons carnassiers. De l'avis des pêcheurs artisanaux de la côte, c'est aussi une activité qui nuit à la pêcherie artisanale, spécialement à celle pratiquée près de ports d'activité de la pêcherie industrielle (Aquije-Ballon \& Ortiz Chavez, 2017).

31 En juin 2008, le ministre de la Production de l'époque, Rafael Rey, a promulgué le décret législatif DL № 1084 - 2008 PRODUCE, qui modifie la politique d'aménagement des quotas de pêche, en passant d'un régime de quota global à celui de quotas individuels. Cette promulgation a divisé le secteur de la pêche industrielle en deux camps, les petits industriels et les petits propriétaires de bateaux se trouvant désavantagés par rapport aux grands industriels qui avaient un énorme avantage pour l'adjudication de nouveaux quotas.

Après 2008, l'évolution des tonnages de capture des ressources, principalement l'anchois péruvien, a évolué de manière relativement stable jusqu'en 2012, année après laquelle les volumes pêchés et transformés ont presque été divisés par deux, en raison d'El Niño et d'une diminution de la ressource. Aujourd'hui, elles sont à nouveau en augmentation. Cela a conduit à de grandes difficultés pour les pêcheurs artisanaux dont la situation ne s'est pas améliorée.

\section{La pêche artisanale en caballito de totora à Huanchaco et son manque de rentabilité : l'impact sur les jeunes et sur l'avenir de la pratique}

De l'avis des vieux pêcheurs, la pêche devient chaque année plus difficile, non pas raison de l'effort nécessaire, mais du fait que l'« on ne gagne rien ». Il s'agit donc selon eux d'un problème de rentabilité qui met en danger leur subsistance.
«Avant, même si la pêche était dure, on rentrait bien chargés de poissons [...] On trouvait de grandes quantités de robalos, cojinovas, corvinas, jureles, sardinas et azules, on pêchait même de l'anchois et on le mangeait [...] maintenant je pêche et qu'est- ce que j'obtiens? Deux ou trois petits poissons! [...] Comment on peut vivre avec ça ? Comment on fait pour payer les charges de la maison? [...] Avant par exemple, on prenait le risque d'aller en mer quand elle était formée, mais maintenant on perd plus en perdant un filet de pêche que ce que l'on gagne à pêcher. »
(Abelino H., pêcheur de Huanchaco)

Les jeunes pêcheurs sont de plus en plus rares, et la plus grande partie des pêcheurs en caballito a 40 ans ou plus. Ils arrivent à pêcher jusqu'à 70 ans, âge à partir duquel ils se rabattent sur la pêche dans la zone littorale, éventuellement en caballito (quand la mer est très calme). Ils aident leurs collègues, entretiennent leurs huachaques et construisent des caballitos. Parmi les jeunes pêcheurs, nous avons rencontré un jeune homme de 25 ans, appelé Junior, marié et sur le point d'avoir son premier enfant. Pour 
lui pas de choix, «Il n'y a pas de travail ailleurs, donc pas d'autre solution que la pêche en caballito, [qu'il avait apprise depuis tout jeune] [...] mais si je trouve autre chose, je quitte la pêche tout de suite ». Il disait cela en continuant à attacher les appâts de viscères de poissons dans ses sacas (pièges à crabes).

Les pêcheurs ont envoyé leurs enfants à l'école, en espérant que leur vie, grâce aux études, serait moins dure. Toutefois, dans une famille nombreuse, il y a souvent l'un des enfants qui décide de perpétuer la tradition de pêche, même s'ils sont de moins en moins nombreux.

C'est le cas de Joël, 20 ans, qui vient d'une famille de pêcheurs huanchaqueros, et qui a fait le choix de continuer l'activité traditionnelle. Quand il parle de ce qu'il fait, il ne se plaint pas - au contraire - et se dit content de son métier. Ses amis disent qu'il l'a bien appris. En plus d'être un bon cuisinier et de savoir faire les repas typiques de Huanchaco, il fait du surf, comme beaucoup de jeunes locaux et de touristes venus exprès pour cela.

Mais devant la crise que traverse la pêche, son incertitude face à l'avenir est évidente. Il suffit d'aller à la plage, de rester là un certain temps et d'observer les pêcheurs : il n'y a que quelques jeunes, tous un peu timides et donnant l'impression d'être toujours pressés/stressés ou trop occupés même pour simplement discuter.

On trouve aussi les jeunes qui ont appris à manier un caballito et même à pêcher, mais pour qui c'est simplement un loisir original et intéressant. C'est le cas d'Erick H., 18 ans, qui est sur le point d'aller à l'université nationale de Trujillo suivre des études en psychologie. Il aime la mer grâce à son grand-père, Fidel H., un homme de la mer depuis toujours : les parents d'Erick ont émigré en Espagne pour travailler, lui est resté à la charge de ses grands-parents. Son grand-père lui a appris à être un bon " cavalier " et à pêcher avec lui. Erick n'a pas encore fini de maîtriser la construction d'un caballito, mais aide toujours son grand-père à les fabriquer.

Pour certains pêcheurs, la tradition culturelle de pêcher en caballito va se perdre mais pour d'autres c'est quelque chose qui va toujours continuer. De l'avis des autorités de la région, la pêche pourrait disparaître mais pas le caballito, parce qu'il est un symbole de la région et du pays qui continue à attirer le tourisme. Les autorités de l'Institut de la Mer du Pérou (IMARPE), pensent que la pêche traditionnelle est très vulnérable voire en danger de disparition, mais ils continuent à penser que des solutions existent encore.

\section{Surexploitation de l'écosystème de macroalgues côtières à Huanchaco à l'échelle locale}

40 Au niveau local, il y a deux problématiques saillantes qui impactent directement les pêcheurs : la surexploitation du mococho ou algue rouge (Chondracanthus chamissoi) et la conservation des huachaques (zones de culture de la matière première).

41 Le mococho est une algue qui peut atteindre $50 \mathrm{~cm}$ de hauteur et qui se trouve entre la zone la plus basse des marées et $15 \mathrm{~m}$ de profondeur environ. Elle se développe sur les rochers du fond marin. Les écosystèmes de macroalgues représentent des excellents refuges pour la faune, permettant l'alimentation et la reproduction des organismes marins (Lardazabal, 2008). La diversité spécifique est considérée comme un facteur-clé 
de la résilience des écosystèmes face à la pression anthropique et notamment à la pression de pêche (Lobry et al, 2003).

Le mococho a été utilisé comme source de nourriture depuis l'époque préhispanique (Rostworowski, 2005) jusqu'à nos jours. Une surexploitation récente de la ressource a été imputée par les locaux à la présence de personnes qui n'appartiennent pas à la communauté de Huanchaco et qui se sont spécialisées dans l'exploitation de cette algue. Celle-ci est vendue sur les marchés locaux et de Trujillo et est destinée aux restaurants.

Selon les statistiques de la pêche artisanale du département de La Libertad de l'IMARPE, Huanchaco représente une part très faible de l'extraction des poissons mais constitue la plus importante zone d'exploitation du mococho. Par exemple, en 2005, au cours du premier et du deuxième trimestre, $26174 \mathrm{~kg}$ et $7274 \mathrm{~kg}$ ont été extraits. En 2006, pour les mêmes périodes, $52000 \mathrm{~kg}$ et $25000 \mathrm{~kg}$ respectivement (Carbajal et al. 2005; DIREPRO, 2006). La variabilité peut s'expliquer par l'augmentation soudaine de l'intérêt pour le mococho comme ressource culinaire après le boom gastronomique mondial péruvien, entre les années 2004 et 2006.

Selon les pêcheurs, les personnes qui exploitent exclusivement le mococho n'ont pas de technique adaptée qui assure une exploitation durable :

«Ces gens viennent d'ailleurs, de la montagne [...] ils coupent tout le mococho en l'arrachant de la pierre [...] tout! [...] comme ça, il ne se reproduira pas.» (Alejandro U., pêcheur de Huanchaco)

Les cueilleurs des algues sont aussi perçus par les pêcheurs huanchaqueros comme des personnes dangereuses, qui ne veulent pas changer leurs mauvaises méthodes d'extraction :

« Il faut faire attention avec ces gens-là [...] on a déjà essayé de leur parler, mais ils nous menacent, ils sont vulgaires [...] On ne sait pas quoi faire.» (Monsieur A.-P., pêcheur de Huanchaco)

Pour les autorités du gouvernement local de Huanchaco, les pêcheurs exagèrent le danger que ces personnes puissent représenter. Ils reconnaissent que les personnes qui surexploitent le mococho, si elles vivent à Huanchaco, viennent cependant bien «d'ailleurs »- des zones de montagne - et habitent les zones les plus défavorisées de la ville. Les autorités sont aussi d'accord sur le fait que ces nouveaux extracteurs de mococho représentent un problème pour la pêche traditionnelle de Huanchaco mais qu'il n'est pas facile de trouver une solution, comme contrôler l'extraction et pénaliser la surexploitation.

47 L'Institut de la mer du Pérou propose d'établir une aire marine protégée à Huanchaco pour y cultiver le mococho, en demandant la participation de la communauté des pêcheurs pour sa protection. De cette façon, l'Institut de la mer pense pouvoir garantir le maintien du mococho et permettre le retour des poissons vers la côte de Huanchaco (Amado Solano, chercheur à l'IMARPE, comm. pers., 2013).

En ce qui concerne les huachaques et la problématique de leur conservation, il existe différentes situations qui affectent directement la conservation des balsares, même si légalement ils constituent un endroit protégé. La croissance de la ville et son besoin de plus en plus important de terrains, principalement face à la mer, occasionne des problèmes techniques comme des constructions trop proches des huachaques, réalisées sur des terrains de la zone humide des balsares, et qui ont de ce fait des problèmes à cause du sol. Ces constructions présentent des désordres structurels, probablement en 
raison de la prise en compte insuffisante des infiltrations d'eau salée. Entre 1962 et 2002 la surface de la zone de huachaques a été réduite de $78 \%$ et ne représente plus qu'environ 14 ha actuellement (Mantilla, 2005). L'augmentation de l'érosion marine côtière détruit les balsares qui se trouvent plus près de la mer. La réduction de la surface de production à Huanchaco, accompagnée de la disparition depuis environ 20 ans d'autres zones de culture proches comme celles de Santa Rosa et Pimentel, causent une érosion de la variabilité génétique de la plante et donc une plus forte sensibilité aux autres perturbations par un affaiblissement de sa diversité génétique (Ñiquen et Vidal, 1993).

Le manque de zones de culture de totora dans les communautés proches, à Santa Rosa et principalement à Pimentel (où le nombre de pêcheurs en caballito de totora est trois fois plus important qu'à Huanchaco), fait que la demande sur la production provenant de Huanchaco est d'autant plus intense. Comme l'offre de ressources ne couvre pas la demande, les pêcheurs ont développé des adaptations pour la construction de leurs caballitos, notamment en utilisant moins de totora. Le gouvernement local essaie de trouver des solutions à ce problème, mais l'opinion populaire est qu'il est largement impuissant. Il y a eu des initiatives pour mettre en valeur les balsares et améliorer leur conservation et leur entretien (il y a en effet de nombreux huachaques abandonnés à cause de la perte d'intérêt de leur propriétaire, de son changement d'activité ou de travail, etc.). Ces projets ont été proposés par des ONG mais finalement, n'ont pas été mis en œuvre ni suivis d'effet, par manque d'implication et/ou intérêt de la population.

50 Certains projets ont même fait empirer les choses, comme celui d'une Poza de oxidación (lagune d'épuration des eaux usées) près de la zone des huachaques. La filtration de l'eau de cette énorme fosse a fait augmenter le niveau des eaux des balsares. Cette eau infiltrée, chargée d'une quantité importante de substances toxiques, a provoqué l'augmentation du niveau des eaux souterraines, qui ont fini par asphyxier les plantes, rendant inutilisables un certain nombre de huachaques. (Felix G., pêcheur de Huanchaco ; TVcosmos. pe, 2016).

\section{Les savoirs des pêcheurs et leur transmission}

51 Les problématiques que nous avons passées en revue ont toutes un impact direct sur la continuité de la transmission de savoirs. Le manque d'intérêt des jeunes pour un métier dangereux et de moins en moins rentable au niveau économique d'un côté, et le souhait des parents que leurs enfants aient une meilleure vie qu'eux d'un autre côté, ont drastiquement diminué la transmission des savoirs et savoir-faire à Huanchaco.

On peut se demander quelles sont les alternatives pour améliorer la qualité de vie de ce peuple, sans mettre de côté ses traditions, sa culture et ses savoirs.

L'impact de la surpêche par la pêche industrielle fait que le caballito de totora devient un outil de pêche de moins en moins efficace pour la pêche, de ressources devenant ellesmêmes plus rares. Cette situation critique risque de le voir intégrer - à court terme - la catégorie des objets pittoresques valorisés surtout par le tourisme, comme c'est le cas pour d'autres outils traditionnels dans le monde. Le chemin est long et difficile pour 
faire que le caballito de totora ne finisse pas dans l'histoire comme un simple souvenir. Le risque est grand de le voir disparaître après qu'il a accompagné la vie quotidienne de ces hommes pendant environ cinq mille ans - témoin d'une longue et étroite collaboration entre l'Homme et la Nature.

On peut espérer que le caballito et son jinete (chevalier) trouveront leur place dans ce qui pourrait être la mise en place et/ou la réinvention d'une pêche industrielle responsable et respectueuse du milieu et de ses richesses. Il semble encore temps de chercher des solutions viables pour arriver à équilibrer le développement de la population d'une façon durable et la continuité dans le temps d'une pratique de pêche millénaire qui fait partie du très riche patrimoine culturel du Pérou.

Il est vital, pour que des solutions puissent être trouvées et mises en œuvre, que la fierté du peuple de Huanchaco pour sa culture millénaire reste vivante.

\section{BIBLIOGRAPHIE}

AMAYO ZEVAllos Enrique, 2020, « El caballito de totora Mochica y el origen del surf. Pacarina del Sur », Éd. Numérique, Revista del pensamiento crítico Latinoamericano, $\mathrm{n}^{\circ} 44$.

[URL: http://pacarinadelsur.com/home/mar-del-sur/83-el-caballito-de-totora-mochica-y-elorigen-del-surf]

ALVA MENDO Jacobo, 2004, Huanchaco y el mar en la memória de un pueblo de pescadores.

[URL:https://sisbib.unmsm.edu.pe/bibvirtualdata/publicaciones/guaca/n1_2004/a01.pdf]

ANHUAMÁN GORDILlo Pedro, 2014, Huanchaco : cultura viva muchik-chimor de la costa norte del Perú :

historia, tradiciones, leyendas y personajes, Trujillo, Editorial Universitaria Universidad Nacional de Trujillo, $303 \mathrm{p}$.

AQUIJE Harry y ORTIZ Luis, 2017, Relación de la pesca industrial de anchoveta con la pesca artesanal : evidencia del caso peruano (Tesis de licenciatura en Economía), Universidad de Piura. Facultad de Ciencias Económicas y Empresariales, Programa Académico de Economía, Lima, Perú, 56 p.

ARNTZ Wolf et VALDIVIA Edgard, 1985, « Visión integral del problema « El Niño » : Introducción », dans Arntz W., Landa, A., Tarazona, J. (eds) , «El Niño » su impacto en la fauna marina, Boletín Instituto del Mar del Perú, Callao (numéro spécial), p. 5-10.

BANACK Sandra, RONDON Xanic et DIAZ-HUAMANCHUMO Wilfredo, 2004, « Indigenous Cultivation and Conservation of Totora (Schoenoplectus californicus, Cyperaceae) In Peru », Economic Botany, 58 (1), p. 11-20.

BERTRAND Aranud, SEGURA Marcelo, GUTIÉRREZ Mariano et VÁSQUEZ Luis, 2004, From small-scale habitat loopholes to decadal cycles: a habitat-based hypothesis explaining fluctuation in pelagic fish populations off Peru. Fish and Fisheries, 2004, 5, 296-316.

Bonilla Amado José, s. d., Perú Prehispanico, Lima-Peru, 160 p. Éd. numérique. [URL: https:// fr.scribd.com/doc/97276627/Peru-Prehispanico-Bonilla] 
CASTILLO Sady et MENDO Jaime, 1987, Estimation of Unregistered Peruvian Anchoveta (Engraulis ringens) in Official Catch Statistics, 1951 to 1982. The Peruvian Anchoveta and Its Upwelling Ecosystem: Three Decades of Change. ICLARM studies and reviews 109, 116 p. Instituto del Mar del Perú (IMARPE), Callao, Perú, Deutsche Gesellschaft fur Technische Zusammenarbeit (GTZ).

CARBAJAL Wilmer, GALAN Julio et DE LA CRUZ Jaime, 2005, Prospección del recurso Chondracanthus chamissoi « cochayuyo » en la playa de Huanchaco, Trujillo, junio-julio 2005, Informe. IMARPE.

CPPS, 2002, Estudio sobre el Impacto Socio-Económico de la Pesca Artesanal en los estados miembros de la CPPS.

[URL: http://cpps.dyndns.info/cpps-docs-web/planaccion/biblioteca/pordinario/

031.Estudio\%20Impacto\%20de\%20la\%20Pesca\%20Artesanal\%20en\%20Paises\%20Miembros\%20de\%20la\%20CPPS\%20version\%203.pdf]

DIAZ Sanchez Walter, 1968, Tradiciones de Huanchaco, Fondo editorial municipal de Huanchaco, 145

p.

DIREPRO - Dirección regional de la producción - La Libertad, 2006, Estadísticas de volúmenes de extracción del recurso C. chamissoi « mococho » del litoral de Huanchaco, 67 p.

FAO, 2018, El estado mundial de la pesca y la acuicultura 2018. Cumplir los objetivos de desarrollo sostenible, Roma, Licencia : CC BY-NC-SA 3.0 IGO, 250 p.

GARCIA Amelia, 2001, « Genero en la pesca artesanal en el Perú », Investigaciones Sociales, ㄲo 5, año 7, p. 43-63.

GUEVARA ARELLANO María Ysabel, 2006, La exportación de la harina de pescado, Éd. numérique, [URL:http://www.monografias.com/trabajos35/harina-de-pescado/harina-de-pescado.shtml]

IFFO, 2008, La producción de harina y aceite de pescado de la anchoveta peruana, Internacional Fishmeal and fish oil Organisation (IFFO), Datesheet, [URL:https://oneproceso.webcindario.com/ La\%20Produccion\%20de\%20harina\%20de\%20pescado\%20en\%20el\%20Peru.pdf] HUAMANCHUMO DE LA CUBA Ofelia, 2004, « Onomastica : Huamanchumo ». Revista Andina de Cultura Sieteculebras, $\mathrm{n}^{\circ} 18$, p. 36-39.

JAHNCKE Jaime, 1998, « Las poblaciones de aves guaneras y sus relaciones con la abundancia de anchoveta y la ocurrencia de eventos El Niño en el mar peruano ». Bulletin IMARPE, vol. 17 (1-2), Lima, Perú, 13 p.

LARDAZABAL Sarah, 2008, Beyond the refugium: a macroalgae primer. Reefkeeping

[URL:http://reefkeeping.com/issues/2007-01/sl/index.php]

LARCO HOYLE Rafael, 1938, Los Mochicas. Tomo I, Lima, Perú, 333 p.

[URL : https://issuu.com/nestordanielvelazquez/docs/rafael_larco_hoyle_-_los_mochicas__6283e72f254195]

LOBRY Jérémy, GASCUEL Didier et DOMAIN François, 2003, La biodiversité spécifique des ressources démersales du plateau continental guinéen : utilisation d'indices classiques pour un diagnostic sur l'évolution de l'écosystème, Aquat. Living Resour, 16, p. 59-68.

MAJLUF Patricia, 2006, El sector pesquero. (UPCH)-World Bank presentation. Siteresources, [URL:https:// slideplayer.es/slide/99320/]

MANTILLA Dionisio, 2005, « La agonía del totoral », Vea del Perú, no⒍

ÑIQUEN Manuel et VIDAL Jorge, 1993, « Conservación ex situ de Schoenoplectus californicus (C.A. Mey) Sojak, en Huanchaco (Trujillo-Perú) », Antenor Orrego, vol. 2, p. 17-27. 
PAREDES Carlos et GUTIÉRREZ Maria Elena, 2009, Los costos del sobredimensionamiento pesquero en el Perú. Instituto del Perú.

[URL:https://usmp.edu.pe/idp/wp-content/uploads/2015/10/

situacin_de_la_industria_pesquera_en_el_per.pdf]

PRODUCE, 2017, Anuario Estadístico de Pesca. Ministerio de la Producción. 196 p.

RODRÍGUEZ RAMOS Jorge, 2002, « Las áreas de manejo de recursos bentónicos y pelágicos : un cambio económico nacional espectacular versus contaminación y depredación por la industria de harina de pescado en Perú ", AquaTIC, $n^{\circ} 17$.

[URL:http://www.revistaaquatic.com/ojs/index.php/aquatic/article/view/174]

ROSTWOROWSKI Maria, 2005, Recursos naturales renovables y pesca, siglos XVI-XVII. Curacas y sucesiones, costa norte. Obras completas, vol. IV, Lima, Instituto de Estudios Peruanos. 330 p.

SCHLÜPMANN J. 1995, « Le commerce maritime à Trujillo au XVII ${ }^{\mathrm{e}}$ et XVIII ${ }^{\mathrm{e}}$ siècles », Histoire et Société de l'Amérique latine/ALEPH, vol. 11. 2015. [URL: http://www.univ-paris-diderot.fr/hsal/hsal95/ js95.html]

Sociedad Nacional de Pesquerías, 2018, Reporte de sostenibilidad - Reporte GRI (Global Reporting Iniciative) del sector de pesca industrial para ingredientes marinos, SNP, $64 \mathrm{p}$.

TOVAR Humberto, 1993, Fluctuaciones de poblaciones de aves guaneras en el litoral peruano, 1960-1981, In FAO Fisheries Report n ${ }^{\circ} 291$, vol. 3, 26 p.

TRAMONTANA Oscar, 2017, «Los pescadores tablistas », dans MEZA Roberto, TRAMONTANA Oscar et PARDo Carlos, Éd. Numérique, « Cinco mil años surcando olas »

[URL:http://www.historiadelatablaenperu.com/capitulo1.htm]

TvCosmos, 2016, Huanchaco : Colapsan lagunas de oxidación y aguas servidas llegan hasta las pozas de totora, 6 septembre 2016.

[URL:https://tvcosmos.pe/huanchaco-colapsan-lagunas-de-oxidacion-y-aguas-servidas-lleganhasta-las-pozas-de-totora/]

VALlADARES-HUAMANCHUMO Percy, 2013, « El apellido Quingnam en Huanchaco », Perspectivas Latinoamericanas, $\mathrm{n}^{\circ} 10, \mathrm{p} .47-55$.

ZUTA Salvador et GUILLEN Oscar, 1970, « Oceanografía de las Aguas Costas del Perú, Dpto. de Oceanografía », Boletín Instituto del Mar del Perú, Callao, 2, p. 157-324.

\section{NOTES}

1. El Niño, et son pendant La Niña sont des phénomènes océaniques à grande échelle du Pacifique équatorial, affectant le régime des vents, la température de la mer et les précipitations. Ils correspondent aux deux phases opposées du phénomène couplé océan/atmosphère appelé ENSO (El Niño/Southern Oscillation). Source : Météo France.

2. Par décret présidentiel $n^{\circ}$ 012-2001-PE du 13 mars 2001, la zone compris entre la ligne de côte et les cinq mille marins correspond à une aire exclusive pour la pêche artisanale et la protection de la zone de reproduction des ressources marines. Le décret présidentiel $n^{\circ} 003-2008$-PRODUCE du 14 octobre 2008, a établi un régime spécial qui permet la pêche industrielle à l'intérieur de cette zone, entre le $16^{\text {ème et le }}$ $18^{\text {ème }}$ parallèle (soit au sud du pays, près de la frontière avec le Chili, pays avec lequel il existe un conflit limitrophe marin). 
3. De l'avis de plusieurs archéologues spécialisés en histoire des peuples préhispaniques, il y a eu une continuité culturelle dans le temps entre le début de la formation des Mochicas et la fin des Chimus avec l'apport, entre le viII et le XII siècle, de peuples comme les Wari-Tiahuanaco. Les Mochicas-Chimus manifestent aussi l'influence de cultures qui se sont développées avant eux, telles que les Cupisnique, Salinar, Chavín, Vícus. (Bonilla, sans date).

4. Tacaynamo fut le fondateur du règne Chimu et le premier gouvernant à Chan Chan, selon les chroniques anonymes écrites en 1604, en parlant de la fondation de Chan Chan. Selon la légende, Tacaynamo, "est arrivé de l'autre côté de la mer dans un radeau fait avec des bâtons. Il était un sage, il avait beaucoup de connaissances de la mer, la terre et des étoiles... » (Bonilla, sans date).

5. Citadelle de Chanchan classée par l'UNESCO comme Patrimoine mondial de l'Humanité en 1986.

6. Quingnam ou Quignam, c'est le nom de la langue chimu. De nos jours, c'est une langue morte.

7. Comme: Pimentel et Santa Rosa (au département de Lambayeque); Huanchaco, Cherrepe, Puémape (au département de La Libertad) ; Urrucape, Chimbote pescador, Los Chimus, Samanco, Visiki (à Chimbote, département de Ancash).

8. Mochica-Chimu en langue Muchik ou Yunga.

9. «À l'origine tout était huanchaquero. »

10. En général des noms de famille qui sont originaires de la langue morte quingnam ou chimu (par ex. Huamanchumo, Guamanchumo, Piminchumo, Ucañan, Sachum ou Chilmasa) mais aussi ceux qui ont été donnés aux indigènes par les Espagnols à leur arrivée, durant le processus de conversion à la religion catholique comme Arroyo, Leytón ou Diaz (Huamanchumo de la Cuba, 2004; Anhuamán, 2008; ValladaresHuamanchumo, 2013).

11. «l'offrande à la mer ».

\section{RÉSUMÉS}

Au Pérou, la pêche est une activité pratiquée depuis plus de dix mille ans, jusqu'à nos jours, où celle-ci n'a pas perdu de son importance. La communauté de pêcheurs artisanaux du nord de la côte péruvienne, Huanchaco est particulièrement bien connue pour posséder une riche connaissance $\mathrm{du}$ milieu marin-côtier et le savoir-faire d'une singulière pratique de pêche millénaire. Celle-ci est caractérisée par l'utilisation d'un bateau en roseaux appelé caballito de totora, construit par les pêcheurs eux-mêmes. Au cours des dernières décennies, ces communautés ont connu des changements importants, comme le déclin des ressources marines, notamment les principales espèces pêchées. Cette situation complexe a eu un impact direct sur la transmission générationnelle des savoirs traditionnels et écologiques liés à la pêche, impact qui affaiblit la réponse adaptative, qui à son tour pourrait avoir un impact direct sur la résilience de ces communautés dans le temps. 


\section{AUTEUR}

\section{MARINA QUIÑE}

Biologiste marine, doctorante en système intégré, environnement et biodiversité à l'École

pratique des hautes études (EPHE), membre du Centre de recherches insulaires et observatoire de l'environnement (CRIOBE, USR 3278, université de Perpignan/Laboratoire d'excellence CORAIL, Mourea, Polynésie française) 


\title{
La transmission de l'art vétérinaire équin en France à travers le prisme de l'ethnobotanique
}

\author{
Mathilde Richard
}

1 L'Homme a de tout temps observé, représenté, mais surtout employé le cheval. En ville, dans les champs, dans les usines, sur les sentiers, sur les champs de courses ou de bataille, cet animal accompagne l'évolution de l'Homme depuis plusieurs millénaires. Dès lors, des pratiques furent mises en œuvre pour maintenir en état de santé ces animaux d'élevage et de compagnie, dès leur domestication, et les documents les plus anciens relatifs à la médecine vétérinaire équine remontent à environ 2500 ans av. J.C..

2 La communauté scientifique admet volontiers que cette médecine peut résulter, encore aujourd'hui, de pratiques thérapeutiques très anciennes, héritées de l'hippiatrie antique puis médiévale, et basées sur le recours aux plantes médicinales, utilisées pour leurs propriétés curatives et thérapeutiques. Transmises oralement pendant des siècles, puis objet de nombreux traités rédigés par d'illustres auteurs ou anonymes, ces connaissances sont devenues peu à peu "poussiéreuses ", pour une civilisation avide de progrès scientifique et de modernité. Dès la fin $d u x^{e}{ }^{e}$ siècle, cette médecine traditionnelle est délaissée, regardée avec mépris et défiance, et parfois à juste titre, au profit de traitements issus de la chimie de synthèse et de technologies innovantes, qui permettent l'élaboration de soins plus efficaces. Plus tard, grâce au développement de nouvelles sciences comme l'ethnobotanique (étude des relations entre l'Homme et les plantes et leurs usages), les savoirs traditionnels suscitent un nouvel intérêt et reprennent progressivement leur place dans la médecine moderne.

Pour bien comprendre la complexité du rapport de la médecine vétérinaire équine aux plantes médicinales, et de son évolution au fil des siècles, un détour par son histoire est nécessaire. 


\section{La médecine vétérinaire équine, un héritage thérapeutique antique}

\section{L'hippiatrie et l'ars ou medicina veterinaria}

4 La médecine vétérinaire équine antique s'inscrit dans une longue tradition médicinale dont les Grecs et les Romains ont hérité, et qu'ils ont largement contribué à enrichir. Compte-tenu de l'importance du rôle du cheval dans les sociétés anciennes et du lien symbolique de la noblesse à cet animal de prestige, les soins médicaux qui lui sont prodigués sont fondamentaux et donnent naissance à « une science du cheval » appelée « hippiatrie » chez les Grecs.

5 L'ars ou medicina veterinaria apparait comme un mélange complexe de connaissances médicales, botaniques et zootechniques, de croyances religieuses et de pratiques populaires, souvent teintées de magie. La médecine équine se construit sur l'expérience acquise et transmise par les soigneurs, fruit de l'observation et du bon sens.

6 À côté des recommandations générales d'hygiène, les écrits anciens livrent des indications sur différentes maladies des chevaux et sur les accidents auxquels les animaux domestiques sont le plus fréquemment exposés. Ces textes d'hippiatres grecs, issus de différentes sphères géographiques méditerranéennes, circulent au départ indépendamment, jusqu'à ce qu'on en réunisse une partie dans une collection hippiatrique, appelé le Corpus hippiatricorum graecorum ${ }^{1}$.

7 Malgré l'état fragmentaire de la documentation et les problèmes techniques liés à leur étude, les témoignages écrits des auteurs gréco-romains véhiculent des connaissances accumulées au cours des siècles, où se combinent l'expérience des éleveurs et des gardiens du bétail à celle des praticiens érudits, anonymes ou non, de la médecine vétérinaire équine.

\section{La naissance d'une pharmacopée vétérinaire}

8 Ces documents, traités grecs ou romains et autres manuscrits antiques, qui constituent le fondement d'une pharmacopée vétérinaire, nous offrent des listes impressionnantes de plantes utilisées en thérapeutique équine. En effet, à cette époque, les substances médicamenteuses sont presque toutes issues directement du règne végétal. La nature des ingrédients utilisés est évidemment marquée par l'origine géographique, principalement méditerranéenne, des prescripteurs, ce qui restreint néanmoins la thérapeutique proposée à la disponibilité des plantes médicinales.

9 Les gommes et les gommes-résines comme le galbanum, l'euphorbe, la térébenthine, la myrrhe, l'aloès sont fréquemment conseillées. Les plantes les plus fréquemment citées sont l'ellébore noir, le safran, le mélilot, le raifort, la mandragore, la gentiane, les baies de laurier, les figues, parfois difficiles à trouver, selon le climat, et les territoires. Des produits comme l'opium, le vin ou le vinaigre sont aussi préconisés. Certains ingrédients sont fournis par les animaux : le lait, la graisse, le miel et la cire, mais aussi les limaces et limaçons, les cloportes, l'urine, les excréments, les bouillons de viande de chien, de chat et de tortue ! Très peu proviennent du règne minéral : le soufre, la chaux, l'alun, le vert-de-gris. 
10 Si la description précise la composition des remèdes et leur mode de préparation et d'administration, on remarque que peu d'indications thérapeutiques sont données sur ces drogues, de même qu'il est peu question du mode de récolte et de conservation des espèces utilisées.

\section{Le Furusiyya au Moyen-Orient}

11 Durant tout le bas Moyen Âge, la médecine vétérinaire se développe dans l'Empire byzantin et au Moyen-Orient, dans des villes comme Constantinople, Bagdad, Alexandrie ou Le Caire.

12 Chez les Arabes, les connaissances théoriques et pratiques qui touchent le cheval: hippologie, hippiatrie, dressage, élevage sont regroupées sous le terme Furusiyya, qui n'a pas son équivalent en Occident. Le Furusiyya naît au viII siècle et il est destiné aux fils de princes. Ces traités, écrits par des écuyers, maitres des écuries, ou vétérinaires, reprenant la science des Grecs et des Romains, en matière d'élevage ou de soins aux chevaux, améliorent la connaissance du dressage équin et enrichissent la pharmacopée.

On note qu'au XII siècle, un traité d'agriculture, le Kitab al Felahah, accorde une place importante à l'art vétérinaire équin, et présente la somme des connaissances professionnelles accumulées par les pays du Moyen-Orient, concernant l'hygiène, les races de chevaux, le dressage, l'obstétrique et la pathologie. La partie thérapeutique traite principalement des purgatifs, des lavements et de la saignée. Dans ce manuscrit, on apprend que les traitements administrés sont variés. Pour la diarrhée, il est recommandé de la boisson d'orge vinaigrée, de la farine de blé, de l'orge cuite, et des feuilles vertes de ronce hachées dans de l'eau. La pneumonie aiguë est soignée par des saignées, du lait de chèvre et de l'orge cuite. Les calculs de l'urètre par injection dans l'urètre d'huile et de musc. En cas d'hématurie, on prescrit le poivre et de la levure de vin. Concernant l'alimentation du cheval, l'orge doit être dépourvue de poussière, car elle peut rendre le cheval poussif ; le grain sera tamisé, pour enlever les petits cailloux qui pourraient endommager ses dents ; l'excès de grain provoque des relâchements, des sueurs, des difficultés respiratoires et des lésions des pieds.

\section{Le soin équin au Moyen Âge}

\section{Un faible bénéfice pour les populations}

14 Durant tout le Moyen Âge, la place du cheval dans la société en France et plus largement en Europe, est déterminée par le contexte militaire, politique, social et économique. Le cheval est largement utilisé pour la guerre, notamment les croisades, ou la diplomatie, le transport, et dans une moindre mesure l'agriculture (cheval de trait). Le cheval, animal noble, est un symbole de prestige, objet de considération et de convoitise, et fait l'objet d'attentions et de soins médicaux particuliers.

Dans les campagnes, dans les villes et sur les champs de bataille, les soins équins sont prodigués majoritairement par les maréchaux, hommes au service des seigneurs et des rois. Ils doivent savoir soigner un animal malade ou blessé, et éviter ou enrayer une épidémie. Néanmoins, leurs connaissances et remèdes médicinaux proviennent principalement de livrets dans lesquels se mélangent les formules des anciens, des alchimistes et des Arabes. Ces documents sont souvent l'œuvre de copistes et de 
traducteurs, qui cousent bout à bout des textes de toute origine, parfois de façon fantaisiste, et la thérapeutique globale consiste alors en une polypharmacie irraisonnée, qui repose sur la pensée d'une meilleure efficacité par l'association du plus grand nombre possible de drogues différentes.

Ainsi, de nombreuses populations n'arrivent pas à endiguer les maladies équines, des plus communes aux plus graves car sans institution d'enseignement, ces connaissances, transmises le plus souvent de bouche à oreille, d'un père à son fils, ou d'un maitre à son élève, restent une science inexacte et aléatoire. De plus, comme la médecine humaine, la médecine vétérinaire équine médiévale est limitée par l'illettrisme, marquée par l'emprise du charlatanisme et encombrée de rituels magiques anciens qui accompagnent l'acte de soin, comme le raconte dans Mascalcia, Dino di Pietro Dini, maréchal en Italie, au XIV ${ }^{e}$ siècle :

«J'ai voulu exercer mon faible talent pour percer l'obscurité qui entourait la médecine des animaux. Tous les artisans de cet art se sont désaccoutumés de l'étudier, parce que la plupart, fils de travailleurs de la terre et gardiens de troupeaux, n'avaient pas reçu l'instruction nécessaire. Il s'ensuit qu'ils ne pouvaient pas être de véritables artistes puisqu'ils étaient illettrés².»

\section{Le rôle des monastères dans le développement de la pharmacopée du Moyen Âge}

17 Le Moyen Âge est, dans le domaine de la connaissance des plantes médicinales, une période de déclin pour l'Europe occidentale. D'une part, aucun progrès dans la découverte scientifique n'apparait, mais beaucoup de savoir disparait avec les destructions accompagnant les grandes invasions. Néanmoins, durant le haut Moyen Âge, dans des lieux de soin et de savoir comme les monastères et les abbayes, en France, en Italie ou en Allemagne, on recueille et on répertorie les écrits et le savoir de l'Antiquité, et notamment les connaissances relatives aux savoirs équins et aux plantes médicinales. Beaucoup de ces textes sont en grec, et les monastères sont d'abord des centres de traduction, de sauvegarde et de diffusion des traditions antiques. En plus de la traduction, les abbayes produisent et commercialisent des plantes médicinales et aromatiques, ou Simples, sur lesquelles la médecine médiévale est basée. Ces plantes servent à fabriquer les médicaments destinés à soigner les diverses infections des chevaux. Les moines et nonnes dispensent les soins à la population locale, aux éleveurs, aux voyageurs et aux cavaliers de passage. Ainsi, les monastères payent souvent des cueilleurs, achètent des plantes exotiques qu'ils acclimatent et échangent des espèces avec d'autres abbayes, selon les spécialisations de chacune.

Un des grands livres des Simples est sans doute celui de l'abbesse allemande Hildegarde von Bingen (1099-1179). Dans son ouvrage Physica, publié au début du XII siècle, elle rapporte qu'il est recommandé d'utiliser la mandragore, le bois de cyprès et les pierres précieuses, afin de protéger les chevaux contre la maladie et de favoriser la production de lait. Elle mentionne également que :

«Les colites et les angines du cheval sont traitées avec de l'ortie et de la laitue sauvage, la tympanite, avec la feuille de châtaignier, la toux avec le suc de fleur de souci introduit dans le nez. Les feuilles de frêne conviennent pour toutes les maladies et la poudre de pulmonaire officinale maintient les poils sains ${ }^{3}$. » 


\section{L'essor des maréchaux et les nouvelles pratiques thérapeutiques}

19 En France, avec l'invention de l'imprimerie, des traités équins, écrits principalement par des écuyers et des maréchaux, commencent à être diffusés largement : Le Parfait Maréchal, de Jacques de Solleysel, écuyer de Louis XIV, rédigé en 1644 ; Le Nouveau Parfait Maréchal dont un chapitre est intitulé « De l'apothicaire ou des remèdes », publié par De Garsault en 1755 ; Le Guide du Maréchal, rédigé en 1766 par Étienne Lafosse. Très cultivés, voire érudits, ces professionnels s'adonnent en véritables spécialistes à la médecine vétérinaire équine. Ils utilisent leurs connaissances acquises sur le terrain et les enrichissent en comparant leurs données avec les textes des Anciens. Leurs écrits sont souvent repris et recopiés, mais aussi plagiés puis vulgarisés dans de petites brochures bon marché, diffusées par des colporteurs, dans les campagnes les plus reculées.

Si on étudie les différents recueils français de médecine vétérinaire équine, on constate que les remèdes sont constitués en majorité d'espèces végétales locales, qui proviennent d'Europe ou des régions circumméditerranéennes (absinthe, ellébore, jusquiame, huiles, vinaigre). Elles peuvent aussi être importées d'Afrique (gomme arabique), du Moyen-Orient (anis, opium) et d'Asie (poivre). Les substances d'origine animale, variées, restent cependant numériquement minoritaires. Quant aux substances minérales et chimiques, elles sont de plus en plus présentes dans les remèdes, avec notamment les dérivés du plomb, du mercure, de l'arsenic, de l'antimoine aux activités caustiques, astringentes, purgatives et/ou diurétiques. Tous ces produits sont regroupés dans des boutiques spécialisées, sur les marchés des grandes villes, places marchandes et carrefours commerciaux situés près des ports.

21 À partir de la Renaissance, les connaissances populaires de la pharmacopée du Moyen Âge perdent du terrain, au profit des nouvelles pratiques basées sur une connaissance plus éclairée et rationnelle des drogues, et sur la vérification de leurs propriétés. Cette évolution d'attitude vis-à-vis des substances actives va entrainer le recours aux techniques de l'extraction, puis de l'isolement et de l'identification des molécules responsables de l'activité observée, annonçant l'avènement de la médecine humaine et vétérinaire moderne.

À partir du $\mathrm{xVI}^{\mathrm{e}}$ siècle, il s'effectue un renouveau de la médecine équine dans toute l'Europe, avec l'expansion vers de nouveaux mondes, notamment grâce aux missionnaires envoyés en Amérique, qui s'intéressent aux vertus thérapeutiques des plantes inconnues de l'Amérique centrale et du sud, ainsi qu'à l'usage qu'en font les populations locales. Ils rédigent des livres sur l'utilisation de ces végétaux et transmettent ces informations en Europe et en France. Ainsi, la découverte de contrées tropicales et équatoriales permet d'importer au cours des siècles suivants, de nouveaux ingrédients, et des substances, destinés aux maladies des Hommes, mais qui viennent également enrichir et compléter l'arsenal thérapeutique équin déjà utilisé.

\section{L'État français s'empare de la santé publique : création des écoles vétérinaires}

$23 \mathrm{Au}$ XVIII ${ }^{\mathrm{e}}$ siècle, face à des nécessités de plus en plus pressantes, où les épizooties déciment les troupeaux bovins et équins dans toute l'Europe, les gouvernements 
insistent pour que des hommes compétents soient mis à leur disposition pour soigner les animaux des grands élevages et de l'armée royale.

En France, un arrêté du Conseil du roi Louis XV, en date du 4 août 1761, autorise l'établissement dans la ville de Lyon d'une école privée pour le traitement des maladies des bestiaux. Si des pratiques vétérinaires existent depuis toujours, elles trouvent alors pour la première fois une forme institutionnelle. Les élèves sont destinés à retourner exercer dans les campagnes, où le nombre de vétérinaires est très faible et où les pertes de bétail sont conséquentes. On y enseigne l'anatomie, la ferrure, la botanique et la chirurgie, et des disciplines tournées presque exclusivement vers le cheval. Les bêtes à cornes et les bêtes à laine sont négligées. En effet, la direction de l'école est laissée à Claude Bourgelat, un avocat-écuyer, ancien directeur de l'académie d'équitation de Lyon, qui oriente presque exclusivement l'enseignement vers l'hippiatrie. Il déclare :

«Je ne puis terminer l'histoire du cheval, sans marquer quelques regrets de ce que

la santé de cet animal utile et précieux a été jusqu'à présent abandonnée aux soins

et à la pratique, souvent aveugles, de gens sans connoissance et sans lettres ${ }^{4}$. ”

Par la suite, des enseignements vétérinaires continuent d'être crées dans tout le pays et l'État décrète, en 1881 puis en 1898, que le vétérinaire diplômé est seul capable, aux yeux de la loi, d'intervenir dans le cas des maladies les plus graves. En effet, il joue, visà-vis de l'économie nationale ou de la santé publique, un rôle de plus en plus important dans le pays. L'État édicte également la liste des mesures à adopter et à opposer à la diffusion des maladies contagieuses ainsi que les pénalités applicables aux contrevenants, et il légitime l'action du vétérinaire dans le domaine de la police sanitaire.

Puis, la loi promulguée le 17 juin 1938, déclare que seuls les vétérinaires ou docteursvétérinaires sont autorisés à exercer la médecine et la chirurgie des animaux, ce qui constitue un véritable tournant dans l'exercice de la profession, de celle des maréchaux et autres soigneurs équins de l'époque.

\section{L'opposition de deux formes de médecine vétérinaire équine}

Dès la création de l'enseignement institutionnel puis du diplôme de vétérinaire, une rivalité se crée entre les praticiens "officiels» qui sortent des écoles et ceux dits «empiriques ». Ainsi, à leur sortie de l'École, les premiers vétérinaires diplômés se trouvent en concurrence avec différents types de soigneurs, du charlatan au maréchalferrant, bien implantés dans les campagnes et dans les villes, et premiers dispensateurs de soins équins, depuis des générations. De plus, ces jeunes vétérinaires, porteurs d'une science moderne et de nouvelles théories médicales, sont parfois en décalage avec les pratiques et attentes des éleveurs, plus pragmatiques.

À partir de la seconde moitié du $\mathrm{XIX}^{\mathrm{e}}$ siècle, la communauté scientifique est divisée quant à l'attitude à avoir face aux savoirs traditionnels équins et à l'utilisation des plantes médicinales. D'une part, certains savants considèrent les maréchaux comme les gardiens d'un savoir-faire et d'une expérience à préserver, et soulignent l'intérêt et les vertus thérapeutiques de certaines pratiques observées. D'autre part, les critiques et les attaques les plus virulentes sont formulées par la communauté scientifique à l'égard des soigneurs empiriques. Ce mot «empirique» devient dès lors synonyme de 
charlatanisme, qui évoque la pratique d'une médecine sans connaissance médicale institutionnelle. Les empiriques sont ainsi vus comme des concurrents mal intentionnés, au savoir hasardeux, même dangereux, et on cherche à discréditer leurs pratiques et leur profession.

\section{La santé équine à l'ère de l'Industrie}

Durant cette période, l'utilisation des plantes médicinales est au centre d'un conflit entre deux médecines vétérinaires, l'une populaire et traditionnelle, pratiquée par les empiriques, et l'autre, moderne et scientifique, revendiquée par les vétérinaires. Ainsi, les drogues héritées de l'Antiquité sont analysées, afin de connaitre précisément leur composition chimique et de statuer sur leur intérêt thérapeutique. Les remèdes populaires et les pratiques artisanales sont dès lors relégués à un passé archaïque et suranné, qui n'a plus sa place dans la thérapeutique du futur, avec l'arrivée victorieuse de la chimie industrielle, dont les succès s'enchainent.

Le $\mathrm{xx}^{\mathrm{e}}$ siècle est celui du « Progrès » et génère une foi quasi absolue de la population et des institutions dans la médecine savante. La confiance dans l'efficacité d'un traitement est bientôt accordée exclusivement à des préparations médicinales de synthèse, à des molécules clairement identifiées. On relègue dès lors les plantes médicinales au rayon du folklore et des croyances dépassées, leur utilisation, bannie, est progressivement oubliée. La transmission des pratiques traditionnelles équines à base de plantes médicinales disparait, à la faveur de la médecine moderne, d'autant que la population des campagnes diminue avec l'exode rural, amenant la décrédibilisation de ces connaissances anciennes par les élites scientifiques et citadines.

\section{La médecine populaire équine, un patrimoine médicinal à redécouvrir}

31 Cependant, au début des années soixante-dix, la critique de la modernité et du progrès, le constat des limites et des effets secondaires des molécules chimiques, les scandales médicaux, commencent à modifier le regard des soigneurs et des populations sur la chimie et son utilisation en thérapeutique humaine et animale. Cette remise en cause $\mathrm{du}$ recours systématique aux molécules de synthèse mène à la réhabilitation progressive des soins de santé transitionnels et naturels appliqués aux chevaux.

32 Les connaissances, les compétences, les méthodes, les pratiques et les croyances associées aux soins prodigués par les membres d'une communauté sont désormais définies par le terme de médecine ethnovétérinaire équine ${ }^{5}$. Cette médecine traditionnelle utilise en grande partie les plantes médicinales locales, et des enquêtes ethnobotaniques sont initiées tant en Europe qu'au niveau international, pour étudier, sauvegarder et revaloriser ce patrimoine naturel, médical et culturel. Ce sont tout d'abord les équipes scientifiques des pays développés, qui reconnaissant les vertus des soins traditionnels et le potentiel thérapeutique de ces savoirs, publient sur le sujet, bientôt rejoints par des équipes issues des pays en voie de développement. L'enjeu est alors double : recenser les pratiques traditionnelles vétérinaires pour en laisser une trace écrite et les revaloriser avant qu'elles ne se perdent, mais aussi permettre de retrouver les racines de pratiques culturelles parfois complexes. Plus largement, 
l'ethnobotanique est fréquemment mobilisée pour répondre à d'autres enjeux globaux, comme la gestion durable des ressources naturelles et la conservation de la biodiversité6.

\section{Les nouvelles perspectives offertes par l'ethnopharmacognosie}

\section{Vers un regain d'intérêt du monde scientifique}

Une nouvelle discipline, crée dans les années quatre-vingt, l'ethnopharmacognosie s'intéresse aux emplois traditionnels des matières premières naturelles, pour les étudier ensuite scientifiquement. L'objectif principal est de valider, grâce à des tests en laboratoire, l'usage des remèdes traditionnels et de vérifier expérimentalement le bienfondé des usages thérapeutiques locaux. L'approche de l'ethnopharmacognosie permet de conforter l'usage d'un remède traditionnel et de le valoriser. Un des principes fondamentaux de cette science repose sur le fait que l'utilisation par des générations successives d'une plante pour soigner une maladie est une indication de validité de son usage, mais elle n'est pas toujours suffisante pour démontrer l'efficacité d'un remède traditionnel. Des études phytochimiques, pharmacologiques et cliniques concernant les recettes utilisées par les populations sont ensuite nécessaires pour une valorisation effective de ces plantes dans la médecine équine.

\section{Vers un regain d'intérêt des éleveurs et des propriétaires équins}

Des universitaires et des passionnés ont tenté de collecter ce qui subsiste des traditions thérapeutiques elles-mêmes ou de leur mémoire en France. Ces différentes enquêtes ethnobotaniques réalisées sur les savoirs équins populaires français ont montré la survivance de savoirs médicinaux anciens, richesse discrète et encore vivante, et parfois même en cours de réappropriation par les nouvelles générations d'éleveurs et de propriétaires, grâce à des sources issues de supports variés: famille, carnets manuscrits, livres et internet ${ }^{7}$. En effet, il y a depuis quelques années un regain d'intérêt pour les médecines vétérinaires dites désormais " alternatives », car elles sont considérées comme moins agressives envers l'organisme et plus respectueuses de la nature.

Les bénéfices recherchés lors de l'utilisation de plantes médicinales sont une meilleure appréhension de la santé animale, une plus grande autonomie et capacité d'action, une meilleure connaissance des produits administrés, contrairement aux médicaments chimiques, une diminution de certains effets secondaires et une diminution des frais vétérinaires ${ }^{8}$.

Néanmoins, ces jeunes éleveurs se heurtent à l'inconvénient majeur de la médecine équine traditionnelle qui est sûrement le fait qu'elle soit encore trop peu connue, documentée et étudiée scientifiquement. En effet, les remèdes traditionnels ne sont souvent pas validés et leur toxicité potentielle est peu évaluée? 
37 Ainsi, la rupture de la transmission des savoirs et des savoir-faire équins traditionnels, depuis déjà quelques générations, devrait motiver de toute urgence des actions de recherche et de sauvegarde approfondie de cet héritage médicinal et botanique, afin d'enrichir le patrimoine végétal moderne, à la lumière des connaissances scientifiques actuelles. Cela pourrait permettre aux éleveurs et propriétaires de chevaux de conserver ou de retrouver une autonomie en ce qui concerne la prévention, et la gestion des pathologies légères de leurs chevaux, et également d'accroitre l'intérêt et l'attention qu'ils portent à la préservation de la biodiversité et des ressources naturelles.

\section{BIBLIOGRAPHIE}

BEAUJOUAN Guy (dir.), POULLE-DRIEUX Yvonne et DUREAU-LAPEYSONNIE Jeanne-Marie, Médecine Humaine et Vétérinaire à la fin du Moyen Âge, Paris-Genève, Droz, 1966.

BOURGELAT Claude, Histoire naturelle générale et particulière, tome IV, Paris, s.n., 1753.

CORNILLET Amélie, « Étude ethnovétérinaire des pratiques thérapeutiques et prophylactiques d'éleveurs Pastos à la frontière Colombie/Équateur », Chartier Christophe (dir.), thèse de médecine vétérinaire, Nantes, 2012.

JEANJOT-EMERY Pol, « Les origines de la médecine des animaux domestiques et la création de l'enseignement vétérinaire », Bulletin de la Société française d'histoire de la médecine et des sciences vétérinaires, Paris, vol. 2, $\mathrm{n}^{\mathrm{0}}$ 1, 2003, p. 64-76.

LABRE Philippe, Phytothérapie et aromathérapie chez les ruminants et le cheval, Thônes, Femenvet Éditions, $3^{\mathrm{e}}$ édition, 2017.

LIGNEREUX Yves, «Les Soins vétérinaires aux chevaux au Moyen Âge », dans Mousnier Mireille (dir.), Les Animaux malades en Europe occidentale ( $\mathrm{VI}^{e}$-XIX ${ }^{e}$ siècle), actes des $25^{\mathrm{e}}$ journées internationales d'histoire de l'abbaye de Flaran 12, 13, 14 septembre 2003, Toulouse, Presses universitaires du Mirail, 2005, p. 45-53.

MC CORKLE Constance, «An introduction to ethnoveterinary research and development ", Journal of Ethnobiology, vol. 6, 1986.

POPPENGA Roberts, « Herbal medicine: Potential for intoxication and interactions with conventionnal drugs ", Clinical Techniques in Small Animal Practice, Vol. 17, Issue 1, February 2002, p. 6-18.

WYNN G. Susan, FOUGÈRE Barbara J., Veterinary Herbal Medicine, Saint Louis, Mo., Mosby Elsevier, 2007. 


\section{NOTES}

1. P. Jeanjot-Emery, Les origines de la médecine des animaux domestiques et la création de l'enseignement vétérinaire, p. 10-11.

2. Y. Lignereux, Les soins vétérinaires aux chevaux au Moyen Âge, p. 22.

3. G. Beaujouan (dir.), Y. Poulle-Drieux et J.-M. Dureau-Lapeysonnie, Médecine Humaine et Vétérinaire à la fin du Moyen Âge, p. 115.

4. C. Bourgelat, Histoire naturelle générale et particulière, p. 75-76.

5. C. McCorkle, "An introduction to ethnoveterinary research and development", p. 41.

6. A. Cornillet, Étude ethnovétérinaire des pratiques thérapeutiques et prophylactiques d'éleveurs Pastos à la frontière Colombie/Equateur, p. 97-98.

7. P. Labre, Phytothérapie et aromathérapie chez les ruminants et le cheval, p. 31-32.

8. G. S. Wynn, B. J. Fougère, Veterinary Herbal Medicine, p. 45.

9. R. Poppenga, Herbal medicine: Potential for intoxication and interactions with conventionnal drugs, p. 54-55.

\section{RÉSUMÉS}

Depuis l'Antiquité, l'Homme a cherché à développer son savoir-faire pour maintenir en bon état de santé ses animaux d'élevage, nécessaires à sa survie. L'espèce équine a vite acquis une valeur supérieure à celle des autres espèces, et les premiers traités vétérinaires lui ont été exclusivement consacrés. Un grand nombre de traditions médicinales orales se sont développées autour d'elle. Ainsi, en France, jusqu'au début du xx siècle, les savoirs institutionnels, construits sur d'anciens textes savants, ont côtoyé les remèdes et usages issus de la médecine populaire orale. Parfois, ces deux médecines se sont entremêlées ou opposées, chacune trouvant sa légitimité dans la faiblesse de l'autre. Dès lors, leur apprentissage a revêtu de multiples formes. À travers le prisme de l'ethnobotanique, nous montrerons l'évolution de l'organisation et de la diffusion des savoirs équins en France ainsi que la place réservée à la transmission des pratiques thérapeutiques équines ancestrales.

\section{AUTEUR}

\section{MATHILDE RICHARD}

Docteur en Pharmacie, Université Paris V - Paris-Descartes, ethnobotaniste, diplômée de l'Université Lille II - droit et santé, membre de la Société Botanique de France (SBF), membre de la Société Française d'Ethnopharmacologie (SFE) 


\title{
La récupération du savoir-faire dans la construction de l'État moderne en Roumanie : l'exemple des frères Lapedatu
}

\author{
Andreas Wild
}

1 Après le printemps du peuple de 1848 , sous la monarchie dualiste d'Autriche-Hongrie, les Roumains de Transylvanie mènent une lutte d'affirmation nationale, tout comme les autres nationalités de la région, contre la politique de magyarisation de la Hongrie qui poursuivait un projet de création d'un État national selon l'idéologie dominante du xIX ${ }^{e}$ siècle. Vers la fin du siècle, leur lutte est visible dans toute l'Europe; Georges Clemenceau écrit dans La Justice le 12 mai 1894 :

«Dans l'intérêt même de la Hongrie il faut souhaiter la liberté pour les Roumains de Transylvanie. »

Les jumeaux Alexandru et Ion Lapedatu, nés à Săcele en 1876, participent activement à cette lutte. Orphelins à un an et demi, ils ont une enfance difficile. Ils commencent l'école ensemble, mais se séparent au lycée: Ion reste en Transylvanie, tandis qu'Alexandru se rend à Iași, dans le royaume de Roumanie. Ion reçoit deux bourses, étudie l'économie à Budapest et revient en Transylvanie pour enseigner. Comme la seule école roumaine existante n'a pas de chaire libre, il est d'abord engagé comme deuxième secrétaire d'ASTRA, l'association culturelle des Roumains, mais ses capacités sont vite reconnues et il devient directeur de banque à Orăștie (1906), puis à Sibiu. Il sera l'organisateur du système de banques roumaines sous la double monarchie. Alexandru finance ses études d'histoire à l'Université de Bucarest par des leçons particulières et différents petits emplois. À la fin des études, il est engagé à la Section des manuscrits de l'Académie roumaine, puis il est nommé secrétaire de la Commission des monuments historiques (CMH). Il se fait connaitre en publiant plusieurs études historiques qui reçoivent des prix prestigieux. En 1910, il sera élu membre correspondant de l'Académie roumaine, dont il deviendra plus tard membre actif, puis secrétaire général et président. 
Durant la Première Guerre mondiale, la Roumanie reste initialement neutre, ayant des intérêts territoriaux des deux côtés de la conflagration. En août 1916, elle rejoint l'Entente. Son armée entre en Transylvanie. Ion se trouve à Sibiu, proche du front, et défend les actifs de la banque "Albina", la centrale des banques roumaines en Transylvanie, dont il est le seul membre du Conseil d'administration resté sur place. Mais l'armée allemande repousse les Roumains. Ion est arrêté et envoyé à Budapest sous suspicion de trahison, pour ne pas avoir évacué la banque devant la menace roumaine. Il est acquitté, mais assigné à domicile à Blaj, la ville natale de son épouse.

4 Entre-temps, l'armée allemande de Transylvanie force le passage des Carpates; une autre armée allemande traverse le Danube; Bucarest est occupée. Le roi et les institutions de l'État roumain se réfugient à Iași, dans le nord-est du pays. Alexandru est parmi les réfugiés. En août 1917, il quitte Iași pour accompagner le deuxième transport du trésor roumain qu'on voulait mettre à l'abri à Moscou (il ne sera jamais restitué dans sa totalité, le litige entre la Roumanie et la Russie est toujours ouvert). Alexandru voit la révolution bolchevique arriver à Moscou, puis revient à Iași début 1918. En anticipant la fin proche de la guerre, il prépare une documentation justificative pour la position roumaine dans les pourparlers de paix à l'intention de Ion I.C. Brătianu, le chef du Parti National Libéral (PNL).

5 Comme leurs collègues de la même génération, les frères Lapedatu traverseront trois étapes: la construction de l'État roumain moderne entre les deux guerres, sa déconstruction et son effacement de l'histoire officielle pendant les dictatures, et finalement la récupération contemporaine et l'intérêt pour la transmission de leur savoir devant le défi posé par la reconstruction du pays dans le contexte européen.

\section{La construction étatique en Roumanie entre les deux guerres}

6 Vers la fin de la Grande Guerre, les tendances lourdes qui vont reformer le monde, notamment la formation d'États nationaux, sont très visibles.

\section{La Roumanie est gagnante dans la paix générale}

7 Le plan en 14 points du président américain Wilson montre la direction à suivre. En 1918, différentes régions avec une majorité ethnique roumaine votent l'union avec la Roumanie : le « Conseil du Pays » en Bessarabie le 9 avril et le 27 novembre, le « Conseil National » de Bucovine le 28 novembre, et finalement les provinces sous domination hongroise le $1^{\mathrm{er}}$ décembre à la «Grande Assemblée nationale » d'Alba Iulia, composée de 1228 délégués parmi lesquels se trouve Ion. Ion est élu membre du Grand Conseil national (organe législatif), il est aussi nommé Secrétaire général du Ressort des finances dans le Conseil dirigeant de la Transylvanie, du Banat et des parties hongroises (organe exécutif).

8 En décembre 1918, Alexandru se rend à Paris en qualité de membre de la délégation roumaine auprès de la conférence de paix. Sa documentation est utilisée dans les pourparlers. Il travaille pour la reconnaissance de l'union des nouvelles provinces avec la Roumanie et assiste à la signature du Traité de Versailles. 
9 À la fin de la Grande Guerre, le monde est restructuré : quatre empires disparaissent (allemand, ottoman, russe et austro-hongrois) et des États nationaux se forment un peu partout (l'Autriche, la Hongrie, puis l'Estonie, la Lettonie, la Lituanie, l'Ukraine, la Pologne, la Tchécoslovaquie, le Royaume des Serbes, Croates et Slovènes qui deviendra la Yougoslavie). La Roumanie se retrouve à peu près 2,5 fois plus grande qu'avant guerre : $295000 \mathrm{~km}^{2}, 18$ millions d'habitants, c'est la «Grande Roumanie ». Mais le travail ne fait que commencer (fig. 1).

Fig. 1. - La formation de la " Grande Roumanie ». a) le traité de Saint-Germain-en-Laye (10 septembre 1919); b) le traité de Neuilly-sur-Seine (27 novembre 1919); c) le traité du Trianon (4 juin 1920); d) le traité de Paris (28 octobre 1920).

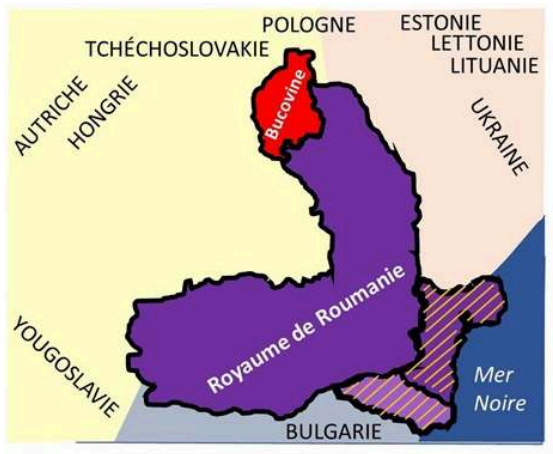

a)

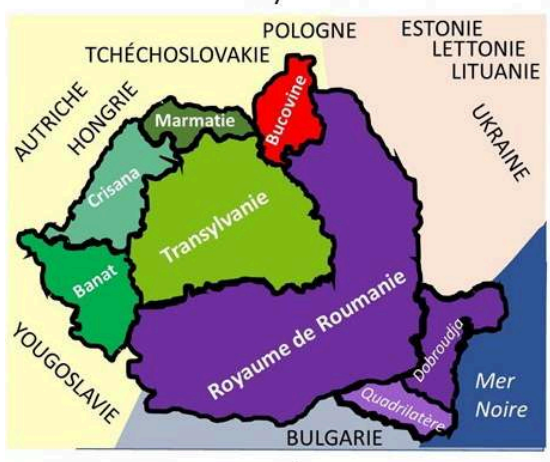

C)



b)

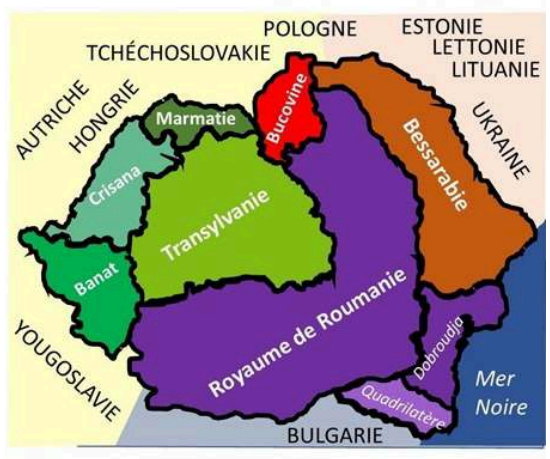

d)

Doc. A. Wild.

\section{Le point de départ}

La construction étatique de la Grande Roumanie a comme fondement la majorité démographique roumaine qui s'est exprimée pour l'union. Mais il y a des différences marquantes entre les régions :

- quatre langues officielles : à part le roumain, il y avait le hongrois en Transylvanie, Banat, Crișana, et Marmatie (sauf dans les écoles primaires confessionnelles); l'allemand en Bucovine (depuis 1775) ; le russe en Bessarabie, où le roumain était appelé officiellement « moldave », et avait été interdit d'usage dans l'administration (1829), dans les églises (1833), dans l'enseignement secondaire (1842) et primaire (1860) et en public (1871) ;

- les systèmes législatifs (russe, autrichien, hongrois, roumain) ;

- plusieurs cultes, avec différentes prérogatives, fonctionnement, etc. ;

- des niveaux de développement économique très différents, cinq monnaies en circulation, fiscalités différentes, etc. 
11 De plus, il y a une grande méfiance entre les Roumains des différentes provinces, de même qu'entre les Roumains et les minorités.

\section{Mesures économiques}

12 Le Conseil dirigeant entame une profonde réforme agraire, en distribuant de la terre arable aux paysans. Ion propose, et fait adopter, un décret établissant une banque agraire pour accompagner la réforme et permettre aux nouveaux propriétaires de financer des travaux et des investissements. Elle démarre son activité à Cluj le 10 janvier 1920 et devient une des plus importantes institutions financières de Transylvanie entre les deux guerres, tout comme la Banque Générale d'Assurance fondée par Ion avant la guerre, qui deviendra un des plus grands assureurs de la Roumanie unifiée sous le nom de "Prima Ardeleană». Ion s'implique aussi dans l'industrie énergétique. Il mène une action tenace pendant douze ans environ, naviguant à travers la complexité des traités des États successeurs de la monarchie dualiste et en rachetant les droits sur le gaz méthane du sous-sol transylvain pour l'État roumain, s'ajoutant ainsi au pétrole exploité dans le sud du pays. Par la suite, il devient président du conseil d'administration de la « Société roumaine de gaz méthane ».

\section{Enseignement}

13 C'est toujours le Conseil dirigeant qui lance la fondation de l'Université roumaine de Cluj en 1919. Pour assurer la qualité académique, on fait appel à la diaspora : on nomme comme recteur Sextil Pușcariu, le doyen de la Faculté de philosophie et lettres à l'Université (autrichienne) de CernăuȚi; on invite Victor Babeș, réputé pour ses travaux en microbiologie dans les laboratoires de Pasteur et de Koch, et Emil RacoviȚa, sous-directeur du laboratoire Arago de Banyuls-sur-Mer et pionnier de la biospéléologie.

Alexandru est invité à l'Université de Cluj comme titulaire de la chaire d'histoire ancienne des Roumains. Il est élu doyen de la Faculté de lettres et philosophie. Avec son collègue et ami Ioan Lupaș, il deviendra co-fondateur de l'Institut d'histoire nationale de Cluj et son co-directeur.

Ion refuse d'abord l'offre d'occuper une chaire universitaire à cluj, en jugeant qu'il était devenu plutôt un praticien, mais en 1922 il accepte une deuxième invitation et devient titulaire de la Chaire de finances publiques et privées à l'Académie de hautes études commerciales et industrielles de Cluj.

16 La Roumanie unifiée marque un progrès important dans l'enseignement de tous les degrés. En 1920, l'Université de CernăuȚi commence elle aussi à enseigner en roumain. Dans l'enseignement secondaire, entre 1919 et 1928 on augmente le nombre de collèges de 32 à 168 et celui des lycées d'État de 35 à 188 ; en 1925, on introduit le baccalauréat napoléonien. Mais c'est dans l'enseignement primaire qu'on déploie les moyens les plus importants : dans la même période, on double presque la capacité en construisant à peu près 7800 nouvelles écoles et en réparant les locaux endommagés par la guerre, surtout en milieu rural. L'enseignement primaire est réorganisé sur des bases unitaires par la loi de 1924. 


\section{Unification politique}

17 Le 28 novembre 1919, les deux frères Lapedatu se retrouvent à Bucarest pour la première séance du Parlement de la Roumanie unifiée, même si la loi électorale diffère encore d'une région à l'autre. Alexandru y participe comme sénateur élu par la nouvelle Université de Cluj, Ion est élu à la Chambre des députés dans la circonscription Nocrich. Ion sera élu quatre fois à la Chambre des députés et deux fois au Sénat.

De son côté, Alexandru se verra élire deux fois à la Chambre des députés et six fois au Sénat, avant de devenir sénateur à vie. Le Parlement entame le difficile travail de légiférer de manière cohérente sur tout le territoire. Une des premières tâches est l'adoption d'une loi électorale unique pour tout le pays. Le 29 mars 1923, on adopte une nouvelle Constitution qui met en accord le cadre légal d'ensemble avec la nouvelle réalité du pays.

Durant ces moments, les deux frères sont actifs dans des partis politiques différents. Ion est considéré naturellement comme adhérant du Parti National roumain de Transylvanie. Alexandru rejoint le PNL qui allait dominer la vie politique les dix premières années après l'Union. Il mène à bien l'implantation du parti en Transylvanie et devient son leader dans la région. Alexandre propose, dans la commission établie dans ce but, le déroulement des festivités pour le couronnement du roi Ferdinand $\mathrm{I}^{\mathrm{er}} \mathrm{de}$ Roumanie et de la reine Maria de Roumanie, culminant avec une cérémonie solennelle à Alba Iulia le 15 octobre 1922. Le couronnement marque la clôture formelle du processus d'unification politique du pays.

\section{Fiscalité, stabilisation monétaire}

20 Comme membre du parti d'opposition, Ion critique les projets fiscaux et économiques proposés par le gouvernement PNL dans une série d'interventions à la chambre des députés, en faisant valoir son expérience internationale gagnée lors des conférences entre les États successeurs de l'Autriche-Hongrie, et ses connaissances détaillées du terrain en Transylvanie. Le PNL mène une politique centraliste, probablement justifié par l'objectif de l'unification, mais Ion fait remarquer, entre autres, que les communes de Transylvanie, qui pouvaient lever des contributions fiscales pour des projets précis, allaient perdre ces revenus dans le cas d'une imposition centralisée et allaient avoir besoin d'une compensation. Les députés du PNL font obstruction à l'intervention d'Ion, mais le ministre des Finances Vintilă Brătianu reconnait la justesse de ses observations et les reprend dans des amendements. Les deux adversaires développent une relation constructive qui va se pérenniser.

21 En 1926, le Parti national roumain de Transylvanie fusionne avec le Parti paysan, formant le Parti national-paysan (PNP - abrégé en roumain « PNȚ »). Ion Lapedatu et ses amis Vasile Goldiș et Ioan Lupaș sont contre la fusion et quittent le Parti. Les trois sont nommés tout de suite ministres dans le gouvernement Averescu (Parti Populaire).

Ion reprend le ministère des Finances, mais restera sans affiliation politique pour le reste de sa vie, un vrai "technocrate». Comme ministre, il est confronté au grave problème de l'inflation excessive, sa priorité est donc la stabilisation monétaire. En 1927, Ion reçoit la visite secrète de deux experts auditeurs britanniques pour examiner le budget du pays en vue d'un emprunt de stabilisation. Il les accompagne tous le long du séjour; leur rapport est favorable, mais Ion devra se rendre à Londres pour 
rencontrer les décideurs. Le gouvernement roumain se rend compte que l'obtention d'un emprunt externe soulève la question de la dette d'État de la Roumanie envers l'Allemagne. Cette dette avait été contractée avant la guerre, mais les pourparlers au niveau des Premiers ministres et des ministres des affaires étrangères n'avaient pas avancé de manière satisfaisante. Mais Ion démissionne du ministère fin mars 1927 ; il rejoint la Banque nationale de Roumanie - où il deviendra administrateur, puis vicegouverneur et finalement gouverneur en 1944. Mais c'est lui que le Premier ministre délègue à Berlin comme envoyé plénipotentiaire le 25 juin 1927. Ion reconnait que les montants estimés d'un côté et de l'autre sont très différents et que les points de vue sont divergents : la Roumanie désirait inclure la dette dans les dédommagements de guerre, l'Allemagne insistait à la traiter séparément, et entendait continuer à recevoir les redevances. Une solution rapide n'était pas envisageable. Lorsque le gouvernement Averescu tombe, fin juin, Ion quitte Berlin.

Le PNL revient donc au pouvoir en juin 1927. Le roi Ferdinand I ${ }^{\text {er }}$ décède en juillet 1927 et Michel $\mathrm{I}^{\mathrm{er}}$, son petit-fils âgé de 5 ans, accède au trône sous une régence. Ion I.C. Brătianu, Premier ministre et président du PNL, décède lui aussi subitement le 24 novembre 1927. Son frère, Vintilă Brătianu, jusque-là ministre des Finances, devient Premier ministre.

En novembre, Ion est délégué par Vintilă Brătianu comme envoyé plénipotentiaire à Londres pour continuer les pourparlers sur l'emprunt de stabilisation. Les Britanniques demandent aux Roumains de résoudre d'abord le différend avec l'Allemagne, mais tout est soudainement bloqué par l'interception à la frontière roumaine de documents suggérant un possible retour au pays du prince Carol, père du roi Michel I, malgré son renoncement au trône. L'apparente instabilité politique de la Roumanie éloigne la perspective d'un emprunt. Ion quitte Londres.

Après la mort de Ion I.C. Brătianu, l'opposition considère le gouvernement Vintilă Brătianu comme illégitime et engage la « résistance civile ». Une grande démonstration a lieu le 18 mars pour demander (sans succès) la démission du gouvernement incapable d'obtenir l'emprunt de stabilisation. Le 6 mai, l'opposition appelle à une grande assemblée à Alba Iulia, demande le changement immédiat de gouvernement (sans succès) et menace de "marcher sur Bucarest» (action qui échoue). Entre-temps, le Parlement adopte les lois autorisant l'emprunt externe le 27 juillet. Le gouvernement engage des pourparlers avec la France, mais elle pose les mêmes conditions que les Britanniques. Et c'est toujours Ion qui part en août à Berlin comme envoyé plénipotentiaire pour résoudre les différends. Les pourparlers sont difficiles, la presse annonce déjà leur échec prochain ${ }^{1}$; mais Ion et son partenaire allemand prennent l'initiative de repartir à zéro avec une proposition nouvelle qui leur semble équitable. Les deux gouvernements la trouvent acceptable. Le gouvernement Vintilă Brătianu offre sa démission en espérant être reconduit pour avoir débloqué l'emprunt de stabilisation.

Le 10 novembre, Ion signe à Berlin, avec les deux autres membres de sa délégation, la « convention destinée à mettre fin aux différends financiers existant entre la Roumanie et l'Allemagne ${ }^{2}$ " (fig. 2). C'est le premier traité de l'histoire entre la Roumanie et l'Allemagne. Il remplace le Traité de Versailles comme base pour les relations bilatérales. Le jour même de la signature de la convention avec l'Allemagne, à Bucarest, surprise! La régence accepte la démission de Vintilă Brătianu et charge Iuliu Maniu (PNP) de former un nouveau gouvernement. Celui-ci dépose le sermon le soir même. La 
convention signée par Ion est attaquée par les ministres PNP, mais Ion la défend énergiquement et obtient sa ratification par le Parlement; elle est promulguée le $1^{\mathrm{er}}$ janvier 1929. L'emprunt souscrit par des entités financières de France, du RoyaumeUni et des États-Unis, sera lancé officiellement par une loi adoptée le 7 mars.

Fig. 2. - Ion Lapedatu, signataire de la Convention du 10 novembre 1928 entre la Roumanie et l'Allemagne (extrait du Moniteur officiel, $n^{\circ} 1,1^{\text {er }}$ janvier 1929).

\section{CONVENTION}

destinée à mettre fin aux différends financiers existants entre la Roumanie et l'Allemagne

Le Gouvernement Royal Roumain et

\section{Le Gouvernement Allemand}

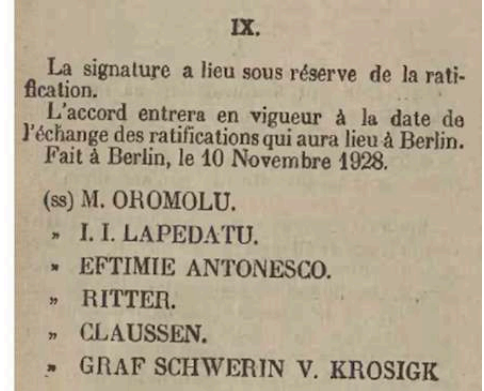

Domaine public. plonge le monde dans la plus terrible crise. Ion se rend à Amsterdam en décembre pour négocier un accord de principe avec la Banque des Pays-Bas, sa dernière mission officielle liée aux emprunts de stabilisation. Il est choqué par l'aspect désolant de la ville ravagée par la crise. Grâce à la mise en ordre de ses finances, la Roumanie peut atténuer les chocs et reprendre ensuite à toute allure son développement économique, atteignant l'apogée en 1938.

\section{Identité nationale par la culture}

Alexandru, ministre des Cultes et des Arts dans six gouvernements et ministre d'État dans quatre gouvernements, poursuit un programme simple : l'affirmation de l'identité nationale des Roumains par la culture, sans mettre en cause la culture et l'identité des autres nationalités ${ }^{3}$.

En quinze ans, 32 musées sont ouverts et plus de 20 monuments sont érigés, on adopte la loi des théâtres nationaux (1926), on institue les prix de l'Académie roumaine pour la littérature. Alexandru est le premier éditeur du bulletin de la Commission des monuments historiques qui, avec ses 126 parutions entre 1908 et 1945, représente aujourd'hui encore la référence la plus complète du patrimoine du pays. Toute sa vie professionnelle, Alexandru est membre - et président depuis 1940 - de cette Commission qui assure la documentation, la restauration et le soutien de plus de 240 monuments d'architecture et d'art de toutes les nationalités coexistant sur le territoire, de toutes les religions, et localisés dans toutes les régions.

\section{Le régime général des cultes}

Le nom d'Alexandru reste lié indélébilement à la loi établissant le régime général des cultes. Les difficultés commençaient déjà avec la Constitution du 1923, qui affirmait la liberté absolue de conscience et la parfaite égalité des cultes, pour ajouter dans le même article qu'il y a deux églises "roumaines", dont l'Église orthodoxe était 
dominante et celle gréco-catholique avait priorité ! Il y avait dans la Grande Roumanie douze cultes reconnus; leur juridiction territoriale ne respectait pas les frontières nationales; dans la même église, il y avait des règles et des compétences (par exemple par rapport à l'état civil : naissance, mariage, décès...) variant d'une région à l'autre ; il n'y avait aucun mécanisme permettant de reconnaitre de nouveaux cultes, etc. Les catholiques et les protestants de Transylvanie demandaient la conservation de leurs " acquis historiques", les orthodoxes demandaient la récupération des biens de l'Église gréco-catholique et une position "dominante» (constitutionnelle!), tandis que les autres cultes exigeaient l'égalité de traitement. Alexandre est appelé au gouvernement le 30 octobre 1923 précisément pour trouver une solution. Il l'importe de France : c'est la laïcité.

31 Alexandru identifie deux défis à relever : l'Église orthodoxe roumaine, qui désire être confirmée comme Église d'État (demande impossible!), et la relation avec le SaintSiège, dont les prérogatives ne devaient pas porter préjudice à la souveraineté de l'État roumain. Pour commencer, il fait adopter le 25 février 1925 une loi pour élever le siège du Métropolite orthodoxe de Bucarest au rang de Patriarcat, puis l'Église Orthodoxe roumaine écrit son statut et Alexandru le fait adopter par le Parlement le 6 mai 1925. Ceci doit donner satisfaction à un culte dont les mérites historiques pour la nation roumaine sont indubitables. En même temps, Alexandre finalise le 15 janvier 1926, en collaboration avec le ministère des Affaires étrangères, le texte d'un Concordat avec le Saint-Siège (celui-ci sera signé avec de petits changements le 10 mai 1926 par son successeur, Vasile Goldiș, et sera ratifié le 12 juin 1929 sous le gouvernement Maniu). La Roumanie sera le premier pays à majorité non-catholique qui ait conclu un concordat avec le Saint-Siège.

Fort de ces avancées, Alexandru entame la phase finale d'élaboration d'une loi sur le régime général des cultes. Chaque culte devra se donner un statut qui sera confirmé par une loi du Parlement : c'est l'État qui aura toujours le dernier mot. En mars 1928, le projet soumis par Alexandru est débattu durant trois semaines à la Chambre des députés et au Sénat. Les discussions sont particulièrement animées; à travers tout le pays, il y a des réunions de soutien ou de protestations, des démonstrations publiques, des processions pour apporter de l'appui aux champions des différentes causes. Mais le texte final est adopté par les deux chambres quasi à l'unanimité et le roi peut promulguer la loi le 22 avril 1928. Pour les vingt ans à venir, elle permettra des relations d'une grande normalité entre les différents cultes, de même qu'entre ceux-ci et l'État (fig. 3). 
Fig. 3. - Alexandre Lapedatu, auteur de la loi sur le régime général des cultes (caricature d'époque).

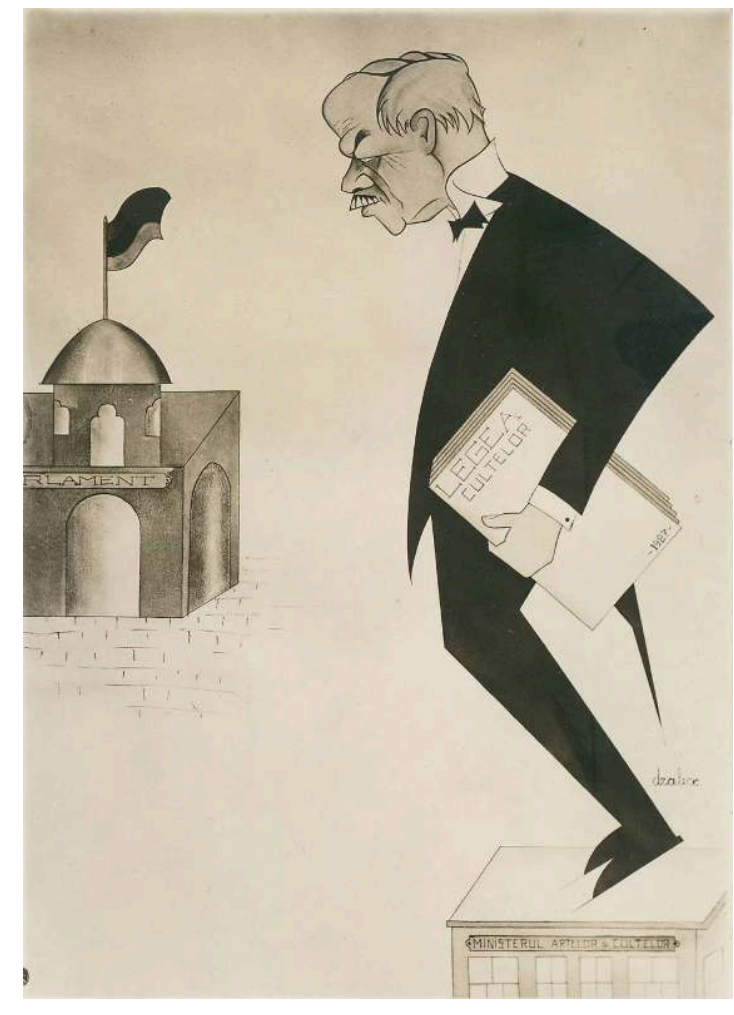

Domaine public.

\section{Euvres sociales et charitables}

Alexandru et Ion sont conscients de leur devoir de reconnaissance pour les institutions sociales qui leur ont permis d'être élevés par une mère sans moyens et de suivre des études supérieures, constituant la base de leur progrès social. Pour citer seulement quelques exemples, Alexandru fait don de sa bibliothèque de dix mille volumes à l'Université de Cluj; Ion établit et finance la « Fondation Veturia Lapedatu » du nom de son épouse pour aider intellectuels pauvres et étudiants méritants; tous les deux font des donations considérables à l'Administration des écoles roumaines de Brașov et contribuent aux souscriptions pour élever des monuments comme la cathédrale d'Orăştie ou le monument des héros de Săcele.

\section{Conclusions sur le savoir dans la construction étatique}

La génération dite "de la Grande Union » a développé entre les deux guerres un remarquable savoir dans la construction étatique. L'unification du pays a été appuyée par la plus grande partie des formations politiques et épousée par la majorité de la population. Les acteurs principaux ont démontré, dans les moments critiques, la capacité de transcender les différences idéologiques et politiques pour le bien commun. La société a fait preuve de ténacité devant les adversités de la politique internationale (la crise de 1929, la montée en puissance des extrémismes). À la fin de la Seconde Guerre mondiale, la Roumanie a été reconstituée presque dans les mêmes frontières, et elle subsiste encore tandis que ses alliés de la Petite Entente (la Tchécoslovaquie et la 
Yougoslavie) sont démantelés. La construction de la Roumanie s'est avérée plus durable.

\section{L'oubli}

La période d'entre les deux guerres (appelée en Roumanie "interbellique ») prend fin en 1938 par le coup d'État du roi Carol II qui instaure sa dictature le 10 février, promulguant une nouvelle Constitution et instituant le parti unique, le Front de la Renaissance Nationale.

Après le pacte Ribbentrop-Molotov du 23 août 1939, l'invasion de la Pologne du $1^{\text {er }}$ septembre marque le commencement de la Seconde Guerre mondiale. La «Grande Roumanie » est neutre, mais souffre un dépeçage sous la pression du III ${ }^{\mathrm{e}}$ Reich et de ses alliés : l'URSS occupe la Bessarabie et le nord de la Bucovine (28 juin 1940, à la suite du pacte Ribbentrop-Molotov), la Hongrie occupe le nord de la Transylvanie (30 août, dû au deuxième arbitrage de Vienne) et la Bulgarie occupe la Dobroudja du sud ou le "Quadrilatère " (7 septembre, l'accord de Craiova). Le 6 septembre, le général Ion Antonescu, nouveau président du Conseil des ministres, force l'abdication du roi Carol II, qui n'a pas su défendre les frontières. Michel I ${ }^{\text {er }}$ devient de nouveau roi, la Constitution est suspendue, le Parlement est dissous. Antonescu s'allie d'abord avec la «Légion de l'archange Michael » d'orientation nationale-fasciste, mais quelque mois plus tard l'alliance est rompue, la rébellion des «légionnaires" est étouffée et Antonescu instaure sa dictature militaire. Le 22 juin 1941, la Roumanie entre en guerre contre l'URSS avec l'espoir de récupérer la Bessarabie, mais après la bataille de Stalingrad, l'Armée rouge reprend l'initiative et arrive à la frontière roumaine pendant l'été 1944. Antonescu refuse de demander l'armistice et est l'arrêté : ce coup d'État du roi Michel (23 août 1944) engage l'armée roumaine contre l'Allemagne, espérant récupérer la Transylvanie du nord. En effet, à la fin de la guerre, la frontière ouest de la Roumanie sera pratiquement reconstituée, mais, à l'est, l'URSS gardera la Bessarabie et le nord de la Bucovine tandis que la Bulgarie récupérera le Quadrilatère.

Le 5 mars 1946, Winston Churchill affirme dans son discours de Fulton (Missouri) : « De Stettin sur la Baltique à Trieste sur l'Adriatique, un rideau de fer s'est abattu à travers le continent ». Et la Roumanie se trouve du mauvais côté (fig. 4). 
Fig. 4. - Le « rideau de fer».



Doc. A. Wild,

Sous la pression de l'Armée rouge, le minuscule Parti communiste de Roumanie, autodéfini comme "section de l'Internationale Communiste", s'empare du pouvoir. Il entame, avec l'aide des agents envoyés par l'URSS, un nouveau projet d'État, la stalinisation du pays sur trois volets : politique, économique, et culturel ${ }^{4}$.

\section{Stalinisation de la vie politique}

Les partis «historiques" sont ressuscités en 1945 et participent aux élections parlementaires du 19 novembre 1946. Alexandru refait en grande partie l'organisation libérale en Transylvanie, forge une alliance régionale avec le PNP et obtient trois mandats, dont un pour lui-même (ce sera son dernier). Mais les élections sont fraudées massivement par le gouvernement asservi aux Soviétiques. Les partis traditionnels sont interdits, le roi Michel I er est forcé d'abdiquer le 30 décembre 1947. Le 27 février 1948, on proclame la nouvelle constitution de la République Populaire Roumaine (RPR). Par des interdictions, cessations "volontaires » des activités, absorption, etc. on aboutira en 1952 à un nouveau parti unique : le Parti Ouvrier roumain.

Selon Alexis de Tocqueville, "L'homme qui juge au criminel est donc réellement le maitre de la société ${ }^{5}$ - et en effet, un nouveau code de procédure pénale criminalise en 1948 des délits vaguement définis, comme « conspiration contre l'ordre social » ou bien "l'omission de dénonciation» qui permet d'entamer des poursuites contre tout membre de famille, ami, collègue ou connaissances des condamnés des procès montés ; le code contient des articles «non-publiés » - voici le paradoxe de la dictature : des lois auxquelles il faut obéir sans les connaitre! 
41 La police secrète, la « Securitate », sous les ordres des officiers du NKVD envoyés par Moscou, prétend lutter contre le fascisme et purge toutes les institutions. Les révoltes des paysans, les protestations des étudiants, les mouvements des travailleurs sont réprimés violemment; les leaders, les participants, leurs familles, leurs amis, leurs connaissances sont emprisonnés dans les camps de travail, les derniers maquisards paysans réfugiés dans la montagne - sont capturés en 1970. Les élites sont éliminées physiquement par simple ordre du ministre, sans procès. Alexandru, ancien ministre, président du Sénat, président de l'Académie roumaine est arrêté dans la rafle « des dignitaires » du 5 et 6 mai $1950^{6}$; il meurt dans la prison de Sigetu MarmaȚiei le 30 août ; c'est aussi le sort de I. Maniu, Gh. Brătianu et tant d'autres personnalités... Ion, ancien ministre, gouverneur de la Banque Nationale de Roumanie, fixé au lit à la suite d'un accident, n'est pas transportable et meurt à la maison le 24 mars 1951.

En 1969, le parti unique devient le Parti communiste roumain, la république est nommée Socialiste et la répression de la "Securitate » amplifiée par un énorme réseau d'informateurs, prend des formes plus subtiles. Le pouvoir du secrétaire général du parti est absolu.

\section{Stalinisation de l'économie}

Sur la base de la nouvelle Constitution de la RPR, l'industrie est nationalisée à partir du du 11 juin 1948. Des entreprises mixtes soviéto-roumaines (SOVROM) siphonnent des valeurs financières à destination de l'URSS. L'agriculture est " collectivisée » malgré l'opposition massive des paysans, une terreur sauvage qui fait plus de 80000 victimes permet de déclarer officiellement l'accomplissement de la "transformation socialiste " en 1962. L'État prend contrôle de toutes les institutions: la Banque Nationale est étatisée en 1948, la Banque de la RPR est subordonnée au Ministère des finances et congédie tous les anciens dirigeants, dont Ion. L'État a le monopole du commerce extérieur.

La planification et la centralisation sont extrêmes : le Comité d'État de la Planification élabore les plans quinquennaux, le Comité d'état des Prix décide les prix de vente de tout produit, etc. D'importants investissements (centrales hydroélectriques, combinat sidérurgique, etc.) ont lieu sans aucun souci pour leur viabilité économique.

\section{Stalinisation de la culture}

45 La section agit-prop auprès du Comité Central du parti unique est toute-puissante. Elle russifie l'enseignement en introduisant la langue russe comme objet d'étude obligatoire et en imposant le manuel unique d'histoire considérant la lutte des classes comme moteur de l'histoire et exagérant le rôle de la Russie slave dans l'histoire de la Roumanie plutôt latine. Les institutions culturelles sont épurées: c'est le cas de l'Académie roumaine, des universités, des lycées, des écoles primaires, des musées - de toutes les institutions de culture. Les études supérieures sont interdites aux enfants de la «bourgeoisie», telle que la fille d'Ion Lapedatu, à part dans certaines disciplines techniques.

Les publications par écrit, le cinéma, la musique, etc. subissent une censure rigoureuse, pour combattre toute expression de «nationalisme, cosmopolitisme, objectivisme ou décadence bourgeoise ». En 1948, la liste des publications interdites comprend déjà 
8779 titres, mais elle continue de croître; de plus, il y a aussi une liste secrète. Personne n'ose plus consulter dans les bibliothèques des publications datant d'avant 1948 et leur simple possession peut être une preuve de «conspiration contre l'ordre social».

Le réseau de délateurs informe la "Securitate " des faux pas idéologiques dans les conversations particulières, dans les blagues, dans les réunions de famille. Même les enfants sont recrutés avec des contrats en bonne et due forme, mettant en avant le devoir patriotique d'informer sur ce que disent leurs collègues ou partenaires de jeux : on ne raconte plus des souvenirs, on ne parle plus de l'histoire ni même chez soi ; les enfants doivent ignorer le passé pour ne pas mettre en danger la famille. L'homme nouveau est amnésique.

Après 1969, le Parti communiste entame une ligne "national-socialiste» et la suppression devient plus sélective, tolérant une partie de la littérature patriotique d'avant la guerre. C'est dans ce contexte qu'en 1976 les « Essais de littérature » par Ioan Alexandre Lapedatu, le père des deux frères, sont publiés dans la collection « Restitutions ».

\section{Conclusion sur la suppression du savoir sous la dictature}

Dans la Roumanie communiste, sur à peu près un demi-siècle, le pouvoir est détenu par seulement deux personnes : Gheorghiu-Dej (période staliniste 1945-1965) et Ceaușescu (période du culte de la personnalité et du "national-communisme», 1965-1989). Le régime se maintient aux prix d'une répression rigoureuse; on estime qu'approximativement deux millions de Roumains - ou $10 \%$ de la population - ont été des victimes directes de l'oppression: tués, incarcérés, torturés, soumis aux travaux forcés, déportés, déplacés avec domicile obligatoire, etc.

50 L'État décide "scientifiquement " combien de calories sont nécessaires par individu, combien d'heures d'électricité suffisent par jour, quelles publications lire... L'économie fonctionne mal et la pénurie se vit au quotidien, aussi bien matériellement que spirituellement. L'humour noir d'un caricaturiste synthétise la situation dans une publication de type "samizdat » : on revient du marché les mains vides, il n'y a pas de viande, pas de lait, pas de fromage, pas d'œufs, pas de café, pas d'Ionesco, pas de Cioran...

51 La génération d'entre les deux guerres et son savoir sont supprimés systématiquement. Les petites ouvertures qui ont lieu vers la fin de la période, sous le contrôle strict de la censure, sont faites pour soutenir la propagande "patriotarde" du régime communiste.

\section{La transmission du savoir}

Après la chute du mur de Berlin et le démantèlement de l'Union soviétique, le couple Ceaușescu est exécuté (1989) ; une nouvelle Constitution garantit la propriété privée et des libertés individuelles. Cent trois académiciens victimes de l'épuration de 1948, dont Alexandru et Ion Lapedatu (post-mortem), sont réintégrés à l'Académie roumaine. La curiosité et l'intérêt pour la période de l'entre-deux-guerres sont toujours croissants, l'époque prend une dimension mythique. 
53 Mais les efforts de suppression n'ont pas réussi à complètement inhiber les vecteurs de transmission du savoir. Il y en a qui maintenant peuvent recommencer à transmettre des informations :

- documents de famille (correspondance et photographies, mais aussi, dans certains fonds de tiroirs, notes, journaux ou mémoires) ;

- fonds public ou restreint d'accès aux Archives Nationales, documents sauvegardés à l'Académie roumaine, à la Banque nationale, à l'Institut national du Patrimoine (successeur de la Commissions de monuments historiques), etc. ;

- archives de la «Securitate» maintenant accessibles au public (publications, documents et notes confisqués pendant les perquisitions et les rafles, etc.) ;

- l'histoire orale : en Roumanie, il y a un projet de sauvegarde des témoignages (audio ou vidéo) ; les filles des frères Lapedatu ont fait, elles aussi, des enregistrements.

Les premières publications ont révélé des aspects surtout anecdotiques, tantôt sérieux, tantôt sensationnels (comme, dans le cas d'Alexandru l'accompagnement du Trésor à Moscou), qui figurent dans les mémoires et la correspondance privée (fig. 5). Ensuite, ils se trouvent dans les articles de l'encyclopédie de Roumanie ou sur le site wikipédia. Mais ils font aussi l'objet d'études universitaires valorisant le savoir généré par leurs actions. Leurs contributions se retrouvent :

- dans la bibliographie du cours et séminaire universitaire «Lieux de mémoire » à la Faculté d'histoire et philosophie, Cluj-Napoca (l'étude des monuments historiques) ${ }^{7,8}$;

- dans plusieurs thèses de doctorat, par exemple celles traitant de la fondation d'institutions : cléricale - à la Faculté de théologie, Cluj-Napoca (le cas d'Alexandru) ${ }^{9}$, ou financières - à la Faculté d'économie, Cluj-Napoca (le cas d'Ion) ${ }^{10}$;

- dans des travaux d'habilitation universitaires, par exemple «Visions politiques sur l'Église, l'État et la nation » à l'Université de Cluj-Napoca, intégrant le régime des cultes légiféré sous Alexandru ${ }^{11}$, ou bien "Historiographie, frontières et l'imaginaire politique " à l'Université d'Oradea, faisant référence aux positions d'Alexandru comme historien et participant aux pourparlers de 1919-1922 ${ }^{12}$;

- dans les contributions présentées dans le cadre du Symposium d'histoire et civilisation bancaire « Ion I. Lapedatu », coorganisé par l'Université Babeș-Bolyai de Cluj-Napoca ;

- dans les communications de la session commémorative du 12 septembre 2016 de l'Académie roumaine marquant leur $140^{\mathrm{e}}$ anniversaire, etc. 
Fig. 5. - Sélection de livres ayant comme sujet les frères Lapedatu parue, à une exception près, après 1989.
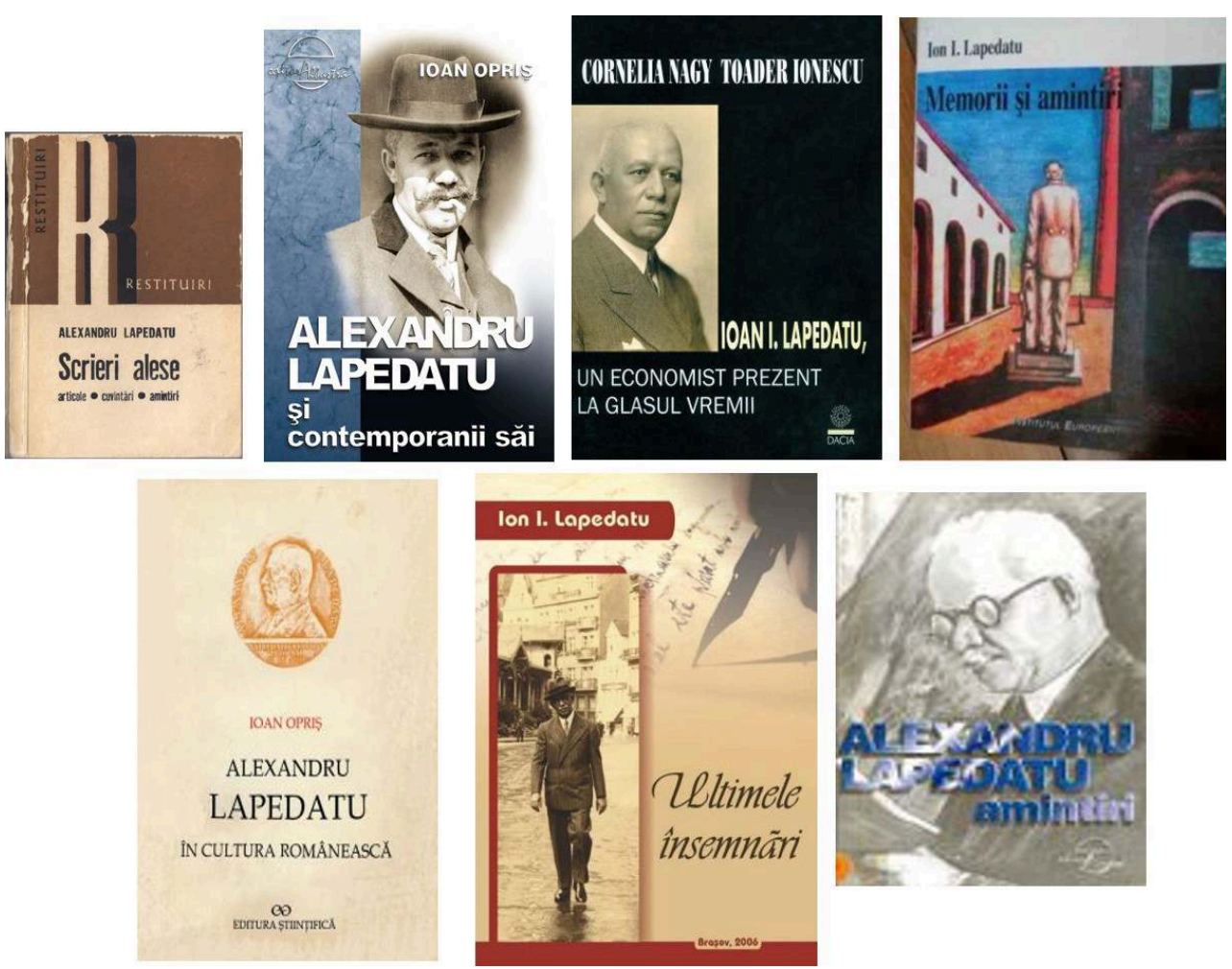

Doc. A. Wild

Entre 2016 et 2018, plusieurs musées leur ont consacré des expositions thématiques : le Musée de la civilisation urbaine de Brașov, le Musée national d'histoire de la Transylvanie de Cluj-Napoca, le complexe muséal BistriȚa-Năsăud, le Musée national Brukenthal de Sibiu, le Musée du pays de Făgăraș «Valer Literat » et le Musée des cartes et des livres anciens de Bucarest (fig. 6).

Fig. 6. - Évènements organisés par des personnalités officielles commémorant les frères Lapedatu.

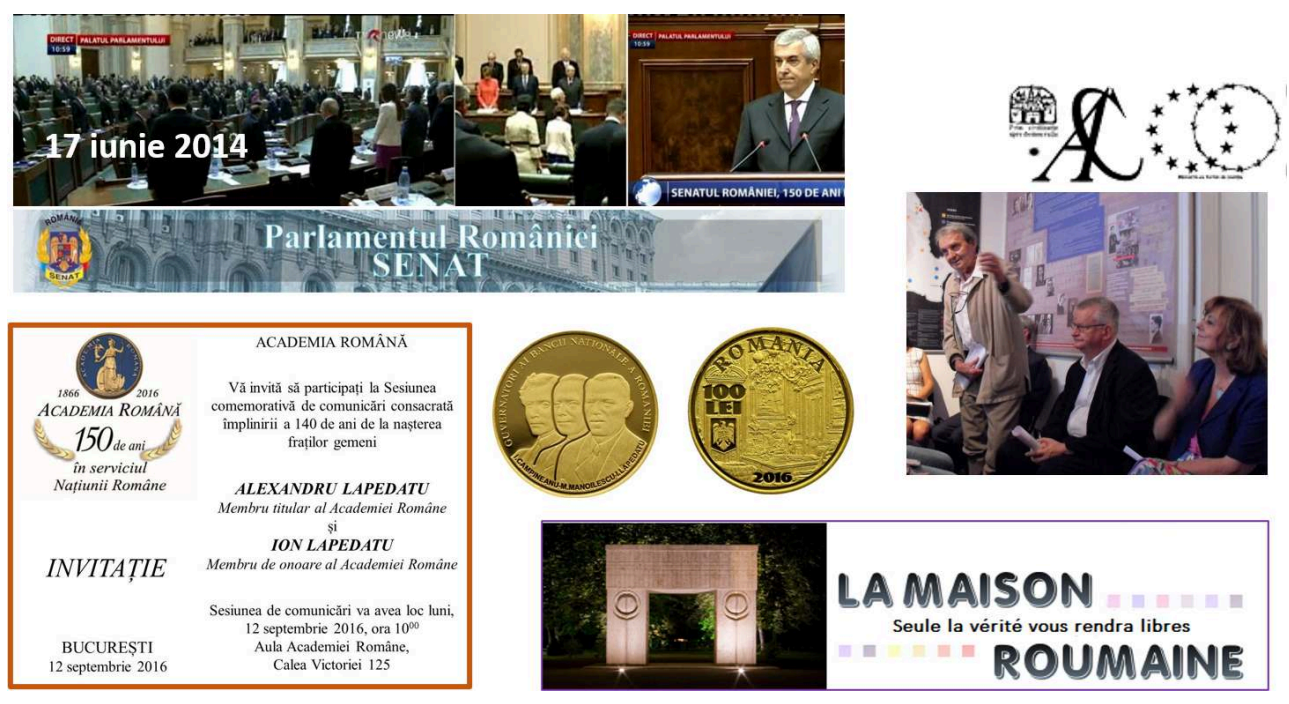

Doc. A. Wild. 
La résonance est amplifiée par des évènements publics :

- le Sénat roumain, commémorant les 150 ans de sa création le 17 juin 2014, honore par une minute de silence ses trois présidents tués par les régimes totalitaires, dont Alexandru Lapedatu ;

- la Banque Nationale de Roumanie lance une édition numismatique célébrant les anniversaires de ses gouverneurs, dont celui de Ion Lapedatu pour les 140 ans de sa naissance (2016) (fig. 7).

Fig. 7. - Affiches de la série d'expositions évoquant les contributions des frères Lapedatu à la construction de la Roumanie moderne (2016-2018).
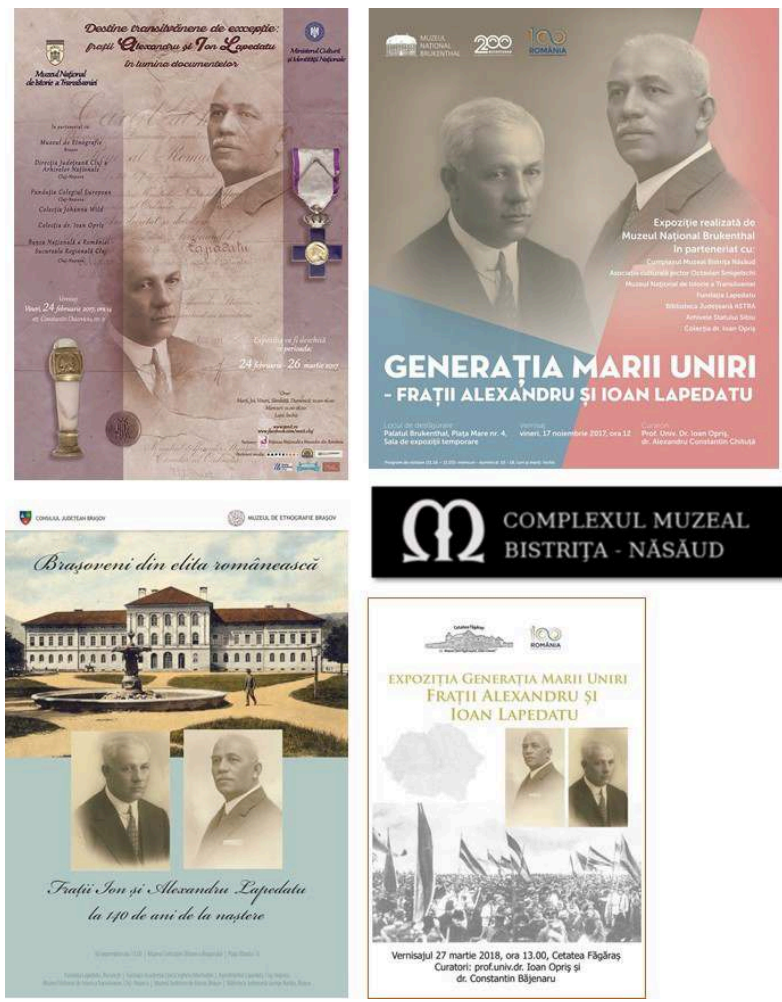

Doc. A. Wild.

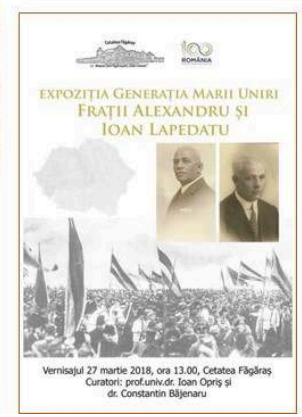

Les descendants des deux frères Lapedatu et leurs familles ont créé la «Fondation Lapedatu » pour continuer la tradition et soutenir les travaux de recherches en histoire et en économie, l'enseignement de tous les degrés, la conservation du patrimoine et des œuvres de charité.

L'histoire des frères Lapedatu est unique, mais s'inscrit dans la trajectoire de toute leur génération. Aujourd'hui, la Roumanie développe, pour la troisième fois depuis cent ans, un projet d'édification étatique, cette fois-ci comme membre de l'Union européenne et de l'OTAN. Trente ans après la chute du communisme, un peu plus de dix ans depuis l'entrée dans l'Union européenne, la récupération et la mise en œuvre du savoir créé par la génération de la Grande Union, dont les frères Lapedatu sont des représentants exemplaires, constitue une référence et une inestimable source d'inspiration et de motivation. 


\section{BIBLIOGRAPHIE}

I. AGRIGOROAIEI, G. IACOB, O.-S. BURUIANĂ, « Politică și cultură în România interbelică », Universitatea « Alexandru Ioan Cuza », Iași, Facultatea de Istorie, ÎnvăȚământ la distanȚă

[URL : https://www.scribd.com/doc/147945447/Politica-Si-Cultura-in-Romania-Interbelica]

V. GEORGESCU, Istoria Românilor de la origini pînă în zilele noastre, Los Angeles, ARA Publications, vol. IV, 1984.

G. LUPU, « Die rumänisch-deutschen Wirtschaftsbeziehungen in der deutschen Presse Hermannstadts von 1920 bis 1929 ", dans D. POPESCU (Organizer), Session 44 : Identity, Globalization and Universality in the Eastern and Central European Economic Area - Evolutions and Involutions in the Modern and Contemporary Period. Experiences, Meanings, Lessons, XIV International Economic History Congress, Helsinki, 2006, p. 1-24.

D. MAN, « Lista de lucrări ale candidatului la abilitare », Facultatea de Teologie Ortodoxă a UniversităŢii Babeş-Bolyai, Cluj-Napoca

[URL :https://doctorat.ubbcluj.ro/sustinerea_publica/sustineri_abilitare/pdf/2015/ Dorel\%20Man/Lista\%20lucrari\%20MAN\%20abilitare.pdf.]

C. NAGY, T. IONESCU, « Ion I. Lapedatu, un economist prezent la glasul vremii », Editura Dacia, ClujNapoca, 2000.

I. oPRIS, Alexandru Lapedatu în cultura românească, Editura știinȚifică, București, 1996.

D. RADOSLAV, Locurile memoriei, Syllabus, Universitatea Babeș/Bolyai, Cluj/Napoca, 2013, [URL :http://hiphi.ubbcluj.ro/Public/File/syllabus/master_2013/Locurile_memoriei.pdf]

I.G. RETEGAN, « Church, State, Nation in the Vision of Some Romanian Politicians from Transylvania (1848-1918). The Orthodox Point of View », Ph.D, Thesis, Babeș-Bolyai University, Cluj-Napoca, 2011.

R. RUSAN, Chronologie et géographie de la répression communiste en Roumanie, Bucharest, Editura FundaȚiei Academia Civică (La Collection « Heure d'Histoire »), 2007.

S. șIPOș, « Historiography, Borders and Political Imaginary », Habilitation Thesis, University of Oradea, 2014.

A. de TOCQUEVILLE, De la démocratie en Amérique, GF-Flammarion, vol. 1, 1981, p. 373.

H. TONCH, Witschaft und Politik auf dem Balkan : Untersuchungen zu den deutsch-rumänichen Beziehungen in der Weimarer Republik unter besonderer Berücksichtigung der Weltwitschaftskrise, Frankfurt am Main, Peter Lang GmbH, 1984.

\section{NOTES}

1. G. Lupu, Die Rumänisch-deutschen Wirtschaftsbeziehungen in der deutschen Presse Hermannstadts von 1920 bis 1929, p. 1-24.

2. H. Tonch, Wirtschaft und Politik auf dem Balkan: Untersuchungen zu den deutschrumänischen Beziehungen in der Weimarer Republik unter besonderer Berücksichtigung der Weltwirtschaftskrise. 
3. I. Opris, Alexandru Lapedatu în cultura românească.

4. V. Georgescu, Istoria românilor de la origini până în zilele noastre.

5. A. de Tocqueville, De la démocratie en Amérique, p. 373.

6. R. Rusan, Chronologie et géographie de la répression communiste en Roumanie.

7. D. Radoslav, Locurile memoriei, Syllabus.

8. I. Agrigoroaiei, G. Iacob, O.-S. Buruiana, Politică și cultură în România interbelică.

9. I.G. Retegan, Church, State, Nation in the Vision of Some Romanian Politicians from Transylvania (1848-1918). The Orthodox Point of View.

10. C. Nagy, T. Ionescu, Ion I. Lapedatu, un economist prezent la glasul vremii.

11. D. Man, Academicianul Alexandru Lapedatu (1867-1950). Atitudini eclesiale.

12. S. Șipoș, Historiography, Borders and Political Imaginary.

\section{RÉSUMÉS}

À la fin de la Grande Guerre, la Roumanie récupère des régions hétérogènes et les intègre, dans un bref délai de vingt ans, dans un État plutôt moderne qui perdure de nos jours. La transmission du savoir-faire dans la construction étatique a été inhibée par cinquante ans de dictature qui a éliminé, souvent physiquement, les architectes et les artisans, a effacé leurs actions des livres d'histoire et a interdit d'en parler même en famille. Mais la suppression n'a pas abouti. Aujourd'hui, on retrouve les contributions des frères Lapedatu, membres exemplaires de la génération dite de la "grande union ", dans les bibliographies des cours universitaires et dans les articles d'encyclopédie: elles sont analysées dans desthèses de doctorat et des études historiques, leur personnalité est évoquée dans des expositions muséales et dans les médias. À l'occasion du centenaire de la formation de la Roumanie moderne, ce savoir-faire suscite l'intérêt: il offre une référence et une source d'inspiration pour un pays en train de se restructurer dans le cadre de l'Union européenne.

\section{AUTEUR}

\section{ANDREAS WILD}

Vice-président de la Fundatia Lapedatu, membre de La Maison Roumaine 